\title{
ODONTOLOGISCHE STUDIEN I.
}

\section{DIE ONTOGENIE DER PRIMATENZÄHNE} VERSUCH EINER LÖSUNG DER GEBISSPROBLEME

\author{
VON
}

\section{PROF. DR. L. BOLK}

DIREKTOR DES ANATOMISCHEN INSTITUTS DER UNIVERSITÄT AMSTERDAM

MIT 2 TAFELN UND 74 ABBILDUNGEN IM TEXT

1913 
West Virginia University Libraries

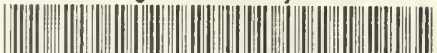

308021019320005

(1) $300 \mathrm{~K}$ 


\title{
ODONTOLOGISCHE STUDIEN I.
}

\section{DIE ONTOGENIE DER PRIMATENZÄHNE}

\section{VERSUCH EINER LÖSUNG DER GEBISSPROBLEME}

\author{
VON \\ PROF. DR. L. BOLK
}

DIREKTOR DES ANATOMISCHEN INSTITUTS DER UNIVERSITÄT AMSTERDAM

MIT 2 TAFELN UND 74 ABBILDUNGEN IM TEXT
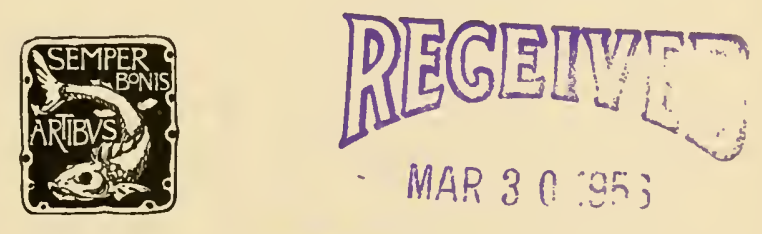

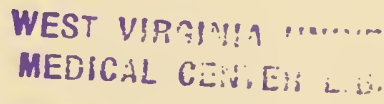

JENA

VERLAG VON GUSTAV FISCHER 


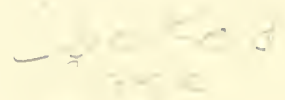

737

.94
1265
$x \rightarrow 2,3$

ALLE RECHTE VORBEHALTEN 


\section{Einleitung.}

Schon seit mehreren Jahren bin ich damit beschäftigt, über die Ontogenie des Primatengebisses eine möglichst vollständige Einsicht zu erlangen. Es sind bereits einige Abhandlungen von meiner Hand erschienen, welche, da sie zu dem Hauptgegenstand der Untersuchung nur in seitlicher Bezichung stehen und überdies in sich abgerundete Fragen behandelten, veröffentlicht werden konnten, ohne allzuviel den Eindruck von fragmentarischen Mitteilungen zu'machen. Als solche nenne ich meine Publikation über die Entwicklung des Gaumens und die Bedentung der Zahnleiste beim Menschen, jene zur Entwicklungsgeschichte der menschlichen Lippen und die Veröffentlichungen, worin meine Ansichten über die Differenzierung des Primatengebisses auscinandergesetzt sind. Die Ergebnisse meiner Untersuchung iiber die Entwicklung der Zähne sind noch nicht erschienen. Der Bausteine habe ich schon viele gesammelt, aber mit dem Aufban selber habe ich noch nicht angefangen. Die Ursache daran liegt nicht in dem Unzulänglichen des vorhandenen Materiales, aber darin, daß es mir an einer klaren Einsicht mangelt, wie ich die Elementarerscheinungen zu einem organischen Ganzen zusammenfügen mußte. Denn es sei sofort die Benerkung vorausgeschickt, daß in der Ontogenese, auch des Menschengebisses, Erscheinungen sich geltend machen, welche merkwürdigerweise bis jetzt unbeachtet blieben, und deren Kenntnis die Probleme, welche sich um das Gebiß gruppieren, meiner Meinung nach einen großen Schritt näher ihrer Lösung bringen. Schon in meiner 1910 erschienenen Arbeit über die Entwickhng des Gaumens habe ich darauf hingewiesen, daß die Beschreibungen der Ontogenie des menschlichen Gebisses, wie dieselben sich in den Lehrbiichern und besonders auch in der monographischen Bearbcitung Röses finchen, unvollständig sind. Ich hatte bei meinen Untersuchungen an einer großen Zahl lückenloser Serien von Menschen- und Affenembryonen Tatsachen beobachtet, welche zwar sehr interessant waren, aber das Problem der Zahnentwicklung der Primaten verwickelter gestalteten, als es auf Grund 
gelänfigerer Vorstellungen der Fall wäre. Es gelang mir nicht, diese Tatsachen in einer Weise zu erklären, welche nach gewissenhafter Überlegung und Beleuchtung von mehreren Seiten mir selbst eine richtige zu sein schien. Ich schob daher die Veröffentlichung meiner Ergebnisse auf und wendete mich zur Untersuehung der Ontogenese des Reptiliengebisses in der Hoffunng, hier Beobachtungen anstellen zu können, welche Licht in den fraglichen Punkten der Ontogenese des Primatengebisses schaffen konnte. Zum Teil ist mir das wohl gelungen, sei es auch, daß das Resultat dieser Untersuchung ein anderes war, als ich vorher hatte ahnen können. Denn ich stieß auch beim Reptiliengebiß auf Erscheinungen, welche die Strulitur desselben in ein neues Licht stellten, und wodurch sich allmählich das prinzipielle Problem der Beziehung zwischen Reptilien- und Säugergebiß in vollem Unfang entfaltete. Diese Bcobachtungen haben mich dazu geführt, in diesem Problem einen neuen Standpunkt einzunehmen, welchen ich auf dem diesjährigen Anatomenkongreß in München in ganz kurzer Weise vorgetragen habe.

Ich sehe mich gezwungen, diese kurze Übersicht über mein Arbeitsprogramm voranszuschicken, erstens weil darin die Erklärung liegt, warum ich bis jetzt mit der Veröffentlichung meiner Untersuchung über die Ontogenese des Primatengebisses, woran Adloff in seiner jüngsten Abhandlung ${ }^{1}$ ) einige Male appelliert, gezögert habe. Weiter liegt in dem oben Gesagten die Berechtigung des fragmentarischen Charakters, welche der vorliegenden Abhandlung zukommt. Denn die Veranlassung zu dieser Veröffentlichung liegt eben in der jüngsten Publikation von Adloff, soweit dieselbe sich mit der Ontogenese des Primatengebisses beschäftigt. Der Inhalt jener Abhandlung nötigt mich, meine Reserve mit der Publikation der Hauptergebnisse meiner Untersuchung preiszugeben, weil durch Adloffs jüngste Publikation die Anschanung über die Entwicklungsgeschichte unseres Gebisses in falsche Bahnen gelenkt zu werden droht. Diese Abhandlung bezweckt jedoch nicht, eine polemische zu sein, ich werde mich bemühen, die Tatsachen, welche, wie aus dem Obenstehenden hervorgeht, mir schon längere Zeit bekannt waren, in knapper Form mitzuteilen. Diese Tatsachen sind für sich von genügender Beredsamkeit, um die hypothetischen Betrachtungen, welche Adloff der Ontogenie des Primatengebisses widmet, zu widerlegen. Ich lasse somit in den folgenden Zeilen die kasuistischen und speziellen Beobachtungen, welche ich im Lanfe meiner Untersuchung habe anstellen können, unerwähnt und hebe nur jene Entwicklungsphänomenen hervor, welche als allgemeine, allen Primaten zukommenden Erscheinungen

1) Zeitschr. f. Morph. u. Anthrop., Bd. XV, Heft 2. 
bei der Entstehung des Gebisses zu betrachten sind. Bei einer dieser Erscheinungen werde ich dann Gelegenheit haben, auf die Adloffsche Arbeit einzugehen.

In der vorliegenden Arbeit habe ich mich jedoch nicht auf eine einfache Mitteilung meiner Befunde beschränkt. Denn die zum Vorschein getretenen Tatsachen, sowohl jene, welche auf die Ontogenese des Primatenzahnes Bezug haben, als jene, welche bei der Untersuchung des Reptiliengebisses festgestellt werden konnten, berühren unmittelbar die beiden großen Gebißproblene: die Beziehung des Sängerzahnes zum Reptilienzahn, und jene zwischen dem Diphyodontisnus der Sängetiere und dem Polyphyodontismus der Reptilien. Beide Relationen erscheinen durch die von mir gemachten Befunde in einem neuen Licht, und ich konnte nicht umhin, in einem Schlußkapitel auf die um das Gebiß sich gruppierenden Fragen einzugehen. Ich glaube, es sei mir gelungen, unter Zngrundelegung meiner Beobachtungen von den Gebißproblemen eine Lösung zu geben, die zwar von den geläufigen ziemlich stark abweicht, aber die eine logische Konsequenz von wahrgenommenen Tatsachen ist.

An mehreren Stellen der vorliegenden Veröffentlichung finden sich schon beiläufige Bemerkungen über Fragepunkte und kurz gefaßte Erörterungen von Beobachtungen, die in einer der folgenden dieser odontologischen Studien eine eingehende Besprechung finden werden. Wenn somit solche Äußerungen in dieser Publikation ungenïgend argumentiert erscheinen, so bitte ich dieselben als vorläufige Mitteilungen betrachten zu wollen.

Amsterdam, Oktober 1912. 
Digitized by the Internet Archive in 2010 with funding from

Lyrasis Members and Sloan Foundation

http://www.archive.org/details/dieontogeniederp00bolk 


\section{Inhalt.}

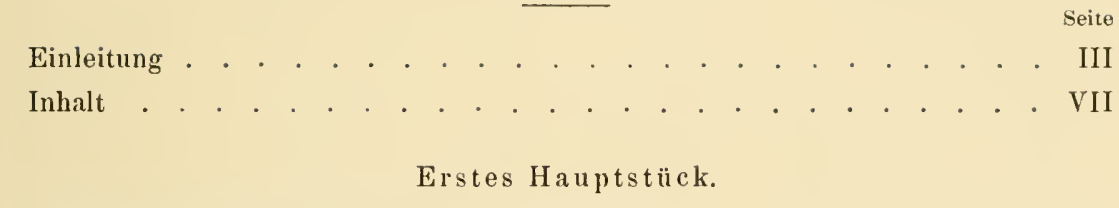

Die laterale Schmelzleiste und die Schmelznische . . . . . . . . . . 1

Zweites Hauptstïck.

Das Schmelzseptum und der Schmelznabel

Drittes Hauptstück.

Die Nebenleiste (rudimentäre Zahndrüsenleiste) . . . . . . . . . . 56

Viertes Hauptstück.

Über die Beziehung des Säugerzahnes und Säugergebisses zum Zahn und Gebiß der Reptilien . . . . . . . . . . . . . 77 



\section{Erstes Hauptstück.}

\section{Die laterale Schmelzleiste und die Schmelznische.}

Die Weise, woranf das Schmelzorgan beim Menschen sich anlegt, von der Zahnpapille eingestülpt wird und von der Zahnleiste sich emanzipiert, ist in der Literatur so oftmals im Detail beschrieben worden, daß deren Kenntnis wohl als Allgemeingut betrachtet werden darf und eine vorangehende Beschreibung dieses Vorganges hier wohl unterlassen werden kann. Um die angedeutete Periode der Zahnentwicklung wird es sich in den nächsten Zeilen zuerst handeln. Demn es treten dabei Erscheinungen auf, welche in der Literatur bis jetzt unerörtert, den Vorgang der ersten Anlage des Zalnes komplizierter gestalten als aus den vorlicgenden Beschreibungen folgt.

Es ist am zweckmäßigsten mit der Beschreibung eines einfachen Falles zu beginmen, und ich gebe daher in den 12 Slizzen von Fig. 1 die Anlage des unteren ersten Incisıvus eines jungen menschlichen Embryos. Die Serie dieses Embryos trägt die Signatur: Homo. Embryo A. Sehnittdicke $15 \mu, m_{2}$ noch nicht angelegt. Die Figuren sind mit dem Zeichenapparat angefertigt, die Serie ist eine liiekenlose. Es ist ein Teil der epithelialen Bekleidung der Mundhöhle und die davon ausgehende Zahnanlage skizziert.

In Fig. $1 a$ ist leicht das den Kieferwall bekleidende Epithel zu erkennen, und ventral davon ausgehend im Kiefermesenchym die links- und rechtsseitige Zahnleiste, welche hier in der Medianlinie noch nicht voneinander getrennt sind. Solches ist wohl der Fall im nächstfolgenden Schnitt $(b)$. Hier sind beide Leisten getrennt, und ihre freien Ränder finden sich noch nahe aneinander. Gleichzeitig ist aus der ventralwärts sehenden Fläche der Zahnleiste eine Sprosse hervorgetreten, welche an Dicke jener der Zahnleiste gleichkommit. Wenn man nicht über die weiter nach hinten folgenden Schnitte verfïgte, wïrde man gewiß das in Skizze $b$ gegebene Bild als die Zahnleiste mit einer eingestülpten Zahmpapille denten, denn es sieht wirklich gerade so aus. Doch muß es bei genauerer Betrachtung anffallen, daß das in der Höhlung sich findende Mesenchym nicht den charakteristischen Kernreichtum einer wahren Zahnpapille zeigt. Im nächsten Schnitt (e) ändert sich noch wenig, die Höhlung zwischen dem medialen Endabschnitt der Zahnleiste und die ventrale (besser laterale) Sprosse erscheint nur etwas eingeengt. Im jetzt folgenden Schnitt dagegen $(d)$ tritt eine Komplikation anf, am freien Rande der lateralen Sprosse bildet sich ein senkrecht auf diese gestellter Ausläufer, der sich in der Richtung des freien Endes der Zahnleiste erstreekt. Der Zutritt zur Aushöhlung zwischen beiden Leisten wird dadureh eingeengt. Im 
nächsten Schnitt (c) hat sich diese horizontale und jetzt deutlich nach unten konkave Sprosse mit dem freien Rande der Zahnleiste verbunden. Dadurch ist ein Teil des Mesenchyms jetzt ringsum vom Epithel der Zahnanlage umschlossen, medialwärts durch die Zahnleiste, lateralwärts durch die laterale Leiste und ventralwärts durch den horizontalen Ausläufer. Das sich unmittelbar unter letzterem findende Mesenchym ist stark verdichtet und kennzeichnet sich sofort als die Anlage der 7ahmpapille. Im nächsten Schnitt $(f)$ ändert sich wenig, nur ist der abgeschlossene Raum etwas enger geworden als Einleitung zum Zustand in dem jetzt folgenden Schnitt $(g)$, wo an der rechten Seite der Raum verschwunden ist, während er an der linken Seite noch eben angedeutet ist, um jedoch im nächsten Schnitt $(h)$ ebenfalls verschwunden zu sein. In diesem Schnitt hat man das Schmelzorgan in seiner typischen kappenförmigen Gestalt vor sich. Diese Form behält die Zahnanlage noch in den zwei nachfolgenden Schnitten ( $l$ und $j$ ), während der

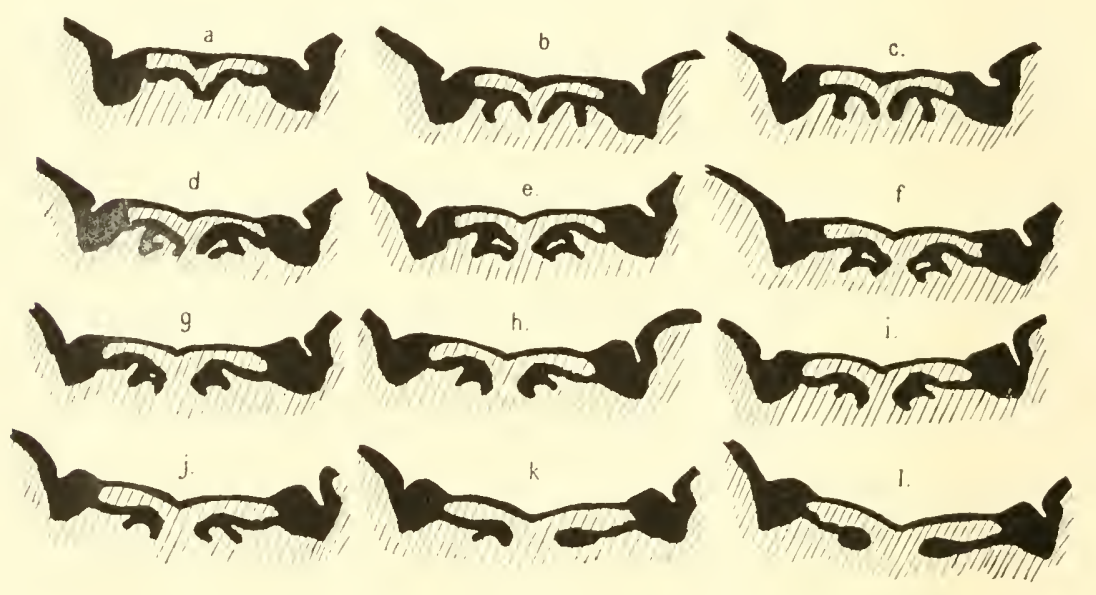

Fig. 1. Homo A. Anlage vom unteren $i_{1}$.

Schnitt $k$ schon durch das hintere Ende der Anlage geht, links ist dieselbe noch kappenförmig, rechts deutet nur eine kolbige Anschwellung der Zahnleiste den letzten Rest des Schnelzorganes an. Wenn man die Skizzen $b$ und $j$ von Fig. 1 miteinander vergleicht wird man überrascht durch die Ahnlichkeit der beiden Zahnanlagen. Und dennoch haben beide Skizzen eine grundverschiedene morphologische Bedeutung denn in Skizze $b$ ist von dem eigentlichen Schmelzorgan noch gar nicht die Rede, wie ähnlich die Bildung einem solehen anch aussehe.

Wenn man diese Schnittserie durch die Anlage des unteren Inzisivus des Menschen mit den Beschreibungen der Zahnanlage in der Literatur vergleicht, dann stimmt dieselbe damit nicht ganz iiberein. Nach den geläufigen Angaben sollte nur durch einfache Einstülpung das knospenförmige Stadium des Schmelzorganes in das kappenförmige übergehen. Wie schon aus dieser ersten abgebildeten Serie hervorgeht, ist der Vorgang etwas komplizierter, die laterale, aus der unteren (identisch mit der bukkalen) Fläche hervortreteude Sprosse tritt als neues Element in der Entwicklungsgeschichte der Zähne 
hinzu. Um gleich am Anfang jeden Gedanken, es handle sich hier $1 \mathrm{~m}$ etwas Abnormales, vorzubeugen, sei hier gleich die Bemerkung vorausgeschickt, daß diese Leiste bei allen Zähnen von den verschiedenen Primaten, welche ich daraufhin untersucht habe, auftritt. Um diese Behauptung genïgend zu dokumentieren, werde ich zunächst noch einige Skizzenserien von Schnitten durch Zahnanlagen folgen lassen und das Essentielle darin kurz hervorheben. Wir werden in dieser Weise bald eine mehr vollständige Einsicht in das morphologische Vorkommen der beschriebenen Bildıng erlangen.

Zunächst gebe ich in Fig. 2 eine Skizzenserie von der Anlage eines unteren Caninus vom Menschen. Das bezügliche Embryo ist katalogisiert als: Homo $V$, Schnittdicke $20 \mu, \mathrm{m}_{2}$ im Oberkiefer knospenförmig. Das Objekt ist also etwas älter als das vorangehende.

In Skizze $a$ und $b$ erkennt man leicht die sichelförmig gebogene Zahnleiste $(Z l$.) von der mächtigen Epithelmasse ausgehend, welehe

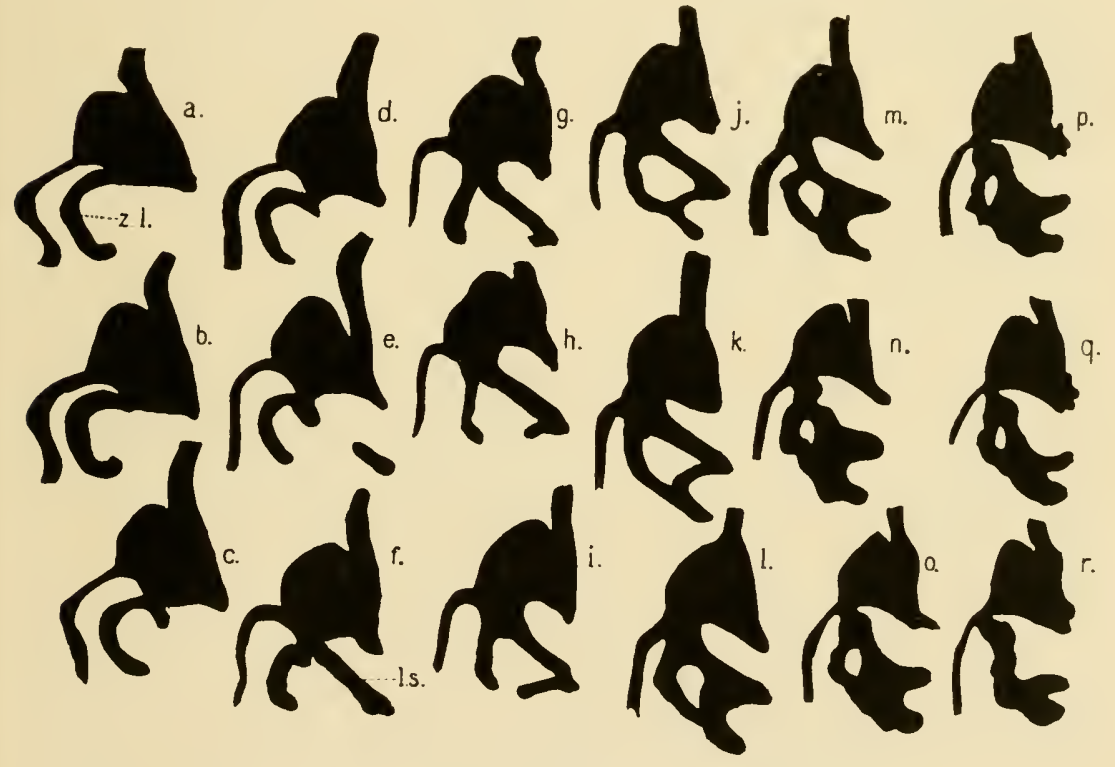

Fig. 2. Homo $V$. Anlage vom unteren Caninus.

die Lücke zwischen Kieferwall und Wange noch ansfüllt. In Skizze $c$ erscheint an der Ansatzstelle der Zahnleiste am Mundhöhlenepithel und bukkal von der Zahnleiste eine zweite epitheliale Sprosse, welche in Skizze $d$ und $e$ ebenfalls zu sehen ist und sich nicht zu verlängern scheint. Doch tritt schon im Schnitt $e$ in einiger Entfernung ein Epithelinselchen auf, das sich in der Richtung der lateralen Sprosse verlängert, um in dem nächsten Schnitt $(f)$ mit derselben zusammenzufließen. Die eigentliche Zahnleiste hat sich inzwischen wenig verändert, und in dem Schnitt $f$ hat man scheinbar mit zwei ganz selbständigen Zahnleisten zu tun, wovon die laterale sogar größer zu sein scheint als die mediale. Wir treffen hier einen von dem in Fig. 1 skizzierten, etwas abweichenden Zustand an, da bei diesem zweiten Objekt die laterale Leiste an der Ansatzstelle der Zahnleiste am Mundhöhlenepithel selbst- 
ständig zu entstehen scheint und nicht aus der Zahnleiste ihren Ursprung nimmt wie im vorangehenden Falle. Diese Differenz ist jedoch eine nebensächliche Erscheinumg, worauf ich später näher eingehe. Um irrtümlichen Vermutungen vorzubengen, betone ich hier ausdrücklich, daß diese epitheliale Sprosse nicht identisch ist mit der Leiste, welche von Adloff kurz beschricben ist und welche im Hauptstück 3 besprochen werden soll. Letztgenannte Leiste habe ich wälırend meiner Untersuchnngen immer als "Nebenleiste" bezeichnet, und die vorliegende, in Fig. 1 und 2 dargestellte als ,laterale Schmelzleiste“. Die beiden Bezeichnungen werde ich auch in dieser Arbeit weiter anwenden.

Zwischen der Zahnleiste und der lateralen| Schmelzleiste (l s) wird auch in Fig. $2 f$ ein Teil des Kiefermesenchyms eingeschlossen, der nach unten breit mit dem übrigen Mesenchym zusammenhängt. Das ist anch noch der Fall im nächstfolgenden Schnitt $(g)$, wo sich jedoch am freien Ende der lateralen Schmelzleiste ein kleines Füßchen ausgebildet hat, das in dem folgenden Schnitt $(h)$ in der Richtung des freien Randes der Zahnleiste sich ein wenig verlängert hat. In Skizze $2 i$ ist diese Verlängerung weiter fortgeschritten und wird die Mesenchymmasse zwischen Zahnleiste und lateraler Schmelzleiste schon zum Teil abgeschnirt. Diese Abtrenmung ist in dem folgenden Schnitt $(j)$ vollständig, der horizontale Fortsatz hat sich mit der Zahmleiste verbunden, indem letztere sich gleichzeitig verlängert hat. Das ganze Gebilde erscheint jetzt als eine breite, mit dem Mundhöhlenepithel verbundene glockenartige Anlage, welche durch cin großes Foramen durchlöchert ist. In der unteren Fläche hat sich die Zahmpapille schon ein wenig eingestülpt. In den folgenden Schnitten vollzieht sich num der nämliche Vorgang, als bei Fig. 1 beschrieben. Die eingeschlossene Mesenchymmasse wird allmählich geringer $(k, l)$, indem das Schmelzorgan an Bedeutung zunimmt $(m)$. Gleichzeitig rückt die ganze Anlage tiefer ins Kiefermesenchym, indem die Zahnleiste auf die mediale Fläche der lateralen Schmelzleiste sich zu verschieben scheint (m). Noch über fünf Schnitte war die eingeschlossene Mesenchymmasse zu verfolgen $(n, o, p, q)$, bis schließlich Zahnleiste und laterale Schmelzleiste ein einheitliches Ganze bilden. Damn sind wir jedoch gleichzeitig an dem hinteren Teil der Zahnanlage angelangt. Noch vier Schnitte, und von der Einstülpung der Zahnpapille ist nichts mehr zu sehen.

Dieser Fall ist besonders lehrsam. Denn er läßt über die genetische Beziehung der lateralen Schmelzleiste zum Schmelzorgan und mithin zur Zahnanlage kaum einigen Zweifel übrig. Ich werde mich vorläufig jedoch auf Beschreibungen beschränken und lasse theoretische Schlußfolgerungen erst später folgen.

Als lritter Fall wähle ich die Anlage vom zweiten Incisivus des Oberkicfers eines Propithecus. Die Spezies war umbekannt. Die Serie ist katalogisiert als Propithecus B., $20 \mu, \mathrm{m}_{3}$ im Unterkiefer angelegt.

Die Fig. 3 bringt die Skizze der ersten neun Schnitte dieser Anlage, welche noch über fünf weitere zu verfolgen war.

Die Skizze a gibt den meist vorderen Schnitt wieder. Es war hier die Anlage des Sclmelzorganes eben getroffen, aber noch ohne Znsammenhang mit der Zahnleiste. Letztere nimmt vom Mundhöllenepithel Ausgang und ist leicht S förmig gekrümmt. Vou der 
Stelle, wo die Zahnleiste vom Epithel abgeht, und welche durch eine kleine Einsenkung der Oberfläche markiert ist, drinet lateral von der Zahnleiste eine zweite epitheliale Sprosse ins Mesenchym ein. Es ist die laterale Sehmelzleiste, welehe am vorangehenden Schnitt zuerst auftrat. Beide Leisten hängen hier somit wie beim vorangehenden Objekt an einer Stelle miteinander und gleichzeitig mit dem Mundhöhlenepithel zusammen. Gleiches. war noch der Fall beinı nächstfolgenden Schnitt (Fig. $3 b$ ), worin die laterale Leiste an Mächtigkeit zugenommen hat, während die Zahnleiste keine Veränderung zeigt. Der Schnitt dureh das Emailorgan hat sich vergrößert und zeigt die erste Andeutung der Einstülpung. Der dritte Schnitt (Fig. 3c) bringt wesentlich Neues. Die Zahnleiste hat sich nämlich vom Mundhöhlenepithel abgelöst mitsant der lateralen Schmelzleiste. Beide Leisten bleiben in Zusammenhang miteinander und bilden eine $\vee$ förmige Figur mit ungleich langen Schenkeln. Dic Zahnleiste ist die längerc. Eine Verbindıng mit dem Schmelzorgan, das jetzt deutlich sein kappenförmiges Entwicklungsstadium verrät, hat noch nicht stattgefunden. Das war auchim vierten Schnitt (Fig. $3 d$ ) noch nicht der Fall, wiewohl hier der Komplex bei der Leisten und das Schmelzorgan einander schon dicht ge-
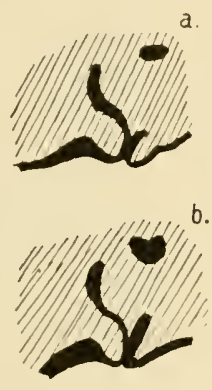

b.
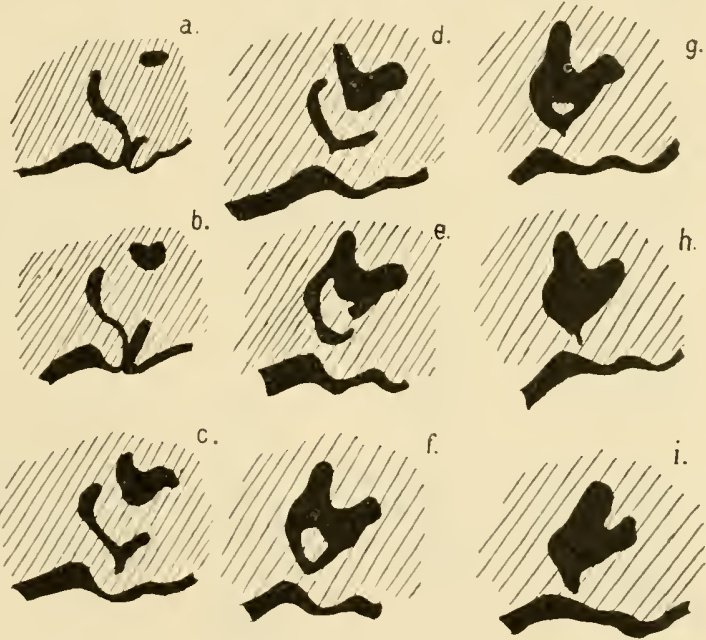

Fig. 3. Propithecus $B$. Anlage des lateralen oberen Incisivus.

nähert sind. In dem nächsten Schnitt (Fig. $3 e$ ) ist die Verbindung zustande gekommen, sei es vorläufig nur zwischen Zahnleiste und medialer Fläche des Schmelzorganes. Doch sieht man letzteres von seiner lateralen Fläche aus bereits einen Fortsatz der lateralen Schmelzleiste entgegensenden. Zwischen Leistenkomplex und Schmelzorgan wird wieder ein Teil des Kiefermesenchyms eingeschlossen, der jetzt noch mit der übrigen Mesenchymmasse zusammenhängt, um jedoch in folgenden Schnitt (Fig. 3f) vollständig abgeschnürt zı werden. In dieser Skizze treffen wir die Zahnanlage mit den beiden Leisten wieder in den uns von den beiden vorangehenden Objekten bekannt gewordenen Formen, jedoch mit dem Unterschied, daß die Leisten nicht mehr mit der epithelialen Bekleidung des Kiefers zusammenhängen. Weun man einen Schnitt, wie der vorliegende, olne Zusammenhang mit den vorangehenden oder folgenden studieren sollte, würde man gewiß leicht zu ganz unrichtigen Auffassungen gelangen. Denn es sicht ganz aus, als wäre das Schmelzorgan durchlöcbert. Doch ist dem nicht so. Die Umrandung des Loches wird nicht von Schmelzorgangewebe dargestellt, sondern von der Zahnleiste und der 
latcralen Schmelzleiste. Es wiederholt sich nun in den weiter nach hinten folgenden Sehnitten der uns schon bekannte Vorgang. Die eingeschlossene Mesenchymmasse wird geringer (Fig. $3 \mathrm{~g}$ ) ind schließlich fließen Zahnleiste und laterale Schmelzleiste vollständig zusammen (Fig. $3 h$ ). Gleichzeitig fängt das Gebilde an, einen kurzen Fortsatz in der Richtung des Kieferepitheliums auszusenden, der in dem letzten abgebildeten Schnitt größer ist. Das Organ wird inzwischen weniger umfangreich. Vier Schnitte weiter ist nun der an seinem Ende etwas verdickte Ausläıfer ïbrig, der sich wieder mit dem Mundhöhlenepithal verbunden hat und die einfache Zahnleiste darstellt.

Aus dieser Beschreibung geht hervor, daß auch beim genannten Halbaffen bei der Zahnanlage Erscheinungen auftreten, welche prinzipiell den vorher beim Menschen beschriebenen entsprechen. Anch bei Propithecus tritt eine laterale Schmelzleiste auf, nur gestaltet das ganze Bild sich"hier etwas anders durch die frühzeitige Aufhebung der Verbindung mit dem Kieferepithel. Diese Ablösung tritt jedoch nur im Bereich einer Zahnanlage auf zwischen den Anlagen verbindet dic Leiste sich wieder mit dem Mundhöhlenepithel.

Der sehr frühzeitige Verhust der Verbindung mit diesem Epithel scheint eine bei den Halbaffen mebr verbreitete Erscheinung zu sein,

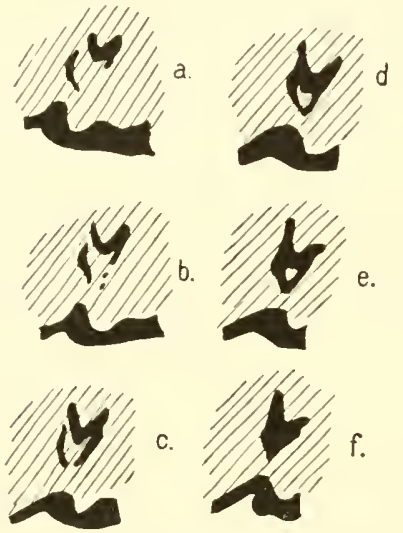

Fig. 4, Lenur melanocephalus $A$. Anlage des oberen dritten Incisivus. wie ans dem vierten Fall hervorgeht, wovon jetzt eine kurze Beschreibung folgt. Es betrifft die Anlage des dritten Incisivus im Oberkiefer eines Lemur melanocephalus. Die Schnitte sind $25 \mu$ dick, das Präparat ist katalogisiert als Lemur melanocephalıs, Serie $A$. In Fig. 4 gebe ich sechs anfeinanderfolgende Schnitte durch die Anlage des bezïglichen Zahnes. Die Zahnleiste war in dem ganzen vorderen Teil der Gebißanlage schon vom Kieferepithel abgelöst. In Fig. $4 a$ liegt medial die Zahnleiste, lateral davon und etwas tiefer ins Mesenchym der Schnitt durch die Anlage des Schmelzorganes. Von derselben geht als Fortsetzung der lateralen Seite eine kurze Sprosse ans. Sie gehört zur lateralen Schmelzleiste, welche jedoch in diesem Schnitt noch nicht als solche zu sehen ist. Auch in dem folgenden Schnitt (Fig. 4 b) noch nicht. Doeh ist hier der Fortsatz etwas verlängert, und zwei kleine Epithelinselchen lassen schon vermuten, wo die laterale Leiste sich im folgenden Schnitt finden wird. Hier ist sie (Fig. $4 c$ ) in der 'Tat über ihre ganze Länge getroffen, hängt jedoch noch nicht mit der Zahnleiste zusammen. Erst im folgenden Schnitt (Fig. $4 d$ ) ist die Verbindung von Zahnleiste und lateraler Schmelzleiste zustande gekommen, und hat erstere sich auch mit dem Schmelzorgan verbunden. Beide Leisten bilden mit dem Schmelzorgan jetzt wieder die henkelartige Verbindung, die uns aus den vorangehenden Objekten schon bekannt ist. Weiter nach hinten wiederholt sich der schon mehrfach beschriebene Vorgang, die beiden Leisten schmelzen miteinander zusammen und bald darauf geht der Schnitt durch das hintere Ende der Anlage vom Schmelz- 
organ. Die beiden letztbeschriebenen Fälle sind sehr wertvoll für die Auffassung der genetischen Beziehung zwischen dem Emailorgan und den beiden Leisten und daher auch von grundlegender Bedentung für die Meinung, welche man über die Zähne der Primaten als norphologische Bildungen hat. Denn es ist ohne weiteres klar, daß die genetisehe Beziehung des Emailorganes zu den beiden Leisten - die Zahnleiste und die laterale Schmelzleiste - eine vollständig gleiche ist. So wie die Zahnleiste mit der medialen Fläche des Schmelzorganes sich verbindet, so verbindet sich die laterale Schmelzleiste mit der lateralen Fläche. Diese Erscheinung ist von prinzipieller Bedeutung. Denn man
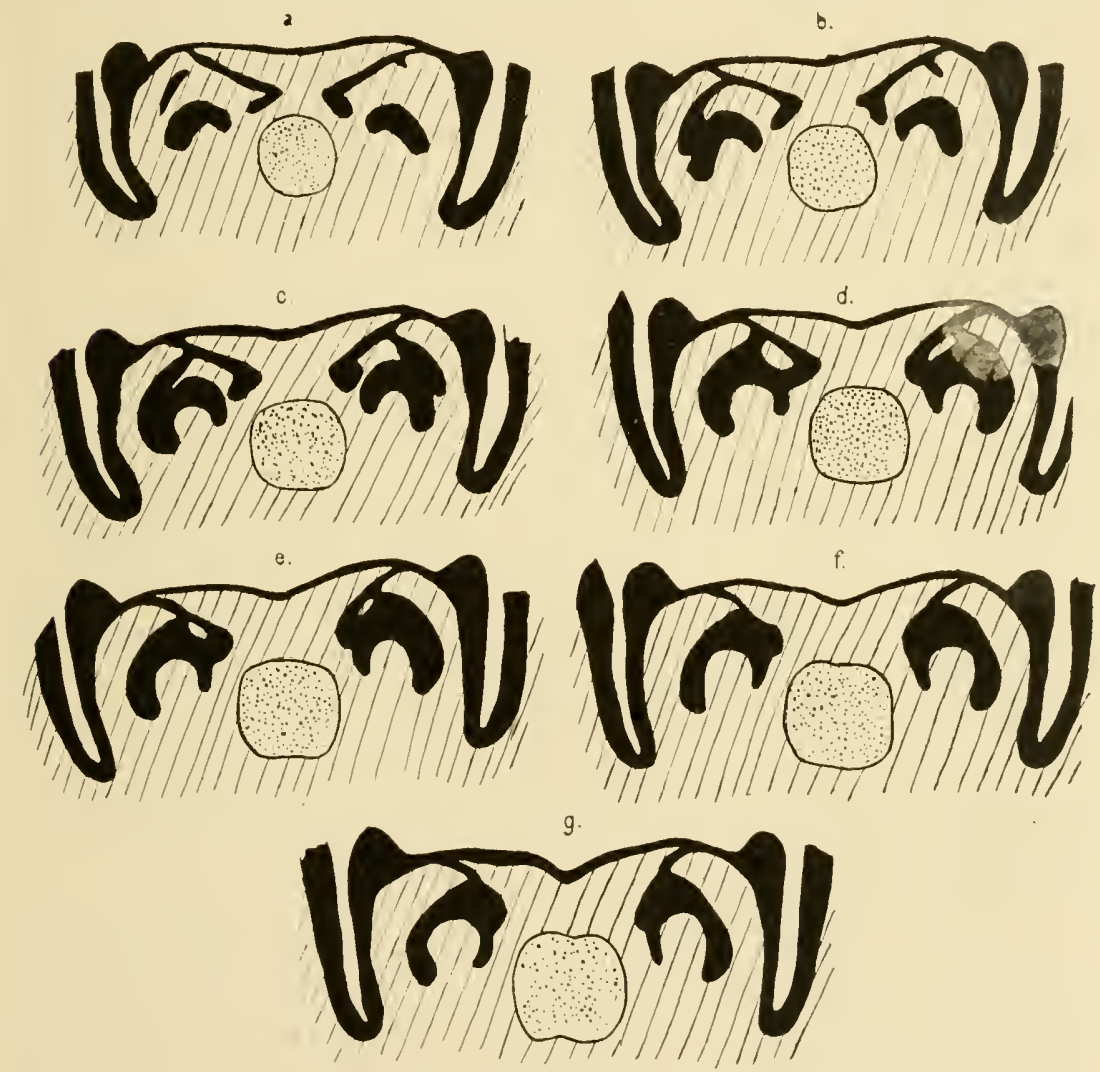

Fig. 5. Macacus cynomolgus. Anlage der unteren medialen Incisivi.

ist dadurch gezwungen, für die Genese des Zahnes der lateralen Leiste eine ganz gleiche Dignität anzuerkennen als der Zahnleiste. Daß dieser Gesichtspunkt ausschlaggebend ist für die Auffassung des morphologischen Wertes des Primatenzahmes, sei hier nur im Vorïbergehen erwähnt.

Wir haben jetzt das Auftreten einer lateralen Schmelzleiste beim Menschen und bei zwei der niedrigsten Primaten konstatiert. Ich werde jetzt noch ein paar Beispiele aus der Gebißentwicklung der wahren Affen anführen.

Die Fig. 5 bringt eine Serie von sieben aufeinander folgenden Schnitten durch den Unterkiefer eines Embryos von Macacus cyno- 
molgus mit der Anlage der beiden medialen Incisivi. Die Schnitte besitzen eine Dicke von $15 \mu$. Die Schnittrichtung weicht nur äuBerst wenig von der frontalen Ebene ab, die Zahnanlage in der linken Seite der Figur ist ein wenig mehr nach hinten getroffen als jene der rechten Seite.

In Fig. 5 a sind sofort die beiden, an ihren Enden hakenförmig umgebogenen Zahnleisten zu crkennen. An der rechtsseitigen macht sich eine kurze Sprosse bemerkbar, die erste Andeutung der lateralen Schmelzleiste. Im folgenden Schnitt (Fig. $5 b$ ) ist die letztgenannte Leiste an der linken Seite in vollständiger Entwicklung zu sehen, sie geht von der lateralen Fläche der Zahmleiste zur bukkalen Fläche des Schmelzorganes. Es macht ganz den Eindruck, als liege sie dieser Fläche angeschmiegt, denn sie läßt noch deutlich ihr freies unteres Ende erkennen. Das Bild, das wir hier sehen, erinnert sehr stark an jenes, das man oftmals an der medialen Wand des Schmelzorganes antrifft, wo die Zahnleiste ein freies Ende zeigt. Daß es sich hier nicht um etwas Zufälliges handelt, geht aus Fig. $5 c$ hervor, wo die Zahnanlage an der reehten Seite fast genan das Spiegelbild darstellt von jener der linken Seite in Fig. $5 b$. In der rechten Hälfte der letztgenannten Figur tritt die laterale Schmelzleiste etwas deutlicher hervor, aber zu einer Verbindung mit dem Organ ist es noch nicht gekommen. Das ist wohl der Fall im folgenden Schnitt, wo die Schmelzorgane beiderseitig mit der lateralen Leiste in Verbindung getreten sind, aber noch nicht mit der Zahnleiste. Dieses creignet sich im nächsten Schnitt (Fig. $5 d$ ), wo beide Leisten mit dem Schmelzorgan verschmolzen sind, oder man konnte es auch ausdrïcken, dab das Schmelzorgan seine beiden Verbindungen mit der Zahnleiste bekommen hat. Doch bevorznge ich es, von zwei Leisten zu sprechen, weil dadurch der wahre Sachverhalt besser zum Ausdruck gebracht wird. Beiderseitig erscheint wieder ein Teil des Mesenchyms wie in der Zahnanlage eingeschlossen. Es ist jedoch ohne weiteres aus den schon gegebenen Beispielen erkenntlich, daß dies nur scheinbar der Fall ist, die bezügliche Mesenchymmasse liegt eingeschlossen zwischen der eigentlichen Zahnanlage und dem Leistensystem.

In dem folgenden Schnitt (Fig. $5 e$ ) sind die Ansatzstellen beider Leisten am Schmelzorgan einander schon sehr dicht genähert, und im nächsten Schnitt sind sie zusammengeflossen (Fig. 5 f). Gleichzeitig ist die größte Breite des Organes erreicht, demn im letzten abgebildeten Schnitt fängt es schon an, sich zu verkleinern.

Die Fig. 5 gestattet ohne Mühe eine Einsicht in die topographische Beziehung der lateralen Schmelzleiste zum Schmelzorgan, die eine etwas andere ist als jene der Zahnleiste. Denn letztere behält ihre Anheftungsstelle immer an der medialen Seite des Organs. Die laterale Leiste dagegen liegt da, wo sie zuerst getroffen wird, also mit ilırem vorderen Rande der Anßenfläche des Organes an. Je weiter man mun nach hinten rückt, desto mehr verschiebt sich die Anheftungsstelle zum Gipfel des Organes, ja wie wir später noch sehen werden, kann die Anheftungsstelle sich sogar auf die mediale Fläche hinüberschieben.

Als Beispiel eines platyrrhinen Affen gebe ich in Fig. 6 eine Schnittserie durch den Caninus des Unterkiefers eines Mycetes (Mycetes, Serie $A, 20 \mu$ ). 
Es brancht nach allem, was bei den vorangehenden Figuren auseinandergesetzt ist, diese Skizzenserie wenig Erklärung. Die verschiedenen Skizzen lassen in ihrer Reihenfolge deutlich das Auftreten der lateralen Schmelzleiste erkennen (Fig. $6 a$ ), welche aus der Zahnleiste ihren Ursprung nimmt, sich verlängert (Fig. 6b,c,d), sich etwas mehr dem freien Rande der Zahnleiste nähert, so dab es den Anschein hat, als spaltete sich die Zahnleiste gabelig in zwei gleich große Schenkel (Fig. $6 e$ ). Es tritt das Schmelzorgan auf (Fig. $6 f$ ), anfänglich ohne Zusammenhang mit einer der beiden Leisten, $11 \mathrm{~m}$ jedoch bald zuerst mit der lateralen Schmelzleiste (Fig. 6 g) und im nächsten Schnitt (Fig. 6h) auch mit der Zahnleiste sich zu verbinden. Es macht den Eindruck, als wiirde das Schmelzorgan in diesem Falle zwisehen den beiden Leisten eingefaßt, wovon die eine sich dessen medialer Fläche anschmiegt, die andere dessen der Mundhöhle etwas zugekehrter bukkalen Fläche (Fig. 6i). Die Skizzen $h$ und $i$ zeigen deutlich die etwas hervorragenden freien Ränder beider Leisten. Es kommt in diesem Falle nicht zur Einschließung einer Mesenchymmasse zwisehen den beiden Leisten und dem Schmelzorgan wie bei den vorigen Präparaten. Besonders diese Erscheinung ist dami auch oftmals entweder gar nicht oder nur sehr undeutlich zu sehen. Wir werden die Ursache davon später nachweisen. Es ist das Fehlen dieses Stadimms in dem bezïglichen Fall deshalb von nicht geringem Wert, da jetzt deutlich hervortritt, dab die beiden I,eisten: Zahnleiste und laterale Schmelzleiste für das Schmelzorgan von ganz übereinstimmender Bedeutung sind.

Wenn man die weiteren Schnitte durch diese Zahnanlage verfolgt, dann wird es dentlich, daß die laterale Schmelzleiste scheinbar ilıre Verbindung nit dem Organ am ersten aufliebt. Denn schon in der Skizze $h$ fehlt jede Andeutung dieser Leiste und es scheint das Organ nur mit der Zahnleiste zusammenzuhängen. Ich mache wieder
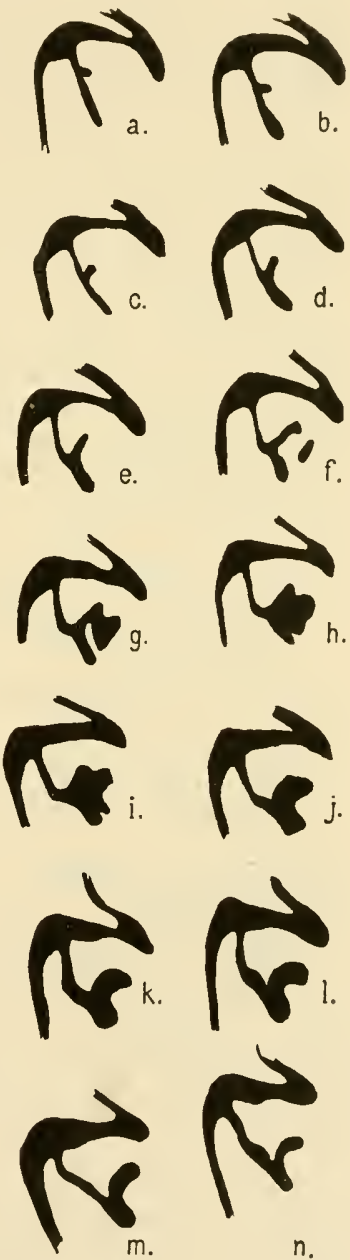

Fig. 6. Mycetes $A$. Anlage des unteren Caninus. auf die oberflächliche Übereinstimmung aufmerksam zwischen dem Leistenkomplex in Skizze $e$ und einem Schnitt durch das hintere Ende der Zahmanlage wie in Skizze $n$. In der erstgenannten Skizze wird eine Einstülpung eines Zahnkeimes vorgetäuscht.

Bis jetzt haben wir Sehnittserien durch Zahnanlagen vorgeführt, worin die Entwicklung der lateralen Schmelzleiste und die Beteiligung derselben an der Bildung des Schmelzorganes sehr evident war. Ich 
werde jetzt eine serie folgen lassen, welche durch das abweichende Betragen der Zahnanlage besoudere Aufmerksankeit beausprucht.

In meiner Abhandlung ïber die Entwicklung des Gammens beim Menschen und die Bedeutung der Zahnleiste habe jch schon darauf hingewiesen, daß es nicht bei allen Primaten zur Entstehung einer Zahnleiste kommit, wenigstens nicht für die Anlage der Milchzähne. Dieselben entwickeln sich ohne Zwischenkunft einer Zahnleiste direkt aus dem Mundhöhlenepithel. Das ist z. B. der Fall bei den Semnopitheeiden, wie mir aus Beobachtungen bei Semuopithecus maurus und nasicus bekannt ist. Auch bei Tarsius kommen die Milchzähne direkt ans dem Kieferepithel zur Anlage. Es findet sich jedoch zwischen den Anlagen eine verbindende niedrige Leiste, sowohl bei Semmopithecus als bei Tarsius. Es war $n$ nutürlich höchst interessant, festzustellen, ob anch bei diesen Formen eine laterale Schmelzleiste auftritt und wie dieselbe sich in diesen Fällen verhält. Die Antwort darauf findet sich in den Figuren 7 und 8.

Die Fig. 7 bringt die Skizzen einer lïckenlosen Serie durch die Anlage vom ersten Milchmolaren im Unterkiefer eines Semnopithecus maurus (Präparat vom Embryologischen Institut zu Utrecht. Semnopitheeus maurus. 125. Glas 27).

Die Schnitte $a$ und $b$ zeigen die sehr gering entwickelte Zahnleiste unmittelbar vor der Zahmanlage. In $c$ ist sie schon etwas an-

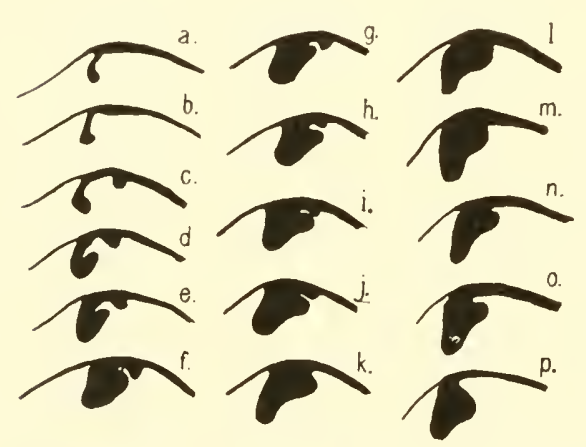

Fig. 7. Semnopithecus maurus. Anlage des ersten unteren Nilchmolaren. gesehwollen, und in geringer Entfermung bukkal vou ihr tritt eine zweite kurze Sprosse auf, welche ebenfalls direkt aus dem Mundhöhlenepithel ihren Ursprung nimmt. Diese Sprosse stellt die erste Andeutung der lateralen Schmelz. leiste flar, welche, da die ganze Zahnanlage hier sozısagen noch in der Kontinuität des Kieferepithels eingeschlossen ist, anch hier direkt ans demselben entsteht. Im uächsten Schnitt (Fig. $7 d$ ) schwillt die Zahnleiste an, krümmt sich hakenförmig an seinem freien Rande $u m$, indem die laterale Schmelzleiste etwas umfangreicher geworden ist. Zwischen den beiden Leisten findet sich wieder eine zum Teil abgeschnürte Mesenchymmasse, ganz wie wir das bei den vorigen Objekten in viel dentlicher Weise schon beobachtet haben. Bei den folgenden Sehnitten ändert sich der Zustand nur wenig. Die laterale Schmelzleiste nimmıt allmählich die Form einer Veraickung des Mundhöhlenepithels an, die durch einen schmalen Einschnitt von der inzwischen stark verdickten, auf dem Durchschnitt dreiseitigen Zahnleiste getrennt bleibt (Fig. 7, Skizze $f$ bis $j$ ). Schließlich kommt es jedoch zu einer Verlötung der beiden Leisten (Fig. $7 \mathrm{k}$ ) und bald ist von der zweifachen Anlage jede Spur verwischt (Fig. $7 l$ ) und die Zahnanlage in ihrer ganzen Breite mit dem Mundhöhlenepithel verbunden. Weiter wach hinten fängt nun bald die Anlage an sich 
von dem Kieferepithel abzusehnïren und auch jetzt erst wird eine Andeutung der Einstïlpung der basalen Fläche des Schmelzorganes durch die Zahnpapille bemerkbar.

Aus diesem Fall ersehen wir erstens, daß auch bei den Molaren die laterale Schmelzleiste an der Bildung des Schmelzorganes beteiligt ist. Bis jetzt war nur von Schneidezähnen und Eckzahn die Rede. Weiter lernen wir, daß auch bei jenen Formen, wo die Milchzähne sich unmittelbar aus dem Kieferepithel differenzieren, die beiden an der Anlage des Schmelzorganes beteiligten Leisten ans dieser Grundlage ihren Ursprung nehmen, und es erscheint die laterale Schmelzleiste in ilırem ersten Erscheinen ganz unabhängig von der Zahnleiste. Zwar ist der vorgeführte Fall an sich nicht so deutlich als die vorigen, und es war die Kenntnis der an jenen gezeigten Tatsachen eine notwendige Bedingung, $1 \mathrm{~m}$ die Erscheinungen bei der Zahnanlage von Semnopithecus begreifen zu können. Es sei ausdrücklich darauf hingewiesen, daß für das Studium der bezüglichen Entwicklungsphänomene nicht alle Objekte glejeh günstig sind. Und die Semnopetheciden - auch Tarsius - gehören gerade durch die eigentïmliche Beziehung der Zahnanlage zu dem Kieferepithel, zu den weniger günstigen $\mathrm{Ob}$ jekten.

Um zu zeigen, daß es sich bei dem oben beschriebenen Semnopithecus nicht 1 m einen isolierten Fall handelt, gebe ich in Fig. 8 noeh eine Skizzenserie dureh die Zahnanlage eines Nasenaffen. Es betrifft den zweiten unteren Molaren. Schon in Skizze a sind die beiden aus der Kieferbekleidung ins Kiefermesenchym eindringenden epithelialen Sprossen zu sehen, medial die mächtiger entfaltete, der Zahnleiste entsprechende Sprosse, bukkal die kleinere, welche die Anlage der lateralen Schmelzleiste darstellt. Die Relation zwisehen beiden ist hier wieder eine etwas andere als bei dem Semnopithecus maurus, denn man sieht, wie die laterale Sprosse allmählich kräftiger wird und wie die beiden Anlagen wovon die mediale allerdings die größere

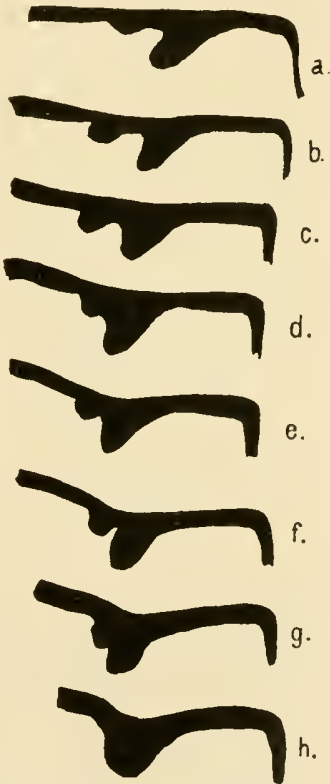

Fig. 8. Semnopithecus nasicus. Anlage eines zweiten unteren Molaren. bleibt - sich einander immer mehr nähern, $1 \mathrm{~m}$ sehließlich zı einer einheitlichen Masse zusammenzufließen. Von einer Einstülpung durch die Zahnpapille war hier noch nichts zu sehen.

Ieh glaube mich mit dem Obenstehenden vorläufig begnïgen zi: können. Es sind jetzt der Tatsachen genügend angeführt, um die Behauptung zu begründen, daß uie Zahnanlage der Primaten komplizierter ist als die in der Literatur geläufige Darstellung. Ehe wir nun die weitere Entwicklung näher verfolgen, werden wir die jetzt bekannt gewordenen Tatsachen kurz zusammenfassen und das Essentielle derselben hervorheben.

Es war in den gegebenen Beispielen - wenigstens in jenen, welche etwas ausführlicher besprochen sind - von Ineisivi und Canini 
die Rede. Nur die Figuren 7 und 8 haben auf Molaren Bezug. Es sind jedoch diese Figuren hauptsächlich gegeben, um zu zeigen, daß auch bei solehen Formen, bei denen die Zähne sich unmittelbar aus dem Mundhöhlenepithel differenzieren, cine laterale Schmelzleiste vorkommt. Eine mehr detaillierte Schilderung der Erscheinungen an den Molaren werde ich erst später geben, die laterale Leiste verhält sich bei diesen Zähnen etwas abweichend von jener bei den Antemolaren.

Als grundlegende Untersuchung für unsere jetzige Keuntnis der Entwicklung des menschlichen Gebisses gilt noch immer die bekannte Arbeit von Röse. Die Darstellung, welche dieser Autor von dem Entstehen der menschlichen Zähne gibt, ist wohl in alle allgemeinen und speziellen Lehrbücher der Anatomic übergegangen, wie eine Reproduktion seiner auf Grund dieser Untersuchumg angefertigten Wachsmodelle sich wohl in jeder anatomischen und zahnärztlichen Anstalt finden.

Das große Verdienst des genamnten Forschers für die Bereicherung unserer Kenntnis der Zilhnentwicklung möchte ich in keiner Weise beanstanden, es darf gerade die klare Auseinandersetzung seiner Beobachtungen und die Einfachheit seiner Modelle als die Ursache angesehen werden, daß eine neue systematische Untersuchung über den bezïglichen Gegenstand in den letzten 20 Jahren unterblieb. Persönlich bin ich dann auch indirckt zu einer Tachprïfung gebracht worden, da mein ursprïnglicher Zweck nur war, die Entwicklung des Gebisses der Affen, wovon bis jetzt noch nichts in der Literatur bekannt war, mit jener des Menschen zu vergleichen. Wenn ich dabei auf die oben als laterale Schmelzleiste beschriebene Bildung stieß und dieselbe bald als eine normale Erscheinung bei den Affen kennen lernte, war ich von selber gezwungen, auch das menschliche Gebiß auf das Vorkommen dieser Bildung zu untersuchen. - Ich glaube, es hat keinen Sinn, die Frage aufzuwerfen, warum diese Leiste Röses Aufmerksamkeit entgangen ist.

Die Fig. 1 hat bezug auf einen menschlichen Embryo, wobei der zweite Milchmolar noch nicht zur Anlage gekommen war, und es fragt sich nun, zu welcher Zeit wird die laterale Schmelzleiste bemerkbar. Wenn wir die Rösesche Beschreibung des jüngsten Entwicklungsstadiums heranziehen, dann heißt es auf S. 453 von einem Embryo von $25 \mathrm{~mm}$ Steiß-Scheitellänge, daß am freien Rande der Zahnleiste im Unterkiefer schon deutlich 10 Erhebungen und dazwischen liegende Vertiefungen sich abgrenzen lassen. (Man vergleiche das jüngste Rösesche Modell.) Das nächste vom Autor beschriebene Stadium hat eine Länge von $32 \mathrm{~mm}$ und davon heißt es (l. c. S. 454): Hier haben sich die vorher beschriebenen Erhebungen der Leiste kolbig verdickt und in diese Verdickungen stülpen sich die bindegewebigen Papillen ein. Icl sehe hier in jedem Kiefer acht eingestülpte Papillen in ziemlich gleichmäßiger Entwicklung. Beim nächsten Stadium von $4 \mathrm{~cm}$ Länge sind bereits alle 10 Papillen des Milehgebisses vorhanden. Das Modell II ist nach einer Sagittalserie dieses Embryos modelliert. Bis so weit die Angaben von Röse.

Zu diesen Erörterungen möchte ich zunächst eine Bemerkung machen. Es ist deutlich, daß zwischen den beiden vou Röse beschriebenen menschlichen Embryonen ein ziemlich großes Hiat sich findet. 
Während am ersteren nur einige Erhebungen sich finden, besitzt das zweite, wie auch aus dem Modell zu ersehen, bereits sämtliche wohl entwickelte, in den Schmelzorganen eingestülpte Papillen der Milchzähne. Beim jüngsten Objekt sind die Zahnanlagen noch knospenförmig im Simne Leches, beim älteren besitzen die Zahnanlagen schon deuthehe Kappenform. Ich habe nun aus dem bezüglichen Entwicklungsstadium mehrere Serien von menschlichen Embryonen und von Affen auf die erste Anlage der Zähne untersucht. Ich habe dabei konstatieren kömnen, daß das erste Erscheinen der lateralen Schmelzleiste mit der ersten Differenzierung der Zahnanlage zusammenfällt. In welcher Weise dieses geschicht und welche Bedeutung man dem sogenannten knospenförmigen Stadium geben muß, werde ich erst später, nach der vollständigen Beschreibung der Tatsachen, auseinandersetzen können. Allerdings sind jene sèhr frühen Entwicklungsstadien weniger geeignet, um eine rasehe Einsicht in der Bedeutung dieser Leiste für die Zahnentwicklung zu bekommen. Man tut am besten, diese Bildung zunächst bei etwas älteren Embryonen von ungefähr $40-45 \mathrm{~mm}$ Steiß-Scheitellänge zu studieren, um dann allmählich zu immer jüngeren überzugehen. Und verfährt man in dieser Weise, damn wird man konstatieren, daß die ersten Spuren der Leiste sich schon im knospenförmigen Stadium der Zahnanlage kemubar machen.

Zum Beweise gebe ich zunä.chst in Fig. 9 eine umunterbrochene Schnittserie durch die vordere Hälfte der Anlage des lateralen unteren Incisivus eines mensehlichen Embryos von noch nicht ganz $3 \mathrm{~mm}$ Steiß-Scheitellänge. Die Serie ist katalogisiert als Homo, Serie $S$, die Sehnittdicke beträgt $10 \mu$.

Wenn man nun einmal vertraut nit dem Auftreten und das Vorkommen der lateralen Schmelzleiste bei den etwas älteren Embryonen die Skizzen der Reihe nach verfolgt, so konstatiert man sehon in Skizze $a$ die allererste Andeutung desselbenals einer ganz niedrigen Sprosse an der Zahnleiste, gerade an der Stelle, wo rliese mitydem Mundhöhlenepithel zısammenhängt. In Skizze $b$ ist die Sprosse sehou etwas mächtiger geworden, und in dem nächstfolgenden Schnitt (Fig. $9 c)$ ist es deutlich, daß man im Bereich einer

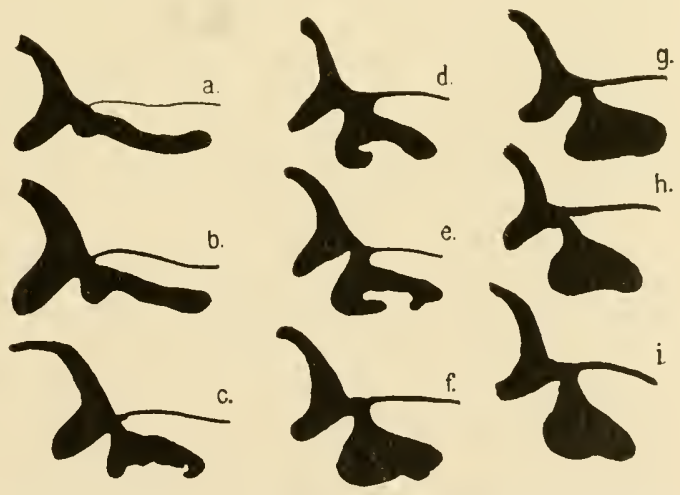

Fig. 9. Homo. Serie $S$. Anlage eines lateralen unteren Incisivus. Zahmanlage sich findet.

Das Bild trägt jedoch den gleichen trïgerischen Charakter, worauf ich bei etwas älteren Stadien (Fig. 1 u. 2) bereits hingewiesen habe. Man könnte meinen, man hätte es hier mit der sehon ein wenig eingestülpten Schmelzorgananlage zu tun, das ganze epitheliale Gebilde ist auf dem Durchschnitt dreicckig mit einer geringen Aushöhlung der Basis. Ganz iibereinstimmende Bilder bekommt man in der Tat, 
wenn das wirkliche Schmelzorgan im Begriff steht, vom knospenförmigen Stadium ins kappenförmige iuberzugehen. Das epitheliale Gebilde in Fig. $9 c$ stellt jedoch nicht die Anlage des Sehmelzorganes dar, sondern die medialwärts gerichtete Zahnleiste, von deren basalem Ende die breit mit ihr zusammenhängende laterale Schmelzleiste abgeht. Das wird dentlicher im nächstfolgenden Schnitt (Fig. 9d), wo die laterale Schmelzleiste ein wenig mehr selbständig geworden ist und sich - in ähnlicher Weise, wie wir es bei den älteren Embryonen beschrieben haben - in der Richtung des freien Endes der Zahnleiste umzubiegen anfängt. Im nächsten Schnitt (Fig. $9 e$ ) hat auch letztere eine hakenförmige Umbiegung in der Richtung der lateralen Schmelzleiste gebildet. Aus der Form des von den beiden Leisten umgrenzten Raumes ist wohl ohne weiteres klar, dab es sich hier nicht um eine Einstïlpung des Schmelzorganes handelt. Dieses Organ tritt erst im nächsten Schnitt auf (Fig. 9f). Weder von Zahnleiste noch von lateraler Schmelzleiste ist in diesem Schnitt etwas mehr zu verspüren, sie sind gleichfalls zusammengeflossen mit der Schmelzorgananlage. Die Skizzen $f$ bis $i$ geben die aufeinander folgenden Schnitte durch den vorderen Teil dieses Organes an, das sich noch über sieben Schnitte weiter ausdehnt. Von einer Einstülpung durch die Zahnpapille war jedoch noch nichts zu sehen, das Organ war noch ganz im knospenförmigen Stadium. Aus diesem Beispiel geht somit zur Genüge hervor, daß die laterale Schmelzleiste schon nachzuweisen ist, wenn die Zahnanlage noch im knospenförmigen Stadium sich befindet. Diese Leiste macht somit gewiß einen integrierenden Bestandteil der Anlage des Zahnes aus.

Daß bei den Affen ganz übereinstimmende Verhältnisse vorliegen, davon gab Fig. 7 schon einen Beweis, demn auch bei diesem Semnopithecus findet sich die Zahnanlage noch im knospenförmigen Stadium und doch ist auch hier die laterale Leiste schon nachweisbar. Wenn man die Skizzen Fig. $7 c, d, e$ und $f$ mit den Skizzen Fig. $9 b, c, d$ und $e$ vergleicht, dann konstatiert man leicht die große Übereinstimmung. Der Unterschied zwischen beiden Serien ist nur die Folge davon, daß bei Semnopithecus die Zahnanlage ganz in der Kontinuität des Kieferepithels sich findet.

Dem gegebenen Beispiele könnte ich noch viele hinzufïgen, ich hoffe jedoch, daß das Vorgeführte genïgt, um die sehr frïhe Differenzierung der lateralen Schmelzleiste zu beweisen. Es muß jedoch bemerkt werden, daß im allerfrïhesten Stadium, wenn die Zahnanlage sich gerade in der Form einer Anschwellung am freien Rande der Zahnleiste kennbar macht, von dieser Leiste nicht die geringste Spur zu sehen ist. Das hängt mit ihrer Bildungsweise zusammen, welcher jedoch erst später eine ausfiihrliche Besprechung gewidmet werden kann.

Nachdem wir somit festgestellt haben, daß die laterale Schmelzleiste einen inhärenten Bestandteil der Zahnanlage bildet, werden wir etwas näher auf ihre topographischen Beziehungen zum eigentlichen Schmelzorgan eingehen. Mit Hilfe der Figuren 1, 2 ı. 5 ist es möglich, sich eine approximative Vorstellung dieser Verhältnisse zu maehen. Denn wenn man z. B. an der Hand von Fig. 1 die Anlage vom unteren Incisivus des Menschen verfolgt, dann konstatiert man folgendes: Der vordere Rand der lateralen Schmelzleiste liegt etwas weiter nach 
vorn als das eigentliche Schmelzorgan. Denn in Fig. $1 b$ und $c$ ist wohl die Leiste getroffen, das Schmelzorgan tritt aber erst in Fig. $1 d$ auf. Selbstverständlich hat die Schnittrichtung einen Einfluß anf das zum Vorschein tretende Bild. Die Präparate wurden dann auch immer möglichst genau frontal zur Mundspalte geschnitten. Wenn die beiden Leisten - die Zahnleiste und die laterale Schmelzleiste - mit ihren Rändern sich mit dem Schmelzorgan verbunden haben (Fig. $1 e$ ), bilden dieselben oberhalb des Organes ein Gewölbe, deren Lichtıng durch Bindegewebe ausgefüllt ist. Je weiter der Schnitt nach hinten liegt, desto niedriger und enger wird das Gewölbe infolge der Annäherung beider Leisten aneinander. Schließlich fließen diese zusammen, wodurch ihre Abgrenzung gegeneinander und gegen das Schmelzorgan verstrichen ist (Fig. 1 h). Diesen Vorgang kann man leicht auch an den übrigen Schnittserien verfolgen.

Wiewohl die räumliche Vorstellung der Zahnanlage auf Grund einiger Schnittserien obne viel Mühe gelingt, habe ich doch im Laufe meiner Untersuchung mehrere Wachsmodelle in der gewöhnlichen Weise angefertigt. Dieser Abhandlung ist anf Taf. I eine Reihe von fünf Abbildungen beigegeben, welche nach Modellen der Entwicklung des ersten Incisivus des Unterkiefers vom Menschen angefertigt worden sind. Es sind fünf aufeinander folgende Entwicklungsstadien. Wir beschränken uns vorläufig auf Tafelfigur 1. Das Modell stellt die Zahnanlage bei Embryo $A$ mit einer Steiß-Scheitellänge von nahezu $35 \mathrm{~mm}$ dar. Die Textfig. 1 (die Schnittbilder der nämlichen Anlage darstellend) und die Tafelfig. 1 vervollständigen einander. Das Modell ist abgebildet von der Vorderseite gesehen.

Man überzengt sich leicht, daß das Modell cine etwas andere Einsicht in die Zahnanlage gewährt als dic von Röse angefertigten Modelle. Nach der bereits beschriebenen Zahnanlage in einem frühen Entwicklungsstadium braucht die Tafelfig. 1, besonders wenn man sie mit Textfig. 1 vergleicht, wenig Erklärung mehr. Dic laterale Schmelzleiste ist sofort zu erkennen und ebenfalls die Zahnleiste. Der vordere Rand des Schmelzorganes ist noch ziemlich schmal, wiewohl das Organ von unten schou deutlich eingebuchtet erscheint. Es sei nun besonders die Aufmerksamkeit auf die Grube gefestigt, welche sich oberhalb des Schmelzorganes befindet, medial oder besser lingual durch die Zahnleiste, bukkal durch die laterale Schmelzleiste und nach unten durch die Anlage des Schmelzorganes begrenzt. Diese Grube ist nach hinten - d. h. vom Zuschauer - abgeschlossen, da die beiden genannten Leisten ineinander ïbergehen; sie hat eine breite Eingangsöffnung. Dieser Ramm hat somit die Form einer Nische, sie wird weiter als ,Schmelzkrypte oder Schmelznische bezeichnet.

Beim ersten Incisivus des Unterkiefers ist die Nische nach vorn - in bezug auf die Körperebcne bei diesem Zahn richtiger nach medial - offen. Das ist auch der Fall bei sämtlichen übrigen Schneidezähnen und bei den Eckzähnen, auch noch beim ersten Milchmolaren. Es verdient diese scheinbar unbedentende Tatsache nachdrïcklich hervorgehoben zu werden, denn wir werden bald sehen, daß bei den Molaren allmählich ein entgegengesetztes Verhalten sich entwickelt. Es streckt sich die Krypte hauptsächlich über die vordere Hälfte der Schmelzorgananlage aus, da letztere, wie aus den Textfiguren leicht ersichtlich, sich noch fortsetzt, wenn die Nische schon verschwunden ist. 
Betrachten wir jetzt noch einmal die Tafelfig. 1, um uns möglichst vollständig über die Beziehung des Schmelzorganes zu den beiden Leisten zu orienticren. Es ist in diesem sehr jungen Entwicklungsstadium deutlich, daß das Schmelzorgan zu den beiden Leisten in vollständig gleicher Beziehung steht. Der untere Rand der Zahnleiste geht in den medialen (lingualen) Rand des Organes über, ganz in derselben Weise, wie der untere Rand der lateralen Schmelzleiste mit dem lateralen (bukkalen) Rand des Organes sich verbindet. Man muß sich dieses primitiven Verhaltens wohl eingedenk bleiben, da sich später infolge von Wachstumsvorgängen am Schmelzorgan die Verhältnisse wesentlich ändern. Und es ist selbstverständlich, daß für eine Auffassung der genetischen Bedeutung dieser Erscheinungen gerade solche Zustände herangezogen werden müssen, welche am wenigsten durch sekundäre Wachstumsvorgänge alteriert worden sind.

Es will mir scheinen, daß eine vorurteilsfreie Betrachtung des in Tafelfig. 1 abgebildeten Modelles, sowie die schon gegebenen T'extfiguren, notwendig zur Auffassung führen muß, daß die beiden Leisten, die Zahnleiste und die laterale Schmelzleiste, an dem Zustandekommen des Organes gleichen Anteil haben. DaB diese Tatsache von tief ins Problem der Zahnentwicklung einschneidender Bedentung ist, brancht kaum hervorgehoben zu werden. Denn das Schmelzorgan erscheint jetzt nicht mehr als eine einfache Bildung, sondern als eine Doppelbildung. Doch werde ich vorläufig auf die theoretische Bedeutung der Tatsachen nicht eingehen.

Wir sind jetzt über die frühe Phase der Zahnentwicklung der Antemolaren bei Primaten genïgend unterrichtet, um zur Beschreibung der Erscheinungen an den Molaren übergehen zı können. Denn wiewohl keine prinzipiellen Abweichungen bei diesen Zähnen vorliegen, ist der Vorgang bei denselben doch in typischer Weise modifiziert.

Es ist oben ausdrücklich die Tatsache ins Licht gestellt worden, daß bei den Antemolaren die Emailkrypte nach vorn offen ist, nach hinten geschlossen. Es streckt sich dann auch in Verbindung damit die laterale Schmelzleiste etwas weiter nach vorn ans als das Schmelzorgan, so daß man an einer Schnittserie zumeist erst die laterale Schmelzleiste aus der Zahnleiste hervorsprossen sieht, und erst einige Schnitte weiter nach hinten tritt das Schmelzorgan auf. Man kontrolliere das an den Fig. 1-9, damit man den Gegensatz zu den Verhältnissen bei den Molaren besser verstehe. Es sei noch eimmal hervorgehoben, daß es sich in allen diesen Fällen um frühe Entwicklungsstadien handelt. Verfolgt man nun eine Serie durch die Anlage eines Molaren, dann ist es bald deutlich, daß bei diesen Zähnen die topographische Bezichung zwischen Schmelzorgan und lateraler Schmelzleiste eine andere geworden ist. Zum Beweise davon fange ich mit einem sehr eklatanten Beispiel an. In Fig. 10 sind einige Skizzen gegeben von Schnitten durch die Anlage des oberen dritten Milchmolaren von Mycetes (Serie $A$ ). Wenn man die Anlage dieses Zahnes von vorn nach hinten verfolgt, dann bemerkt man zunächst von einer lateralen Schmelzleiste nichts, die Zahnleiste schwillt an der bukkalen Fläche regelmähig an, bis die typische, auf dem Durchschnitt ungefähr dreieckige Anlage entstanden ist. Ohne viele Umänderungen rückt man in den folgenden Schnitten dem hinteren Ende der Anlage immer näher, was daraus zu erkennen ist, daß die Verbindung mit der Zahnleiste schmäler wird. Nun tritt 
am lateralen Rande in der in der Figur nach oben gekehrten Basis der Zahmanlage eine Einkerbung auf. Der bezügliche Schnitt ist in Fig. 10 a abgebildet, und im nächsten Schnitt tritt plötzlich die Schmelznische anf (Fig. 10 b), wodurch die Zahnanlage in doppelter Verbindung mit der Zahnleiste erscheint. Denn aus den weiter folgenden Schnitten ist es deutlich, daB auch hier die laterale Schmelzleiste aufgetreten ist. Im nächsten Schnitt (Fig. $10 \mathrm{c}$ ) ist die Schmelzkrypte vergrößert, das schon stark verkleinerte Schmelzorgan hängt nur noch mittels einer schmalen Brükke mit der lateralen Leiste zusammen und im folgenden Schnitt (Fig. $10 d$ ) ist diese Verbindung gelöst, die laterale

Schmelzleiste ist ganz selbständig geworden und geht von der bukkalen Fläche der Zahnleiste aus. Mit dem unteren

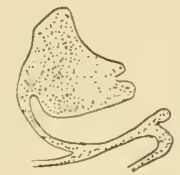
a.

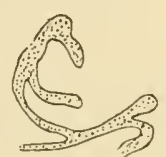

e

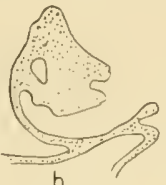

b
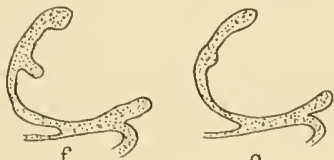

9 .

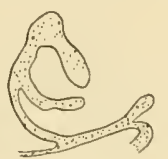

d.

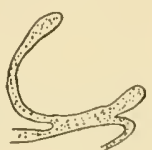

h.

Fig. 10. Mycetes $A$. Anlage des oberen dritten Milchmolaren.

nannten ist in senkrechter Richtung der hintere Rand des Schmelzorganes noch verbunden, der im nächsten Schnitt noch spurweise zu sehen ist. Die laterale Schmelzleiste erscheint auf dem Durchschnitt noch ziemlich lang, aber in dem nächsten Schnitt (Fig. 10f) ist sie auf eine kurze Sprosse reduziert, die in Fig. $10 \mathrm{~g}$ noch eben angedentet ist, und im letztabgebildeten Schnitt ist nur die Zahnleiste noch da in unkompliziertem Zustand.

Durch diesen Fall ist zunächst festgestellt, daß es auch bei den Molaren eine laterale Schmelzleiste gibt und weiter, daB diese zu dem Schmelzorgan des Molaren vollständig sich verhält wie jene der Antemolaren. Nur besteht der Unterschied, daß hier die Leiste sich manifestiert nicht an der vorderen, sondern an der hinteren Seite des Organes. Wenn man die Skizzen in Fig. 10 z. B. mit jenen in Fig. 1 vergleicht, damn ist die Übereinstimmung überraschend angenfällig. Die Aufeinanderfolge der Bilder in Fig. 10 ist aber geradezu nmgekehrt. Der meist hintere Schnitt durch die Anlage von $m_{3}$ und der meis: vordere durch jene von $i_{1}$ s:immen miteinander überein. Man vergleiche weiter Fig. $10 \mathrm{f}$ mit Fig. $1 \mathrm{c}$, Fig. $10 \mathrm{e}$ mit Fig. $1 \mathrm{~d}$, Fig. $10 \mathrm{c}$ nit Fig. $1 e$, Fig. $10 b$ mit Fig. $1 \mathrm{~g}$ und Fig. $10 a$ mit Fig. $1 \mathrm{~h}$.

Bei der Besprechnng der Antemolaren ist darauf hingewiesen, daß der Vorderrand des Schmelzorganes wie zwischen den unteren Rändern von Zahnleiste und lateraler Schmelzleiste eingefaßt ist. Gleiches gilt für den Hinterrand des Organes von $m_{3}$. Und es ist leicht einzusehen und aus den Figuren ersichtlich, daßs anch die Topographie der Schmelznische eine andere sein muß. Bei den Antemolaren liegt sie im vorderen Abschnitt der Zahnanlage und ist nach vorn offen, bei $m_{3}$ findet sie sich in der hinteren Hälfte und ist nach hinten geoffnet. Das wird später noch durch Figuren illustriert.

Man bemerkt, daß es einen prinzipiellen Unterschied zwischen Antemolaren und drittem Milchmolaren nicht gibt, nur eine Modi- 
fikation topographischer Art. Und daß es dabei nicht eine Erscheinung gibt, welche zu der Gebißdifferenzierung in Molaren und Antemolaren in Beziehung steht, geht daraus hervor, daß die soeben von $m_{3}$ beschriebene Sachlage keine ist, die plötzlich beim ersten Nolaren auftritt, sondern allmählich zustande kommt. Der erste und zweite Milchmolar bilden - wir sprechen bis jetzt immer noch ron Mycetes einen Übergangszustand zwischen den Antemolaren, wo die Emailkrypte ganz vorn gelagert ist, und den dritten Molaren, wo sie ganz hinten sich findet.

Um das zu zeigen, ist in Fig. 11 die Schnittserie gegeben durch die Anlage vom ersten unteren Milchmolaren von Mycetes $A$. Es ist wieder eine munterbrochene Reihe, welche von vorn nach hinten geht, die Skizze a gibt den meist vorderen Schnitt. Die Zahnleiste ist hier stark gekrümmt und an der Knickungsstelle geht von der lateralen Fläche eine kurze Sprosse aus. Diese ist die erste Andentung der lateralen Schmelzleiste, welche also anch bei dem ersten Milchmolaren, ganz wie bei den Antemolaren, noch vor dem Schmelzorgan in die Erscheinung tritt. In den drei folgenden Schnitten (Fig. 11b, c und $d$ ) wächst die Sprosse zu einer wirklichen Leiste an, und in Fig. 11 e

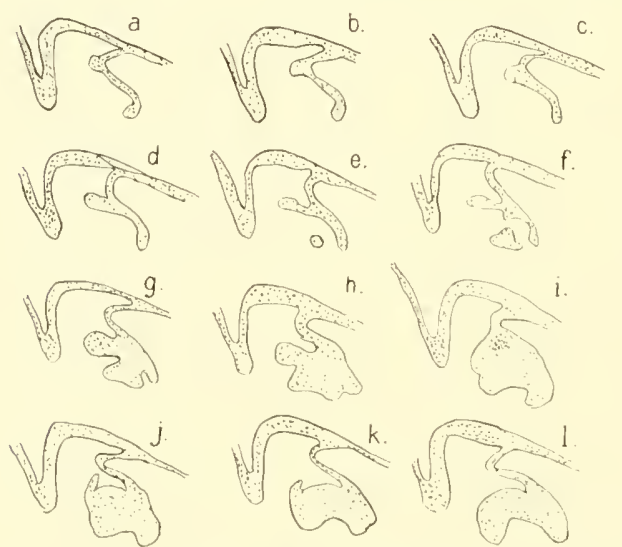

Fig. 11. Mycetes A. Anlage des ersten unteren Milchmolaren. taucht num zwischen dieser Leiste und der Zahnleiste das Schmelzorgan auf, das in Skizze $11 f$ schon über cine größere Breite getroffen ist. Es erscheint die Anlage hier zwischen ten beiden Leisten, wird von derselben überwölbt, ohne in Zusammenhang mit derselben getreten zu sein. Dis ist wohl der Fall inn nächsten Schnitt (Fig. $11 \mathrm{~g}$ ) und, indem die Verbindung zustande kommt, an der Stelle, wo Zahnleiste und laterale Schmelzleiste sich miteinander rerbunden, ragen

die treien Enden beider Leisten noch medial resp. lateral von der Anlage hervor. In Fig. $11 \mathrm{~h}$ ist die Verbindung zwischen dem Schmelzorgan und den beiden Leisten schon eine breitere geworden, aber noch immer sind die freien Enden derselben zu sehen. Im nächsten Schnitt ist jede Spur der medialen Leiste als selbständige Bildung verloren gegangen, die ganze mediale Fläche des Schmelzorganes stellt die Fortsetzung der Zahnleiste dar, an der lateralen Fläche ist noch durch eine seichte Einsenkung zil sehen, wie weit sich die laterale Schmelzleiste ansdehnt, aber anch diese Andentung fehlt schließlich im mächsten Schnitt (Fig. 11j), die laterale Leiste streckt sich bis zur Grundfläche des Organes aus. Gleichzeitig hat sich nun aber diese Leiste von der Zahnleiste gelöst, ragt noch als freie Sprosse aus der oberen lateralen Ecke des Organes hervor, die Sprosse ist in dem nächsten Schnitt niedriger (Fig. $11 h$ ), in der letzten Skizze verschwunden. 
Die topographische Bezichung der Schmelzorgananlage zu den beiden Leisten besitzt bei dem ersten Milchmolaren noch große Übercinstimmung mit den Antemolaren, doch bestehen schon geringe Unterschiede. Demn es kommt im beschriebenen Falle nucht zur Bildung einer eigentlichen Emailnische, da die Spitze des Organes sich mit den beiden Leisten gleichzcitig verbindet. Die Leisten setzen sich nicht zuerst am vorderen unteren Rande des Organes an, sondern zu selbiger Zeit an den beiden Seitenflächen. Es ist somit die erste Beriihrungsstelle schon etwas auf dem Organ nach rïckwärts verschoben. Diss ist beim zweiten Milchmolaren in noch stärkerem Maße der Fall. Ich glaube es überflüssig von Mycetes auch von diesem Zahn Schnittserien zu geben. Man kann sich leicht die Bezichmng seines Schmelzorganes zu den beiden Leisten als einen Übergangszustand denken zwischen den Verhältnissen beim ersten und dritten Molaren. Es folge überdies auch vom zweiten Molaren noch eine Serie eines menschlichen Emibryos.

Es ändert sich somit in der Richtung von vorn nach hinten die Beziehung des Schmelzorganes zu den beiden Leisten. Aus dem Umstand, daß diese Umänderung ganz allmählich sich vollzieht und nicht plötzlich, ist zu schließen, daß diese Erscheinung mit dem verschieden morpholoigschen Charakter vun Molaren und Antemolaren nichts zu tun hat. Und weiter folgt dic Unabhängigkeit beider Erscheinumgen noch daraus, daß die Beziehung von $m$, zur lateralen Schmelzleiste im Oberund Unterkiefer versehieden ist. Indem im Oberkiefer bei $m_{2}$ die Emailkrypte schon deutlich nach hinten sich öffnet, die laterale Schmelzleiste sich also im hinteren Abschnitt der Zahnanlage manifestiert, ist bei der Anlage von $m_{2}$ im Unterkicfer die Krypte noch nach vorn offen. Es ist überhaupt, wie mir aus der Untersuchung verschiedener Serien durch Embryonen von Affen und Menschen klar geworden ist, die Beziehung der lateralen Schmelzleiste zum Organ bei den Mo-

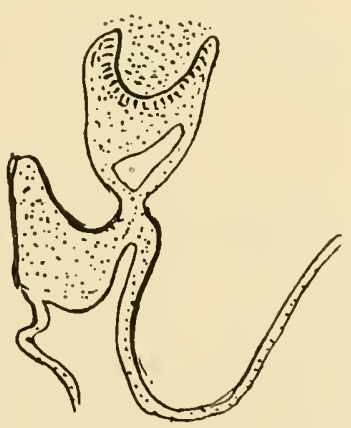

Fig. 12. Ifomo. Serie $C$. Schnitt durch die Anlage vom oberen $m_{1}$. laren cine etwas schwankende. Es liegen hier nicht jene konstanten Verhältnisse vor wie bei den Antemolaren. Es besteht dabei im allgemeinen jedoch die Tendenz, daß die Emailnische mehr nach hinten gelagert ist, je mehr der Zahn eine rückwärtige Stellnng im Gebiß eimnimmt. Diese Unterschiede besitzen jedoch nur geringe Bedeutung. Hauptsache ist, daß auch bei den Primaten an der Anlage der Milchmolaren eine laterale Schmelzleiste beteiligt ist.

Daß solches auch beim Menschen der Fall ist, geht aus Fig. 12 hervor, die einen Schnitt durch die Mitte der Anlage des ersten oberen Milchmolaren von Embryo $C$ bringt, und aus Fig. 13, welche eine Schnittserie durch den hintersten Teil der Anlage des zweiten oberen Milchmolaren von Embryo $E$ gibt. Diese Figuren genïgen, um das Auftreten der lateralen Schmelzleiste anch bei den menschlichen Holaren zı beweisen und brauchen keine weitere Erklärung. Nur kurz sei an dieser Stelle anf die Wucherungen hingewiesen, welche das Schmelzorgan in Fig. 13 aufweist. Diese sind nach Robin und Nagitot, welche 
zuerst eine gute Beschreihung derselben lieferten, öfters beschrieben und verschieden gedentet worden. Sogar für rudimentäre Anlagen der hypothetischen prälaktalen Zähne hat man sie angesehen. Ich komme später auf diese Erscheinungen zurück, da auch auf diese Bildungen durch das nachgewiesene Vorkommen der lateralen Schmelzleiste licht geworfen wirl.

Tachdem uns diese Tatsachen bekannt geworden sind, ist es wohl erwiinscht, das Hauptergebnis dieses Teiles meiner Untersuchung kurz zusammenzufassen.

Jedes Schmelzorgan steht gleich vom Anfang an nicht nur mit der Zahnleiste, sondern dazu noch mit einer zweiten Leiste in Verbindung: die laterale Schmelzleiste. Diese zweite Leiste nimmt an
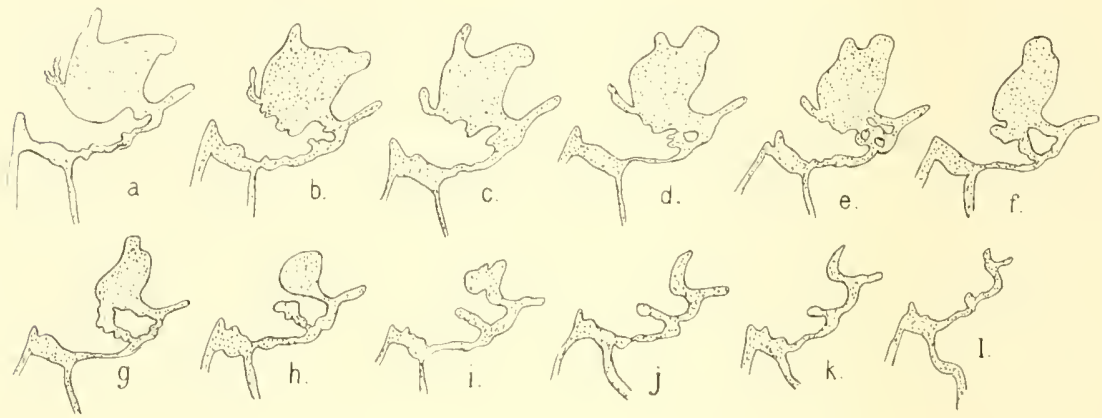

Fig. 13. Homo. Serie E. Anlage des oberen $m_{2}$.

der Bildung des Organes gleichen Anteil als die eigentliche Zahnleiste. Das Schmelzorgan steht mit seinem bukkalen Teil zur lateralen Schmelzleiste in ganz gleicher Bezichung wie der linguale Teil zur eigentlichen Zahnleiste. Das Schnelzorgan der Primaten ist daher genetisch nicht als eime Einfachbildung. sondern als eine Doppelbildnng zu betrachten. Man muß sich denken, daß die bukkale Hälfte zur lateralen Schmelzleiste, die linguale Hälfte zur Zahnleiste in engerer genetischer Beziehung steht.

Fïr letztere Behauptung ist bis jetzt noch kein zwingender Grund angeführt worden. Es ist, solange die Untersuchung auf junge Embryonen beschränkt bleibt, eine sich von selbst anfdringende Vermutıng. Es werden jedoch später anch für diese Behauptung Beweise beigebracht.

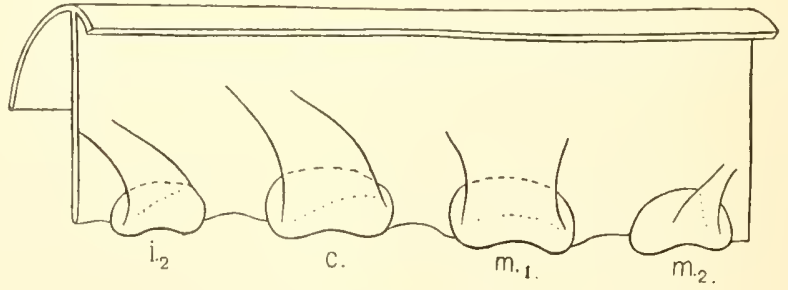

Fig. 14. Erklärung im Text.

Ich gebe in Fig. 14 eine auf die bis jetzt mitgeteilten Befunde basierte halbschematische Vorstellung der Gebißanlage eines Primaten, 
wobei ich mir die Anlage in Unterkiefer von der bukkalen Seite gesehen gedacht habe. Es sind nur zwei Antemolaren und zwei Milchmolaren angegeben. Die Figur erheischt wenig Erklärung. Der Hintergrund wird dnrch die bukkale Fläche der Zahnleiste gebildet. Der obere Teil derselben ist indifferent. Am mnteren Rande finden sich die vier Schmelzorgane, wobei ich die Andentung jedes Details unterlassen habe. Von der Mitte der Zahnleiste macht sich die laterale Schmelzleiste frei und zicht zum unteren lateralen Rande des Sehmolorganes. Die fein punktierte Linie, welche schräg über das Schmelzorgan verläuft, stellt die Ansatzlinie an Organ dar. Das verschiedene Verhalten der Leiste zu den verschiedemen Zahnanlagen ist ebenfalls zum Ausdruck gebracht, beim zweiten Incisivus (der zuerst angegebene Zahn) verläuft dieselbe von vorn nach hinten und beim zweiten Milchmolaren von hinten nach rorn, die beiden zwischenliegenden Zahnanlagen bilden Übergangsstadien.

Welches ist num das weitere Schicksal der lateralen Schmelzleiste? Es ist von der größten Bedeutung, daß es sich feststellen Iäßt, daß die Leiste während einiger Zeit mit der Größenzunahme des Schmelzorganes gleichen Schritt hält und dab ihre Beziehnug zum Organ auch in älteren Stadien in nichts zurïcksteht bei jener der medialen Leiste.

Fïr eine erste allgemeine Orientierung über die weitere Entwicklung der lateralen Schmelzleiste verweise ich anf die Tafelfiguren 2-5. Alle Figuren sind nach Wachsmodellen angefertigt. In Fig. 1 war die Anlage des ersten unteren Incisivus vom Menschen abgebildet (Embryo A). In Fig. 2-5 ist vom nämlichen Zahn die weitere Entwicklung in vier aufeinander folgende Stadien zur Darstellung gebracht. Die Fig. 2 gibt die Anlage wieder bei Embryo B. Fig. 3 bei Embryo $C$, Fig. 4 bei Embryo D, Fig. 5 bei Embryo $E$.

Die Fig. 1 ist früher genügend besprochen worden. Beim nächstälteren Embryo (Fig. 2) sind progressive Entwicklungserscheinnngen zu konstatieren. Das Schmelzorgan ist von unten tiefer eingebuchtet und hat jetzt eine wesentlich kappenförmige Gestalt angenommen. Die Schmelznische hat sich vertieft und wird von den beiclen Zahnleisten umschlossen. Die mediale hat sich gegen die Anlage des Organes schärfer differenziert; bein jüngeren Embryo setzt sie sich noch unmittelbar in den medialen Rand des Organes fort, beim Embryo $B$ ist die Abgrenzung zwischen Leiste und Organ schon dentlich durch eine Rinne markiert. Das ist bei der lateralen Leiste nicht der Fall. Dieselbe hat sich scheinbar infolge der Vergröberung des Organes vom lateralen Rand zurückgezogen nnd die Anheftung am Organ ist dadurch ein wenig auf die Seitenfläche nach oben geschoben. Dic ursprïnglich topographische Beziehnng zum lateralen Rande des Organes ist dadurch weniger deutlich geworden. Yon einer Regression der Leiste ist in diesem Stadium noch nichts zu sehen.

Auch im nächstfolgenden Stadium (Fig. 3, Embryo C) ist das noch nicht der Fall. Das Schmelzorgan ist stark abgeplattet und die Abgrenzung gegen die mediale Leiste hat an Schärfe gewonnen, die laterale Leiste zieht noch in der Richtung zum lateralen Rande des Organes und begrenzt samt der nedialen die Sichmelzkrypte. die nach hinten geschlossen ist. Ein großer Teil der oberen Fläche des Schmelzorganes bildet zugleich die Bodenfläche der schmelzlirypte, und es 
ist deutlich, daß das Organ sich in die Krypte einzuwölben anfängt. Sonst sind die Verhältnisse jenen in Fig. 2 noch sehr ähnlich.

Wesentliche Fortschritte zeigt der nächste Embryo (D, Fig. 4). Das Schmelzorgan hat die Glockenform erreicht, es erscheint in der Rekonstruktion wie ein eingestülpter Ballon. Die Eingangsöffnung ist - der Form der Zahnpapille entsprechend - quer ausgezogen, was in der Figur nicht deutlich hervortritt, da die nach vorn schanende Wand den Eingang zmm Teil rerdeckt. Die Abgrenzung gegen die mediale Leiste ist nicht nux durch eine ziemlich tiefe Furche angedentet, sondern der freie untere Teil der Leiste ragt schon etwas hervor; der Rand fängt an frei zu werden. Es hat also die Abtrennung des Organes von der medialen Leiste angefangen. Ganz anders verhält sich clie laterale Leiste. Es ist dentlich, daB dieselbe jetzt nicht mehr in gleichem Haße wic das Organ wächst, sie ist relativ schmäler geworden. Infolge der Größenzunahme des Oroanes ist ihre Ansatzlinie überdies weit vonn nuteren Rande gerückt und nach oben verlegt worden. Es macht den Eindruck, als schmiege sich die laterale Leiste infolge der starken Ausdehnung des Organes sich dessen lateraler Fläche an, denn eine scharfe Grenze tritt im Gegensatz zur medialen oder Zahnleiste nicht auf. Diese Tatsache verdient besondere Berücksichtigung, denn wie schon früher bemerkt worden ist, haben wir darin die Erkiärung der zahlreichen Epithelwucherungen, welche oftmals an der bukkalen Fläche des Schmelzorganes zu sehen sind. Die Schmelzkrypte hat in diesem Stadium ihre größte Ausdehnung erreicht. Ihre Bodenfläche ist infolge der starken Aufblähung des Schnıelzorganes stark gewölbt. Außer der relativen Verkleinernng der lateralen Leiste sind in diesem Stadinm schon Anzeichen von Degeneration oder Regression festzustellen. Denn in der Tiefe der Schmelzkrypte, an der Stelle, wo die laterale Leiste mit der Zahmleiste sich verbindet, treten Epithelsprossen auf, welche vou ersterer ausgehen und sich mit der Oberfläche des Schmelzorganes verbinden. Sie stellen unregchäßige strangartige Verbindungen dar zwischen Schmelzorgan und Leistensystem mnd entstehen teils als Wucherungen der Leiste, teils sind sie die Folge von Durchlöcherungen in diesem Teil des Leistensystemes.

Beim ältesten Embryo (Embryo E. Fig. 5) ist das Schmelzorgan so stark vergrößert, daß die Leisten ganz in den Hirttergrund der Bildung gerückt sind. Wie die Figur zu erkennen gibt, gibt es hier immer noch ein Stadium, worin die Zahnleiste mit dem Mundhöhlenepithel zusammenhängt. Das Schmelzorgan ist kugelförmig geworden und überzicht die Zahnpapille schon sehr weit. Die punktierte Linie gibt den Verlauf des Bodens der Einstülpung an. Der Eingang zu derselben ist spaltförmig. Die mediale Leiste hat angefangen sich rom Organ abzuheben, ein ziemlich tiefor Einschnitt grenzt das freie untere Ende der Zahnleiste vom Organ ab. Doch ist die Ablösung noch nicht vollständig. Die Schmelzkrypte ist durch die Ablösıng der medialen Leiste viel kleiner geworden, doch bleibt sie immerhin noch zu erkennen. Die laterale Leiste ist ebenfalls in der Entwicklung zurückgegangen, doch von einer Ablösung wie bei der medialen Leiste ist keine Rede. Infolge der enormen Entwicklnng des Organes ist dic Ansatzstelle dieser Leiste jetzt ganz auf die Spitze des Organes gerückt, eine scharfe Abgrenzung gegen das Organ besteht auch hicr jedoch nicht. Es ist 
merkwürdig zu sehen, wie in diesem Stadium das Schmelzorgan noch mittels seiner beiden Verbindungen mit der Zahnleiste zusammenlängt.

Auf diese Erscheinung, die besonders beim Menschen sehr deutlich ist, möchte ich nachdrücklich hinweisen. Denn es scheint dadurch, als wäre die Beziehung der Milchzahnanlage zu der lateralen Leiste etwas inniger als jene zur medialen Leiste. Und wenn man regelmäßig die Ablösung des Schmelzorganes von der Zahnleiste bei mehreren Serien studiert, dann bekommt man ganz den Eindruek, daß die Bezichung der lateralen Leiste zmm Organ nicht allein bei jener der medialen nicht zurücksteht, sondern sogar eine etwas nähere zu sein scheint. Denn wenn sich das Schmelzorgan ablöst von dem Leistenkomplex, damm ist nicht selten die mediale Verbindung schon ganz aufgehoben, wenu die laterale Verbindung noch in irgendwelcher Forml da ist.

Zum Beweise davon gebe ich in Fig. 15 einen Schnitt durch cine Zahnanlage, die im Begriff steht, sich von der Lciste zu emanzipieren. Er ist einem menschlichen Fötus entnommen (Serie $F$ ), wo in Oberkiefer die Anlage des ersten bleibenden Molaren in der Form einer knospenförmigen Anschwelhung zu sehen war. Der Schnitt geht durch die Anlage cines unteren Caninus. In diesem Falle ist das Organ clureh einen einzigen Strang noch mit der Zahuleiste in Verbindung. Dieser Strang ist der letzte Rest, welcher von der lateralen Leiste sich noch zwischen Zahnleiste und Schmelzorgan erstreckt. Die mediale Verbindung ist schon völlig anfgehoben. Auf den ersten Anblick konnte man der Meinung sein, es sei die

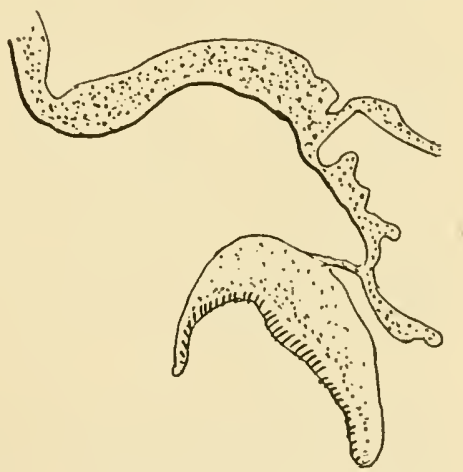

Fig. 15. Homo. Serie F. Querschnitt durch die Anlage eines unteren Eckzahnes. mediale Verbindung, welche hier noch anwesend ist, denn der Strang setzt sich nicht an der lateralen Fläche des Organes an. Doch ist dem nicht so. Wie bei den Incisivi verschiebt sich auch bei den übrigen Zähnen infolge der Ansdehnung des Schmelzorganes die Anheftungsstelle der lateralen Leiste nach oben (vgl. die Textfiguren), erreicht die oberste Spitze des Organes und kann schließlich sogar anf die mediale Fläche hinübertreten.

Einen sehr lehrsanen Einblick in die topographisehen Bezichungen zwischen Schmelzorgan und Leistenkomplex gewährt die Tafelfig. 6. Diese Figur ist angefertigt mach einem Wachsmodell der Anlage ron ersten und zweiten obcren Incisivus des menschlichen Embryo, Serie $H$. Die Schnittrichtung war eine sagittale. Es ist mur ein Stück des Modelles dargestellt, die eine Zahnanlage sieht man daher vollständig, die andere durchschnitten. Das Kieferepithel ist ganz, das Lippenepithel sehr unvollständig abgebildet. Letzteres findet sich in der Figur an der rechten Seite. Betrachten wir zunächst die durchschnittene Zahnanlage. Links findet sich dic Verbindung mit der Zahnleiste, die in dieser Ebene nur noch durch eine schmale Verbindungsbrïcke mit dem Schmelzorgan zusammenhängt. Diese Verbindung findet 
sich an der lingualen Fläche des Organes. Die laterale Schmelzleiste heftet sich in dieser Ebene an der Spitze des Organes fest. Die Schmelznische, welehe in ihrer größten Ausdehnme getroffen ist, liegt daher lingual und oben von dem Sehmelzorgan, und es seheint sogar die laterale Schmelzleiste die eigentliche Fortsetzung der Zahnleiste zu sein. An der zweiten, vollständig abgebildeten Zahnanlage ist in sehr deutlicher Weise zu sehen, wie die Insertion der lateralen Sehmelzleiste am Schmelzorgan in schräger Richtung über dasselbe herläuft. Auch hier steht die mediale Verbindung im Begriff sich abzulösen, was in der Figur noeh gerade zu sehen ist.

Bei Affen kommen andere Zustände vor, welche das urspriingliche Verhalten auch in späteren Entwicklungsstadien verraten.

Ich darf diese Bemerkungen über die Ablösung der Zahnanlagen von der Zahnleiste nicht beenden, ohne anf eine weitere Erscheinmng hingewiesen zu haben. Der Vorgang, wie er in Fig. 15 wiedergegeben, ist als ein Beispiel einer ganz regelmäBigen Ablösung zu betrachten. Es gibt jedoeh beim Menschen Komplikationen, welche den Vorgang undeutlich erseheinen lassen. Über die Art, in welcher die Abschnürung der Milchzähme sich von der gemeinsanen Zahmleiste vollzieht, hat auch Röse (l. c. S. 457) Mitteilungen gemacht, und der Autor sehlägt vor, in Übereinstimmung mit Waldeyer, die von älteren Autoren als ,Hals des Sehmelzorganes ${ }^{66}$ angeführte Bildung kïnftighin als ,Verbindungsbrücken der Milehzähne zu bezeichnen. Der Autor spricht an gleicher Stelle von ,, Schneidezähmen, welche nur noch eine oder mehrere schmale Verbindungsbrïcken aufweisen". Derartige Bilder bekommt man in der Tat zu sehen und entstehen in folgender. Weise. Wie aus den Tafelfiguren von der Entwickhng des ersten Incisivus zu ersehen, wird die Schmelznische im Lanfe der Entwicklung relativ kleiner. In der Tiefe fließen laterale Schmelzleiste und Zahnleiste miteinander zusammen. Und an der Verbindungsstelle kommt es zu sekundären Perforationen der lateralen Leiste infolge ron Durchwachsung mit Bindegewebe, wie es auch an anderen Stellen der Zahnleiste als Äußerung von Reduktion bekanntlich rorkommt. Dazu kommt, daß die nämliche Stelle der Sitz wird von mregehmäßigen Epithelwucherungen, cine Erscheinung, die man ebenfalls in der ersten Phase der Reduktion an anderen Stellen der Zahnleiste antrifft.

Als Beispiel einer solchen scheinbar unregelmäBigen Ablösung verweise ich auf Fig. 13, wo in Skizze $e$ eine solche netzartige Verbindung besteht, welche sich jedoch schon im nächstfolgenden Schnitt als die perforierte Wand der Schmelznische erweist.

$\mathrm{Es}$ ist schon öfters betont worden, daß der lateralen Schmelzleiste für die Zahnanlage eine ganz gleiche Bedeutung zuerkannt werden muß als der medialen. Wir führten 11. a. oben als Stütze für diese Behauptung an, daß beim Canimus die Verbindung des Organes mit der lateralen Leiste sich länger erhält als jene mit der medialen. Das war nur möglich, wenn die laterale Leiste während der ersten Periode der Zahnentwicklung progressiv sich entfaltet, größer wird. War es eine indifferente, bedeutungslose Bildung, deren Auftreten bei der Zahmanlage der Primaten in irgendwelcher Beziehung stehen sollte mit einer bei den Vorfahren der Säuger stattgefundenen normalen Entwicklungserscheinung, welche bei der Entstehung des Säuger- 
gebisses unterdrückt worden war, dann konnte man erwarten, daB die erste Anlage, die damn als eine ontogenetische Wiederholung eines einstmaligen phylogenetischen Prozesses zu deuten war, rasch zugrunde ginge. Das ist jedoch nicht der Fall. Die laterale Schmelzleiste entwickelt sich während der ersten Entwicklungsphase progressiv und steht in ihrer Beziehung zum Emailorgan in nichts bei der medialen Leiste zurück. DaB ich diese Tatsache wiederholt hervorhebe, findet seinen Grund darin, daB dieselbe - wem es auf eine genetische Deutung clieser Leiste ankonmt - für unseren Geclankengang bestimmend ist.

Die progressive Entwicklung der lateralen Leiste schafft unter gewissen Umständen Zustände an dem Zahnapparat, welche auf den ersten Blick unerklärlich erscheinen müssen, oder - wie es ans der jüngsten Arbeit von Adloff hervorgeht - bei ungenügender Kenntnis der Erscheinungen leicht zu ganz irrigen Vorstellungen und Ansichten führen können.

Zum leichteren Verständnis der jetzt zu beschreibenden Erscheinung muB ich liurz ein Hauptergebnis meiner Untersuchung über die Entwicklung des Gammens hervorheben. In jener Ablandlung habe ich nachgewiesen, daß die Zahnleiste des Menschen nicht ansschließlich mit der Genese der Zähne in Bezichnng steht, sondern daß anch ein Teil des gingivalen Epithels von ihr abgeleitet werden muB. Wenu man ihrer ganzen genetischen Bedentung Rechnung trägt, ist die Bezeichnung dento-gingivale Leiste fïr die Zahnleiste eine mehr zutreffende. Der Modus, in welchem das Epithel der Zahnleiste in gingivales Epithel übergeht, ist in der bezüglichen Abhandlung detailliert verfolgt worden und ich kann an dieser Stelle nicht weiter darauf eingehen.

Es sei jedoch hervorgehoben, daß ich in jener Abhandlung, $11 m$ die Besprechung nicht zu komplizieren, von dem Vorkommen der lateralen Schmelzleiste geschwiegen habe, wiewohl sie an mehreren Figuren zur Abbildung gelangt ist (vgl. z. B. 1. c. Fig. 28, 35, 37, 47) und einige Male ansdrücklich betont worden ist, daß auf die Form der Zilhnanlage und anf die Verbindungen derselben mit der Zahnleiste nicht eingegangen wurde (1. c. S. 284 u. 301). In der genamnten Arbeit unterschied ich an der Zahnleiste drei Zonen: eine periphere, eine mittlere und eine tiefe. Die periphere Zone erstreckt sich vom Mundhöhlenepithel bis zur Anlage der Milchzähne. Diese Zone lat mit der Zahnanlage nichts zu schaffen, sie wird zur Bekleidung des sich ausbildenden Zahnwalles verwertet. Diese Zone konnte man als den gingivalen Teil interscheiden.

Nur wenn man diesen Entwicklungsvorgang an der primitiven oder generellen Zahnleiste Rechnung trägt, werden Verhältnisse begreiflich, wie sie uns in weiter vorgerïckten Stadien der Zahnentwicklung begegnen. Ich gebe dazu in Fig. 16 ॥. 17 zwei Schnitte durch die Anlage eines menschlichen oberen ersten Molaren. Die Fig. 16 ist der Serie $F$ entnommen, Fig. 17 dem etwas älteren Embryo, Serie $G$. In beiden Fällen ist die doppelte Terbindung des Organes sofort zu sehen, die Insertion der lateralen Schmelzleiste ist anf die Spitze des Organes gerückt, die mediale Leiste hängt in Fig. 16 noch ziemlich breit nit dem Organ zusammen, beim älteren Embryo nur noch mittels eines zarten Epithelstranges. Es interessiert uns hier jedoch an meisten 
die Verbindung beider Leisten mit dem Mundhöhlenepithel. Bei jungen Embryonen geht die laterale Leiste von der bukkalen Fläche der Zahnleiste ans. Aber die periphere Zone letzterer wird zur Bekleidnng des Kieferwalles verwendet, und sobald dieses sich vollzogen hat, ist die laterale Schmelzleiste mit ihrer Anheftungslinie ebenfalls anf das den Kieferwall bedeckende Epithel gerïckt. In Fig. 16 gehen mediale und laterale Leisten von einer gemeinschaftlichen Stelle schon direkit aus dem Mnndhöhlenepithel hervor. Bei dem älteren Embryo $G$ sind beide leisten anseinander gerïckt und die laterale bildet einen vollkommen selbstständigen Strang, der vom Mundhöhlenepithel zum Schmelzorgan zieht.

Diese und derartige Bilder liefern einen nenen Beweis für die in der oben zitierten Abhandlung schon gründlich erwiesene Tatsache, dab die Zahnleiste des Menschen nicht nur für die Zahnanlage benützt wird, sondern auch zum Teil zur Bildung des gingivalen Epithels. Wenn, wie in Fig. 17, die beiden Leisten, woraus die Zahnanlage hervorgeht - die laterale und die mediale -, mabhängig vomeinander vom Kieferepithel ins Mesenchym dringt, dam liegt bei diesem älteren

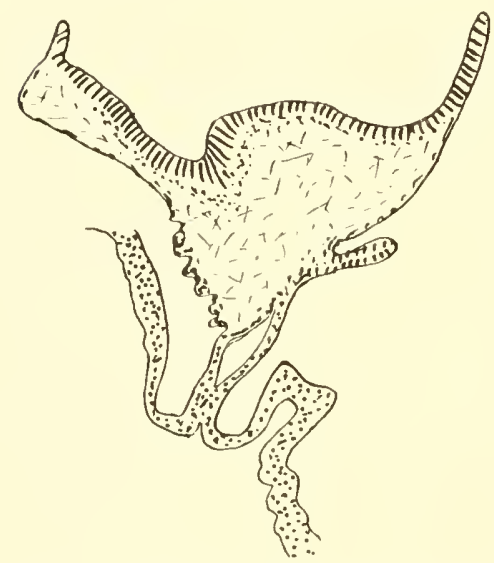

Fig. 16. Homo. Serie $F$. Schnitt durch den oberen el'sten Milchmolaren.

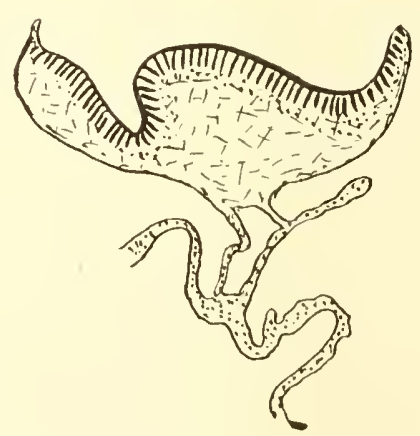

Fig. 17. Homo. Serie $G$. Schnitt durch den oberen ersten Milchmolaren.

Entwicklungsstadium des Menschen ein sekundärer Zustand vor, der prinzipiell ïbereinstimnt mit den primären Verhältnissen jüngerer Entwicklungsstadien solcher Formen, wo die Zähne gleich von Anfang an aus dem Mundhöhlenepithel entstehen (Semnopithecus).

Es brancht kaum betont zu werden, daß Bilder, wie sie in Fig. 16 und 17 vorgeführt sind, ganz unverständlich sind bei der bis jetzt gelänfigen Vorstellung der Zahnentwicklung. Die Schwierigkeit wächst noch. wenn, wie z. B. bei den Antemolaren, die laterale Leiste sich ziemlich weit nach vorn erstreckt und an Querschnitten der Mundhöhle schon auftritt, ehe das Schmelzorgan getroffen ist Das ist besonders bei der Anlage der Eckzälnne der Fall, wie an den folgenden zwei Beispielen gezeigt wirl. In Fig. 18 findet man einen Schnitt durch den Oberkiefer von Embryo $C$, dem das Spatium interdentale zwischen $i_{2}$ und $c$ entspricht, kurz vor der Anlage von $c$. In 
Virklichkeit sind hier zwei Zahnleisten zu sehen, welche von einem gemeinsehaftlichen Punlit des Kieferepithels ins Mesenchyn eindringen, cine horizontal, die andere melır vertikal. Die Erklärung dieser Verhält nisse würde bei der geläufigen Vorstellung von der Zahnentwicklung gewiß große Schwierigkeiten bieten, und doch ist die Sache sehr einfach. Von der ursprïnglichen Zahnleiste (dento-gingivale Leiste) ist die periphere Zone (die gingivale Zone) zu der gewaltigen Epithelmasse angeschwollen, welche den Raum zwischen Tektalwall des Gaumens ${ }^{1}$ ) und Wange ausfüllt. Dis geht bis zur Stelle der Anlage der Milchzähne, d. h. zu jener Stelle, wo dic laterale Schmclzleiste aus der bukkalen Fläche der Zahnleiste hervortritt. In Fig. 18 fällt der abgebildete Schnitt durch das Leistensystem vor der Anlage von $c$. Die horizontale Leiste ist die mediale, die eigentliche Zahnleiste oder generelle Leiste, und die vertikale ist die laterale Schmelaleiste für die Zahnanlage von $c$, welche sich in diesem Stadium weiter nach vorn erstreckt als das Organ dieses Zahnes.

Ehe es zur Abschniurmng der Zahnleiste vom Mnndhöhlenepithel kommt, kann noch eine geringe Strecke der Leiste als Gingivalepithel

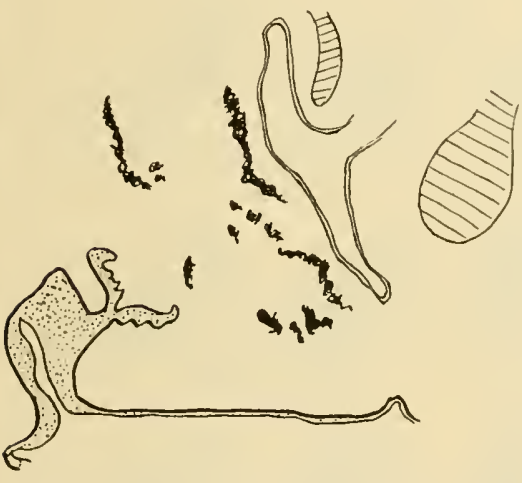

Fig. 18. Hom o. Serie $C$. Schnitt durch das Spatium interdentale zwischen $i_{2}$ und $c$.

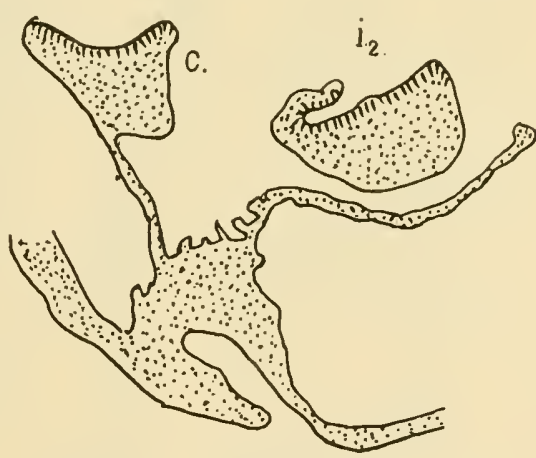

Fig. 19. Hom o. Serie E. Schnitt zwischen $i_{2}$ und $c$.

Verwendung finden, und darin kann sich auch im Bereich der Anlage von $c$ der Zustand ereignen, daß die mediale mud die laterale Leiste unabhängig voneinander aus dem Mundhöhlenepithel hervorgehen, wie das in Fig. 16 und 17 für die ersten Molaren gezeigt worden ist. Dab dieser Zustand sich verwesentlichen kann, geht aus Fig. 19 hervor, welche dem menschlichen Embryo $E$ entnommen ist. Diese Figur ist dieselbe als Fig. 45 in meiner Abhandlung ïber die Gaumenentwicklung beim Menschen. Der Zustand ist hier etwas mehr kompliziert, da hier infolge der starken Vergrößerung der Schmelzorgane der himterste Teil der Anlage von $i_{2}$ und der vorderste Teil der Anlage von $c$ getroffen ist. Das ist möglich, da $c$ beim Embryo nicht ganz hinter, sondern auch ein wenig seitlich von $i_{2}$ gelagert ist. so daß man an Querschnitten beide Zahnanlagen, sei es in sehr verschiedenem Nivean, treffen muß. Es sind nun auch in Fig. 19 zwei Leisten getroffen, eine

1) Für die Bedeutung dieses Begriffes verweise ich auf meine Abhandlung über die Gaumenentwicklung. 
mehr horizontal verlaufende, welche sich einige Schnitte woiter oralwärts von der Anlage von $i$ abschnürte, und eine mehr vertikale, welche sich mit der buklialen Fläche der Anlage von $c$ verbindet. Tatsächlich liegt hier somit cin übereinstimmender Zstand als in Fig. 18 vor, aber vom Zahnleistenmaterial ist noch etwas mehr zu Gingivalepithel geworden, und demzufolge kommt die laterale Schmelzleiste von $c$ jetzt direkt aus dem Mundhöhlenepithel.

In seiner jüngsten Abhandlung hat Adloff die hier als Fig. 19 gegebene Abbildung reproduziert. Er erklärt dabei obne die geringste Argumentierung, nicht zu glauben, daß mein Nachweis vom Übergang eines Teiles der Zahnleiste im Epithel des Alveolarwulstes, welches aus den beigegebenen Figuren sofort zu ersehen ist, viel Wahrscheinlichkeit besitzt, und benïtzt dann meine Figur zu ganz unbegrïndeten, auf keine einzige Beobachtung basierten spekulativen Betrachtungen ïber Zahnleistenkrümmungen, auf welche ich nicht einzugehen branche, da die oben mitgeteilten Tatsachen genügend dieselben als völlig verfehlt kennzeichnen.

Die in Fig. 16-19 abgebildeten Zustände werde ich sehließlich noch dureh die bildliche Darstellıng eines Falles erläntern, nicht weil mir die Sache noch weiterer Beweise bedürftig erscheint, aber weil ich meine, dabich das Vorkomnen und die Bedeutung der lateralen Schmelzleiste bej der Zahnanlage gleich bei ihrer ersten Darstellung in der Literatur des Primatengebisses nicht scharf genug betonen kann. Es hat großen Wert, diese primzipielle Erscheinumg sofort in fester TVeise zı begrïnden.

Ich gebe dazu in Fig. 20 die Abbildung der Anlage vom unteren Eckzahn des Embryos D. Die Figur ist nach einem Wachsnodel

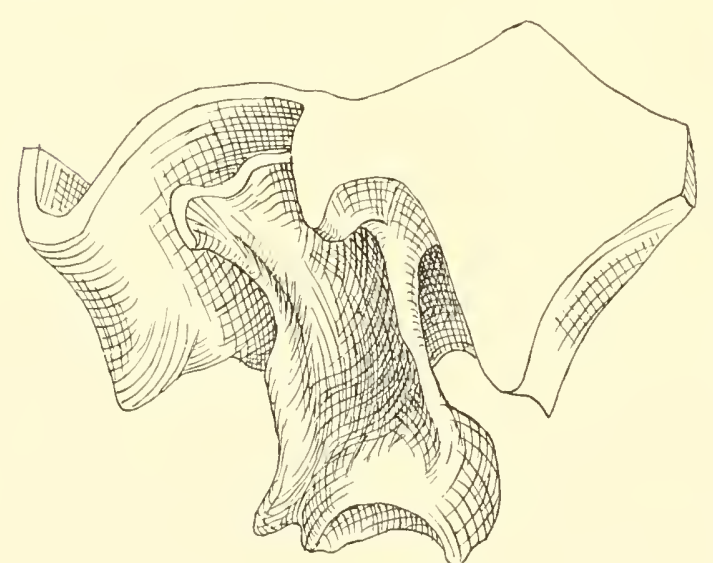

Fig. 20. Homo. Serie D. Anlage des unteren Caninus. Nach einem Modell.' angefertigt, man sieht die Anlage von der oralen Fläche. Zır Kontrolle gebe ich in Fig. 21 die Schnittserie der Anlage dieses Zahnes. Die Serie ist ununterbrochen. Betrachten wir zunächst die Fig. 20 etwas genaner. Das Schmelzorgan lat das kappenförmige Stadium erreichi, und periplserwärts von ihm findet sich die länglich ausgezogene, aber ziemlich tiefe Schmelznische oder Emailkrypte. Seitlich wird dieselbe von der stark hervorragenden lateralen Schmelzleiste begrenzt, welche sich mit dem bukkalen Teile des Schmelzorganes verbindet. Der vordere Rand der lateralen Leiste ist frei, nach hinten setzt sie sich an der generellen oder medialen Leiste an. Der Hintergrund der Nische ist noch nicht perforiert, es finden sich überhaupt noch 
keine Reduktionserscheinungen am Leistenkomplex. Mit dem Mundhöhlenepithel steht die laterale Leiste durch seine meist vordere Strecke schon clirekt in Verbindung. Die Skizzenserie in Fig. 21 gibt nun eine Vervollständigung der gegebenen Abbildung. Die Skizze $a$ ist am meisten oralwärts, sie entspricht jedoch nicht genan der vorderen Fläche des in Fig. 20 abgebildeten Modelles, sondern liegt ein wenig weiter nach hinten. Man erkennt leicht die Zahnleiste, welche an ihrem freien unteren Rande die hakenförmige Umbiegung aufweist, welche in älteren Stadien im Gebiet der Antemolaren geradezı typisch ist. Die lateral von ihr sich findende Anhäufung von Epithel srellt die noeh nicht eröffnete bukko-gingivale Furche dar. In den Schnitten $b$ und $c$ ändert sich wenig. Im Schnitt $d$ erscheint neben der generellen Zahnleiste eine zweite, es ist die laterale Schmelzleiste für die Anlage des Caninus, die an dieser Stelle direkt vom Mundhöhlenepithel Ausgang nimmt. In den Schnitten $e$ und $f$ wird die laterale Leiste länger, kommt der medialen oder generellen an Länge gleich und im Schnitt g

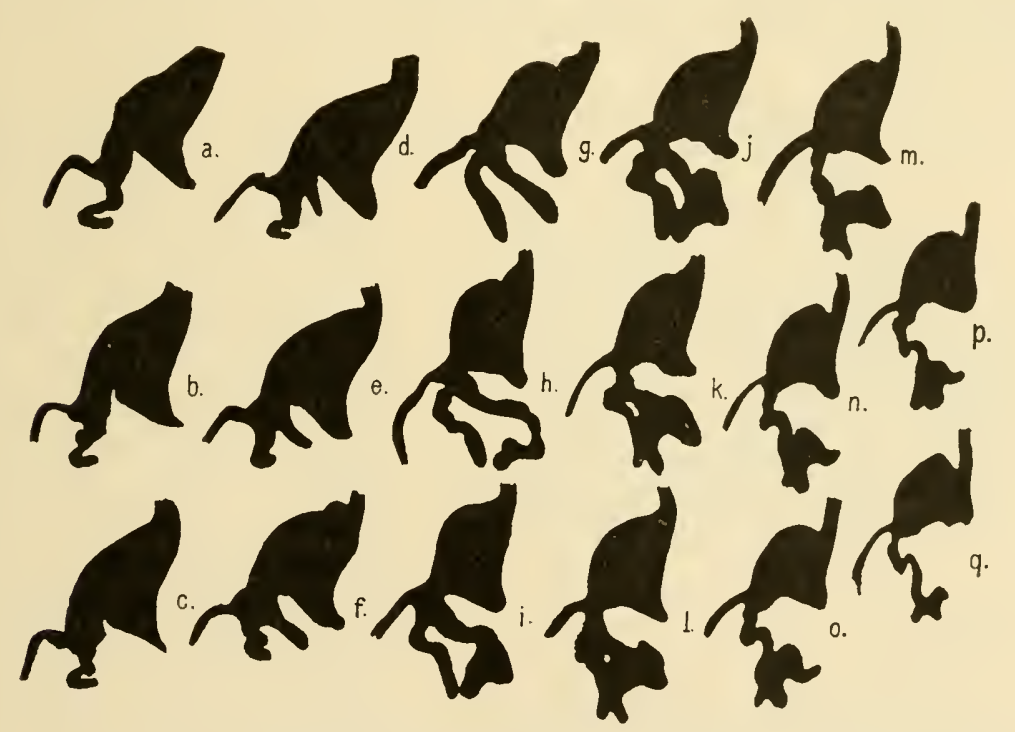

Fig. 21. Homo. Serie D. Anlage des unteren Caninus.

wachsen beide stark aus, indem gleichzeitig die mediale Leiste ihren Charakter ändert. Die hakenförmige Umbiegung am freien Rancıe ist verschwunden, die Lejste verläuft gestreckt. Noch immer ist vom Sehmelzorgan nichts zu sehen. Es macht sogar in Slizze $g$ den Eindruck, als verschiebe sich die mediale Leiste auf die laterale, welche die Verbindung mit dem Kieferepithel zu ïbernehmen scheint. Im nächsten Schnitt tritt das Schmelzorgan zum ersten Nale in der uns bekannten Teise auf. Es geht von der lateralen Leiste ein horizontaler Ausläufer aus, der im Schnitt $i$ stark anschwillt und in der Richtung des freien Eendes der medialen Leiste sich vergröBert, $11 \mathrm{~m}$ letztere in Schnitt $j$ zu erreichen und die Emailkrypte naeh unten zum Abschluß zu bringen. Letztere ist noch in den Schnitten $k$ und $l$ zu verfolgen, aber schon in $l$ ist es zu sehen, daß die laterale Leiste der me- 
dialen sich nähert und in Schnitt $n$ ist das Organ nur noch mit der medialen Leiste in Verbindung.

Es sind jetzt wohl genïgende Tatsachen mitgeteilt worden, ım die Bezichung der literalen Schmelzleiste zur Milchzahnanlage und zum Kieferepithel beim Menschen festzustellen. Wir werden uns jetzt wieder eimmal den Affen zuwenden, nm zu erfahren, wie diese Bildung bei den übrigen Gliedern der Primaten sich in seiner weiteren Entwicklung verhält. Dafin auch bei den Affen die Zahnanlage durch Vermittlung einer lateralen schmelzleiste zustande kommt, ist früher schon festgestellt worden. Etwas prinzipiell Abweichendes haben wir nicht konstatieren kömmen. Es wäre mir sehr erwünscht gewesen, wenn ich von einem Affengeschlecht rine genügende Zahl Embryonen verschiedenen Alters besessen hätte, denn ich habe den Eindruck bekommen, dab wenigstens bei den Platyrrhinen die laterale Schmelzleiste schärfer noch als beim Menschen als ein essentielles Element der Zahnanlage sich erweist. Aus Mangel an solchem vollständigen Material werde ich mich anf einige Bemerkungen beschränken, denen ich einige Abbildnngen ron Embryonen von Mycetes und Chrysothrix zugrunde lege.

Wie schon gesagt, bleiben die ursprïnglichen topographischen Verhältnisse beim Affenfötus offenbar länger erhalten als beim Men-

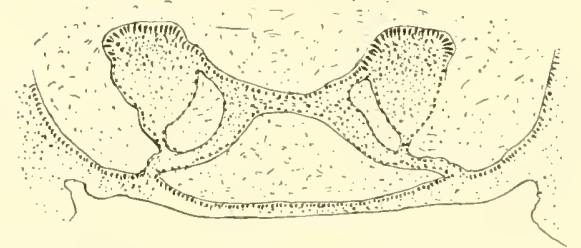

Fig. 22. Mycetes. Serie A. Anlage der medialen oberen Incisivi.

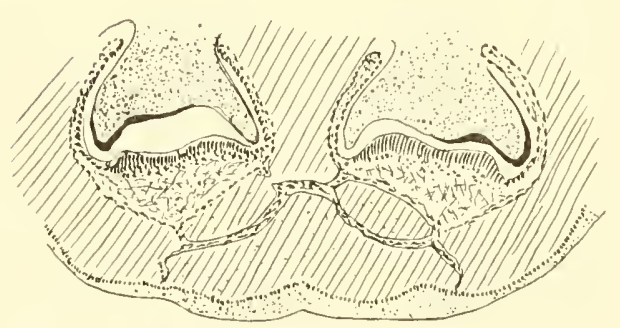

Fig. 23. Mycetes. Serie $D$. Anlage der medialen oberen Incisivi. Schmelzleiste setzt sich an der Spitze des Organes an, die Emailkrypte ist in ihrer größten Ausbreitung getroffen. Vergleicht man nun mit dieser Figur den in Fig. 23 abgebildeten Zustand, dann erkennt man sofort, wie konservativ die ursprünglichen Verhältnisse in der Bezichung der Zahmanlage zum Zahmleistensystem beibehalten sind, 
wiewohl die Zalnentwicklung solche große Fortschritte gemacht hat. Auf der Zahnpapille ist es bereits zur Ablagerung von Dentin gekommen. Doch findet die laterale Verbindung sich noch an entsprechender Stelle des Emailorganes wie beim jüngeren Embryo, nur die mediale Verbindung - die im Begriff steht, sich zu lösen - ist verschoben. Die Emailkrypte hat sogar an Größe zugenommen.

Es ist früher nachgewiesen worken, daß beim Menschen die laterale Schmelzleiste, welche bei der ersten Anlage des Schmelzorganes sich an dessen lateralem Rande ansetzt, später immer nehr ihre Festheftungsstelle in der Richtung des Gipfels verschiebt, um diesen schließlich $z u$ erreichen und bisweilen sogar auf die mediale Fläche des Organes zu gelangen. Wir dürfen hierbei nicht an eine aktive Wanderung der Anheftungslinie denken. Wenn das Schmelzorgan sich vergrößert, schmiegt die laterale Wand sich der lateralen Schmelzleiste an und es tritt eine Verwachsung von dieser Leiste mit der bukkalen Fläche des Organes anf. Es ist im Anschlub an dieser Verwachsungserscheinung auf die vielen Epithelsprossen hingewiesen, welche sich an den äußeren Epithel des Schmelzorganes bilden und die als Produkte der lateralen Leiste angesehen werden müssen. Wir werden bald bei Chrysothrix sehr überzeugende Beweise dafür anführen. In dieser Frage war ein Befund sehr lehrreich, den ich beim unteren dritten $\mathrm{M}_{0}$ laren des Mycetes-Embryos $B$ machen lionnte. In Fig. 24 ist ein Teil von einem Schnitt durch die Anlage dieses Zahnes dargestellt. Es ist das Schmelzorgan fast ganz und dazu ein kleiner Bruchteil der Zahnpapille

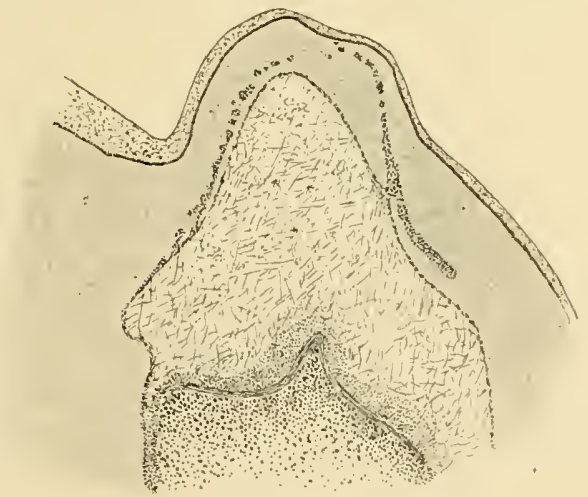

Fig. 24. Mycetes. Serie B. Schnitt durch die Anlage des unteren Molaren. skizziert. Der Zahnleistenkomplex ist schon ziemlich weit auf dem Wege der Reduktion fortgeschritten. Es ist jedoch noch ohne Mühe die mediale Zahnleiste zu sehen, welche noch in knapper Verbindung mit dem äußeren Epithel des Schmelzorganes steht, jedoch schon vom Kieferepithel abgelöst ist und zum Teil in Epithelinselchen auseinander gefallen. Besonders interessiert uns jedoch die laterale Leiste. Auch diese ist in einer großen Anzahl Epithelinselchen zerklïftet, aber offenbar war ihre Verwachsung mit der bukkalen Fläche des Schmelzorganes hier nicht zustande gekommeh, wenigstens nicht ïber die totale Länge. Und so lagern die Epithelinselchen, welche aus dieser Leiste hervorgegangen sind, in kurzer Entfernung von der bukkalen Fläche des Schmelzorganes. bilden nach unten eine immer mehr zusanmenhängende Masse, welche schließlich mit dem äußeren Epithel des Organes sich verbindet. Unter der Ansatzstelle finden sich einige epitheliale Wucherungen. Und denkt man sich die ganze Leiste mit dem Organ verschmolzen, damn würde diese bukkale Fläche mit Exkreszenzen ausgestattet sein, welche 
jetzt in der Form von Epithelinselchen in kurzer Entfernung von ihr gelagert sind. Dieser Fall beweist wieder anfs sehönste, daß die Epithelsprossen, welche sich an der äuBeren Fläche des Emailorganes finden, nicht Produkte des sogenannten äuBeren Epithels sind, sondern auf die laterale Schmelzleiste zurïickgefülurt werden mïssen.

Die Tatsache, daß bei den Platyrrhinen die laterale Schmelzleiste länger sich zu erhalten scheint als beim Nenschen, trifft anch für das Geschlecht Chrysothrix zu. Und da ich bis jetzt von diesem Affen noch keine Bilder gegeben habe znm Beweise, dab anch hier die Zahnentwicklnng in gleicher Weise wie bei den anderen Primaten verläuft, lasse ich einige Figuren folgen, wodurch diese Tatsache auch für diesen Affen bewiesen wird und wobei gleichzeitig einigen schon früher geäuBerten Behanptmigen nene Stütze verliehen wird. Ich entnehme alle Figuren einer lückenlosen Serie durch den Kopf eines Fötus, katalogisiert als Chrysothrix $A$. Es war im Ober- und Unterkiefer der erste bleibende Molar bereits angelegt. Die Entwicklung des Gebisses war mithin schon ziemlich weit fortgeschritten, wie anch aus den Entwicklungsgrad der einzehen Zähne zı schließen war.

Die Fig. 25 bringt einen Schnitt durch den ersten Incisivus des Oberkiefers. Dieser Schnitt durchstreift ungefähr die Mitte des

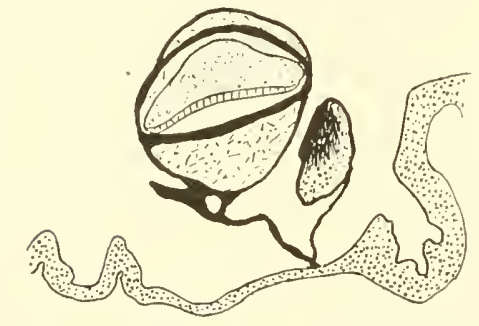

Fig. 25. Chrysothrix. Serie $A$. Schnitt durch die Anlage les oberen medialen Incisivus. stark horizontal liegenden Zahnes mit dessen Emailorgan. Seitlich vom ersten Schmeidezahn ist anch die Anlage des zweiten durch dessen vordere Wand getroffen. Wenn man nun die Beziehung beider Zahn anlagen zil cler Zahnleiste betrachtet, damn trifft man den etwas komplizierten Zustand an, den ich anch beim Mensehen fand und beschrieb (vgl. Fig. 21). Es scheinen nämlich zwei Zahnleisten zu bestehen. Denn jede Zahnanlage steht durch eine eigene epitheliale Lamelle mit dem Kieferepithel in Verbindung. Ich wiederhole, dab solehe Bilder bei der bis jetzt geläufigen Vorstellung der Zahnentwickhnng absolnt merklärlich sind. Die Interpretation der Verhältnisse in Fig. 25 ist folgende: Der mediale Incisivus ist durch die generelle Zahnleiste mit dem Kieferepithel in Verbindung, doch sieht man von derselben in nächster Nähe des Schmelzorganes eine kurze zweite Verbindung von dieser Leiste zum Organ sich erstrecken. Diese Verbindung gehört noch der lateralen Schmelzleiste an. Der Schnitt geht nämlich durch den hintersten Teil der Schmelznische, wo laterale nud mediale Leisten einander sehr dicht genähert sind. Die epitheliale Lamelle, die von der Anlage des lateralen Incisivus zum Kieferepithel zieht, ist die laterale Schmelzleiste dieses Zahnes und heftet sich dann anch demgemäß an der bukkalen Fläche des Schmelzorganes fest. Wenn man diese Verbindung als die Zahnleiste in Sime der älteren Antoren auffaßte, dam würde sich hier ein Zustand finden, wobei die Zahmanlage medial von der Zahnleiste sich fand. Wir haben hier ein Bild vor uns, das jenem in Fig. 21 sehr ähnlich ist. Dort handelt es sich um den unteren Canimus des Menschen, und 
wie dort, sehen wir auch hier beim Incisivus ron Chrysothrix, daß die laterale Schmelzleiste selbständig aus denı Kieferepithel hervorgeht. Der Zustand ist hier jedoch etwas komplizierter, da die beiden Schneidezähne mehr nebeneinander gelagert sind, wodurch die Anlage beider gleichzeitig in einem frontalen Schnitt erscheinen.

Wenn man die Serie weiter nach hinten verfolgt, dann löst sich bald die Verbindung der Zahnleiste mit dem medialen Incisivus, während die Anlage des zweiten rasch an Unfang zunimmt. Bald nach ihrer Ablösung von der Anlage des ersten Tncisivus verbindet die generelle oder mediale Zahnleiste sich nit der medialen Flärhe der Anlage des zweiten Incisivis und das uns bekinnte, schon vielfach beschriebene Bild der doppelten Verbindung ist zustinde gekommen. Anfünglich - d. h. im vorderen Teil der Anlage - liegen die Verbindungsstellen der medialen und der lateralen Leisten am Oroan einander nahezu diametral gegenüber, je weiter man jedoch die Serie durch die Anlage hinterwärts verfolgt, desto mehr nähern sich die Ansatzstellen beider Leisten auf dem Schmelzorgan einander, während gleichzeitig die laterale Leiste ihre Ausgangsstelle vom Kicferepithel auf die bukkale Fläche der generellen Leiste verlegt. So entsteht kurz hinter der Mitte der Zahnanlage des zweiten Incisivus ein Verhältnis, das jenem zum ersten Incisivus in Fig. 25 sehr ähnlich ist. In Fig. 26 ist versucht worden, in halbschematischer Weise die Anlage eines Incisivus von Chrysothrix in Entwicklıngsstadium von Fig. 25 bildlich darzustellen. Demjenigen, der der Beschreibung der Entwicklung des Primatenzahnes bis

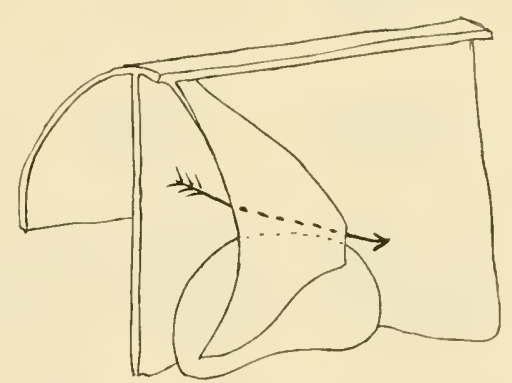

Fig. 26. Zahnleisten und Schmelzorgan eines Incisivus von Chrysothrix. jetzt gefolgt ist, ist diese Figur leicht verständlich. Die bukkale Fläche der generellen Leiste ist dem Zuschaucr zugewendet, die spezielle, laterale Leiste reicht vorn bis zum Kieferepithel und tritt sodamn mit ihrem angehefteten Rande auf die bukkale Fläche der generellen Leiste (die Zahnleiste im Sinne der älteren Autoren) ïber. Die Anheftungshinie am Schmelzorgan zieht über letzteres hin von vorn und unten nach hinten und oben, nähert sich deshalb immer mehr jener der generellen Leiste. Die Emailnische. welche nach vorn eine weite Eingangsöfnung hat, wird nach hinten immer mehr eingeengt. Auf einen Lmstand möchte ich noch aufmerksam machen, da derselbe in immer dentlicherer Weise bei den folgenden Zähnen dieses Fötus auftritt, die Nische nämlich ist in ihren Hintergrunde schon durchlöchert, sie ist schon zu cinem trichtelförmigen Kanal geworden, wie durch das in der Zeichnung eingetragene Pfeilchen verdeutlicht wird. Dieser Zustand bildet die Ausgangsform für Verhältnisse, wolche wir bei den Molaren dieses Fötus werden kemnen lernen.

In Fig. 27 sind sieben aufeinanderfolgende Schnitte durch die Anlage des ersten oberen Molaren vom selbigen Chrysothrix-Embryo abgebildet. Die generelle Zahnleiste ist noch kräftig entwickelt. stchit 
nit dem Kieferepithel in Verbindung nnd zeigt noch keine Spur von Ablösung oder sonstiger Reduktion. Ganz anders jedoch verhält sich die laterale Schmelzleiste, deren freie Teile nur als winzige Epithelreste da sind, welehe jedoch in den Schnitten $e, f$ und $g$ noch eme wohl erkembare Verbindung zwischen Schmelzorgan und genereller Zahnleiste darstellen. Es haben diese Schnitte Aufnahme gefunden, da sie wiederum zeigen - was schon öfters behauptet worden ist - , daß die Wucherungen, welche man am änBeren Epithel des Schmelzorganes beobachtet, nichts anderes sind als die Produkte des mit der bukkalen Wand des Schmelzorganes verwachsenen Absehnittes der lateralen Leiste.

Die Enailnische war bei diesem Zahn nach hinten schon sehr weit offen, denn im anf Fig. $27 \mathrm{~g}$ folgenden Schnitt bildete die laterale

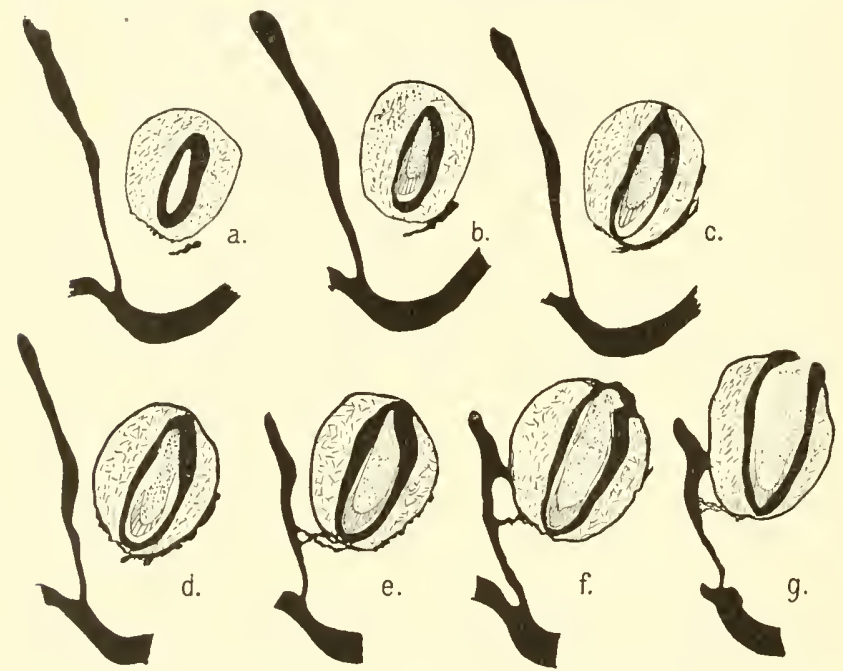

Fig. 27. Chrysothrix. Serie A. Sieben Schnitte durch die Anlage vom ersten oberen Molaren.
Leiste keine Verbindung melır zwischen Schmelzorgan und genereller Zahnleiste.

Auch war letztere bei diesem Molaren an keiner Stelle mit dem Kieferèpithel in direktem Zusammenhang, sie entsprang über aine immerhin sehr kurze

Strecke an der bukkalen Fläche der generellen Zahnleiste.

Beim zweiten oberen Molaren dagegen fand sich wieder eine direkte Verbindung mit dem Epithel der Mundhöhle, wie aus Fig. 28 ersichtlich ist. In dieser Figur erkennt man wieder leicht den mit ler bukkalen Fläche des Schmelzorganes verklebten Teil der lateralen Leiste. Das ganze Gebilde streckt sich jedoch bei diesem Zahn mur ïber einige wenige Schnitte ans, es ist die Leiste bis anf einen schmalen Strang reduziert. Und statt einer Nische findet sich zwischen der generellen Leiste und der lateralen Schmelzleiste ein sehr gerämmiger, aber kurzer Kanal.

Die Molaren des Unterkiefers ähnehn in ihrer Beziehung zum Leistenkomplex jenen im Oberkiefer sehr, wie z. B. aus Fig. 29 ersichtlich ist, welche einen Schnitt durch den zweiten unteren Molaren darstellt. Die laterale Schmelzleiste geht selbständig vom Kieferepithel aus. Doch ist auch bei den unteren Molaren diese Leiste äußerst schmal geworden und stellt beim dritten Molaren nur einen zarten Strang dar, der vou der generellen Leiste zur bukkalen Fläche des Schmelzorganes zieht. In Tafelfig. 7 ist eine Abbildung des Modelles, 
gegeben das ich von der Anlage dieses Zahnes anfertigte. Das Kieferepithel ist dargestellt mit der davon ausgehenden generellen Zahnleiste, die noch mit der medialen Fläche des Schmelzorganes zusammenhängt und von deren bukkalen Fläche die laterale Zalunleiste ausgelnt, bis auf einen zarten Strang reduziert. Diese Figur vervollständigt die

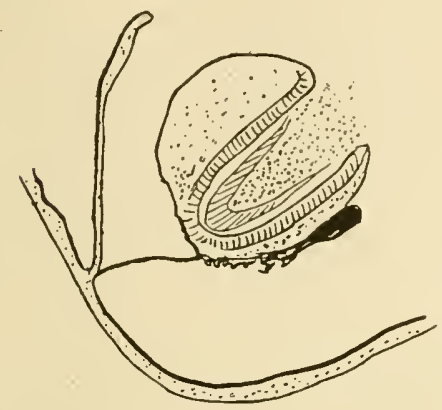

Fig. 28. Chrysothrix. Serie $A$. Schnitt durch den zweiten oberen Molaren.

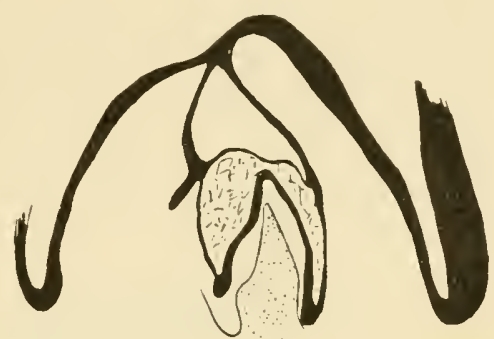

Fig. 29. Chrysothrix. Serie $A$. Schnitt durch den zweiten mnteren Molaren.

Serie der in Tafelfig. 1-5 gegebenen Abbildungen, denn sie zeigt, daß hier die Schmelznische verschwunden ist, es besteht nur ein tumnelartiger Kanal, der von der generellen Leiste, der oberen Wölbung des Schmelzorganes und von der pfeilerartigen lateralen Leiste begrenzt wird.

Noch ein letztes Beispiel vom Vorkommen der lateralen Schmelzleiste bei den Milchzähnen sei schließlich angeführt und kurz beschrieben
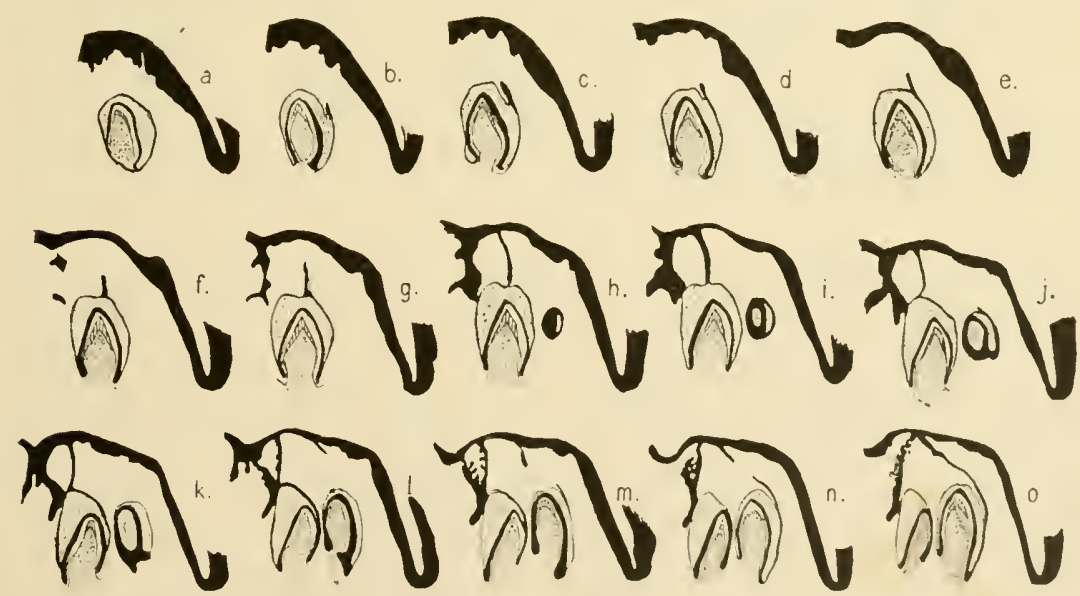

Fig. 30. Chrysothrix. Serie A. Anlage rom unteren medialen Incisivus.

unter Zugrundelegung vou Fig. 30. Es betrifft den unteren medialen Incisivus von Clurysothrix $A$, wovon 15 aufeinander folgende Schnitte dargestellt sind. In den Skizzen $a-f$ ist die allnı̈hliche Ausbildung 
der die Zahmanlage zusammensetzenden Teile leicht verfolgbar. Es sei besonders auf die an der bukkalen tläche des Sehmelzorganes sich entwickelnde laterale Schmelzleiste aufmerksam gemacht, welche die Ansatzstelle am Organ immer mehr zur Spitze verschiebt, je weiter man in der Anlage nach hinten vorrïckt. Von der medialen Leiste (die generelle Zahnleiste) treten die crsten Spuren erst in der Skizze f auf in der Form zweier isolierter Epitbelinseln, welehe in der Skizze $g$ mit dem Mundhöhlenepithel bereits in Verbindung getreten sind und in Skizze $h$ eine Verbindungsbrïcke zwischen diesen Epithel und der Zahnanlage bilden. Im nämlichen Schnitt hat auch die laterale Leiste das Epithel der Kioforbekleidnug erreicht, so daß die Zahnanlage jn der bekannten Weise jetzt mittels zweier epithelialer Stränge mit dem oberflächlichen Epithel verbunden ist. Bukkal von der Anlage des medialen Incisivus erscheint jene des lateralen. Wenn man jetzt die Beziehung beider Zahnleisten zueinander verfolgt, damn trifft es, dab diese sich ein wenig anders verhalten als bei den bis jetzt beschriebenen der Fall war. Demn in den weiter hinten folgenden Schnitten verschiebt sich die Ansatzstelle der lateralen Jeiste am Schmelzorgan immer mehr in der Richtung der medialen Leiste, indem die Ursprungsstelle an dem Mundhöhlenepithel zwar medialwärts rückt, aber nicht so schmell als die Ansatzstelle am Organ. Die Folge davon ist, daß die Selbständigkeit der lateralen Leste länger gewahrt bleibt mnd die Ansatzstelle an den Organ schließlich auf die bukkale Fläche der medialen Lamelle ïbertritt. Dadureh wird die Schmelzkrypte vom Organ abgetrennt und findet sich ron den bejden Leisten und dem Kieferepithel umsehlossen. In den frïher beschriebenen Fällen war immer das Gegenteil der Fall, die Ursprungsstelle der lateralen Leiste geht da vom Kieferepithel anf die mediale Leiste ïber. Da mir dieser Fall nur einmal begegnete. ersehien es mir erwünscht, denselben abzubilden. Er zeugt vieder für die grobe Bedentung dex lateralen Leiste. In den Skizzen $l$-o ist auch die Entstehung dieser Leiste für den lateralen Incisivus zu verfolgen. Die hier zum Vorsehein tretenden Verhältnisse sind bei den vorangehenden Fällen schon öfters besehrieben worden und ich brauche daranf somit nicht einzugehen.

Ist die laterale schmelzleiste cine Bildıng, welche mur bei den Milchzälnen anftritt oder ist sie anch bei den Anlagen der permanenten Zälne aufzuweisen? Die Antwort auf diese Frage ist selbstverständlich von der gröBten Wichtigkeit für die Ansichten, welche man sich ïber die Bedeutung der Leiste bilket. Denn wäre sie nur bei den Milchzähnen nachweisbar, dann kann ihre Bedentung keine allgemeine sein, und es wäre ein prinzipieller Untersehied in der Anlage der Zähne beider Dentitionen ans Licht getreten. Ieh habe mich bei meiner Untersuchung darauf beschränkt, eine vorläufige Beantwortung der Frage zu geben. Demn komnte einmal festgestellt werden, daß, sei es nur bei einigen wenigen Zähnen des permanenten Grebisses, die laterale Schmelzleiste vorkommt, damm hat man allen Grund zu vermuten, daß es auch bei den übrigen der Fall sein wird.

Es ist mir mun in der Tat gelungen festzustellen, daß auch bei der Anlage der bleibenden Zähne eine laterale Leiste sich an der Entstehung des Sehmelzorganes beteiligt, und zwar komnte es konstatiert werden für die ersten Molaren und den medialen Incisivus. Bei den erst- 
genannten Zähnen gelingt der Nachweis allerdings viel leichter mul in ganz unzweidentiger Weise. Znm Beweise gebe ich in Fig. 31 eine Serie von anfeinanderfolgenden Schniten dureh die Anlage des ersten unteren bleibenden Molaren ron Mycetes (Serie $B$ ). Die Skizzen brauchen nur wenig Erklärung. In Skizze a ist nur die Zahnleiste getroffen, die keine Reduktionserscheinungen anfweisend, mit dem Epithel der Mundhöhle in Verbindung steht. In Skizze $b$ erseheint als isoliertes Feld die Aulage von $M_{1}$, die in Skizze $c$ veroröbert ist. Das untere Ende der Zahnleiste biegt sich ein wenig medialwärts und stellt sich der medialen Fläche der Zahmanlage parallel. In Skizze d erscheint an der Abknickungsstelle eine geringe Ansehwellung, die erste Andeutung der lateralen Schmelzleiste. Letztere vergröbert sich in den Schnitten $e$ und $f$, aber noch immer tritt keine Verbindung zwischen Zahnleiste und Schmelzorgan auf, ein schmaler spaltförmiger

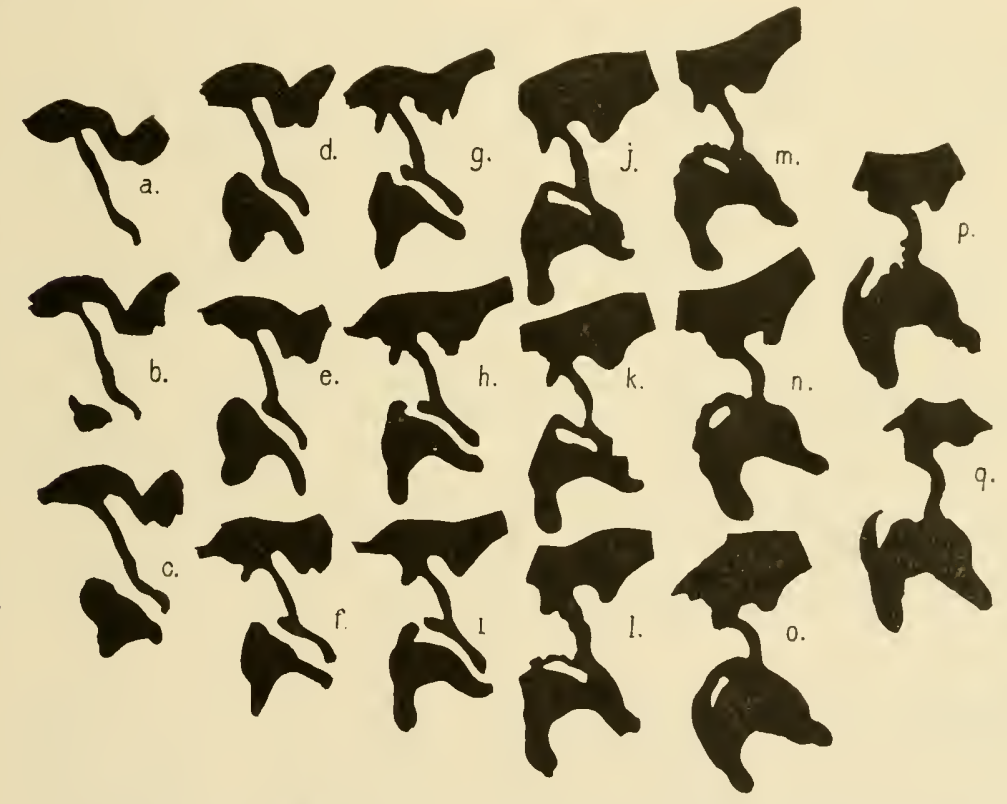

Fig. 31. Mycetes. Serie B. Anlage des ersten unteren bleibenden Molaren.

Raum trennt beide. In dem Schnitt g geht von der Spitze des Organes eine kurze sprosse aus, die der lateralen Leiste entgegenwächst und in den Sehnitten $h$ und $i$ immer deutlicher hervortritt. Erst im nächsten Schnitt $(f)$ vollzieht sich die Verbindung zwisehen Sehmelzorgan und Zahnleiste mud wohl gleichzeitig mit der medialen nnd der lateralen Verbindung. Dio uns bei den Milchzähmen bekannt gewordene Emailkrypte ist anch hier jetzt anwesend und hat im Querschnitt eine längliche Gestalt. Verfolgt man mun die Serie weiter, damn sieht man, daß - wie es anch bei den Nilehmolaren von Chrysothrix der Fall war - ron einer Krypte in wahrem Simme hier nicht die Rede ist. denn die laterale Leiste fließt nicht mit ihrem hinteren Rande mit der medialen Leiste zusammen. Statt eincr Nische besteht auch hier ein Kanal, der vom Schmelzorgan und von den beiden Leisten be- 
grenzt wird. In Schnitt $p$ wird das Dach des Kanales zerbrochen, und von der lateralen Wandfläche des Schmelzorganes geht eine zur Zahnleiste gerichtete Sprosse ans, der Rest der lateralen Leiste.

Der Fall ist sehr deutlich und stellt wohl außer Zweifel, daB wenigstens die unteren bleibenden Molaren sich in ihrer Entwicklung vollständig den Milchzähnen anschließen. Für den oberen bleibenden Molaren wird der Beweis durch Fig. 32 erbracht. Es betrifft hier den oberen ersten Molaren von Mycetes (Embryo D). Die laterale Schmelzleiste ist hier nur über vier Schnitte zu verfolgen, aber diese genügen für die Feststellung der Tatsache.

Das Anftreten der lateralen Schmelzleiste bei den bleibenden Molaren läßt sich also mnschwer nachweisen. Teniger leicht gehingt es für die Wechselzähne. Die Unstände sind hier ungleich viel un-

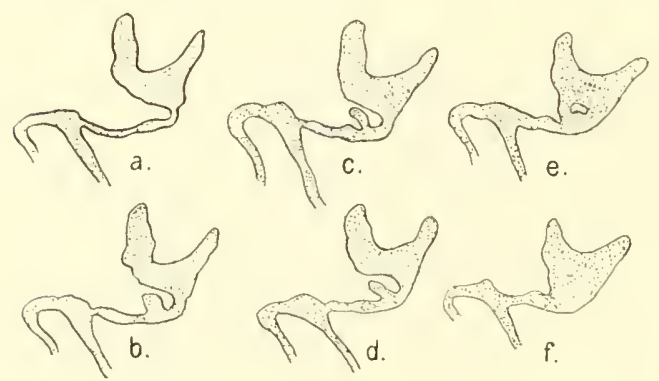

Fig. 32. Mycetes. Serie D. Sechs Schnitte durch die Anlage vom oberen ersten permanenten Molaren. günstiger, da zur Zeit, da diese Elemente des Gebisses angelegt werden, die Zahnleiste schon die bekannten Zeichen von Reduktion und Degeneration aufweist und dieser Vorgang mit Wucherungen der Leiste verbunden ist. Ich habe diese Frage überdies nicht griindlich verfolgen können, da ich noch keine genügenden Serien aus den erforderlichen Entwicklungsstadien besitze. Ich setze meine Untersuchungen in dieser Richtung noch fort. Doch glaube ich, daß die vier Skizzen in Fig. 33 wenigstens auch für den bleibenden Schneidezahn die Frage
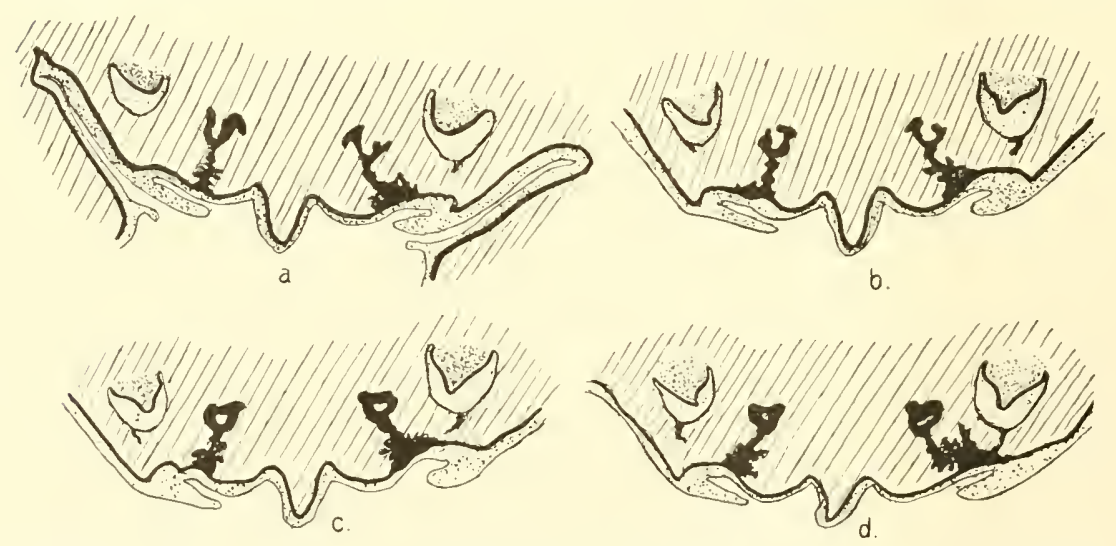

Fig. 33. Homo. Serie E. Anlage der bleibenden medialen oberen Schneidezähne.

zur Genüge lösen. Diese Figur gibt vier anfeinander folgende Schnitte wieder durch die Anlage des permanenten oberen medialen Incisivus vom menschlichen Embryo, Serie $E$. Die Zahnleiste bildet eine Menge 
epithelialer Sprosse, hängt jedoch noch mit dem Oberkieferepithe] zusammen. Am unteren Ende spaltet sich die Jeiste gabelförmig, und wiewohl die Spaltungsprodulte etwas unregelmäßig gebildet sind, ist die Tatsache, dab links und rechts nahezu übereinstimmende Bilder cntstehen, von genügendem Wert, 1 m hierin keine indifferente Erseheinung zu erblicken. Besonders nicht, wenn man bemerkt, daf, in Schnitt $c$ die beiden Gabeläste durch eine Querbrïeke miteinander in Verbindung treten, wodurch an Ende der Zahnleiste das eigenartige steigbügelartige Crebilde entsteht, das, in durehaus größerem Unfang, nns wiederholt bei den Milchzähnen begegnete. Besonders in Schnitt $d$ werden wir stark an jene Bildung erinnert, welche oftmals bei den Milchzähnen getroffen wurde, wo eine Schmelzkrypte von der lateralen und medialen Zahnleiste begrenzt war und die quere Verbindung zwischen beiden Leisten die erste Andeutung der Einstülpung durch die Zahmpapille zeigte.

Ieh bin dann aueh der Meinung, daß man den lateralen Gabelast in den Schnitten $a$ und $b$ als die laterale Schmelzleiste zu betrachten hat, wodurch auch - falls diese Meinung richtig sei - für die bleibenden Ineisivi der Beweis geliefert ist, daß deren Anlage prinzipiell nicht von jener der Milchschneidezähne abweicht.

Hiermit beendige ich die Beschreibung des anf die laterale Schmelzleiste Bezıg habenden Materials. Ich muß den geneigten Leser, der meinen Auseinandersetzungen bis jetzt gefolgt ist, um Entsehuldigung bitten, daß ich vielleicht der in ilnem IVesen übereinstimmenden 'Tatsachen etwas zu viel gegeben habe. Aber ich glaubte mich dazu verpflichtet. Es gilt hier ein neues normales Element in der Zahnanlage. und der Nachweis desselben kamn nicht anders als von grundlegender Bedeutung sein für die Ansichten über den morphologischen Wert der Zähne und deren Genese. Es kam mir deshalb erwïnscht vor, endgïltig den Beweis zu bringen, daß es sich hier um ein Element handelt. das konstant bei allen Zähnen der Primaten auftritt, und nicht um eine individuelle Variation. Nur in dieser Weise wird eventucllen Fragen nach Allgemeinheit des Vorkommens sofort vorgebeugt. Und diese Beweisfülbrung lonnte nur an der Hand zahlreicher Beispiele erbracht werden, wobei der bildlichen Darstellung eine hervorragende Rolle zuerkannt werden mußte.

Es ist im vorangehenden jetzt wohl genügendes Tatsachenmaterial angeführt, um die Behauptung zu berechtigen, dab unsere Vorstellung von dier Zahmanlage beim Mensehen und Affen bis jetzt cine lückenhafte war und einer Vervollständigung bedürftig ist. In den folgenden Zeilen werde ich jetzt versuchen, eine Skizze zu geben von der Entwickhngsgesehichte des Primatenzahnes unter Berücksichtigung der Erscheinungen, welehe wir in diesem Abschnitt kennen gelernt haben. In dem folgenden Hauptstück werden wir noch weiterc Erseheinungen kennen lernen. Es handelt sich dabei jedoch um innere Differenzierungserseheinungen, welehe die Bestätigung bringen ron dem, was schon auf Grund des jetzt Erkannten geschlossen werden kamn. Ich werde - 1 m die Darstellung nicht zu komplizieren - die Frage nach der Beziehmug der Zahnleiste zur Vestibularleiste und von der Zahnleiste als ILatrix ron gingivalem Epithel nicht berïhren. Für diese Frage verweise jeh naeh meiner Abhandlung ïber die Entwicklung des Gaumens beim Menschen. 
Die GebiBanlage, wird eingeleitet durch die Entstehung einer aus dem Mundhöhlenepithel ins Kiefermesenchym sich einsenkenden Leiste. Letztere - die Zahnleiste oder Schmelzleiste der Antoren ist an zweekmäßigsten als die ,generelle" Zahnleiste oder .Gebißleiste " zu bezeichnen. Die Zahnanlagen erscheinen in der bekannten Weise als Anschwellungen an freien Rande der generellen Zahnleiste. Zwar findet man in der Literatur nicht selten die Angabe, dab. die Zahnpapille seitlich in die Zahnleiste einwuchert, aber es kommt mir nicht nuwahrseheinlich vor, daß es sich dabei num eine nicht ganz richtige Dentung der Schnittbilder handelt. Bei den Primaten erscheint allerdings die erste Zalmanlage als eine am freien Rande der Zahnleiste sich findende Anschwelhung. Fs sind somit die Vilehzähne terminale Produkte des generellen Zahnleiste. Später rückt die Anlage immer mehr auf die bukkale Fläche, so daß die generelle Zahnleiste die mediale Wand des Sehmelzorganes bildet. ITährend sich dies vollzieht, tritt immer dentlicher eine zweite Verbindung der Zalmanlage mit der generellen Zahnleiste zutage. Sie wird hergestellt durch eine Iamelle, die von der bukkalen Fläche der generellen Zilhnleiste ihren Ursprung nimmt und sich an der bukkalen Fläche der Zahnanlage ansetzt. Diese Leiste tritt bei jedem Zahn auf und steht unr mit einer einzigen Zahnanlage in Beziehnng. Es ist somit im Gegensatz zur gencrellen Zahnleiste eine spezielle Lamelle. Da sie sich mit der lateralen Seite der Zahnanlage, später des Schmelzorganes verbindet, ist sie am treffendsten als laterale Schmelzleiste zn bezeichnen. Über ihre Entstehmngsweise ist es nicht leicht, sich rasch an wenigen Präparaten eine Vorstellıng zu bilden. Denu sie entsteht nicht als eine freic Ausstülpung der bukkalen Fläche der generellen Leiste, welche sich sekundär mit der Zahnanlage verbindet. Die Verbindung ist eine primäre. Man muß sich den etwas komplizierten Vorgang folgenderweise verlaufend denken. Die erste Anschwellnng an der generellen Zahnleiste. welche die Entstehung eines Zalnnes einleitet, enthält potentia nicht ansschließlich das Material des Schmelzorganes. sondern auch die beiden Verbindungen, wodurch schließlich das Organ mit der generellen Zabnleiste zusammenhängt. Diese erste Anschwellung, welche am zweckmäBigsten als primäre Zahnanlage zu bezeichnen ist, differenziert sich in die Sehmelzorgananlage und das Leistensystem, und zwar folgenderweise. Im oberen zıgespitzten Teil der primären Zahnanlage bildet sich an der nach vorn, odler bei gewissen Zähnen nach hinten gekehrten Fläche ein Grübchen, das bei der Vergrößerung der Zahnanlage sich immer mehr vertieft. Indem nun die Zellmasse nnterhalb dieses Grübchens an Breite gewinnt und sich zur Sehmelzorgananlage differenziert. wird anch das Güibchen geränmiger und bleibt dabei seitlich und nach oben von der jetzt zu einer Lamelle ungestalteten Zellmasse begrenzt, die sich schon anfänglich seitlich und oben von ihm fand. Diese seitliche Wand des Grübchens ist somit ans der primären Zahnanlage hervorgegangen. Beim weiteren Wachstum erlangt nun die laterale Wand des inzwischen zn einer Nische oder Krypte gewordenen Grïbchens immer mehr den Charakter einer Leiste oder Lamelle. Die sehmelznische oder Emailkrypte wird jetzt begrenzt durch die Sehmelzorgananlage, welche den Boden des Raumes bildet, und seitlich durch die laterale Schmelzleiste. Ihre mediale Wand, welche 
wie die direkte Fortsetzung der generellen Zahmleiste hervortritt, ist infolge der Entstehungsweise der Krypte in Wirklichkeit auch aus Material hervorgegangen, das ursprünglich zur primären Zahnanlage gehörte. Letztere dehnte sich anfänglich aus bis zur Stelle, wo die laterale Schmelzleiste mit der gencrellen Zahnleiste sich rerbindet, denn die Schmelznische ist durch Aushöhlung des oberen Teiles der primären Zahnanlage entstanden.

Bei den Antemolaren wohl aller Primaten ist die Nische nach vorn, bei den Molaren des Menschen und anch wohl bei Affen nach hinten offen.

Man kann an der lateralen Schmelzleiste einen freien Vorderrand unterscheiden (vgl. die Textfiguren 14 und 26), einen unteren Rand, der in die bukkale Wand der Schmelzorgananlage übergeht, und einen hinteren Rand, der sich in schräger Riehtung ron vorn oben nach hinten unten an der generellen Zahnleiste festheftet. Dieser hintere Rand, der somit ursprïnglich nirgends frei ist, setzt sieh in dem an der Schmelzorgananlage festgehefteten Unterrand fort.

Mit Hilfe der Fig. 26 und der beiden vorderen Zähne in Fig. 14 meine ich, daß die Vorstellung der Entstehungsweise der lateralen Sehmelzleiste jetzt keine Sehwierigkeit mehr bietet.

Die primäre Zahnanlage haben wir somit als ein kompliziertes Gebilde kennen gelernt. Es umfaßte nicht nur die Schmelzorgananlage, sondern auch die laterale Schmelzleiste nnd jenen Teil der generellen Zahnleiste, der die Schmelznische medial hegrenzt, gehen ans ihr hervor. Es ist die mediale Wand der Nisehe als mediale Sehmelzleiste zu unterseheiden. Kurz zusammengefabt gehen also aus der primären Zahnanlage folgende Bildungen hervor: Schmelzorgananlage. laterale Schmelzleiste, mediale Schmelzleiste und Schmelznische.

Es kann sich num ereignen, daß die primäre Zahnanlage bis zum Mundhöhlenepithel sich erstreekt. Tenn in solch einem Fall die Schmelznisehe sich zu bilden infängt, kommt dieselbe direkt unter das Mundhöhlenepithel zu liegen. Und dann entsteht jener Zustand. der in Fig. 26 bildlich dargestellt ist, wobei das Kieferepithel eine kurze Strecke zur Begrenzung der Nisehe beiträgt und die laterale Schmelzleiste als eine selbständige, von der generellen Zahnleiste unabhängige Bildung, direkt aus dem Mundhöhlenepithel entsteht. Bei den Semmopitheciden haben wir die jüngsten Stadien dieses Zustandes kennen gelernt.

Wenn eimmal aus der primären Zahnanlage die Sehmelzorgananlage und das Leistensystem sich differenziert hat, ist das ganze Gebilde zweckmäBig als , sekundäre Zahnanlage“ anzudenten. In den Figuren 34 und 35 habe ich versucht, den Differenzierumgsvorgang sehematisch wiederzugeben. Die Fig. 34 hat Bezug auf jene Formen. wo der Milchzahn aus einer generellen Zahnleiste entsteht. die Fig. 35 auf solche, wo die primäre Zahmanlage bis zum Kieferepithel reicht. In der Fig. $34 A$ ist die primäre Zahnanlage z. B. eines Incisivus dargestellt. Das Kieferepithel ist nit a bezeichnet, die generelle Zahnleiste mit $b$, die kolbenartige primäre Zahnanlage mit $d$ und die Grenze zwischen primärer Zahmanlage und genereller Zahnleiste mit c. In Fig. $34 B$ ist ein weiter vorgeschrittenes Stadinm dargestellt. Es hat sich im oberen Teil der Vorderwand das Grïbchen gebildet. 'woraus die Schmelznisehe hervorgehen wird. Es ist mit $e$ bezeichnet worden. 
In dem Sehema $34 C$ hat das qumze Gebilde an Cröße zngenommen und ist durch Verticfung und Verbreiterung der Nische die primäre Zahnanlage dentlich in den drei Unterteilen differenziert. Es erheischt die Figur ebensowenig wie Fig. 35 nach dem Vorangehenden keine weitere Erklärnng.

Ich hoffe, dab durch diese Schemata die Einsicht in der Entstehungsweise der ,.sekundären Zahnanlage" wesentlich erleichtert
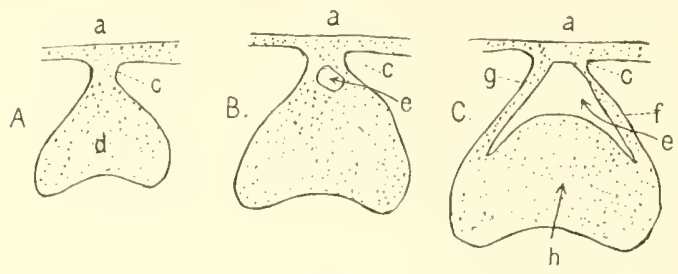
wird. Es würden wohl unch mehrere Details derAulage bei den unterschiedenen Zähnen zı verzeichnen sein, jedoch 11 m die Beschreibung nicht zu viel auszudehmen, unterlasse ich es, daranf einzugehen.

Durch die Entste-
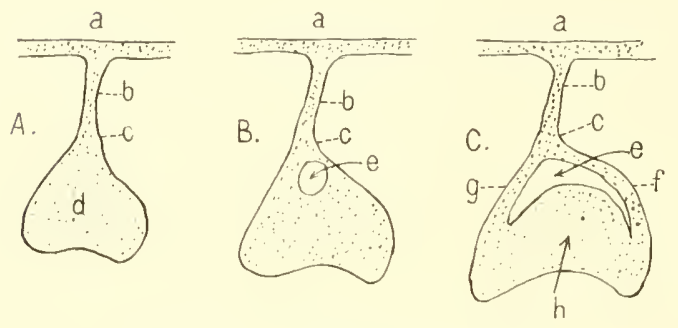

Fig. 35. Erklärungen in Text. hung der Schmelznische hat das Schmelzorgan eine doppelte Verbindung mit der Zahnleiste bekommen, eine an der medialen und eine an der lateralen Seite. Es geht aus der Entstehungsweise klar hervor, dab. beide Verbindungen einander vollkommen gleichwertig sind, man darf einer der Leisten in Hinsicht auf die Entstehung des Zahues, keine andere oder minderwertige Bedentung zuerkemnen als der zweiten. Die mediale Verbindung, die mediale Schmelzleiste hat für die nediale Hälfte des Schnelzorganes rollkommen rie gleiche Bedentung als die laterale Schmelzleiste für die laterale Hälfte. Und man darf nit Recht folgendes behaupten: die Schmelzorgananlage bei den Primaten ist eine Doppelbildnng. umfabt eine bukkale und eine linguale Anlage. Oder mit anderen Worten: die Schmelzorgananlage der Primaten enthält potentia die Anlage zweier Zähne, welche topographisch sich als eine laterale und mediale oder äubere und innere verhalten. Auf diese wichtige Schlubfolgerung komme ich später noch zurïck.

Verfolgen wir zunächst das sichicksal der ans der primären Zahnanlage entstandenen Bildungen. Über die weitere Entwicklung des Schmelzorganes werde ich an dieser Stelle nicht ausschweifen, denu im nächsten Hauptstïck bildet dieses Organ g'erade den Hauptgegenstand der Besprechung. Wir wenden uns sofort zu den beiden Schmelzleisten.

Es ist festgestellt worden, dab beide Leisten sich an der lingualen resp. bukkalen Seite der Schmelzorgananlage ansetzen. Das Organ wird immer breiter und die Wachstmmsrichtumg ist dabei vorzüglich bukkalwärts. Die Folge davon ist, daß die mediale Schmelzleiste immer mehr als die Fortsetzung der generellen Zahmleiste erscheint (vgl. Fig. 31 und $32 c$ ), während die bukkale Leiste einen immer größer 
werdenden Winkel mit der lingualen Leiste bilket. So entsteht der Zustand, der von verschiedenen Fällen abgebildet worden ist, als nähme die bukkale Leiste ihren Ursprung von der bukkalen Seite der ,Zahnleiste" (im Sinne der Autoren). Und in dom deskriptiven Teil habe ich es dann anch oftmals in dieser Weise ansgedrïckt. Dadurch erlangt die laterale oder bukkale Schmelzleiste einen stetig zunehmenden Anteil in der Bregenzung der Schmelznische. Wenn die Schmelzorgananlage jetzt noch mehr in die Breite wächst, und dazu in die Emailnische einzuwölben anfängt, kommt die Imnenfläche der bukkalen Leiste mit der Außenseite des Schmelzorganes in Berührung, und streckenweise kommen beide Epithelschichten sogar zur Verwachsung miteinander. In späteren Entwicklungsstadien lagert dann anch dem bukkalen Teil des sogenannten äußeren Epithels ein Teil der lateralen Schmelzleiste auf. Und wie früher an mehreren Figuren nachgewiesen worden ist, ist in dieser Verwachsung die Erklärung zu suchen von dem Auftreten der epithelialen Wucherungen an der Außenwand des Schmelzorganes. Demn die bukkale Leiste degeneriert in ganz gleicher Weise wie die generelle Zahnleiste: Durchlöcherung, Sprossenbildung, Epithelperlenbildung.

Die Schmelznische verschwindet während des weiteren Wachstums. Die Weise, wie sich das vollzieht, ist jedoch nicht immer die gleiche, es gibt Modifikationen. Bei gewissen Zähnen wird die Nische einfach relativ kleiner, die laterale Leiste wird durchsiebt und bildet die oben schon angedeuteten Epithelwucherungen und Zellstränge, welche auch in die Nische einwuchern können, dieselne zum Teil ausfüllend.

Bei anderen Zähnen bildet sich vorher im Hintergrunde der Nische ein Loch, durch Resorption von Material der bukkalen Leiste und infolge davon wird die Schmelznische zu einem anfänglich trichterförmigen Kanal. Es ist leicht einzusehen, daß dadurch die laterale Schmelzleiste eine größere Selbständigkeit erlangt, da sie jetzt einen zum Teil freien Hinterrand bekommt (siehe Fig. 26). Bildet sich dieses Loch frïhzeitig aus, und das ist z. B. beim zweiten Milchmolaren des Menschen der Fall, dann entsteht ein Kanal, der fast dic gleiche Iänge hat als die Schmelzorgananlage (vgl. Fig. 31). Bei weiterem Wachstum zerfällt nun die laterale Schmelzleiste mehr oder weniger schmell, gleichzeitig mit die generelle Leiste. Die mediale Schmelzleiste hat meistenteils längeren Bestand, doch ihre Verbindung mit den Organ kann sich bisweilen früher lösen als jene der lateralen Leiste.

Hiermit möchte ich die Übersicht über die Ontogenie des Primatenzahnes, soweit es die Differenziermng der, primären Zahnanlage" bctrifft, schließen. Die gegebene Darstellung enthält nichts was theoretisch konstruiert ist, alles Dargestellte gründet sich auf tatsächlich Beobachtetes. Es hat freilich eine längere Untersuchungszeit erfordert. ehe es mir gelungen war, die Einzelbeobachtungen zu einer vollständigen Entwicklungsreihe aneinander reihen zu können. Oftmals hatte ich mir - besonders im Anfang meiner Untersuchungen - Vorstellungen gebildet, welche sich später als unrichtig erwiesen. Besonders das Epithelderivat, das später als Nebenleiste beschrieben werden soll. licferte viele Schwierigkeiten.

Als Hauptergebnis dieses Teiles meiner Ǔntersuehung betrachte ich den Nachweis, daß das Schmelzorgan der Primaten zweier einander 
vollständig gleichwertigen epithelialen Leisten seine Entstehung verdankt, dab dieses Organ potentia eine Doppelbildung ist. Zwar tritt diese Doppehatur nicht gleich bei der ersten Anlage zur Schan, aber das darf uns kamm wundern. Bei der prinären Zahnanlage findet sich der ganze Zahnentwicklungsappalat noch zu einer einheitlichen Masse zusammengefabt. Erst im Liufe del weiteren Entwicklung und zwal sehr bald manifestiert sich die wahre interne Natur der Anlage. An dieser Stelle werde ich diese Tatsache noch nicht in Beziehung bringen zu den allgemeinen odontologischen Problemen, und verweise dazu auf das SchuBkapitel. Nur in Hinsicht auf die im nächsten Hauptstück zu beschreibenden Erscheinungen, möchte ich kurz hervorheben, dab meiner Meinung nach die Ontogenie des Primatenzahnes, soweit wir dieselbe bis jetzt rerfolgt haben, genïgend Grund abgibt für die Ansicht, dab dieser Zahn aus der Konkreszenz zwoier Elementarclementen hervorgegangen ist, welche sich topographisch als ein bakkaler und lingualer verhalten. Durch diese Ansicht wird die Erscheinung, zu deren Beschreibung ich jetzt ïbergehe, sofort verständlicher. 


\section{Zweites Hauptstück.}

\section{Das Schmelzseptum und der Schmelznabel.}

In folgenden werden Differenzierungserseleinungen zur Sprache gebracht, welehe bei der weiteren Entwicklung des Sehmelzorganes sich hervortun und besonders mit der Entstehimg der sogenamuten Schmelzpulpa zusammenhängen.

Es sei daran erimert, daf das Sehmelzoroan sieh bald nacholem es das glockenförmige Stadium erreicht hat, histologiseh zu differenzieren anfängt. Die der mesenchymatösen Zahnpapille unmittelbar aufliegenden Zellen bilden sich zı den Ameloblasten aus. Die an der Oberfläche liegenden Elemente gehen in platte Zellen über, welche eine oberflächliche absehließende ILmbran bilden, und als äuBeres Sehmelzepithel unterseheiden werden. Diezentrale Zellmasse differenziert sich zu dem bekannten aus sternförmigen Zellen aufgebauten Schwammgewebe, das als Sehmelzpulpa belannt ist. Diese Sternzellen sind umgewandelte Epithelzellen, zwischen welchen weite mit Flïssigkeit gefïllte Interzellularränme sich finden. Besonders in den älteren Stadien, wenn die Schmelzpulpa gut ausgebildet ist, ist es deutlich, daß letztere nicht unmittelbar an die Ameloblastensehicht stößt, dem diese Sichicht von hohen zylindrischen Zellen ist noch mit einer Lage von Zellen überzogen, welche ziemlich dicht gedrängt aneinander lagern. und dic primitive runde Form länger behalten, um jedoch später sich mehr abzuplatten. Diese Sehicht, das Stratum intermedium vou Waldeyer. ist auf die höehste Wölbung der Ameloblastensehicht am stärksten entwickelt, seitlich wird es dünner.

Über die Weise, wie die Schmelzpulpa auftritt, fassen sich die Lehrbüeher im allgemeinen nur kurz. So schreibt von Ebner in Köllikers Handbuch (Bd. III, S. 106): , Nach der Einstiilpung der Schmelzorgane durch den Zahnkeim tritt die eigentliche Sehmelzpulpa durch Bildung ron Interzellularräumen auf, und wachsen die Zellen des inneren Epithels zu hohen regelmäBigen Zylinderzellen aus." In Tomes Mannal of Dental Anatomy finde ich iiber diesen Vorgang (S. 139) : ..The transformation of the eells ocenpying the centre and constituting the bulk of the enamel organ into a stellate reticulum goes on progressing from the centre outwar(st), but it stops short of reaching the layer of columnar cells wich constitute the surface of the enamel organ next to the dentine papilla; a narow layer of unaltered cells wich remain between the stellate cells and the colummar enamel cells constituting the stratum intermedium". In seiner an gemanen

1) Ich kursiviere. 
Beobachtungen reichen ., Untersuchungen über die Entwicklung der Zähne" (Danzig 1864) sagt Wa ldeyer (S. 55) ïber die Differenzierung des Schmelzorganes: ,Num beginnt zunächst in der Mitte des Schmelzkeimes ${ }^{1}$ ) eine Umformung derselben zu einem bestimmt gestalteten Gewebe."

Ich möchte meine Bemerkungen an dem in den beiden letzteren Zitaten von mir Kursivierten anknüpfen. Tomes und Waldeyer behaupten, daß die Umbildung der zentralen Zellen zu der Schmelzpulpa im Zentrum der Organanlage anfängt und von hier aus peripherwärts weiter rückt. Obwohl von Ebner sich dariiber nicht äußert, findet sich auch bei diesem Autor keine entgegengesetzte Angabe.

Nun ist die Behauptung, daß die Schmelzpulpabildung im Zentrum anfängt, nicht richtig. Es sollte aus dieser Aufgabe folgen, daß es im Organ nur eine einzige Stelle gibt, von wo die Pulpabildung ausgeht. Das ist nun nach meinen Befunden nicht der Fall, die Pulpabildung geht von zwei Stellen aus. Das ist jedoch nicht an allen Präparaten und an allen Zähnen gleich leicht zı konstatieren. Aber wenn man einmal auf die Erscheinung und die Folge, welche sic bezïglich des inneren Baues des Schmelzorganes hat, aufmerksam geworden ist, dann ist es nicht sehr schwierig, die Spuren dieses Vorganges bei allen Zähnen nachzuweisen. Warum dieser Nachweis nicht so leicht bei gewissen Zähnen gelingt, wird wohl noch erklärt werden.

Am leichtesten ist die Differenzierung der Schmelzpulpa von zwei Zentren aus an den Molaren zu konstatieren. Tch gebe in Fig. 36

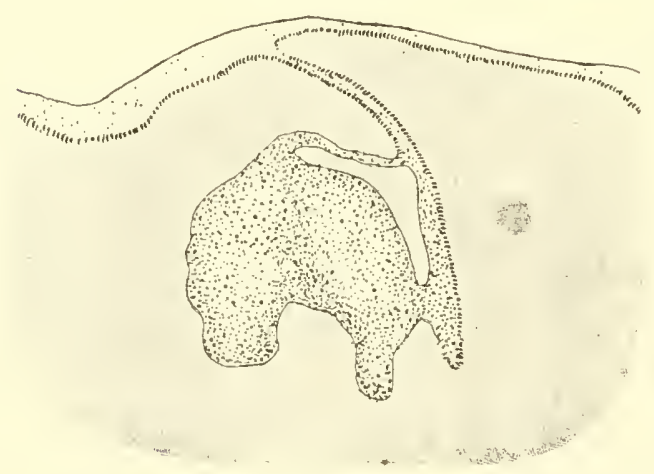

Fig. 36. Mycetes A. Schnitt durch die Anlage des unteren $m_{3}$. z. B. den Frontalschnitt eines interen dritten Molaren von Mycetes (Serie $A$ ). Die Form der Zahmanlage darf ich jetzt in ihren Einzelheiten als bekannt roraussetzen; man erkennt die generelle Zahnleiste, die noch mit dem Kieferepithel verbunden ist, die laterale Schmelzleiste, die sich an der Spitze der Schmelzorgananlage ansetzt, die mediale Schmelzleiste, die mit der Innenwand des Organes verbunden ist,

und die Schmelznische. Das Schmelzorgan steht im Begriff die Pulpabildung anzufangen. Die Diffferenzierung, welche mit einer Erhöhung des Fliissigkeitsgehaltes gepaart ist, hat demzufolge eine Aufhellung im Inneren des Organes zur Folge. Und wie nun die Fig. 36 ersehen läßt, tritt die Aufklärung nicht an einer einzigen Stelle auf im Zentrum des Organes, sondern letzteres behält gerade seinen mehr dunklen Ton, ist nicht durchsichtiger geworden. Es gibt dentlich zwei Aufhellungszentren, eines in der bukkalen und eines in der lingualen Hälfte des

1) Ich kursiviere. 
Organes. Wir haben hier das erste Stadium der Pulpabildung vor uns, wahre Sternzellen bestehen noch nicht, auch ist die sehieht der Ameloblasten noch nicht differenziert, ebensowenig als schon von einem äuBeren Epithel die Rede sein kann. Zwischen den zwei Aufstellungszentren findet sich ein mehr dunkler Streifen, der sich ron der Basis des Sehmelzorganes zur Spitze erstreckt und die gleichsam eine V'erbindung zwischen beiden darzustellen scheint. Es sei sofort darauf aufmerksam gemacht, dafo die laterale Schmelzleiste sich an jenem Teil der Oberfläche des Organes ansetzt, der regional zum lateralen Aufhellungszentrum gehört, die mediale Leiste setzt sich im Gebiet des medialen Anfhellungszentrums an. Der Schnitt ist ein transversaler, und wenn man sich das ganze Organ in dieser Differenzierungsphase ränmlich vorstellt. damn stellt der dunkle in der Mitte sich findende Streifen eine Art Septum dar, das im Schmelzorgan in sagittaler Richtung die beiden Pulpabildungszentren voneinander trennt. Ich schlage vor, diese Bildung als ,,Schmelzseptum" zu bezeichnen. In dem in Fig. 36 abgebildeten Entwicklungsstadium trägt es allerdings noch wenig den Charakter eines Septnm, wir stehen hier eben am Anfang der Differenzierung, es bestehen noch keine scharfen histologischen Differenzen.

Ein weiteres Entwicklungsstadium ist in den Tafelfiguren \& und 9 abgebildet. Die Figur 8 stellt einen Frontalsehnitt dar durch das Schmelzorgan des unteren ersten Milchmolaren eines Macacus eynonolgus und die Fig. 9 einen solchen des unteren Eckzahnes des nänlichen Fötus. Teh gebe diese Fignren nebeneinander, mm sofort feststellen zu können, daß die Differenzierung des Organes eines sogenamnten monokuspidaten Zahnes sich vollkommen wie jene eines multikuspi(laten verhält ${ }^{1}$ ). In Fig. 8 geht der Schnitt durch den hinteren sehr engen Teil der Schmelznische, es sind dadurch die laterale und die mediale Schmelzleiste gerade noch als selbständige Bildungen zu sehen, der Schnitt in Fig. 9 verlief hinter der Schmelzkrypte. In beiden Figuren ist das zweifache Bildungszentrum der Schmelzpulpa so augenfällig, da $\beta$ diese Figuren an sich genügen, un die Angabe, da $\beta$ die Pulpabildung im Zentrum des Organes anfängt, endgültig zu widerlegen. Das Schmelzseptum, das in Textfig. 36 in seiner ersten Anlage eben angedentet war, tritt hier, infolge der inzwischen weiter vorgeschrittenen Aufhellung der beiden Regionen, als eine wohl ansgebildete Scheidewand zwisehen beiden Hälften im Innern des Organes anf. Es hat sich inzwischen auch die Differenzierung in den ïbrigen Elementen des Organes kennbar gemacht, wobei das Organ des Eckzahnes (Fig. 9) jenem des Molaren voransgeeilt erscheint. Die Ameloblsatenschicht ist in den beiden Anlagen schon aus den bekannten zylindrischen Zellen aufgebant, auch das äuBere Epithel ist schon differenziert, obwohl es noch nicht aus den stark abgeplatteten Elementen besteht. welche in späteren Entwicklungsstadien die Membran zusammensetzen. Die Elemente des Schmelzseptums besitzen noch ihre früh-embryonale Form, und während diese nach oben munterbrochen in die Zellen des änßeren Epithels übergehen, setzen sic sich nach unten ohne Unterbrechung in der auch schon kemnbaren intermediären Schicht fort. Besonders in Tafelfig. 9 erscheint letztere als eine Kappe anf die Ameloblasten-

1) In Wirklichkeit kommen im Primatengebiß keine wahre monokuspidate Zähne vor; die Incisivi und Canini sind, wie in einer folgenden Arbeit nïher begrïndet werden soll, pseudomonuknspidate Zähne. 
schicht gelagert, und es billet das Schmelzseptum gleichsam ihre stark zugespitzte Fortsetzung nach oben.

In dem auf Tafelfig. 9 abgebildeten Schnitt geht das Schmelzseptum in das äußere Epithel über, gerade an der Stelle, wo an der Außenseite die Zahnleiste sich am Organ festheftet.

Wemn man nun die ganze Schnitserie durch die bezüglichen Schmelzorgane rerfolgt, damn wird es wohl deutlich, daß die Angabe von I I lde yer und Tomes nicht aus der Luft gegriffen ist. Das weitere Wachstum, die Vergrößerung des Oroanes mit sich bringend, ruft wesentliche Komplikationen zum Vorschein. welche jedoch leicht verständlich sind. Denn in den meist vorderen Schnitten durch die beiden bezüglichen Zahnanlagen ist rom Schnelzseptum nichts zu sehen, es scheint in der Tat eine einzige Pulpamasse zu bestehen, damn tritt bei den weiter nach hinten liegenden schnitten das Septum auf, un in den meist hinteren Schnitten wieder zu verschwinden. Wie ist diese Erscheinung zu deuten? Die Sache ist ganz einfach. Am Beginn der Pulpabildung streckt sich das septum in sagittaler Richtung noch durch das ganze histologisch wenig differenzicrte Organ aus. Letzteres wächst jedoch in die Jänge, es schwillt infolge der Pulpabildung raseh an. Aber das Septum wächst nicht in gleichem Mabe mit, als das Organ, verliert daher an Vorder- und Hinterwand des Organes den Zusammenhang mit dem äußeren Epithel und die beiden Bildungszentren der Pulpazellen fließen zusammen vor und hinter dem Septum. Es wäre damn anch vielleicht die Bezeichnung Schmelzseptum zu beanstanden, ich wählte jedoch diesen Namen, der so den Anfangsstadien entspricht, und wie wir später sehen werden, der phylogenetischen Entstehungsweise gerecht wird.

Was wird nun aus der Scheidewand beim weiteren Wachstum des Schmelzorganes? Die Antwort hicrauf kann kurz lauten, sie wird zu einer rudimentären Bildung reduziert. Aber dürfe Redulition das Charakteristikum dieser Bildung sein, so treten dennoch eigentïmliche Erscheinnugen dabei auf. anf welehe wir jetzt näher eingehen müssen.

In den Tafelfigmen 8 mol 9 handelt es sich um Stadien, worin das Schmelzorgan nuch nicht den Höbcpunlit seiner Differenziermug erreicht hat, die Schmelzpulpa ist auf dem Wege sich zu bilden, aber die typische Form der sternzellen ist noch nicht aufgetreten. In Fig. 8 macht sich die Ameloblastenschicht eben benerkbar, in Fig. 9 ist die Entwicklung schon etwas weiter fortgeschritten, das Schmelzseptum hebt sich hier gegen die Pulpazellen scharf ab. Die Septumzellen behalten anfänglich ihre früh-embryonale Ciestalt und setzen sich in den Elementen des stratum intermedium fort, das in Fig. 9 ebenfalls schon gut angedentet ist.

Bei der weiteren Entwicklung wächst das Septum nicht mit, aber die Beziehungen zum äuberen Epithel werden dagegen viel deutlicher. Wir werden jedveh, ehe wir das zeigen, erst die Gestalt des Septums in einem weiteren Entwicklungsstadiun mit Hilfe einer Figur klar machen.

Es ist oben schon betont worden, da B die beiden Pulpazentren, wemn eimmal die Differenzierung im Gange ist, vol und hinter dem Septum ineinander ïbergehen. Infolge der Tlüssigkeitsansammlung in den Interzellularräumen schwillt das Organ rasch an, und je stärker sich dasselbe vergröbert, desto kleiner wird relativ das Septum. Fs 
verliert daher seine Bedeutung als Scheidewand, und bei einer gewissen Sehnittrichtung erscheint es schlieblich mehr in der Form eines Stranges, der sich rom Stratum intermedium, rings von Sternzellen umgeben, bis zum äußeren Epithel erstreckt. Will man sich von der Talsache überzengen, daß die Bildung ihre ursprïngliche Bedeutung als Schmelzseptum, je länger um so mehr einbüßt, dann gelingt solehes an jedenı etwas weiter entwickelten Organ dureh Vergleichung der Schnitte einer frontalen Serie sehr leicht (siehe muten). Vollständiger jedoch sind die Verhältnisse zu überblicken, wenn man durch ein nicht allzuweit differenziertes Organ Schnitte anfertigt in der Ebene des Septums. Ein Beispiel davon gibt Fig. 37. Diese Figur stellt das Schmelzorgan dar, vom oberen Caninus eines menschlichen Embryos (Serie $H$ ). Dic Schnittrichtung war eine sagittale. Das Septum ist, da die beiden Pulpabildungszentren als eine bukkale und linguale sieh verhalten, anfänglich auch beim Caninus in sagittale Richtung gestellt, und in Fig. 37 ist es dann anch der Länge nach getroffen dargestellt. Man sieht, daß es sich gar nicht mehr von der Vorder-bis zur Hinterwand des Organes ausdehnt. Vor und hinter dem Septum ist Pulpamasse zwischen Wand und Septum gelagert. DaB letzteres auch in anderer Richtung, auf dem Wege der Regression sich findet, wird erkembar aus den helleren Partien, welche mit mehr dunklen - zellenreicheren - abwechseln. Nach oben ist jedoch die Verbindung mit dem äıßeren Epithel nicht gelöst.

Beim fortschreitenden Wachstum und Ausclehnumg des Schmelzorganes nimmt das Septum in den meisten Fällen die Form eines bandartigen Zellstreifens an, der von der Spitze des Stratum intermedium in einer wechselnden Richtung die Pulpamasse durchstreift. Die Zellen bleiben stark tingierbar und heben sich dadurch deutlich von der umgebenden Pulpamasse ab. Daß es sich zu einem Strange zusammenzieht, geht daraus hervor, daß es bei etwas älteren Em-

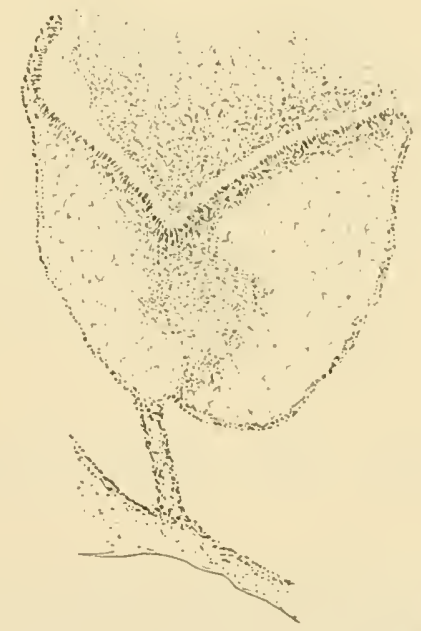

Fig. 37. Homo H. Sagittalschnitt durch den oberen Caninus. bryonen nur über wenige Schnitte sich erstreckt. Ich gebe zum Beweis in Fig. 38 eine Serie von sechs Slizzen von anfeinander folgenden frontalen Schnitten dureh die Anlage des oberen ('aninus rom mensehlichen Embryo, Serie $F$, Schnittdicke $25 \mu$. Das Organ steht dureh die laterale schmelzleiste mit dem MLundhöhlenepithel in Verbindung, die mediale Leiste steht in dieser Schnittreihe nicht mit dem Organ in Verbindung, diese tritt erst mehrere Schnitte nach hinten anf, jetzt streckt die mediale Leiste sich noeh in horizontaler Richtung im Kiefermesenchym aus. Ich brauche auf diese zuvor ausführlich besprochenen Verhältnisse nicht einzugehen. In Schnitt $a$ ist von einem Septum noch nichts zu sehen. In Fig. $b$ erscheint es in der Form eines unregelmäBigen Zellkonglomerates, das von der Ansatzstelle der lateralen Schmelzleiste an äußeren Epithol sich in der Richtung der

B o lk, Die Ontogenie der Primatenzähne. 
Ameloblastenschicht erstreckt. Es macht sogar den Eindruek, als setze sich die laterale Schmelzleiste eine Strecke weit in die Pulpamasse fort. Im folgenden Schnitt ist die Zellmasse ein wenig vergrößert und der von einer dünnen intermediären Schicht überzogenen Ameloblastenschicht genähert. Im Schmitt $d$ ist das Septum iiber die ganze Länge getroffen. Es tritt wieder als eine vom Stratum intermedinm ansgehende Zellmasse hervor, welche die Basis des Schmelzorganes mit der Kuppe verbindet und in diesem Sehnitt wenigstens die Pulpamasse noch vollständig in einer bukkalen und lingualen Hälfte trenut. Da sich - was öfters zutrifft - das Septum in diesem Falle an der Innenseite des änBeren Epithels festheftet, gerade an der Stelle, wo an der AnBenfläehe die laterale Schmelzleiste in diese Epithelmenbran übergeht, macht es den Eindruck, als setze die Schmelzleiste sich im Organ fort bis zur intermediären Schicht. Ähnliches
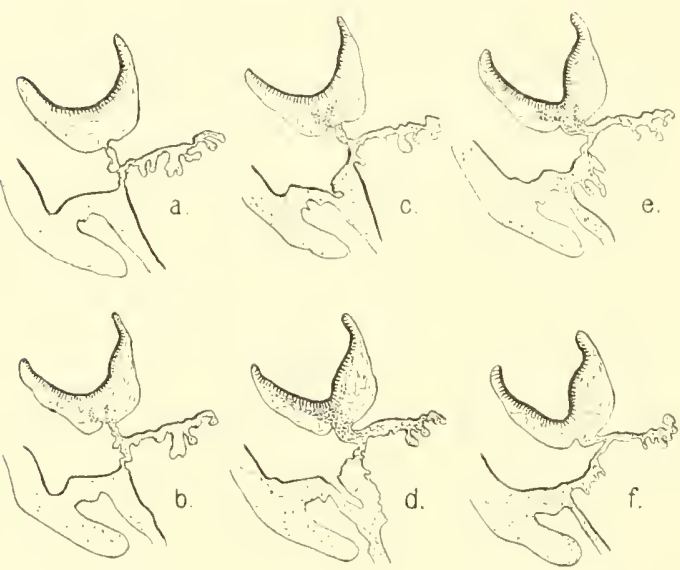

Fig. 38. Homo. Serie F. Sechs Querschnitte durch die Anlage des oberen Caninus. war beim unteren Eckzilhu von Macacus, der in Tafelfig. 9 abgebildet ist, der Fall. Doch hat man es hier mit einer zwar nicht zufälligen, aber durchaus nicht ursprünglichen Erscheinmng zu tuin.

Schon im nächsten Schnitt (e) ist das Septum wieder unvollständig und im darauffolgenden $(f)$ ist sogar nichts mehr von der Bildung zı sehen.

Diese Skizzenserie bezweckt zu zeigen, dab das Septum bei der weiteren Entwicklıng sich zn einem Strange von sehr geringer Dicke konzentriert. Und bei den älteren Stadien gelingt es dann auch nicht immer, die Anwesenheit festzustellen. Das wird auch noch dadurch bewirkt, dab das zu einem Strang ungebildete Septum oftmals in sehr schräger Richtung die Pulpamasse durchzieht. Nicht selten anch kommit es im Verlaufe desselben zur Bildung der bekannten konzentrisch gebanten Epithelperlchen, die man anch beim Zerfall der Zahnleiste, aber viel größer, wahrnimmt.

Es ist oben bemerkt worden, daß bei einer frontalen Schnittrichtung das Schmelzseptum bei den Incisivi nieht leicht in seiner Beziehung zu den ïbrigen Unterteilen der Zahnanlage zu verfolgen ist. Die Ursache davon ist, daß die Pulpabildungszentren als eine bukkale und linguale sich verhalten. Bei den Incisivi stellt sich somit das Sehmelzseptum nahezu in die frontale Ebene und erlangt man nur selten gute Bilder bei Frontalschnitten. Dagegen bilktet eine sagittale Serie durch diese Zahmanlage alles Wünschenswerte nnd läßt an Dentlichkeit nichts zu wünschen übrig. Zum Beweise davon gebe ich in Fig. 39 eine Skizzenserie von sagittalen Schnitten durch die 
Anlage vom oberen medialen Incisivus beim mensehlichen Embryo $H$. Diese Serie ist besonders lehrreich, denn sie bringt nicht nur dis Schmelzseptum zur Schau, sondern ebenfalls die besonderen Bildungen, welche wir schon früher kennen gelernt haben. Die Skizze 39 a z. B. konnte fast als ein vollständiges Schema der Anlage eines l'rimatenzahnes gelt en.

In Skizze a erkennt man die generelle Zahnleiste, die vom Mundhöhlenepithel ausgeht und sich in die mediale und laterale Schmelzleiste trennt. Die mediale ist hier die längere. Zwischen beiden speziellen Leisten und der Kuppe des Schmelzorganes findet sich die sehr geräumige Schmelznische. Am Schmelzorgan ist die Ameloblastenschicht und das äuBere Epithel, sowie die eine einheitliche Masse bildende Schmelzpulpa sofort zu erkennen. Von einem Schmelzseptum ist nichts zu sehen. Im nächsten Schnitt (b) hat sich am I,eisten-

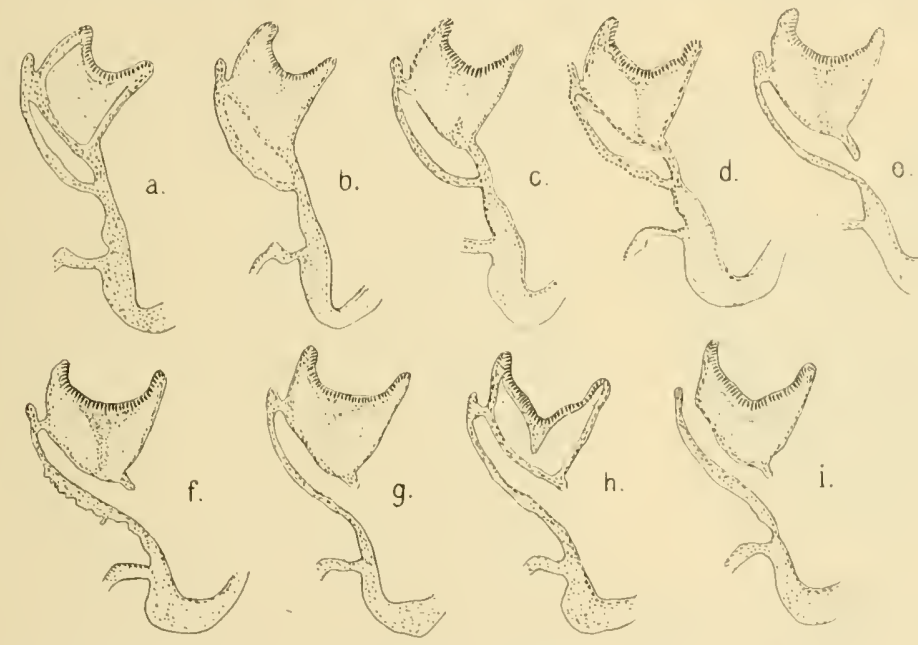

Fig. 39. Homo. Serie $H$. Sagittale Schnitte durch die Anlage des oberen medialen Incisivus.

system nichts geändert, doch im Schmelzorgan ist eine Verlickung des Stratum intermedium zn konstatieren. Dieselbe ist im Schnitt $c$ stärker ausgeprägt und gleichzeitig erscheint an der Kuppe des Organes, von der Imnenfläche des äußeren Epithels ausgehend, eine Sprosse, welche der Verdickung des basalen Stratum intermedium entgegenwächst. Im nächsten Schnitt $(d)$ hat sich diese Sprosse mit der verdichteten Stelle des Stratum intermedium verbunden und die Pulpamasse wird im Nivean dieses Schnittes vollständig in eine bukkile und linguale Hälfte getrennt. Ich mache darauf aufmerksam, daß auch hier wieder die mediale Schmelzleiste und die laterale je an einer anderen Seite der Anheftungsstelle des Septım am änßeren Epithel mit dieser epithelialen Membran sich verbinden. Allerdings liegt die Ansatzstelle der lateralen Schmelzleiste jener des Septum seln dicht genähert, aber sie fallen nicht zusammen. Wenn solches - wie z. B. in Fig. 38 - der Fall ist, hat man es mit einer Folge ron Verschiebung zu tun (man vergleiche das frïler darüber Gesagte).

Auch in Schnitt $e$ ist das Septum noch vollständig, es hat sich jedoch die laterale Schmelzleiste von der generellen Zahnleiste getrennt, 
bleibt jedoch noch in allen folgenden abgebildeten Schnitten als eine von der Kuppe des Schmelzorganes ausgehende Sprosse bemerkbar. In Schnitt $f$ ist das Septum nicht mehr komplett, es hat sich vom äuBeren Epithel zurüekgezogen, und die bukkale und linguale Pulpamasse lä̈ngen wieder zusammen. In den Schnitten g und $h$ wird die Scheidewand immer unvollständiger und im Schnitt $i$ ist keine Spur mehr davon anwesend. Anch hat sich hier die Verbindung des Organes mit der medialen Sehmelzleiste gelöst. Tremn man mit Hilfe dieser Skizzen die Form des Septum rekoustruiert, daun erseheint es auch hier wieder als ein Strang von pyramidenförmiger Gestalt, die breite Basis wird durch das Stratum intermedium dargestellt, die Spitze geht in das äubere Epithel der Kuppe rom Sehmelzorgan über.

Ich hoffe, daß das Vorangehende genügt für eine Vorstellung von Entstehungsweise, weitere Enrwicklung und topographische Beziehnng des Schmelzseptum. Wir werden jetzt

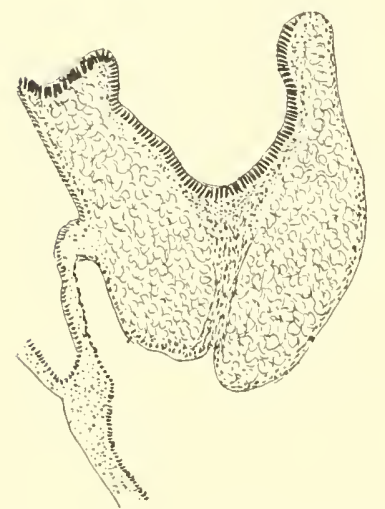

Fig. 40. II $0 \mathrm{~m}$ o $D$. Querschnitt durch den ersten oberen Molaren:'

Wemn einmal die Schmelzpulpa vollständig entwickelt ist und das ganze Organ als ein prall angeschwollenes erscheint, hat sich auch in Schmelzseptum eine wichtige Differenzierung eingestellt, welche man jedoch mur bei gïnstiger Sehnittriehtung zu beobachten Gelegenheit hat. Wenn man nämlich das Septum gerade der Länge nach durchschneidet, damn bemerkt man, dab die Zcllen sich gestreckt haben, mehr plattenförmig geworden sind. Es sei dazı auf Fig. 40 rerwiesen, welche einen transversalen Schnitt dureh das Schmelzorgan des ersten oberen Molaren des menschlichen Embryo $D$ darstellt. Es war in dem Präparat gerade die erste Tätigkeit der Odontoblasten bemerkbar. Was nun die Zusammensetzung des Septum betrifft, ist es deutlich, daß die in das änBere Epithel übergehenden Zellen sich in der Längsrichtung des Septum gestreckt haben, sie scheinen gleichsam vom äußeren Epithel in die Pulpamasse des Organes einzuströmen. In der Mitte setzen sie sich in den mehr rundkernigen Elementen des Stratum intermedium fort.

Sehr interessant ist nun die Beziehung des Septum zum äußeren Epithel. Denn an der Stelle, wo es sich an diesem Epithel ansetzt, bildet die Oberfläche des Organes eine dentliche Verticfung. Für diese 
Erscheinung - die, wie aus den folgenden Figuren hervorgeht, lieine Zufallsbildung ist - möchte ich den Namen ,Schmelznabel" vorschlagen. Es ist dieser Nabel nicht an allen Präparaten nit gleicher Deutlichkeit anwesend, man muß, um denselben zu sehen, die geeigneten Entwicklungsstadien wählen. Und öfters ist er noch undeutlich, da, wie es z. B. in Fig. 38 der Fall ist, dic laterale Schmelzleiste sich gerade an Rande des Nabels an Schmelzorgan ansetzt. Doch bestätigt auch diese Figur das Vorkommen dieser Einsenkung inu Schmelzorgan des Menschen.

Bei gut gelungener Sehnittrichtumg macht es num auch beim Menschen sehr stark den Eindruck, als biege sich das äußere Epithel am Nabel einwärts im Schmelzseptum ım. Bei anderen Primaten ist das bisweilen sehr deutlich und es ist schließlich nicht zweifelhaft, daß eine wirkliche Einbiegung des äußeren Mantels des Schmelzorganes nach innen stattfindet. Wenn dann, wie in Fig. 38, die laterale Schmelzleiste gerade am Rande des Schmelznabels ansetzt, macht es den Eindruck, als bildete das Septum die Fortsetzung jener Leiste.

Bei Propithecus habe ich von dieser Umbiegung des äußeren Epithels im Schmelzseptum sehr schöne Bilder gefunden. So gebe ich in Fig. 41 einen Schnitt durch das Schmelzorgan vom oberen ersten Incisivus von Propithecus $A$. Der Schmelznabel ist sehr dentlich, findet sich auf der Kuppe des Organes. Die Plattenepithelien des äußeren Epithels biegen sich von beiden Seiten in der Nabelwand nach innen und das Septum ist nichts anderes als die Fortsetzung jenes Epithels. Daß dieses wirklich so aufzufassen ist, geht daraus hervor, daß in der Tiefe der Nabelgrube das äußere Epithel eine Unt erbrechung aufweist, dasEpithellager der cinen Hälfte ging nicht direlit in jenes der anderen Seite des Nabels über.

Noch deutlicher war das beim in Fig. 42 abgebildeten Fall. Es betrifft hier sechs aufeinander folgende Schnitte durch das Schmelzorgan vom zweiten unteren Molaren von Propithecus $B$. In allen Schnitten bildet das äußere Epithel an der bukkalen Seite die bekannten Epithelwucherungen. Im Schnitt $a$ ist rom Nabel noch nichts zu sehen. Das Stratum intermedium bildet einen etwas ausgezogenen Gipfel als erste Andeutung des Schmelzseptum. In Schnitt b hat letzteres das äußere Epithel erreicht, die Kerne erscheinen wie jene des Stratum punktförmig, eine Folge der Schnittrichtung. An der Oberfläche des Organes erscheint medial des mit Exkreszenzen besetzten Feldes eine noch undeutliche unregelmäBige Einsenkung, die im folgenden Schnitt (c) zu einer Grube geworlen ist. und die Septalzellen strömen aus dem Boden dieser Grube fontäneartig ins Innere des Organes ein, 1 m unter allmählicher Verbreiterung ins Stratum intermedium überzngehen. Is war nicht zweifelhaft, daß in der Tiefe dieser Grube das äußere Epithel unterbrochen war, da die Zellen desselben, ihren Charakter ein wenig ändernd, sich in dem Septum fortsetzen. 
Gleiches war noch der Fall im nächsten Schnitt (d). Hier war der Sehmelznabel am tiefsten, das Septum am vollständigsten entwiekelt. Die Struktur der Scheidewand war hier, da der Schnitt wohl ungefähr der Längsachse des Septum folgte, äußerst klar zu sehen. Und es blieb anch hier kein Zweifel übrig, daß das äußere Epithel sich in die Scheidewand mmbiege. Im folgenden Schnitt (e) ist die Verbindung zwischen Septum und Boden des Schmelznabels gelöst, die Kontimuität des äußeren Epithels wieder hergestellt, während in letzten abgebildeten Schnitt vom Schmelznabel nichts mehr, vom Schmelzseptum nur die letzte Andeutung zu sehen war.

Es sind, hoffe ich, die gegebenen Figuren genügend, um die Beziehung des Schmelzseptum zum äußeren Epithel des Schmelz-
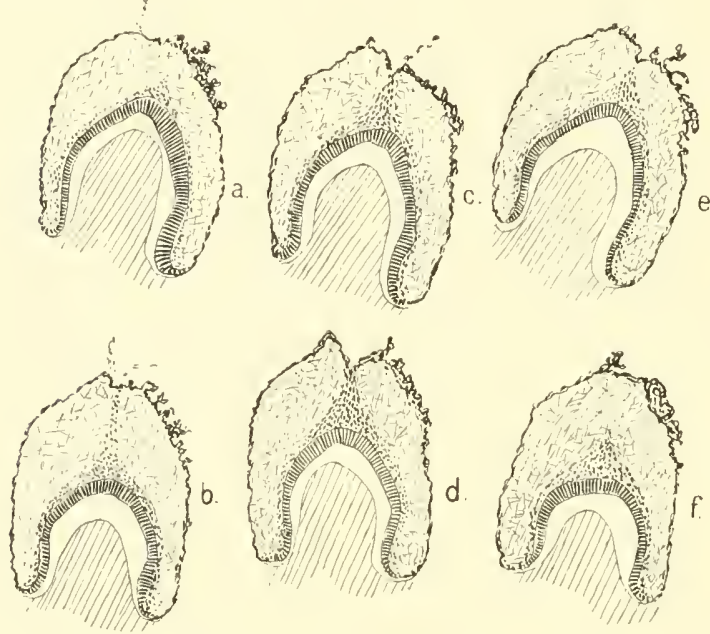

Fig. 42. Propithecus $B$. Sechs Schnitte durch die Anlage des zweiten unteren Molaren. organes klarzulegen. Das Septum erscheint zur Zeit, als die zelligen Elemente des Organes ihre definitive Gestalt erlangt haben, als ein Produkt des äußeren Epithels, und zwar in der Weise, daß sich letzteres nach innen einstülpt. Zwar ist dieser Zustand nur an einer ganz beschränkten Stelle zu beobachten, aber man behält dabei im Auge, daß in jenem Entwicklungsstadium das Septum der Form und Größe noch relativ schon bedentend zu rückgebildet ist, daß es nicht mehr die

Bedeutung eines Septum im eigentlichen Sinne hat, sondern zn einem Strang geworden ist. Aber wenn man an diesem Strang so deutlich die Beziehıng zwischen Septum und äıßerem Epithel feststellen kann, dann war diese Relation anch anwesend in jenem frïheren Stadinm, wenn sich das Septum noch durch das ganze Organ erstreckt. Man ist jedoeh nicht imstande, von früheren Entwieklungsstadien die Beziehung zwischen Septum und äuberem Epithel nachzuweisen, da diese erst mit der histolngischen Differenzierung kembar wird. Es ist nicht ausgeschlossen, daß die nachgewiesene Beziehung bei Embryonen anderer Säugetiere auch in jüngeren Stadien, wenn das Septum vollständiger ist, sich nachweisen läßt.

Für die Primaten darf es wohl als feststehend betrachtet werden, daß das Septum nicht als eine Wucherung des änßeren Epithels zu denten ist, sondern dadurch entsteht, daß letzteres nach immen biegt, um in dem Stratum intermedium sich fortzusetzen.

In der mir zur Verfügung stehenden deutsehen Literatur habe ich eine Beschreibung dieser Bildung nicht angetroffen. Das ist wohl 
befremdend, da schon im Jahre 1864 Waldeyer die Elenente des Septum gesehen und beschrieben hat. Nur die Deutung, diß es verschleppte Elemente des Stratum intermedium sein sollten, mu ich ablehnen. Sie sehen in einer früheren Periode zwar ganz als Intermediumzellen aus, später nehmen sie jedoch, wie gezeigt, den Charakter der Elemente des äıßeren Epithels an. In der französischen Literatur fand ich bei Renaut ${ }^{1}$ ), S. 248 des zweiten Teiles folgende Bemerkung, die ich in Übersetzung wiedergebe: Dieses System (nämlich die Ameloblastenschicht und das Stratum intermedium) bildet auf dem Gipfel der Zahnpapille einen Kegel, dessen Spitze sich aufwärts richtet und das Innere des Sehmelzorganes in zwei Gebiete zerlegt, ein inneres und ein äußeres. Dieser Kegel bildet gerade die Eruptionsichse des Zahnes, weshalb ich ihm den Namen ,Führungskegel" beilege („Cône adamantin directeur"). Der Autor beschreibt hier offenbar die spätere Form des Septum, wenn es von pyramidaler Gestalt geworden ist.

Ich meine, durch die gegebenen Beispiele das Schmelzseptum und der Schmelznabel in ihren allgemeinen Zügen genügend kennen gelernt zu haben. Wir haben es hier zu tun mit Bildungen, welche ebensowenig wie die laterale Schmelzleiste und die Schmelznische eine alktive Rolle spielen bei der Zahnentwicklıng, sie treten infolge der Differenzierung in Erscheinung. Sie sind mit den beiden genamnten als ,wertlose Nebenprodukte" zu betrachten, welche bei der Genese des Zahnes gebildet werden, denn ihre Entstehung ist nicht Zweck der Genese, sondern eine notwendige Folge. Mit dem Mechanismus der Zahnentwicklıng als solche bei den Primaten stehen sie nur in einer sehr entfernten Beziehung. Aber clesto größer ist wohl ihre historische Bedeutung. Denn wo wir schon auf Grund des Vorkommens zweier Schmelzleisten schließen komnten, daß der Primatenzahn eine Doppelbildung ist, aus einem bukkalen und lingualen Komponent zusammengesetzt, da erlangt diese Behauptung festeren Grund durch den Nachweis vom Auftreten zweier Pulpabildungszentren, welche durch ein Septum getrennt waren, das bald der Reduktion anheimfällt. Die histologische Differenzierung des Schmelzorganes zengt ebenso stark für die Doppelnatur desselben als dessen Beziehung zur Zahnleiste. Und wo der Nachweis zweier Schmelzleisten Anla B war, um in dem Schmelzorgan zwei Hälften zu unterscheiden, jede Hälfte mit ciner der Leisten in Beziehıng stehend, da können wir jetzt einen Schritt weiter gehen und die Vermutung aussprechen, es sei das Sehmelzorgan des Primatenzahnes ein zusammengesetztes Gebilde, es besteht aus zwei einander eng angeschlossenen Einzelorganen, welche je mittels ilırer eigenen Schmelzleiste mit der generellen Zahnleiste zusammenhängen.

Ich beschränke mich an dieser Stelle auf diese kurze Andeutung meiner Auffassung über Schmelzseptum und Schmelznabel. Im Sehlußabschnitt dieser Arbeit werde ich die Frage beantworten, welches Licht die ontogenetische Entwicklung des Primatenzahnes in der Form, welche wir jetzt kemmen gelernt haben, auf die Phylogenese des Gebisses dieser Säugergruppe wirft.

1) J. Renaut, Traité d'histologie pratique. Paris 1897. 


\section{Drittes Hauptstück.}

\section{Die Nebenleiste}

\section{(rudimentäre Zahndrüsenleiste).}

Ich wende mich jetzt einer dritten Erscheinung in der Entwicklung des Primatengebisses zu, welche schon lange meine Aufmerksamkeit gefesselt hat, nämlich jene Bildung, die ich als, ,Nebenle iste" bezeichnen möchte. Über die Bedentung dieser Bildung war ich lange im Unsicheren; anfünglich war ich der Meinnng, daß es sich hier $11 m$ eine rudimentäre Zahnleiste laındelte, und da f. sonnit bei den Primaten eime doppelte Zahnleiste auftreten sollte. Thiese Ansicht war allerdings berechtigt, da bei gewissen Entwicklungsstadien die Nebenleiste in der Tat die Vermutung wachruft, es handle sich hier um eine rudimentäre Bildung, welche an der Entstehung der Molaren sich beteilige. Die fortgesetzte Untersuchmmg hat mich indessen von der Unrichtigkeit dieser Vermutung überzengt. Doch hat die Dentung dieser Leiste ricle Sehwicrigkeiten gemacht und es hat lange gedauert, ehe ich die befriedigende Erklärung gefunden hatte. Auch in diesem Punkt hat die Untersuchnng des Reptiliengebisses die endgültige Lösung gebracht.

Tn seiner jüngsten Abhandlung ${ }^{1}$ ) kommt auch Adloff auf diese Bildung zu sprechen, hat dieselbe bei drei menschlichen Embryonen beobachtet und grïndet auf diese Beobachtumg weitgehende entwicklungsgeschichtliche Spekulationen. Der Autor benutzt die Beobachtung, $11 \mathrm{~m}$ noch einmal gegen meine Hypothese der terminalen Reduktion des Primatengebisses das Tort zul ergreifen. Ich werde an der Adloffschen Erklärungsweise keine Kritik üben und auch nicht den Wert seiner Beobachtung als Beweis gegen die Richtigkeit meiner Hypothese einel Prüfung nnterwerfen, die in diesem Kapitel zu beschreibenden Tatsachen genügen für ein vernichtendes Urteil über ,.diesen weiteren einwandfreien Beweis für die Unmöglichkeit der ron Bolk inangurierten. wenig glïeklichen nenen Theorie von der Differenzierung des Primatengebisses", wie Adloff 1. c. S. 397 es ausdriickt.

Un die Adloffsche Ansicht kennen zul lernen, werde ich mir erlauben, aus seinem Aufsatz die bezüglichen Sätze zu zitieren. Der Autor nntersuchte einen ca. 9 wöchigen, einen 12 wöchigen Embryo und einen, der etwas jünger war als letzterer. .Das jüngste Stadinu", sagt der Autor l. e. S. 393, ,bot für meine Zwecke nichts besonders

1) Zeitschr. f. Morph. u. Anthrop., Bd. XV, S. 301. 
Bemerkenswertes! Interessunt war schon die Durchsicht der mir von Herm Prof. Kallius überlassenen Serie. Labial der Anlage des ersten Milchmolaren im Unterkicfer senkt sich hier nämlich vom Mundhöhlenepithel ein ziemlich starker Fortsatz ins Bindegewebe hinein. Derselbe ist eime Strecke weit verfolgbar, ohne da aber eine weitergehende Differenzierung zu bemerken wäre. Wichtiger und entscheidend für die Bedeutung dles Befundes war das älteste Stadium.

„Kurz vor der Anlage des ersten Milehmolaren im Unterkiefer erscheint auch hier labial der Schmelzleiste ein weiterer Fortsatz des Mundhöhlenepithels, der nach einigen Schnitten dentlich die Form eines rudimentären Schmelzkeimes amnimmt. Diese zweite Schmelzleiste bleibt immer labial der Anlage des ersten Milchmolaren währemd 59 Schnitten verfolgbar und läßt gegen Ende desselben noch einen zweiten rudimentären Schmelzkeim hervorgehen. Daß es sich hier direkt 1 m einen Schmelzkeim handelt, geht aus der Betrachtung bei stärkerer Vergrößerung olne allen Zweifel hervor. Nach einimen Schnitten verschwindet dam diese sekundäre Schmelzleiste. Die rudimentären Zahmanlagen sind auch noch weiter entwicklungsfähig; das geht ans dem einzelnen Schnitt hervor, der angenscheinlich einem noch älteren Stadium entstammt. Hier ist der Schmelzkeim größer und kappenförmig eingestülpt, damit sind auch wohl die Grenzen der Entwicklungsfähigkeit erreicht, demn es scheint gerade hier eine Loslösung vom Mundhöhlenepithel zu erfolgen."

„Es erhebt sich nun die Frage, was diese Anlagen vorstellen? Ich habe zunächst daran festgehalten, daß es sich in del Tat $\mathbf{n}$ m prälakteale Anlagen handelt, habe dann aber diesen Gedanken fallen lassen müssen. Gegen diese Annalıme spricht vor allen Dingen die weite Ansdehnung dieser zweiten Schmelzleiste und ihre zeitlich lange Konstanz, wie sie in diesem Maße bei prälaktealen Resten niemals beobachtet worden ist."

,Gehören die rudimentären Schmelzkeime aber nicht der prälaktealen Reihe an, so kömnen es nur die letzten Reste der dem Menschen verloren gegangenen Prämolaren sein; damn bliebe zunächst die weit labialwärts gerückte Lage zu erklären. Die räumliche Trennung der ursprünglich zu derselben Dentition gehörenden Anlagen müßte dann als Folge aufgefaßt werden einer durch die im Laufe der Stammesgeschichte eingetretenen Kieferverkürznng hervorgerufenen Einfaltung der Schmelzleiste. Es ist diese Amnahme $1 m$ so wahrscheinlicher, als sich ähnliche Vorgänge auch gegenwärtig im menschlichen Gebib wiederum abspielen." Der Autor führt damn zum Beweise das in Fig. 19 der vorliegenden Arbeit wiedergegebene Bild an, das auch schon in meiner Abhandlung iiber die Entwicklung des Gaumens Aufnahme fand, und interpretiert es in vollständig verfehlter Wreise, Worauf an geeigneter Stelle schon hingewiesen wurde. Die hypothetischen und in diesem Falle auf unrichtigen Grundauschammegen basierten Faltungen der Zılnuleiste genügen jedoch dem Autor für die Behauptung, , „laß wir nummehr mit Sicherheit annehmen kïnnen, daß es sich um die Reste der verloren gegangenen Prämolaren handelt".

Es bemerkt der Autor auch noch, daB im Oberkiefer Spuren dieser ausgefallenen Zähne nicht nachgewiesen werden. Und die Erklärung ist wieder ganz naheliegend! ,.Es ist", sagt er l. c. S. 397, ,das nicht weiter anffallend! Fast allgemein ist der Unterkiefer das 
Konservativere Element. Es liegt das wohl daran, daß der Oberkiefer ein integrierender Teil des Schädels ist nnd an den sich hier abspielenden Unformungen in erster Linie teilnimmt, während der Unterkiefer als besonderer Knochen erst sekmndär in Mitleidenschaft gezogen wird".

Bis so weit die Adloffschen Erörterungen. Es sind dieselben so ausführlich zitiert, nm den Autoren gerecht zn sein und nm dent Vorwurf zul entgehen, vou seinen Auffassungen eine unvollständige Darstellung gegeben zu haben. Gehen wir jetzt zı den Tatsachen über.

Ich werde die Beschreibung des Gebildes, wormm es sich hier handelt, anfangen mit jenem Objekt, an dem ich dasselbe zuerst beobachtete, um daran die versehiedenen Erklärungsversuche anzuknüpfen, welche ich im Ansehluß an den Befund in Überlegung nahm. Es betraf einen jungen Embryo von Macacus cynomolgus, bei dem der zweite Milchmolar das kappenförmige Stadium erreicht hat. Die Fig. 43 bringt eine Serie Sehnitte dureh die Mundhöhlenschleimhant mit der Zahnleiste in Ober- und Unterkiefer. Die Schnittdicke betrug $20 \mu$. Die Schnitte sind um den anderen abgebildet. In Skizze $a$ sind untere Zahnleiste und Sehmelzorgan von $m_{2}$ leiclst zu erkennen, die Wangenschleimhant setzt sich auf den Oberkiefer fort und läßt die obere Zahnleiste aus ihr entstchen. Im Oberkiefer ging der Schnitt hinter der Anlage des $m_{2}$. Diese Skizze bietet nichts Besonderes, als eine niedrige Erhebung vom Epithel an der Stelle, wo die obere Zahnleiste sich am Kieferepithel ansetzt. Zwei Schnitte weiter (Fig. 43 b) ist diese Erhebung zu einer wirklichen Sprosse geworden, welehe ich gleich mit dem vorgestellten Namen ,Nebenleiste" anführe. Letztere entsteht hier somit in ummittelbarer Berïhrung mit der Zahnleiste. In der Ungebung der nuteren Zahnleiste gewahrt man gerade an der Ecke, wo die Wangenschleimhant sich auf die Kieferwölbung umbiegt, eine zweite wenig erhabene Epithelverdiekmng, es ist die erste Andeutung der unteren Nebenleiste. In Skizze $c$ ist letztere nur wenig vergrößert, die obere Nebenleiste scheint eine etwas breitere Verbindung mit der Zahnleiste bekommen zul haben. In $d$ ist das noch deutlicher der Fall, die untere Nebenleiste ist auf dem Durchsehnitt etwas vergrößert. In $e$ hat die untere Nebenleiste die Form einer ziemlich hohen schmalen Sprosse angenommen. welehe gerade wie die obere Nebenleiste bei ihrem ersten Erseheinen Ausgang aus der Ansatzstelle der Zahnleiste am Kieferepithel nimmt. Die obere Nebenleiste hat ihre Verbindung mit der Zahnleiste weiter ausgedehnt, am bukkalen Epithel tritt eine Drüsenanlage anf. In $f$ ist die Verbindung zwischen Zahnleiste und Nebenleiste so weit gegangen, daß beide aus einer gemeinschaftlichen Epithelknospe hervorzugehen erscheinen, die nntere Nebenleiste hat sich der Zahnleiste mehr genähert. Diese Annäherung ist die einleitende Phase zu dem Abschnürungsprozeß, der in den nächstfolgenden Schnitten zustande kommt. In g hat sich die Zahnleiste mit der von ihrem oberen Ende jetzt senkreeht ansgehenden Nebenleiste tiefer ins Kiefermesenchym gesenkt, ist jedoch noch durch eine dicke Zellmasse mit dem Oberflächenepithel in Verbindung.

In $h$ und $i$ sehreitet dieser Prozeß weiter, indem sich zwischen Wange und Kiefer eine gewaltige Epithelanhäufung entwickelt. Es bleibt dabei die Nebenleiste in ständiger Verbindung mit dem oberen Ende der Zahnleiste. In $j$ macht sich eine Einsehnürıng bemerkbar, 
welche jedoch den Zusammenhang zwisehen Zahnleiste und Tebenleiste nicht berïhrt. Jetzt wird es schon deutlich, daß die Nebenleiste mit der Zahnleiste zusammengehört, was schließlich wohl durch die nächste Skizze $k$ außer Zweifel gestellt wird. Hier ist die Abschnürung vollständig und es ist wohl muweifelhaft, daß mit der Zahnleiste anch die
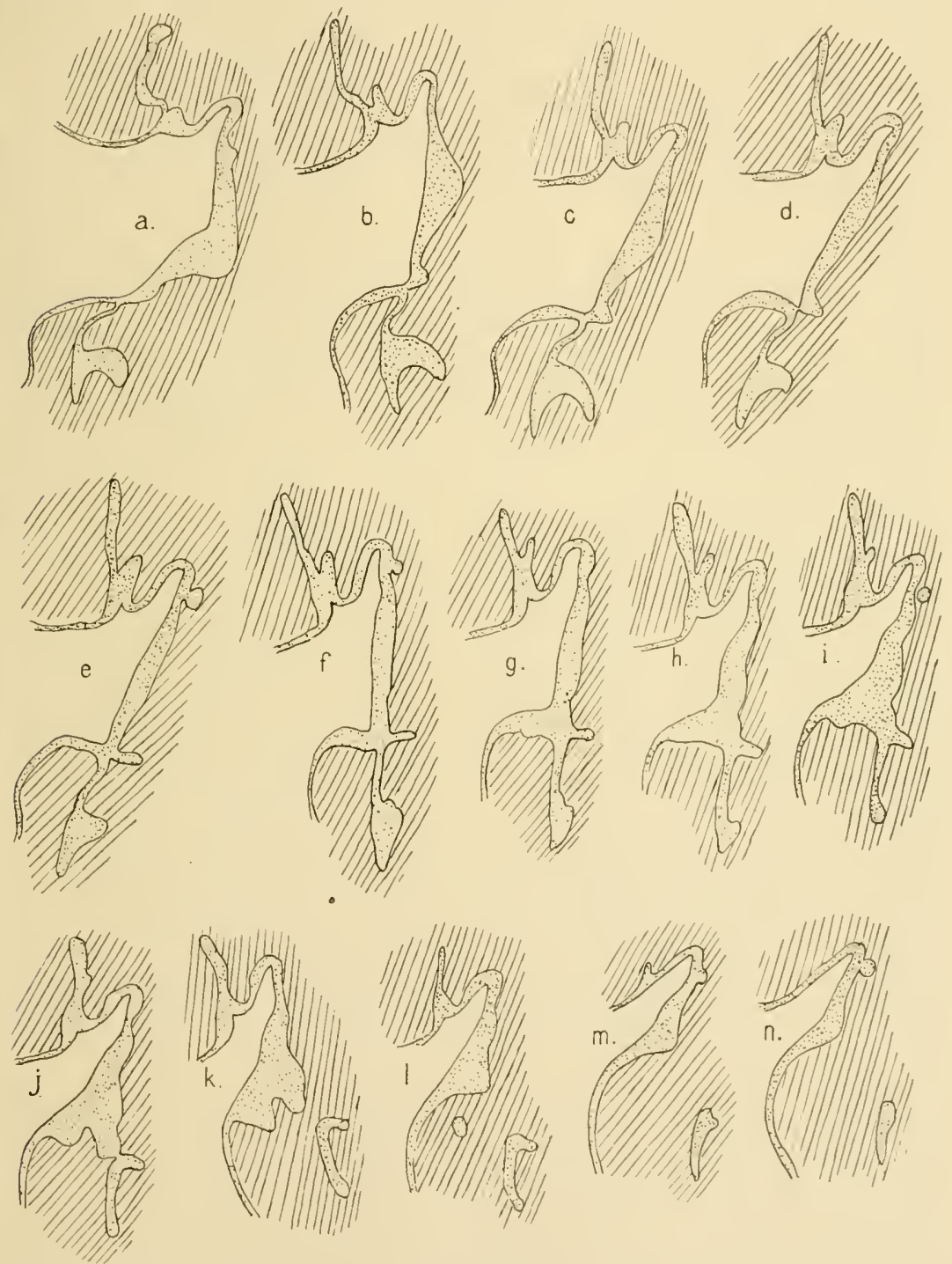

Fig. 43. Macacns cynomolgus. Hinterer Teil der Zahnleiste im Ober- und Unterkiefer.

Nebenleiste vom Mundhöhlenepithel abgetrennt worden ist. Znsammen bilden sie jetzt ein auf Querschnitt hackenförmiges Gebilde, das ganz frei im Kiefermesenchym liegt. Die Nebenleiste weicht senkrecht von der Zahnleiste ab und ist allerdings der kïrzere Ko mponent. In den Skizzen $l$ und $m$, werden Zahnleiste und Nebenleiste kleiner 
und an dem letzten abgebildeten Schnitt - es war der letzte, in dem die Zahmleiste noch getroffen wird - verrät die Nebenleiste sich nur durch eine geringe Anschwellnug der Zahnleiste.

Die obere Nebenleiste schwindet etwas früher. In Skizze $g$ erscheint sie schon als eine von der bukkalen Fläche der Zahmleiste unter scharfem Winkel abgehende Sprosse, welche in $h$ kürzer geworden ist, in $i$ noch als eine niedrige epitheliale Erhabenheit an der AnBenfläche der Zahnleiste bemerkbar ist, in $j$ nur eine geringe Ansehwellung bildet, wnd in $h$ nicht mehr bemerkbar ist. Jetzt versehmälert mnd erniedrigt sich aweh noeh die Zahnleiste, aber es kommt nicht wie bei der unteren zu einer Abschnürung vom Kieferepithel, und in dem zwischen $m$ und $n$ liegenden Sehnitt ist von der oberen Zahnleiste nichts mehr zul sehen.

Zusammenfassend hat diese Skizzenserie die folgenden Erscheinungen ans Lieht geführt. Es gibt bei diesem Nacacus eine epitheliale Leiste, welche sich in unmittelbarer Berührung mit der Zahnleiste aus dem Epithel des Unterkiefers und des Oberkiefers bildet. Diese Leiste bleibt in inniger Beziehung zur Zahnleiste, tritt an Oberkiefer auf die bukkale Fläche der Zahnleiste äber, an Unterkiefer wird sie gremeinschaftlich mit der Zahmleiste abgeschniirt md bleibt dabei ständig mit dem oberen Ende dieser Leiste in Verbindung. Sie streckt sich am Unterkiefer bis zum hinteren Ende der Zahnleiste aus, im Oberkiefer verschwindet sie etwas vor dem hinteren Ende der Leiste. Dieser Unterschied ist jedoch mur nebensächlich.

Wenn ich diesen Befund gemacht hatte, erhob sich matürlich unmittelbar die Frage nach der Bedentung dieses Gebildes. Versehiedene Mögliehkeiten verdienten Überlegung. Es komnte sein, dab die Leiste einer prälaktealen Anlage entsprach, oder daß sie das Homologon der im vorangehenden Abschnitt beschriebenen lateralen Schmelzleiste war, welche an den schon zur Anlage gelangten Zähnen dieses Embryo sehr deutlich entwickelt war. Damn mubte es die laterale Schmelzleiste für die noch nicht differenzierte Anlage der ersten Molaren sein. Es komnte jedoch auch sein, daß man es hier mit einer besonderen Leiste zu tun hat, welche speziell zu der Anlage der bleibenden Molaren in irgendwelcher Beziehung stand. Damn wïrden somit die bleibenden Molaren von den ïbrigen Zähnen in ihrer Anlage dadurch differieren, daf. sie nicht ausschließlich aus der generellen Zahmleiste gebildet wurden, sondern ans dieser unter Mitbehelf einer besonderen Leiste. Konnte es weiter nicht sein, daß diese Leiste eigentlich die zur Seite gertrungene Milchzahnleiste war, woraus folgen sollte, daß die bleibenden Molaren nur Produkte der Zahnleiste der bleibenden Zähne wären und also homolog mit den Elementen des bleibenden Gebisses. Oder komnte es vielleicht auch sein, dab das Gebilde mit der Zahnanlage in gar keiner Beziehung stand, und mur die vestibulare Leiste darstellte, welche im hinteren Abschnitt des Mundes sich etwas abweichend verhielt? Alle diese Möglichkeiten drängten sich allmählich auf. Und bei weiter fortgesetzter Untersuchung neigte ich mich bald mehr dieser, bald mehr jener Ansicht zu. Eine mir genügende Entscheidung konnte ich nicht nehmen, bis die Untersuchmo an Reptiliengebissen die wahre Natur der Bildung ans Licht brachte.

Der Gedanke, daß es sich hier um ein Knickumgsprodukt der Zahnleiste handelte (vide Adloff) kam nicht bei mir anf, da die Be- 
ziehung dieser Nebenleiste zur Zahnleiste eine derartige Entstehungsweise von selbst ansschlob. Demn wir haben es hier nit einer Leiste zu tun, die in Unterkiefer vom wheren Rande der Zahnleiste unter einem geraden Winkel abgeht und somit horizontal gestellt ist, im Oberkiefer unter einem mehr scharfen Winkel. In beiden Fällen ist die Nebenleiste der Länge nitch mit der Zilhnleiste verbunden. Ton einer Entstehung durch Auswärtsbiegung und Kinickung der Zahnnleiste kamn daher wohl keine Rede sein.

Es schien mir anfänglich die Ansicht am wahrscheinlichsten, daß, die Nebenleiste das Homologon bei den bleibenden Mrolaren der lateralen Schmelzleiste bei den Milchzähnen war. Daßs diese Ansicht jedoch unrichtig war, wurde im Lunfe der weiteren Untersuchung dentlich. Denn bei Embryonen, die schon so alt waren, daB anch das Organ des ersten bleibenden Molaren ziemlich weit entwiekelt ist, erwies es sich, daß zwischen Nebenleiste und lateraler Schmelzleiste gar keine Beziehung besteht, beide Bildungen entwickeln sich ganz unabhängig voneinander nud bestehen gleichzeitig.

Daß anch bei den bleibenden Moliren eine laterale Schmelzleiste zur Entwicklung kommt, ist schon im ersten Hauptstück nachgewiesen,
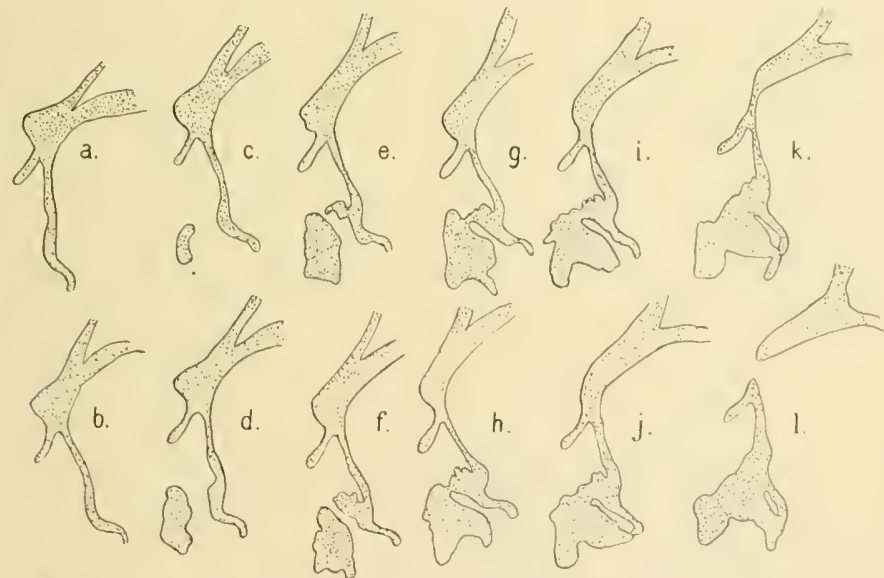

Fig. 44. Mycetes $D$. Hinterer Teil der unteren Zahnleiste mit der Anlage des ersten bleibenden Molaren.

doch werden die unten folgenden Beispiele diese Tatsache weiter begrïnden.

Ich gebe in Fig. 44 eine Serie Schnitte durch die Anlage des unteren ersten bleibenden Molaren von Mycetes Serie $D$. In den Skizzen $a$ und $b$ sind Zahnleiste nnd Tebenleiste sofort zu erkennen, letztere geht wieder von Mundhöhlenepithel aus an der gleichen Stelle wie die Zahnleiste. In Schnitt $c$ und $d$ erscheint bukkil von der Zilhnleiste das Sehmelzorgan des ersten Molaren und biegt das untere Ende der Zahnleiste medialwärts. Die Nebenleiste verändert sich nicht, sie bleibt mit dem Epithel an gleicher Stelle wie die Zahnleiste rerbunden. In Schnitt $e$ erscheint an der Knickungsstelle der Zalmleiste die erste Andentung der lateralen Sehmelzleiste, welche der Anlage des ersten Molaren zustrebt. In Schnitt $f$ hat sich die kurze laterale Leiste 
unregelmäßig verdickt, berïhrt das Schmelzorgan, um im nächsten Schnitt mit demselben sich zu verbinden. Die Versehmelzung findet an der Spitze des Organes statt. Im Sehnitt $h$ und $i$ nimmt das Organ die mehr regelmäßige Glockenform an, steht jedoch immer noch mittels der lateralen Schmelzleiste mit der Zahnleiste in Verbindung. Die Nebenleiste verändert ihren Clarakter nicht, sie bleibt der Anlage des Molaren fern. Im Schnitt $j$ ist anch die zweite Verbindung durch die mediale Schmelzleiste zustande gekommen, und die Schmelznische ist abgegrenzt. Wir nähern uns inzwischen der Stelle, wo die Zahnleiste sich vom Mundhöhlenepithel abschnüren wird. Es macht sich im Schnitt $k$ schon eine dentliche Einschnïrung der Verbindung mit Kiefer- und Wangenepithel bemerkbar, und im nächsten Schnitt $l$ ist die Abtrennung vollzogen. Nun tritt hier wieder der gleiche Zustand anf wie beim Macaeus, daß nämlich die Absehnürung gerade an jener Stelle sich vollzieht, wo Zahnleiste und Nebenleiste miteinander zusammenhängen, die Nebenleiste wird als ein offenbar zu ihr gehörendes Element mit der Zahnleiste abgetrennt. Wenn wir nun die weiter abgebildeten Schnitte betrachten, dann ist die Nebenleiste fortwährend als eine hakenförmig abgebogene Sprosse am oberen Ende der Zahnleiste zn verfolgen, und wie beim Macacus streckt sie sich bis zum hintersten Ende der Zahnleiste aus und erlöseht gleichzeitig mit dieser. Von einer Beziehung zur lateralen Schmelzleiste der Anlage von $M_{1}$ ist nichts zu bemerken. Dieser Fall an sich ist schon genïgend, um jede Mögliehkeit einer Identität von Nebenleiste und lateraler Schmelzleiste zu beseitigen. Beide Bildungen sind zwei ganz unabhängig voneinander vorkommende Erscheinungen bei der Zahnentwicklung.

Um diese Tatsache möglichst fest zu begründen, habe ich von dem hinteren Teil der unteren Zahnleiste eines etwas älteren Embryo von

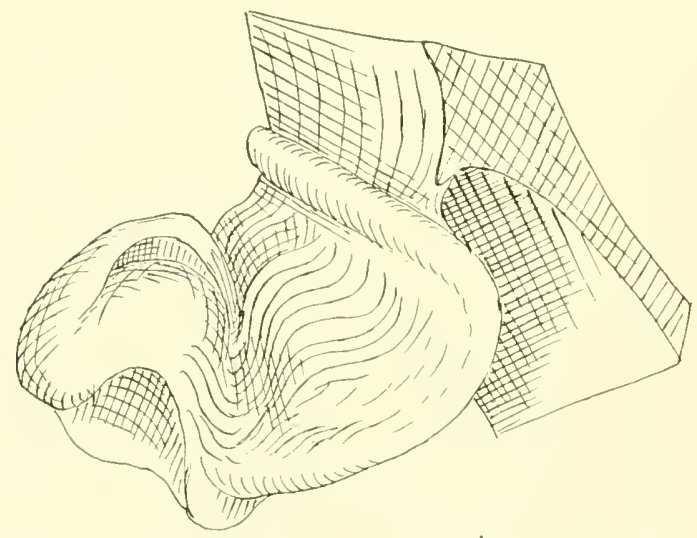

Fig. 45. Mycetes $B$. Hinterer Teil der Zahmleiste des Unterkiefers mit Nebenleiste und Anlage von $M_{1}$. Nycetes (Serie $B$ ) ein Modell angefertigt, das in Fig. 45 wiederg eg eben ist. Es ist ein Teil des Mundhöhlenepithels dargestellt und die davon ausgehende Zahnleiste, die an der bukkalen Seite die Anlage vom ersten bleibenden Molaren trägt. Die topographischen Verhältnisse sind an der Figur leicht ersichtlich. Die Zahnpapille ist schon tief ins Schmelzorgan eingedrungen. Von der bukkalen Seite des Organes geht die laterale Schmelzleiste ab, welche das Organ zu überwölben scheint. Die Schmelznische war schon nicht mehr vollständig, ist schon kanalförmig geworden. Zwischen Schmelzorgan und lateraler Schnelzleiste sieht man in die Lichtung dieses Kanales. Von der Ansatzlinie der generellen Zahnleiste am Mundhöhlenepithel geht die Nebenleiste 
ab, welche mit der Zahnleiste verbunden bleibt, auch dann, wenn der Zusammenhang mit den Mundhöhlenepithel gelöst ist. Sie stellt dann gleichsam den oberen nach außen umgeklappten Rand der Zahnleiste dar, der bis zum hinteren Ende zur verfolgen ist. Auch diese Abbildung bringt einen einwandfreien Beweis, daB zwisehen Nebenleiste und lateraler Schmelzleiste der bleibenden Molaren keine Beziehung besteht. Letztere betragen sich - es ist nicht überflüssig das noch einmal zu wiederholen - in ihrer Anlage und Entwicklung vollständig wie die Zähne des Milchgebisses. Es fehlt jede Andeutung eines divergierenden Entwicklungsganges.

Vergleicht man die bei Mycetes bekannt gewordenen Verhältnisse mit jenen bei Macacus, damn wird man über die Natur der Nebenleiste doch wohl etwas unterrichtet. Beim Macacusembryo war die Zahnleiste bis kurz hinter dem zweiten Milchmolaren angelegt, bei Mycetes bis hinter dem ersten bleibenden Molaren. Das war in beiden Fällen bis zum hinteren Ende der Zahnleiste. Da der erste bleibende Molar des platyrrhinen Mycetes als das Homologon zu betrachten ist, des zweiten bleibenden Molaren bei dem katarrhinen Macacus, ersehen wir also, daß die Nebenleiste in ihrer Entwicklung nicht auf eine kurze Strecke beschränkt ist, sondern mit dem weiteren Anwachsen der Zahnleiste nach hinten ebenfalls weiter wächst. Die Beziehung zum hinteren Ende der Zahnleiste bei den verschiedenen Embryonen stellt dieses außer Zweifel. Man lat sich den Entwicklungsgang derart vorzustellen, daß das hintere Ende der Zahnleiste, indem es weiter rückwärts ins Kiefermesenchym vordringt, seinen oberen Rand sofort bukkalwärts umklappt, der Unbiegungslinie entlang setzt sich dann das Ganze am Mundhöhlenepithel fest. Dieser Vorgang ist natürlich nicht mechanisch gedacht, und es wäre vielleicht richtiger, wenn man sagt, das hintere Ende der Zahnleiste produziert Material zur Verlängerung der Zahnleiste und in gleichem Maße zur Verlängerung der mit letzterer verbundenen Nebenleiste.

Es bildet somit die Nebenleiste einen integrierenden Bestandteil der generellen Zahnleiste. In der Gegend der Milchmolaren trifft man jedoch die Nebenleiste, wie wir das bald näher zeigen werden, nicht mehr mit der Zahnleiste in Berülırung, wenigstens nicht bei etwas älteren Enbryonen. Das ist jedoch ein sekundärer Zustand.

Die älteste von mir an einer lïckenlosen Serie untersuchte Gebißanlage betrifft das Embryo Chrysothrix $A$, wovon ich in Fig. 46 eine Skizzenserie von Schnitten gebe durch den hinteren T'eil der unteren Zahnleiste. An den ersten vier Skizzen ist noch die dem hinteren 'T'eil der Anlage des ersten Molaren entsprechende Anschwellung zu erkennen. Die Schnitte bringen nichts prinzipiell Neues, die Nebenleiste erscheint hier in gleicher Gestalt und Lagerung wie bei Hacacus und Mycetes, wird aber ebenfalls mit der Zahnleiste abgeschnürt. Ich möchte jedoch besonders die Anfmerksamkeit auf die Schnitte $h, l$ und $m$ lenken. Wem man diese drei Schnitte ohne Zusammenhang mit den vorangehenden betrachtet, dann wïrde man zweifelsohne zu einer falschen Dentung gelangen, demn das Bild ist wohl imstande, den Beobachter irre zu führen. Es sieht doch die ins Kiefermesenchyn eingesenkte Epithelleiste ganz so aus wie eine Zahnleiste, die am unteren Ende eine kappenförmige Zahnanlage trägt. Und doch haben wir hier gar nicht mit der Anlage des zweiten bleibenden Molaren zu tum, 
sondern Zahnleiste mo Nebenleiste sind in diesen Quersehnitten mahezu gleich lang, letztere geht bukkalwärts vom oberen Rande der ersteren ab, und dadureh wird eine von bukkal eingestülpte Zahn-

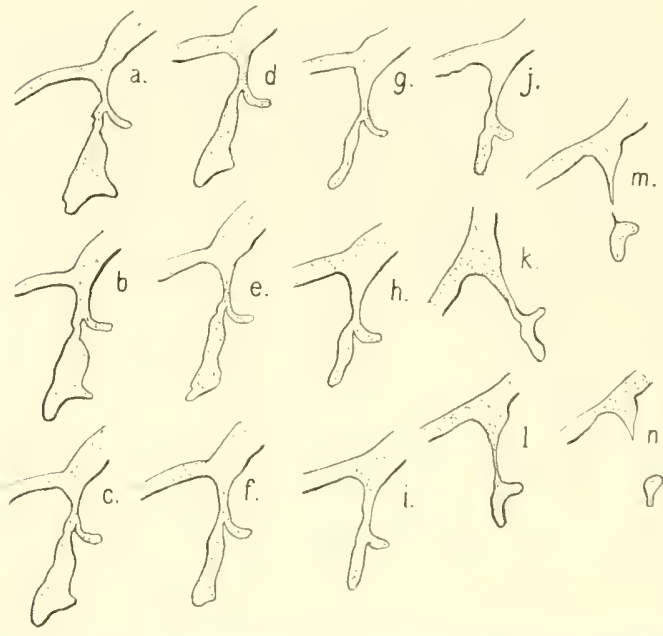

Fig. 46. Chrysothrix $A$. Hinterer Teil der unteren Zahnleiste mit Nebenleiste. anlage vorgetäuscht. Dieser Fall warnt wieder davor, in bezug auf die Gebißent wicklung doeh niemals Behauptungen zu äußern auf Grund isolierter Schnitte.

Tlir haben jetzt die Nebenleiste in ihren allgemeinen Beziehungen zur Zahnleiste kennen gelernt. Diese Beziehungen sind jedoch nicht immer deutlich, denn bei der weiteren Entwicklung treten besonders an vorderen Ende infolge von Versehiebungs- und Resorptionserscheinungen andere Verhältnisse auf. Bei Untersuchung älterer Embryonen wird es bald klar, daß man es hier mit einer Erscheinung zu tun hat, die wesentlich rudimentärer Natur ist. Dem an der Zahnbildung beteiligt sie sich - wie wir gezeigt haben - gar nicht, und es ist kein einziger Befund anzuführen, worans zu folgern wäre, daß sie es jemals getan hat. Nachdem sie einen gewissen Entwicklungsgrad erreicht hat, fällt sie der Regression anheim und verschwindet schließlich. Der Reduktionsprozeß äußert sich natürlich zuerst am vorderen Ende. Ich traf ihre Anlage bei den Affen bis in die Gegend des Eckzahnes. Damit soll jedoch nicht ansgeschlossen sein, daß sie im vorderen Kieferteil sich auch nicht bemerkbar nachen kann. Allein Quersehnitte durch dieses Gebiet eignen sich nicht, um das festzustellen. Vor der Reduktion erlangt sie eine gewisse Selbständigkeit in der Weise, daß sie sich von der Ansatzstelle der generellen Zahnleiste in bukkaler Richtung entfernt, um als eine isolierte Sprosse aus dem Mundhöhlenepithel bukkal von der Zahnleiste hervorzugehen. Das sind aber sekundäre Verhältnisse. Adloff hat, wie aus den gegebenen Zitaten ersichtlich, bein mensehlichen Embryo die Reste der Leiste in geringer Entfernung der Ansatzstelle der Zahnleiste am Kieferepithel angetroffen, und komnte dieselben bis gegenïber der Anlage der ersten Milchmolaren verfolgen. Die von diesem Autor mntersuchten Embryonen waren offenbar schon zu alt, es war dabei schon eine räunliche Trennung zwischen Ansatzstelle der Zahnleiste am Kieferepithel und Tebenleiste zustande gekommen. Daß anch beim menschliehen Embryo, beim ersten Anftreten, beide Leisten zusammenhängen, wie wir es bei den Affen beschrieben haben, greht zuerst aus den Figuren 47 und 48 hervor. In der erstgenamnten Irigur ist die Zahnleiste und Nebenleiste im Oberkiefer vom mensehlichen Embryo $B$ abgebililet, 
Fig. 48 stellt beide Leisten im Unterkiefer des nämlichen Embryo dar. In letzterer Figur geht der Sehnitt dureh den hinteren Teil der Anlage von $m$, in Fig. 47 verlänft der Schnitt gerade hinter der Anlage dieses Zahnes. WIan sieht, dafo die Lagerungsverhältnisse beider Leisten zneinander im Ober- wie im Unterkiefer vollständig mit jenen bei den Affen übereinstimmen. Es muß bemerkt werden, daß es hier ein Präparat gibt, wo die Nebenleiste besonders in Oberkiefer sehr stark entwiekelt war. Das Bild in Fig. 48 kann den Gedanken wachrufen, daß die Nebenleiste die Grundlage des tiefsten Teiles der bukkogingivalen oder vestibularen Spalte darstellt. Was aber nicht der Fall ist. Weiter nach hinten wird anch hier die Nebenleiste nit der Zahnleiste vom Mundhöhlenepithel abgetrennt.

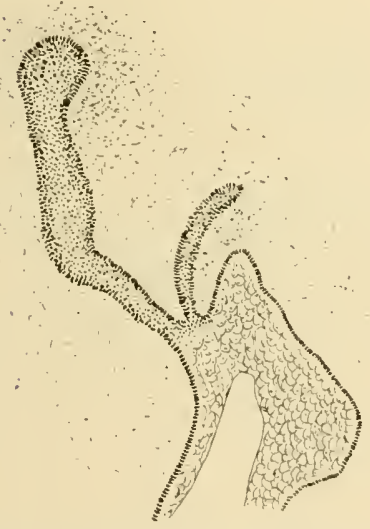

Fig. 47. II om o. Serie B. Zahnleiste mi Nebenleiste im Oberkiefer.

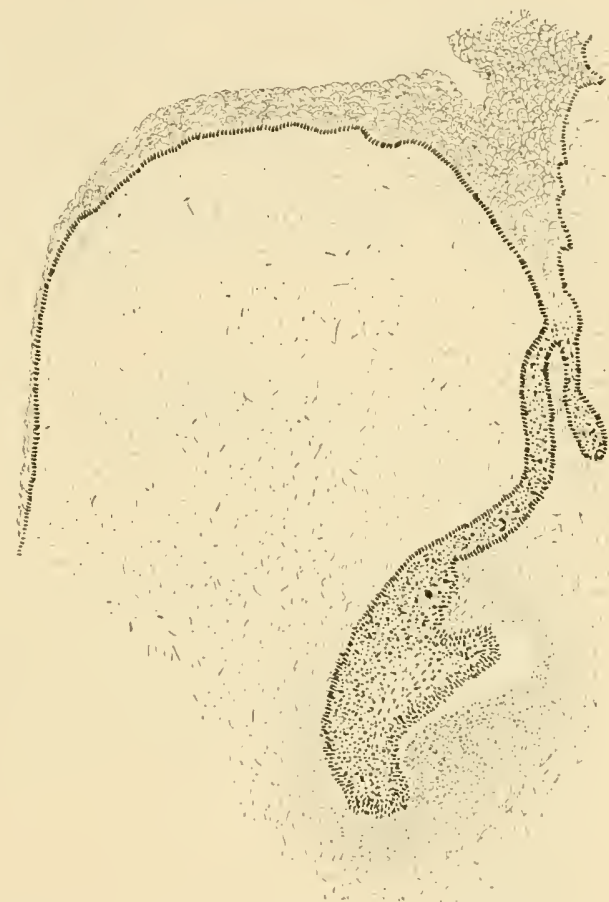

Fig. 48. Homo. Serie $B$. Zahnleiste und Nebenleiste im Unterkiefer.

Untersucht man sehr junge menschliche Embryonen, damn ruft das Auftreten der Tebenleiste in Zusammenhang mit der ersten Differenzierung des Zahnes bisweilen Verhältnisse ins Leben, die sehr fremdartig aussehen, und die ich dann anch erst allmählich im Laufe meiner Untersuchung richtig zu deuten gelernt habe. Icl gebe dazu in Fig. 49 einen Schnitt durch den hinteren Teil der Zahnanlage vom mensehlichen Embryo Serie $Z$. Es waren die Gaumenfo tsätze schon oberhalb der Znnge gelagert, beriihrten einander in der Medianlinie, aber waren noch nicht vollständig miteinander verwachsen. Die Zahnleiste in Unterliefer bietet nichts besonderes, die Nebenleiste ist noch nicht bemerkbar. Die Zahnleiste im Oberkiefer erscheint dagegen als ein mehr kompliziertes Gebilde, das anfänglich einen etwas fremdartigen Eindruck macht. Die Dentung ist folgende. Man erkennt drei Sprossen. Die meist laterale stellt die erste Anlage der Nebenleiste dar, die beiden medialen die Anlage des ersten DLolaren. Der Sehnitt geht jedoeh noch 
nicht durch die Anlage des Schmelzorganes dieses Zahnes, sondern durch die beiden Leisten, welche mit diesem Organ in Zusammenhang stehen, die laterale der beiden sprossen repräsentiert die laterale Schmelzleiste, die mediale ist die erste Andentung der medialen Schmelzleiste. Drei Schnitte weiter nach hinten sind beide zusammengeflossen, wie wir das im ersten Hauptstück wiederholt beschrieben haben. Die Anlage der Tebenleiste ist anch in diesen Falle in ummittelbarer Verbindnng mit jener der generellen Zahnleiste.

Die Tremnung beider Anlagen wird verursacht durch die Ausbildung des Alveolarabschnittes des Kiefers. Infolge der Entstehung desselben werden Tebenleiste und Zahnleiste voneinander getrennt, und die zwischen hnen sich findenden epithelialen Elemente werden für die Bekleidung eines Teiles des Alveolarfortsatzes benützt. Beim Menschen ist das jedoch im Unterkiefer viel deutlicher als im Oberkiefer. Hier bleibt die Nebenleiste der Zahnleiste imniger angeschlossen, wie z. B. aus Fig. 50 ersichtlich, die einen Schnitt durch die Anlage des oberen

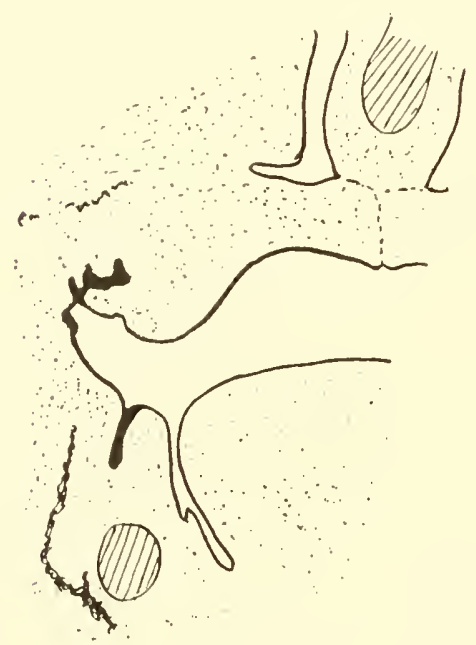

Fig. 49. Homo. Serie $Z$.

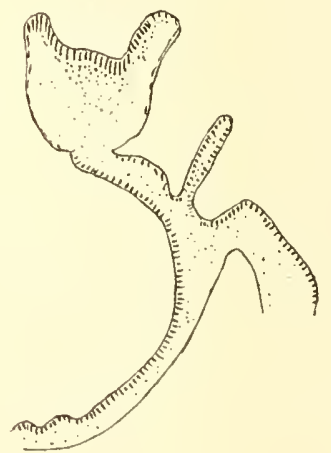

Fig. 50. Homo. Serie $l$. Schnitt durch die Anlage des oberen zweiten Milchmolaren.

zweiten Milchmolaren vom Embryo $V$ darstellt. Man ïberzengt sich, daß die Nebenleiste hier mit der bukkalen Fläche der Zahnleiste verbunden bleibt. Bei Affen rïckt sie auch im Oberkiefer mehr seitlich. emanzipiert sich von der Zahnleiste, wie ans Fig. 51 ersichtlich. Diese Figur ist einem Schnitt durch den Oberkiefer von Mycetes $A$ entnommen und liegt hinter der Anlage des zweiten Milehmolaren. Doch es verrät die Nebenleiste auch hier ihre Beziehung zur Zahnleiste noch durch die gleichmäßige Fortsetzumg der zylindrischen basalen Epithelien von der einen anf die andere Leiste. Nebenbei sei bemerkt, daß durch die oben gegebenen Beispiele die Behanptung Adloffs, daß im Oberkiefer die Nebenleiste nicht vorkommen sollte, endgültig wiederlegt ist.

Dieser Autor hat weiter darauf aufmerksam gemacht, daß die Leiste lokalisierte Anschwellnugen aufweist, und diese Verdickungen sich sogar kappenförmig gestalten könmen. Er findet an den von ihm untersuchten Objekten zwei solcher Stellen, die er als Rudimente von Zahn- 
anlagen (ausgeschaltete Milchmolaren) deutet. Diese eigentünlichen Produkte der Nebenleiste sind auch mir öfters begegnet, nnd ich gebe z. B. in Fig. 52 die Abbildung eines Schnittes durch den hinteren 'T'eil der Anlage eines ersten oberen Molaren von einem Macacusembryo Bukkal von der Ausatzstelle der Zahnleiste liegt dio Nebenleiste, dessen

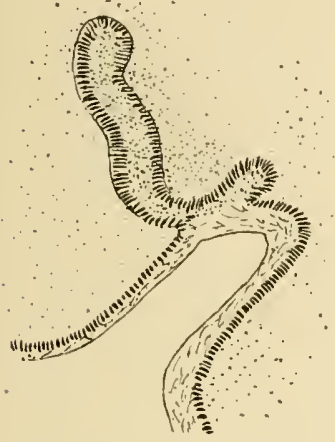

Fig. 51. Mycetes $A$. Schnitt zwischen den Anlagen des oberen zweiten und dritten Milchmolaren.

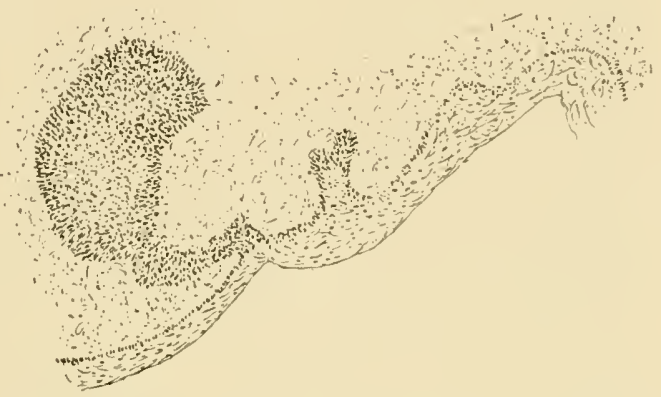

Fig. 52. Macacus. Schnitt durch die Anlage des ersten oberen Milchmolaren.

freier Rand sehr dentlich eine Differenzierung sehen läBt. Es macht ganz den Eindruck, als spaltete er sich in zwei Sprosse.

Anch in Oberkiefer des Menschen habe ich diese eigenartigen lokalisierten Anschwellungen gefunden, und gebe zmm Beweis in Fig. 53 a und 53 z zwei Sehnitte dureh den hinteren T'eil der oberen Leiste rom menschlichen Embryo $A$. Der Schnitt a liegt 10 Schnitte vor $b$. Die
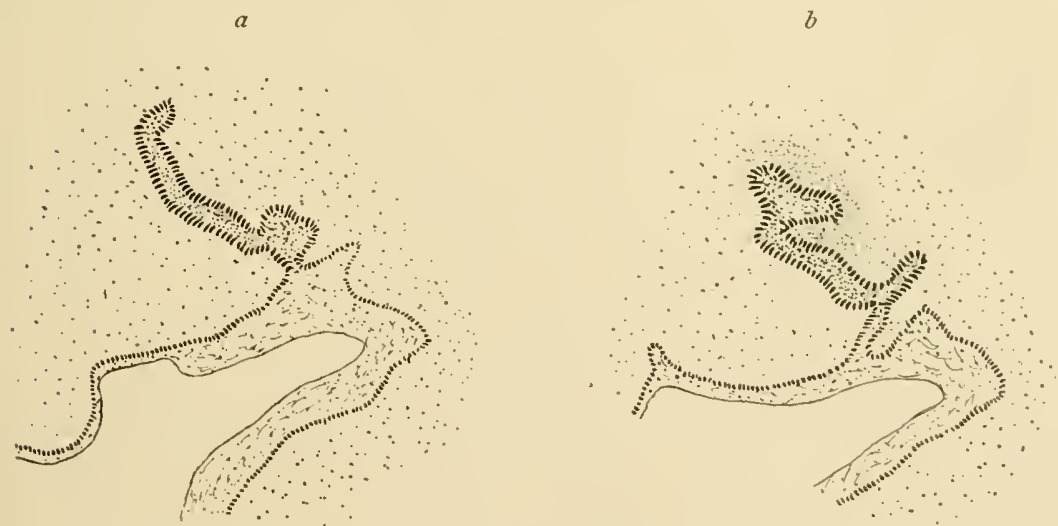

Fig. $53 a$ und $53 b$. Homo. Serie A. Hinterer Teil der oberen Zahnleiste.

Nebenleiste, welche in den weiter nach vorn liegenden Schnitten einfach war, schwillt ziemlich rasch an und nimmt anf dem Quersehnitt die Form an, wie in Fig. $53 a$ wiedergegeben, sie wird etwas kürzer unter gleichzeitiger Verbreiterung. Hinter dieser Anschwellung erlangt sie wieder ihre schlanke Gestalt, wie ans Fig. $53 b$ ersichtlich. 
Hiernit können wir die Beschreibung der Nebenleiste abschließen. Wir haben sie kennen gelernt als ane anfänglich kontinnierlich sich erstreckende Jeiste, die bei ihrer Anlage anfs engste mit dem oberen Rande der Zahnleiste, I. h. der Ansatzlinie dieser Leiste am Kieferspitlel verbunden ist. Wenn sich bei älteren Embryonen die Zahnleiste im hinteren Tril des Kiefers vom Nundhöhlenepithel abschnürt. bleibt die Nebenleiste mit ihr verbunden, $n$ in gleichem Maße als die Zahnleiste mit dieser nach hinten sich zu verlängern. In mittleren Teil der Zahnleiste. in der Gegend der Anlage der Wilchmolaren, rückt sie im Unterkiefer, und bei den Affen anch im Oberkiefer, seitlich von der Zahnleiste, indem ein Teil ihres Epithels zu Gingivalepithel wird. An bestimmten Stellen bildet die Nebenleiste in beiden Kiefern Anschwellungen. welche jedoch bald nach ihrer Anlage ebenso wie die Tebenleiste selbst, der Reduktion anheimfallen. Das ganze Betragen dieser Leiste kennzeichnet sie als eine rudimentäre Bildung, die jedoch rimmal mit der GebiBanlage anfs engste verkniipft gewesen sein muß.

Es erscheint mir wïnsehenswert, an dieser Stelle sofort anf die Frage nach der Bedentung dor Tebenleiste einzugehen. Wie ich am Eingang dieses Hanptstïckes herrorhob, war ich sehr lange über die Natur dieser Bildung im Zweifel goblieben, konnte keine mir befriedigende Entscheidung zwischen deu verschiclenen Möglichkeiten treffen. Tängere Zeit neigte ich der Meinung zu, dab diese Tebenleiste in irgendwelcher Beziehung zu eincr rudimentären Dentition stehen müsse, obwohl ich in allgemeinen kein unbedingter Anhänger einer prälaktealen Dentition war. Eine solche Dentung finclet aber in den tatsächlichen Beobachtungen immerhin zil wenig Grund. Die Untersuchungen am Reptiliengebib haben schlieBlich die Lösung der Frage ïber die Herkunft dieser Leiste gebracht, und zur Überzengung geführt, daß sie zu einer hypothetischen prälaktealen Zahmanlage in gar keiner Beziehmng steht. Ich gebe hier gleich ron dieser İberzeugung Ausdruck, denn ich glaube wohl nicht weit fehl zu gehen, wemn ich vermute, daß manche - wenn nicht sogar alle - Epithelsprossen, welche bei plazentalen Sängetieren bukkal von der Zahnleiste beschrieben wurden und als Anlage prälaktealer Zähne gedentet sind, in der Tat nichts anderes sind als Zerfallsprodulite des oben als Nebenleiste beschriebenen Gebildes. Dieser Überzengung habe ich schon Ansdruck gegeben in meiner Abhand. lung ïber die Gaumenentwicklıng des Menschen und die Bedentung der oberen Zahnleiste, wo es 1. c. S. 790 heißt: ,Ich darf hier schon vorausgreifend anf den Inhalt einer folgenden Publikation die Bemerkung machen, dab ich weder beim Menschen, noch bei Affen auch nur ein einziges Mal die Anlage eines prälaktealen Zahnes gefunden habe. Dagegen manches, was als solche angeführt wird, aber mit prälaktealen Zähnen nichts zu tun hat. Eine vollständigere Kenntnis der Zahnentwicklung beim Menschen hatte gewib das Gebiet der prälaktealen Zähne sehr eingeschränkt." Ob ïbcrhaupt prälakteale Zahnanlagen bei plazentalen Sängern rorkommen, darïber werde ich mich an dieser Stelle nicht äıBern. verweise dazı nach den folgenden Absehnitt. Nur sei bemerkt, daß die Doktrin einer Vormilehdentition die Gebibprobleme riel komplizierter gemacht hat als sie es in der Tat sind.

Kehren wir nach dieser Abschweifung zur Bedeutung der Nebenleiste zurïck. Wie gesagt, lehrte die Tntersnchung an Reptiliengebissen die Herkunft derselben kennen. Es ist die Nebenleiste der Primaten 
nichts anderes als die zu einem rudimentären Rest zurückgebildete Leiste, welche bei vielen Reptilien sehr kräftig entwickelt ist, und welche ich als ,Zahndriisenleiste" dieser Tiere bezeichnen möchte.

Zur Verdentlichung des Obenstelenden muß ich etwas näher auf die Anatomie des Drüsenapprarates im Munde der Reptilien eingehen: werde mich dabei aber möglichst kurz fassen, da ich nicht bezwerke, auf die Ergebnisse meiner Untersuchung an Reptiliengebib allzu tief cinzugehen. Ieh teile nur das mit, was für das Verständnis der Nebenleiste der Primaten erforderlich ist.

Bekamntlich kommt der Drïsenapparat bei den Reptilien zı kräftiger Entfaltung. An den von primitiven Formen vererbten sublingualen und palatinalen Drïsen gesellt sich eine neue Gruppe. die im allgemeinen als die Glandulae labiales bekannt sind. Gregenbaur sagt davon (Vgl. Anat., Bd. II, S. 118): „Eine neue Entfaltung von Drüsen folgt den Kiefern, in deren Schleimllant sie sich zu Einzelorganen ausbildeten, wolche, wie es scheint, in ilner Anordnung Bcziehungen zı den Zähnen erkennen lassen. Von diesen , Glandulae labiales" fehlen die superiores manchen Lacertiliern, während die inferiores konstanter sind." Es ist jetzt die Frage: woher stanmen diese Drïsen? In der oben zitierten Bemerkmng, daß in der Anordnung der Drüsen eine Bezielnung zu den Zähnen zu bestehen scheint, liegt der Schlïssel zur Jösung dieser Frage, denn wirklich besteht jene Beziehung, und zwar in zweierlei Richtung, nicht allein in der Anordnung, sontern auch in der Genese.

Es nehmen nämlich die Drïsen ontogenetisch Ausgang aus einer ins Kiefermesenchym cingesenkten ununterbrochenen Leiste, die nichts anderes ist als ein Teil der generellen Zahnleiste, wodurch die genetische Beziehung wenigstens zum Gebiß in allgemeinen zum Ansolruck konmt. Weiter münden bei verschiedenen Formen diese Drüsen in die jeden Zahn umhüllende Scheide aus, wodurch ihre nöhere Bezichung zum Zahn zum Ausdruck kommt. Bei solchen Formen gibt es eben so viele Drïsen als Zähne. Und auch bei jenen Formen, wo die Ausmïndungsstelle der Drïsen mehr lateral gerïckt ist, und in einer Rinne sich findet, welche als Lippen rinne zu bezeichnen ist, wird die Beziehnng zum Zahnsystem noeh dadurch bewiesen, claß die Zahl der Zähne noch gleich ist an jener der Drüsengänge, so clab jeder Zahn einer Drüse entspricht. Es hat Gegenbanr ganz reeht, wenn or bemerkt. daß im Unterkiefer die ..Lippendrüsen" mehr konstant sind als im Oberkiefer. Anch sincl erstere durchschnittlich kräftiger entwickelt.

Die Bezeichnung der Drüsen als, , Lippendrïsen" ist zu beanstanden. Deun es könnte dadurch der Terdacht geweckit werden, daß diese Bildungen in genetischer Bezichung zu den gleichnamigen Organen der Säuger stehen, was wohl nicht der Fall ist, und weiter möchte man in der Lippenrime, worin sie bei vielen Formen ausmünden, die Ansgangsform des Vestibulum oris der Säuger erblicken, was eine noch nicht erledigte Frage ist. Es wäre zu empfehlen, auf Grund ihrer Genese diese Organe als ,Zahndrïsen" zu bezeichnen.

Ich werde $n \mathrm{~m}$ an der Hand einiger Figmen die beschriebenen Tatsachen und die daraus gezogenen Schlubfolgerungen zn beweisen versuchen. Die primitive Ausmündung der Zahndrïsen in die epithelialen Zahnscheiden wird durch Fig. 54 bewiesen. Die Figur stellt einen Schnitt dar durch einen Oberkiefer cines noch jungen Iguana sapi- 
dissima. Von einem wohl entwickelten Zahn, dessen Pulpahöhle angeschnitten ist, ragt in dem vorliegenden Schnitt die Spitze gerarde aus der Zahnseheide hervor. Der Schnitt durchquert die hintere Hälfte des Zahnes, liegt somit hinter der größten Iänge. Man sieht wie cer Zahn nit semer Basis an der Maxilla angewachsen ist und daß die nach mnten gekehrte Hälfte von der epithelialen Zahnscheide nmfafot wird. An der medialen Seite setzt sich die Zahnscheide in die generelle Zahnleiste fort, an deren freiem Ende ein Ersatzzahn in Entwicklung begriffen ist. Bukkal liegt die Zahndrüse, deren Ausführungsgang nicht an der Oberfläche mündet, sondern im peripheren Teil der Zahmscheide. Die Scheide liegt gewöhnlich nicht der Oberfläche des Zahnes eng an, es bleibt wohl immer eine enge Spalte übrig. Darin ergießt die Zahndrïse ihr Sekret.

Es ist num die Frage, woher stammt der epitheliale Schlanch, welcher den Zahn zum T'eil nmfaßt und hier als .Zahnscheide" bezeichnet worden ist? Anf diesen in seiner

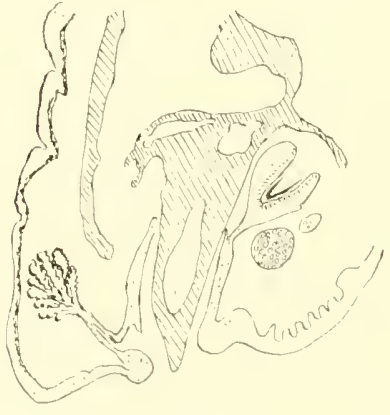

Fig. 54. Iguana sapidissima. Oberkiefer mit Zahn, Ersatzzahn und Zahndritse. Entstehung etwas komplizierten Zustand kamn ich nicht in Einzelheiten eingehen. Nur sei kurz hier mitgeteilt, daf die Zahmscheide nichts anderes ist als der obere Teil der Zahnleiste. Man hat sich die Leiste als eine Doppellamelle zu denken, und bei seiner Entwicklumg drängt der anwachsende Zahn zwischen den beiden Blättern dieser Lamelle nach auBen. Indem num der more Teil der Jeiste sich zmm mehr aktiven Teil mmgestaltet und die Ersatzzähne produzieren bleibt, differenziert sich der obere T'eil zu einer bisweilen sehr dicken Hülle, welche den von muten her in sie hinemwachsenden Zahn umschließt. Es stellt somit die Zahmscheide den in seinen beiden Blättern voneinander gespalteten peripheren 'Teil der generellen Zahnleiste dar.

Wemn man das eimmal festgestellt hat, dann wird die Herkunft der Drüse, die bukkal von dem Zahn sich findet, deutlich. Denn sie miundet an Eingang der Scheide ans, ist als eine Bildnng der Zahnscheide, d. h. der peripheren Zone der Zahnleiste anfzufassen. Mit anderen Worten: die generelle Zahnleiste produziert bei den Reptilien nicht nur Zähme. sondern anch noch einen Drïsenapparat. Den in Fig. 54 abgebildeten Fall mul. man als einen noch ziemlich primitiven Zustand auffassen, denn jede Zahndrïse stellt noch ein selbständiges Gebilde dar, steht noch nicht in irgendwelcher Weise mit den übrigen in Verbindung, dem die Zahnscheideränme sind in den Interstitien noch voneinander getrennt. Bei anderen Formen wird wohl eine zum Teil durchlanfende Rimne gebildet. Bei Iguana ist es nun leicht festzustellen, daß mit jedem Zahn eine Drüse korrespondiert, deren Ausführungsgang in die Zahuscheide endigt.

Der für Ig uana beschriebene Zustand erleidet bei anderen Sauriern wesentliche Umgestaltung, welche direkt an die bei Säugern zu beobachtenden Verhältnisse anschließen. 
In Fig. 55 gebe ich einen Schnitt durch den Unterkiefer eines noch jungen Lacerta-Embryo. Der Meckelsehe Knorpel und das Dentale sind zu erkennen. Anffallend ist nun das Betragen der Zahnleiste. Das Ektoderm, das den Kiefer medial bekleidet ist nur äuBerst dïnn, ebenfalls an Kieferrande. Dazwischen liegt eine vorgewölbte Stelle, welche mit einer bedentend dickeren Zellschicht bekleidet ist. Diese Schicht sendet zwei Leisten ins Kiefermesenchym ein, eine mediale, die Zahnleiste, die eine glockenförmige Zahnanlage trägt, und eine bukkale, welche jetzt schon als eine Driisenleiste sich verrät, da sie am unteren Ende schon zwei Sprossen treibt. Es ist aus der histologisehen Zusammensetzung, aus dem Charakter und der Anordnumg der Epithelzellen dentlich zu ersehen, daß wir es hier mit einer einheitlichen Anlage zn tun haben. Gehen wir vom soeben bei Iguana geschilderten Zustand, als einem mehr primitiven aus, dann kann man sich denken, daß bei Lacerta der periphere Teil der Zahnleiste nicht mehr ganz zur Bildung der Zahnscheide verwendet wird, sondern zum Teil zur Bildlung von gingivalem Epithel benützt wird. Es gerät dadurch die Drüse, welche aus der peripheren Zone der Zahnleiste ihren Ursprung nahm, mit ihrer Ausmïndungsstelle an die Oberfläche, mïndet nicht mehr in die Zahnscheide, sondern bukkal von ihr aus. Daß die Strecke zwischen der Ansatzlinie der Zahnleiste und die Ausmündung der Drüsen genetisch zur Zahnleiste gehört, ist wohl nicht zweifelhaft und wird durch folgende Figuren noch näher bewiesen werden.

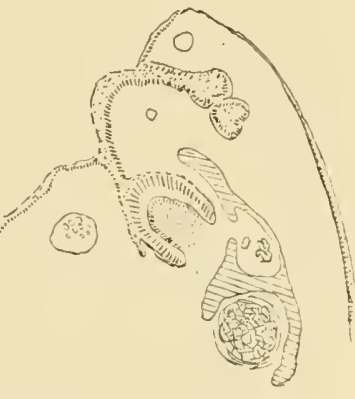

Fig. 55. Lacerta agilis. Querschnitt durch den Unterkiefer mit Zahnleiste und Drüsenleiste.

Es muß jetzt noch auf eine Besonderheit hingewiesen werden, welche für das Verständnis der bei den Primaten konstatierten Zustände von Bedentung ist. Wenn man clie Serie, aus der die Fig. 55 entnommen ist, verfolgt. dann sieht man, daß in gewissen Intervallen eine Drüsenanlage erscheint, aber zwischen diesen Anlagen bleibt die Leiste, aus der diese Anlage ihren Ausgang nehmen, ununterbrochen fortbestehen. Man ist somit völlig berechtigt von einer ,ZZahndrïsenleiste "zu sprechen. Denn daß anch bei den Lacertillae die Bezeichunng Zahndrïsen einc richtige ist, geht aus dem Umstand hervor, daß, obwohl die Drüsen bei Lacerta sich topographisch mehr von den Zähnen emanzipient haben (sie münden auf die Oberfläche und nicht mehr in den Zahnseheiden aus), democh die Zahl der Drïsen jener der Zähne entspricht. Ungeachtet der räumlichen Sonderung von Zahnanlagen und Drïsenanlagen verraten dieselben inmer noch ihre ursprïngliehen Bezichungen zueinander.

Am schnellsten ist das zu beweisen durch einen Horizontalschnitt, wie in Fig. 56 abgebildet. Die Figur stellt einen Teil eines horizontalen Schnittes dar dureh den Oberkiefer eines erwachsenen Lacerta (spec.?). Der Schnanzenteil ist in der Figur nach unten gerichtet. Die Zähne sind quer durehschnitten, das sehr variabele Aussehen dieser Quersehnitte rïhrt von dem versehiedenen Entwicklıngsgrad derselben her. In der Mitte der Fignr geht der Schnitt der Länge nach dureh die epitheliale Zahnscheide, welche sich bei diesen Fornen den Zälnen eng 
anschließt, im vorderen und hinteren Teil durchläuft der Schnitt mehr die Basis der Zähne, es waren hier die tiefer nach innen dringenden medialen Teile der Zahnseheiden getroffen. Peripher von den Zähnen erstrecken sich in einer Reihe die Querschnitte durch die Ausführungsgänge der Drüsen. Es gehört der obere Querschnitt zu dem obersten der getroffenen Zähne. Wem man nun letztere in ihrer Auffolgermng mit jener der Drïsengänge vergleicht, dann ïberzeugt man sich leicht, daß jedem Zahn ein Drüsengang entspricht. Zwar liegt Zahn und Ansführmesgang der Drüse nicht immer in einer gleichen Ebene, aber das ist auch kaum zu erwarten. Zählt man die Drüsengänge und die Zähne, damn crfährt man, daß es zwei Gänge mehr gibt als Zühne. Das war bedingt durch den Umstand, daß im nnteren Teil die zu den prämaxillaren Zähnen welche, da sie außerhalb des Cresichtsfeldes lagen, nicht gezeichnet sind - in Beziehnng stehenden Drüsengänge, mehr ineinander gedrängt sind. Zn zwei solchen Zäbnen gehörten die überflüssigen Drüsengänge. Diese Figur genügt zun Beweis, daß, anch bei jenen Formen, wo die Drïsen nicht mehr in der Zahnseheide ansmünden, die mrsprüngliehe Beziehung sich immer noch durch die numerische Übereinstimmmo verraten kann. Ich darf jedoch nicht unterlassen darauf hinzuweisen, daß die in Fig. 56 wiedergegebenen Terhältnisse nicht bei allen Reptilien anfgefunden werden. Der Zahndrüsenapparat bietet bei den verschiedenen Fanilien stark varierende Verhältnisse. Nicht selten kommt

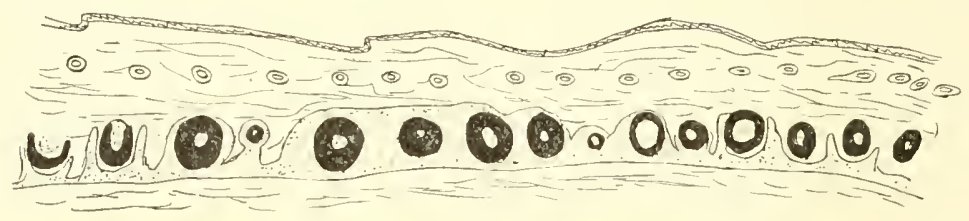

Fig. 56. Lacerta. Erklärung im Text.

er vor - wie z. B. bei Calotes - daß die Drüsenanlage nicht eine einlreitliche geblieben ist. sondern sich spaltet, so daß die Ausführungsgänge in den beiden Kiefern sowohl in der Zahnscheide als anf der Oberfläche ausmünden. Doch ist es nicht die Aufgabe dieser Abhandlung, auf die Anatomie des Zahndrüsenapparates der Reptilien einzugehen. Für unsere Zwecke genügt es, nachgewiesen zu haben, daß diese Drüsen Produkte sind der nämlichen epithelialen Leiste, welcher anch die Zähne ihre Entstehung verdanken. Und weiter, daß bei der phylogenetischen Entstehung jede dieser Drüsen ursprünglich einem Zahn entsprach. Bei solchen primitiven Verhältnissen - wie z. B. in Fig. 54 dargestellt ist - minndet jede Drüse in eine Zahnseheide ans wie die Haarbalgdrüse in die Haarscheide.

Im Vorübergehen sei im Anschluß an die nachgewiesenen topographischen und ontogenetischen Terhältnisse daran erimnert, daß dieser Zustand als die Ausgangsform betrachtet werden darf, wodurch die Beziehung zwischen Drüse und Zahn bei den Giftschlangen möglich geworden ist. Man hat sich doch zu denken, daß die Drüse in dem Boden der Zahnscheide ausmündlet, und dessen Ausführungsgang oder vielleicht ein zum Ausführungsgang nmgebildeter Teil der Zahnscheide rom wachsenden Zahn rimnenförmig nmwachsen wird, $11 \mathrm{~m}$ Verhältnisse zu bekommen, wie sie uns bei den Schlangen bekannt sind. Auch 
bei den Sauriern kommet eine Form vor, wo die sehn eigentiinliehe Bezichung zwischen Drise und Zahn durch den Tarhweis der primitiven Verhältnisse begreiflich wirl. Es ist ron J. G. Fischer (Anatomische Totizen über Heloderma horridum, Verhandl. d. Ver. f. naturw. T'nterhaltung zu Hamburg 1882, B(l. V) beim Geschlecht Heloderna eine von ihm sogenannte U’nterkieferdrïse beschricben worlen. Diese läßt vier Ausführungsgänge entstehen, die in vier an der Anbenseite des [nterkiefers gelegene Öffnungen in letztere eindringen. Der Stanm jedes Ganges teilt sich in vier kleincre Zweige, die einzeln in medialer Richtung den Knochen durchsetzen und je vor der Irurzel eines der der medialen Seite des Knochens ansitzenden Furchenzähne münden. Die Drïsenkörper sind hier offenbar weit peripherwärts verschoben, die Ausführungsgänge rom Dentale umwachsen, aber ihre ursprüngliche Ausmündungsstelle in der T'iefe der Zahnscheide haben sie behalten.

Kehren wir uach ilieser Ausschweifung wieder zu der allgemeinen Betrachtung der Beziehung zwisehen Zahu und Drüse bei Reptilien zurïck. Wenn man sich einmal von dieser Beziehnng bewubt geworden ist, dam bietet die Erklärung der vorher bei den Primaten als Nebenleiste bezeichneten Bildung keine Schwierigkeiten mehr. Nur ist es wirklich ïberraschend, daf diese Bildnng sich so zäh erhalten hat, dab es möglich wird, zwei Bilder nebeneinander zu stellen, das cine einem Schnitt durch dic Zahnanlage eines Reptils und das andere einer Zahnanlage eines Affen entnommen, welche einander sogar in histologischen Details auBerorlentlich ähneln. Man vergleiche dazı Fig. 57 mit Fig. 58. Erstere stellt die Wölbung des Unterkieferwalles cines Embryo von Henidactylus frenatus dar. Es ist nur das bekleidende Epithel und die davon ansgehende Drüsenleiste und generelle Zahnleiste mit einer Zahnanlage dargestellt. Die Zellkerne sind mit dem Zeichenappa-

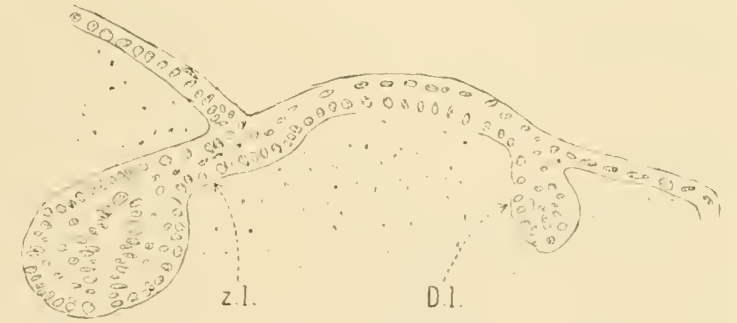

Fig. 57. Hemidactylus frenatus. Zahnleiste (Z. l.) und Drüsenleiste (D. l.).

rat genan eingetragen worden. Gleiches ist der Fall in der Fig. 58, welehe einen Teil der Unterkieferwölbung eines Embryo von Mycetes darstellt. Der bezügliche Schnitt durchquerte das Interstitiun zwischen Eckzahme und erstem Milchmolaren. Betrachten wir zunächst die Fig. 57 genaner. Die Kieferbekleidung schiebt zwei Lamellen ins Mesenchyn, die größere ist die Zahnleiste, die kleinere stellt die Drüsenleiste dar. An der Drüsenleiste, welche anch bei den Geckoniclen eine kontinuierliche Leiste darstellt, macht sich noch keine Differenziermng von Drüsen bemerkbar. Das ist als ein glïcklicher Unstand zu betrachten, denn jetzt ist leicht nachzıweisen, daß die Drüsen nicht einzeln und sofort aus dem Kieferepithel - entstehen, sondern Produkte einer Leiste sind. Diese ist zu betrachten als eine Tebenbildung der Zahnleiste. Es macht den Eindruck, als wäre die Zahnleiste zum Teil zur Bekleidung des Kieferwalles rerwendet worden, mol daß ihre primitive Ansatzlinie sich nach innen ins Kiefermesenchym eingebogen hat. Das geht deutlich aus dem verschieden 
histologischen Charakter der Kieferwallbekleidung hervor. Es besteht diese ans einem einschichtigen Epithel. Medial ron der Zahnleiste sind die Kerne grob. rund. stehen mehr senkrecht zur Oberfläche. lateral ron der Drïsenleiste erseheinen die Kerne stärker abgeplattet. Es verrät die Zahnleiste in dem zellularen Bau sofurt ihren Charakter der Doppellamelle. Bei sehr jungen Objekten sind nur zwei Zellsehichten zu menterscheiden, ein laterales und ein mediales Blatt; jedes besteht aus ciner einzigen Zellschicht. Bald treten jedoch zwischen beiden Blättern kleinkernige Zellen auf. welche in der Leiste selber nie-

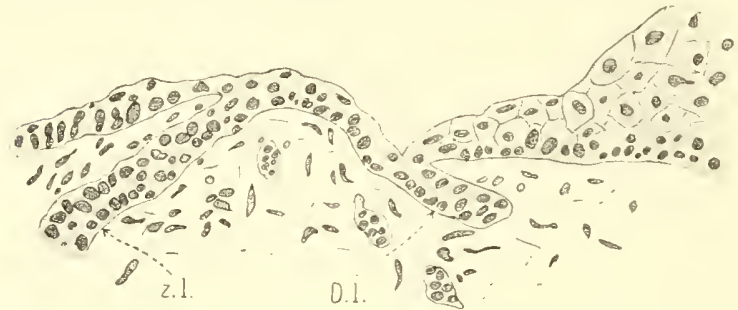

Fig. 58. Mycetes. Unterkieferepithel mit Zahnleiste (Z. l.) und Nebenleiste (D. l). mals eine mäehtige Schicht bilden. $11 m$ sich jedoth im Bereiche einer Zahnanlage zu rermehren und die Pulpazellen aus sich hervorgehen lassen. Diese kleineren Zellen sind in jeden gut konservierten Präparat sofort ron den ïbrigen Zellen der Zahnleiste zu unterscheiden. da sie sich weuiger stark tingieren. Verfolgt man mun diese mittlere Zellage, dann setzt sie sich als oberflächliche Schicht anf den Kieferwall fort in der Strecke durch die Zahnleiste nnd die Drïsenleiste begrenzt, um hier im Innern der Drüsenleistenanlage abzubiegen und an der Zusammensetzung der letzteren sich zu beteiligen. Das erscheint vielleicht in Fig. 57 micht so dentlich, da die Drüsenleiste in diesem Stadium noch

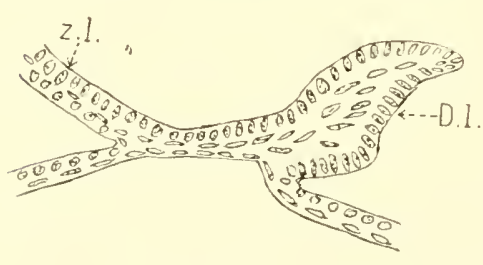

Fig. 59. Cyclodus Hoddaerti. Z. I. Zahnleiste; D. l. Drïsenleiste. aus rundkernigen Zellen besteht, die keine Differenzierung anfweisen. Ich gebe daher in Fig. 59 cinen Sehnitt durch die ïbereinstimmende Strecke des Oberkiefers eines Embryos ron Cyclodus Boddaerti (das ich der Gïte des Herrn Professor Spengel verlanke). Die histologische Differenzierung ist in diesem Präparat einen Schritt weiter gegangen, denn es ist das den Kieferwall bekleidende Epithel sehon zweischichtio. Es ist die Zugehörigkeit der zylindrischen basalen Zellen der Zahnleiste und jene der Drüsenleiste wohl anber Zweifel, und die abgeplatteten Elenente der mittleren Schicht der Zahnleiste setzen sich ebenfalls umunterbrochen in der zentralen Zellmasse der Driisenleiste fort. Übrigens haben wir es hier mit einem Terhalten zu tun, zu dessen Studium man nicht gezwungen ist sich den Reptilien zuzuwenden, man kann sich anch bei Primatenembryonen leicht daron überzengen. Denn daß die Drïsenleiste der Reptilien wohl homolog ist mit der Nebenleiste der Primaten, daran ist nicht zu zweifeln und geht aus einer Vergleichung: der Figuren 57 und 58 miteinander dentlich hervor. Letztere Figur ist, wie gesagt, einem Mycetes-Embryo entnommen. Die mur in ihrem Anfangsteil abgebildete Zahnleiste verrät ihren Charakter als Doppellamelle sofort. In der meist peripheren Strecke liegen die Zellen weniger 
regeluäBig geordnet, mud diese etwas unregehmäßjuge Anordnung setzt sich fort in der Zone des oberflächlichen Epithels zwischen der Ansatzstelle der Zahnleiste und jener der Tebenleiste. In letzerer sind die Zellen wieder ganz als eine eingefaltete Membran geordnet.

In Anschln, an das oben Gesagte kann ich noch einmal auf die Figuren 47, 48,51 und 53 verweisen, woraus die histologische Zusammengehörigkeit von Zahnleiste und Nebenleiste zu ersehen ist.

Die Homologie der Nebenleiste der Primaten mit der Drïsenleiste der Reptilien unterliegt meiner Meinung nach keinem Zweifel. Da, soweit mir bekannt, echte Zahndrüsen bei den Säugetieren nicht vorkommen, diese Bildungen sonit längst schon aus der Entwickhngsreibe ausgeschaltet sind, muß man sich wundern, daß bei den Primaten diese Leiste ontogenetiseh noeh so deutlich in Erscheinung tritt, ja sogar noch Anlaß geben kann zur Fntstehung rudimentärer Drüsenanlagen. Denu die Ansehwellungen, die am freien Rande dieser Leiste von Stelle zu Stelle auftreten kömnen, mud später, wenn die Leiste in Fragmente aufgrelöst und gröbtenteils ganz versehwunden ist, als isolierte Bildungen zu erseheinen, sind wohl nichts anderes als letzte schwache ÄuBerungen der erlöschenden Funktion dieser Leiste. Es sind gleichsam Versuche zur Sprossenbildung, die rudimentäre Zahmanlage vortäuschen, welehe ein wenig eingestülpt sind. Ich bin der Überzeugung, daB manche sogrenannte prälakteale Zahnanlage, welche in der Literatur beschrieben worden ist, in Wirklichkeit eine rudimentäre Anlage einer Zahndrüse gewesen ist. Doch ich möehte mich vorläufig auf die Primaten beschränken.

Das Auftreten der Drüsenleiste der Reptilien in rudimentärer Form bei den Primaten ist wohl etwas überraschend, aber doeh auch nicht ganz unverständlich. Denn man bedenke, daß cliese Leiste ihrer Genese nach ein Produkt, ein Bestandteil der ursprünglichen generellen Zahnleiste gewesen ist. Ihre Derivate, die Drïsen, kommen zwar nicht mehr zur Entwicklung, aber das ist die Folge, daß die Funktion dieser Derivate nicht mehr erfordert wurde. Aber die Matrix, die Driisenleiste selber hat niemals eine spezifiseh physiologische, sondern nur eine Bildungsfunktion. Und es begegnet uns hier bei der Nebenleiste der Primaten eine analoge Erseheinumg wie bei der Milehleiste dieser Gruppe. Auch hier treten die Derivate, die Milehdrïsen, mit Ausnahme von zwei, nicht mehr auf, sie hatten nur physiologische Funktion, die in letzter Instanz mit Zelheubildung verkniupft ist. Die Leiste jedoeh hat Bildungsfunktion, ihre Aufgabe war es nicht mur Zellen zu bilden, sondern Organe. Und dieser Bildungstrieb erliseht, da er von einer höheren Ordnung ist, riel langsamer als jener, weleher mit einfacher Zellproduktion verkuüpft ist. Diesem Beispiel könnte man aus der Ontogenie mehrere zur Seite stellen. Das morphologisehe Substrat, woran eine Bildungsfunktion verknüpft ist, erhält sich bei rïckgängiger Entwieklung länger als die morphologische Grundlage für spezifisch-physiologische Funktionen.

Der Nachweis, daß die Nebenleiste der Primaten der Drüsenleiste der Reptilien homolog ist. erklärt es anch, warum erstere bei der rïckwärtsen V'erlängerung der Zahnleiste in gleichem Taße in der Länge wächst. Der hintere Rand der generellen Zahnleiste enthält potentia anch die Anlage der Nebenleiste. So wie sie sich pliylogenetiseh herausdifferenziert aus dem oberen Rand der generellen Zahnleiste, so tritt 
sie auch ontogenetisch noch an diesem Rande auf, wemn letztere sich vom Mundhöhlenepithel abgelöst hat.

Es ist die rudimentäre Anlage der Drüsenleiste der Reptilien bei den Primaten noch von einem anderen Standpunkte zu betrachten. Man Kann diese T'atsache anführen zugmensten der Ansicht, dab die Primaten in ihrer Crebißanlage noch manches Primitires aufbewahrt haben, und daß anch in dieser Hinsicht das Primatengebib als eine Form mit nrsprünglichen Charakteren zu betrachten ist.

Und daß letztere Ansicht eine richtige ist, wird ans dem folgenden Hauptstïck hervorgehen, worin ich zunächst die Erklärmng bringen werde jener ontogenetischen Erscheimungen, welche ich im ersten und zweiten Hanptstiick ansführlich beschrieben habe: die laterale Schmelzleiste, die Schmelznische, das Schmelzseptım und den Schmelznabel. Diese Erscheinungen sind nicht unahhängig voneinander. Tn Gegenteil, siestellen einen Phänomenkomplex dar. Welche, im Lichte der Entwicklungsgeschichte der Reptilienzähne betrachtet, als ÄuBerungen eines einheitlichen Bildungsvorganges erscheinen, welche die Beziehmng zwischen Säugetierzahn und Reptilienzahn in erfrenlicher Weise entschleier'n. 


\section{Viertes Hauptstück.}

\section{Über die Beziehung des Säugerzahnes und Säugergebisses zum Zahn und Gebiß der Reptilien.}

In diesem Schlıßkapitel werde ich zuerst die im ersten und zweiten Hauptstück beschriebenen Entwicklungserscheinungen, welche bei der Entstehung des Prinatenzahnes anftreten, erklären, sodann werde ich die Frage beantworten, ob auch bei anderen Säugetieren die nämlichen Erscheinungen zu beobachten sind, nn schließlich einzugehen auf die Frage der Beziehung des Gebisses der säugetiere als ganzes zı jenem der Reptilien. Ich erimnere daran, da.. in den beiden ersten Hauptstücken die laterale Schmelzleiste, die schmelznische, das Schmelzseptum und der Sehmelzmabel beschrieben worden sind.

Bei der Beschreibung der lateralen Schmelzleiste ist immer darauf hingewiesen, daß die Bedentung derselben für die Genese des Schmełzorganes - d. h. für jene des Zahnes - eine gleiche sein muß als die der medialen Leiste. Davon war ich sehon überzengt, obwohl es mir noch nicht gelungen war, ihr Auftreten zu erklären und ich den Zusammenhang der vier soeben namhaft genachten Erscheinumgen noch nicht durchschanen komnte. Zwar brach sich bald, nachdem ich festgestellt hatte, daß die laterale Schmelzleiste eine allen Primaten zukommende Bildung war, die Ansicht bei mir Bahn, daß die Morphologie der Zahnkrone der Primaten in irgendwelcher Beziehung zu der aufgedeckten ontogenetischen Erseheinung stehen sollte, aber in weleher W'eise ich mir diese Beziehung denken mußte, war mir nicht kłar. Un zu rersuchen Lieht in diese Frage zu bekommen, fing ich daher an das Relief des Primatengebisses genauer $z u$ studieren. Ich tat es ganz unabhängig von dem Einflub der gelänfigen Theorien ïber die Entstehung des Kronenreliefs, welche sich auf die Cope-Osbornsche Theorie stïtzen. Ich war schließlich wohl gezwungen, diesen mehr freien Standpunkt einzmuehmen, da ich bei dem Versuch, die Kronenhöcker der Primatenzähne in ihren versehiedenen Spezialisiermgen vergleichend-anatomisch unter Anwendung der Osbornschen Theorie zu homolngisieren, auf große Schwierigkeiten stieb. Jeder Homologisierung anf Grund des Osbornschen Schemas war eine andere zur seite zu stellen. welche gleichberechtigt erschien, es ist hier der Williür freier Spielranm gegeben. Nur unter Beriicksichtigung der ontogenetischen Entwicklung der Kronenreliefs - wie es rou Taeker, Röse. Leche und Wood ward geschehen ist - und wodurch einstimuig das Fehlerhafte der Cope-Osbornschen Ansichten für die oberen Molaren hervor- 
getreten ist - können wir hoffen in dieser Materie weiter durchzudringen.

In dieser l̈berzengung liegt der Grund, warum ich bis jetzt nicht anf ein Argument eingegangen bin, welehes von Adloff gegen meine Theorie der Differenzierang des Primatengebisses angeführt worlen ist. Doch erforthert dieses Argument eine Viderlegung, da es anf einer Beobachtung beruht. Ich werde dieselbe an dieser Stelle knrz einschalten.

Wiederholt hat der Autor das Argmment angefïhrt. Es betrifft (lie 'Tatsache, dab beim Gorilla an unteren letzten Milchmolaren ein Höekerchen auftritt, das der Autor als Parakonid definiert, und das bei den bleibenden Molaren nicht vorkommt. Dagegen kommt nach Adloffs Beobachtungen an übereinstimmender Stelle ein Höckerchen vor am dritten Milchmolaren von Cebus. Diese Beobachtung genïgt dem Autor Im den letzten Milchmolar der Platyrrhinen mit den letzten Milchmolar der Katarrhinen zu homologisieren. Und er erblickt in diesem Befund wieler einen unwiderleglichen Beweis von der Unrichtigkeit neiner Hypothese der terminalen Reduktion des Primatengebisses, demzufolge der dritte Milchmolar der Platyrrhinen mit dem ersten bleibenden Molar der Katarrhinen homolog sein sollte. Teh werde auf die Beweiskraft der Adloffschen Homologisierung nicht eingehen, ich stehe bezïglich der Höckerbildnngen und der Anomalien darin auf cinem vom Autor abweichenden Standpunlit. Ich möchte jedoch mich einen Augenblick auf den Standpunkt des Autor stellen. Fassen wir knrz die Tatsachen zusammen. Der Antor trifft bei einem Gorilla ein Parakonid an zweiten nnteren Milchmolaren, er trifft ebenfalls ein Parakonid am dritten unteren Milchmolaren eines Cebus, also diese beiden Zähne sind einander homolog und meine Hypothese ist inrichtig. Aber es ist ohne weiteres klar, dab wemn einmal auch am zweiten Wilchmolaren von C'ebus ein Parakonid vorkommt, damn würde die vom Antor aufgestellte Homologie hinfällig werden. Ich muß leider auch in dieser Angelegenheit dem Antor die Illusion entnehmen, einen unwiderleglichen Beweis gegen die Richtigkeit meiner Hypothese geliefert zu haben, dem in der Tat kommt bisweilen auch am zweiten unteren Milchmolaren ron Cebus ein Parakonid vor, zwar nicht so stark entwickelt als am dritten, aber immerhin sehr dentlich zu sehen.

Durch dieses Auftreten wird das Adloff sehe Argument geniigend widerlegt, demn wemn der Parakonid anch am zweiten Milchmolaren der Platyrrhinen gelegentlich auftritt, kann man mit gleichem Recht diesen Zahn dem zweiten Milchmolaren von Gorilla homolog stellen.

Ich bin im Voriibergehen auf dieses Argument Adloffs eingegangen, weil es sich anf eine tatsächliche Beobachtung stützt. Cranz abgesehen davon, daß die Interpretation derselben meiner Meinung nach wenig beweiskräftig ist (anch Bluntschli hat schon das Unzulängliehe des Argumentes ins Licht gestellt ans ganz anderen Gründen) ist die Tatsache durch den oben mitgeteilten weiteren Befund als Beweis gegen meine Deitmng des Katarrhinengebisses wohl ganz wertlos geworden.

Wie schon gesagt, kann ich mich mit der iiblichen Methode der Homologisierung der Höcker bei den Primaten nicht einverstanden crklären, da eine vorurteilsfreie Untersachung meines Materials mich zu einer anderen Dentung der Erscheinungen geführt hat. Die Anf- 
fassung stimmt im Prinzip mit jener ïberein, welche von d'Eternod in seinem Vortrag auf der Leipziger Anatomenversammlung verfochten worden ist. Der Genfer Anatom ist, hauptsächlich anf Grund der Variationen aus menschlichen Zähneı, zum Sehluß gekommen, daß die Urform aller menschlichen Zähne cierBienspidat sei. Auf Grund meiner Untersuchungen am Milehgebiß und permanenten Gebiß der Affen war ich schon damals zn einer in Prinzip ganz übereinstimnenden Überzengung gelangt, und sehloß mich dann auch in der Diskussion dem Vortragenden an. Zu dieser Meinung war ich auf dem vergleichendanatomischen Wege gelangt, und im AnschlıB daran erhob sich von selbst clie Frage, ob dem vielleieht die zweifache Verbindung des Emailorganes mit der Zahnleiste in irgendwelcher Beziehung zu dieser Doppelnatur der Zahnkrone stehen möchte. War es nicht möglich, daP in der lateralen und medialen Sehmelzleiste die spezielle Leiste zu erblieken war, für je eines der Komponenten des Zahnes? Ein Lösungsversuch dieses Problems konnte uur durch Untersuchung von Reptiliengebissen mit Voraussicht anf guten Erfolg angestellt werden. Und ich bin überzengt, daßes mir wirklich gelıngen ist, die etwas verwickelten Entwieklungserscheinungen beim Entstehen des Primatenzahnes in einfachster Weise von Verhältnissen abzuleiten. die bei der Entwicklung des Reptiliengebisses auftreten.

Unsere Kenntnis von der Entwicklungsgeschichte des Reptiliengebisses ist noch nicht als eine vollständige zu betrachten. Es treten auch hier Besonderheiten und Variationeu auf, welehe in der Literatur noch unerwähnt sind. Auf eine derselben habe ich auf der Anatomenversammlıng in Münehen die Aufmerksamkeit gelenkt, und ich komme später noch auf den Inhalt dieses Vortrages zurück. Vorläufig gilt es die Lösung nicht eines generellen Gebißproblems, sondern die Entstehungsweise des Primatenzahnes zu untersuchen.

Ieh fange dazu an mit einer Verweisung auf Fig. 60. Diese stellt einen Frontalsehnitt dureh die generelle Zahnleiste und zwei Zahnanlagen aus dem Unterkiefer eines jungen Varanus ehlorostygnia mit sehon funktionierendem Gebiß dar. Die größere Zahnanlage liegt bukkal von der kleineren. Diese Anlagen stellen zwei Zahngenerationen dar. Es war in dem Präparat noch eine

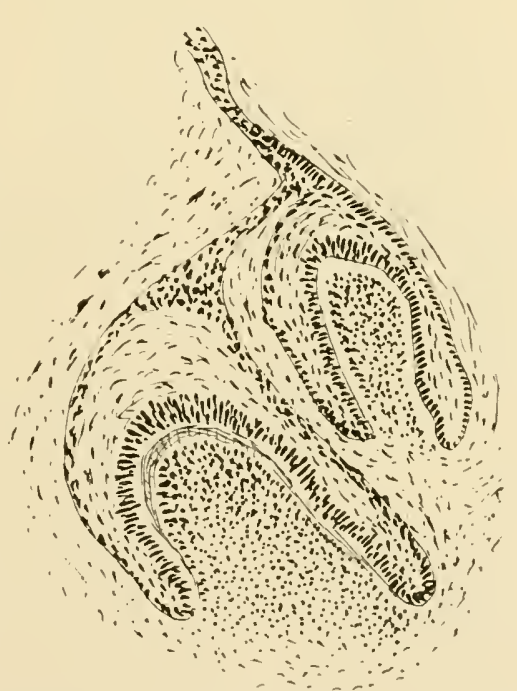

Fig. 60. Valanus chlorostygma. Zwei Zahmanlagon am Unterkiefer. dritte Generation - die zurzeit funlitionierende - vorhanden. Die beiden dargestellten Generationen gehören zueinander, die größere Anlage stellt die ältere dar, welche bukkal gelagert ist von der jüngeren. Letzere ist angewiesen einmal den bukkal von ihr sich entwickelnden Zahn zn ersetzen. Es ist anffallend, wie wenig die ältere und die jüngere Generation in diesen Falle in Ent- 
wicklnngsgrad roneinander differieren. Das ist eine Tatsache, worauf ich ganz besonders aufmerksam mache, da es nicht als liegel zu betrachten ist. Doch herrschen in rieser Hinsicht bei den Reptilien die gröbten Verschiedenheiten. Bisweilen trifft man, wie in Fig. 60, zwei anfeinander folgende Generationen an nut nur sehr geringen Differenzen in ihrer Entwicklung, die also kurz nacheinauder angelegt sein müssen, so daß der Ersatzprozeß nur eine kurze Zeitdaner umfaßt. Im Gegensatz dazu sucht man ein anderes Mal neben dem funktionierenden Gebil.j an der generellen Ersatzleiste vergebens anch nur eine Spur einer Anlage der folgenden Zahngeneration, wiewohll die Ersatzleiste vollständig entwickelt ist und nicht die geringste Andeutung ron Zerfall anfweist. Zwischen beiden Extremen findet man alle Übergangsstadien. Die Verhältuisse sind außerordentlich weehsehnd. Der Zahnweehsel, d. h. die zeitliche Anfe uanderfolge der Zahngenerationen und die Funktionsdaner einer Generation sind von mohreren Ursachen abhängig. Tur eine taron sei hier mamhaft gemacht, da sie mit der von uns verfolgten Frage in engen Konnex steht, es ist das Alter des Individumms. In Präparaten jugendicher Tiere erseheint der Zahnwechsel im allgemeinen intensiver als bei älteren. Ich glaube die Ursache davon darin erblicken zal dïrfen, dab hier das Längenwachstum des Fiefers einen mehr schnellen Zahnersatz crfordert. wobei die Elemente jeder folgenden Generation jene der Vorangebenden an Größe ïbertreffen. Dadurets hält das Gebib gleichen Schritt nit der Verlängernng des Kiefers.

Dab in Fig. 60 die jüngere Generation der älteren wenig an Entwieklıng zurieksteht, geht genügend aus der Abbildung hervor. Das einzige wodurch die ältere Generation sich von der jüngeren unterscheidet, ist die Anwesenheit der Dentinschicht, die schon anf die Papille zur Ablagerung gekommen ist.

Betrachten wir nns die beiden Anlaren etwas genaser. Besonders interessiert uns die Bezichnn zur generellen Zahnleiste. Dic ältere Generation ist noch mit letzterer in Zis sammenhang, aber nur durch Vermittlung eines epithelialen Stranges, der von der Spitze des Sichmelzorwanes ansgeht, $11 m$ an der generellen Zahnleiste sich anzuheften, kurz oberłalb der Stelle, bis wohin das Sehmelzoryan der jüngeren Generation reicht.

Das Besondere in den ontogenetischen Erscheinnngen, welche dieser Schnitt sehen läBt, mug in dem Tmstand gesucht werden, dab) es inn vorliegenden Fall zur Entstehung einer speziellen Zahnleiste gekommen ist. welche sich zwischen einer älteren Zahnanlare nnd der generellen Zahnleiste aisspannt. Die Ursache der Entstehung dieser speziellen Zahnleiste mulb gesucht werden in der sehnellen Aufeinanderfolge der Zahngeneration. Die jüngere Anlage drückt die ältere gleichsan zur seite, aber es mul. letztere mit der generellen Zahnleiste in epithelialer Verbindnug bleiben, da bei der weiteren Entwickhnng dieser "pitheliale Verbindungsstrang den Weg vorbereitet, welchen der Zahn beim Emporrïcken zil folgen hat. Anf ein Eingehen in weitere Details dieses Vorganges mul. ich an dieser Stelle verzichten. Es sei mur darauf hingewiesen, dab bei diesem Emporrïcken der Zahn nicht durch das Bindegewebe des Kiefers dringt, sondern einem epithelial angebahnten Weg folgt. Wäre das nicht eine Totwendigkeit, dam konute der zur Seite gedrängte ältere Zahn scine Verbindung mit der generellen Zahnleiste lösen. Diese Lösung kann nieht zustande ko nmmen, weil er diesen 
epithelialen Strang beim Enporwachsen beniitzen muß. Darin liegt die Ursache, warum bei der bukkalen Verschiebung des älteren Zahnes eine spezielle Leiste von der generellen wie ausgezogen wird.

Wenn man ein Bild von der Zahnentwicklıng bei Varanus wie in Fig. 60 nach Kenntnisnahme der Entwicklungserscheinungen, welche wir bei dem Primatenzahn nachgewiesen haben, anfmerksam betrachtet, dann mubs sofort die Tatsache auffallen, daßs nur ein elementarer Vorgang zustande zu kommen brancht, um clas Bild in Fig. 60 in eine typische Anlage eines Primatenzahnes umzugestalten. Man hat sich nur zu denken, daß die beiden Zahnanlagen in ein gleiches Niveau gerückt, ihre einander zugekehrten Flächen aneinander legen. Sobald das geschehen ist und die beiden Zahnanlagen in dieser Weise eine morphologisch einheitlich scheinende Doppelbildung formen, hat man es mit einem Gebilde zu tun, worin man die vier Bildungen, welche wir bei der Entwicklung des Primatenzahnes nachgewiesen haben: die laterale Schmelzleiste, die Schmelznische, das Schmelzseptum und den Schmelznabel in vollkommener Übereinstimmung vor sich hat. Um das deutlich hervortreten zu lassen, hahe ich in Fig. 61 zwei Schemata nebeneinander gestellt. Eines, Fig. 61a, stellt den Zustand dar der zwei in Fig. 60 abgebildeten Reptilienzähne, wenn der oben angedentete Vorgang sich vollzogen hat, das zweite, Fig. $61 b$, stellt eine Primatenzahnanlage dar, worin die vier oben namhaft gemachten Bildungen zu sehen sind. Letzteres Schema. und daranf weise ich ausdrücklich hin, hat nichts Hypothetisches oder Phantastisches, es ist tatsächlich Beobachtetes. Wenu man eine glückliche Schnittrichtung getroffen hat, und ein geeignetes Entwicklungsstadium, tritt in dem Sehnitt jede Besonderheit des embryonalen Primatenzahnes, die in Schema Fig. $61 b$ wiedergegeben ist, zutage. Tch

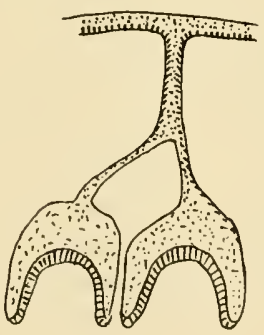

a.

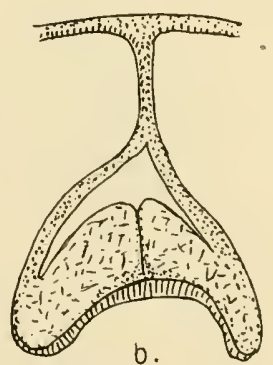

b.

Fig. 61. a Halbschematische Darstellung zweier Zahngenerationen von Varanus (vgl. Fig. 60). $b$ Halbschematische Darstellung der Anlage eines Primatenzahnes (vgl. u. a. Fig. 39d).

verweise, um davon zu ïberzeugen, nach Fig. 39d. Die Fig. $61 b$ ist nichts als die halbschematische Widergabe der letzteren.

Vergleicht man nun die beiden Schemata niteinander, damn kostet es gar keine Mühe, um die laterale Schmelzleiste, die Schmelznische, das Schmelzseptum und rlen Schmelznabel des embryonalen Primatenzahues in ihrer ontogenetischen Entstehungsweise zu erfassen. Die laterale Leiste des Primatenzalmes ist die spezielle Leiste des älteren, bukkal gelagerten Zahnes; das Schmelzseptum stellt die miteinander verwachsenen Abschnitte des äußeren Schmelzepitheliums beider Reptilienzähne dar. welche bei ihrer Auseinanderweichung an der Stelle, wo die Wände wieder frei werden, sanft abgerundet sind und den Schmelznabel bilden; die Schmelznische schließlich ist der Ramm. welcher sich ursprïnglich zwischen den beiden Zahnanlagen fand. Es will mir vorkommen, daß die Übereinstimmung nicht vollständiger sein kann. Und ich wiederhole, daß es sich hierbei nicht 1 m et was Hypo- 
thetsiches handelt, sondern um etwas Reelles. Nur eines ist nicht wirklich beobachtet, nämlich die Aneinanderlagerung der äußeren Wände der Schmelzloroane beider Reptilienzähne und die darauf folgende Verwachsung. Denn in Fig. 60 ist es genügend zu sehen, daß wenn die Zahnanlagen etwa weiter in der Entwieklung vorgerückt sind, dann trennt eine dïnne bindegerebige Schicht beide Anlagen voneinander. Nun wïnsche ich jedoch in Anbetracht dieser Tatsache, auf etwas hinzuweisen, wovon ich bis jetzt keine Meldung gemacht habe. Es ist nümlich die Tatsache, daß bei Propitheeus ich an ein paar Zahnanlagen im Zweifel war, ob nicht anch Mesenchynzellen in den Schmelznabel nach innen dringen. Ich habe bis jetzt diese Erseheinung nieht erwähnt, da es mir nicht gelungen war, darüber Sicherheit zu erlangen. Die Anordnung der Bindegewebskerne in und oberhalb des Nabels gab genïgenden Grund zur Vermutung ab. Vielleicht gibt es andere Objekte, welche die Frage zur Entscheidung bringen kömmen, und es schien mir daher erwïnscht, die Aufmerksankeit darauf zu lenken. Aber ich branche nicht einmal den Nachweis, daß dieses bei irgendwelchen Säugern in der Tat der Fall ist. Denn es findet sich sogar bei Reptilien zwischen den beiden Zahnanlagen nicht immer eine vollständig trennende dïnne Schicht von Bindlegewebe. Das geht z. B. aus Fig. 62 hervor. Hier

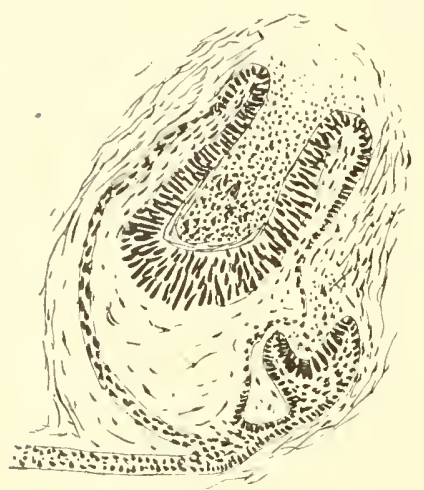

Fig. 62. Taranus chlorostygma. Zahnleiste (zum Teil) und zwei Zahnlagen in Oberkiefer. gilt es einen Schnitt durch die generelle Zahnleiste und die Zahnanlage des nämliehen Objektes wie in Fig. 60, aber des Oberkiefers. Auch hier finden sich zwei Zahngenerationen, aber in bedentend verschiedener Entwicklungsphase. Die größere, ältere Zahnanlage liegt wieder bukkal, medial die jüngere, kleinere. Zwischen beiden liegt ein mit Bindegewebe ausgefüllter Raum, welcher sofort an die Sehmelznische des Primatenzahnes erinnert. Sehr wichtig ist es nun, zu beobachten, wie in diesem Falle ein unmittelbarer Kontakt zwischen den beiden Zahnanlagen besteht und zwar dlerart, daß dlie jüngere Zahnanlage clas äußere Epithel der älteren Anlage sogar ein zufalten scheint. In Wirklichkeit muß man sich die aktive Rolle in diesem Voroano beim bukkalen älteren Zahn denken. Denn das Schmelzorgan schwillt, wenn die interzellulären Hohlräume sich zu bilden anfangen, sehr stark an. Es kommt dabei bei den Reptilien nicht so deutlich zur Entstehung jener typischen Sternzellen, welche bei den Säugern anftreten, die Pulpazellen nehmen nehr eine längliche Form an. Durch die Schwellung des Organes wird das umgebende Bindegewebe zur Seite gedrängt und es kommt dadurch dlas äuBere Epithel des älteren Zahnes in Berührung mit dem Schmelzorgan der folgenden Generation, und wird von diesem sogar eingestülpt.

Ich glaube, daß die Übereinstimmung der Befunde bei der Entwicklung zweier Zahngenertaionen des Varanus, und die Entwicklungserscheinungen an der primären Zahnanlage und der Zahnleiste eines einzigen Primatenzahnes so augenfällig ist, daß wohl kein Raum für 
Zweifel mehr übrig bleibt, daß das geschilderte Reptilienstadium als ein phylogenetisches Ausgangsstadium betrachtet werden darf für die Differenzierung des Primatenzahnes. Es brancht doch nichts newes mehr hinzuzukommen, es ist nur erforderlich, daß die Zeit, welche zwisehen der Anlage zweier Generationen verläıft, möglichst kurz geworden ist, so daß die beiden Reptilienzähne, der bukkal gelarerte ältere, und der medial gelagerte jüngere nahezu gleichzeitig zur Anlage kommen. Ist das der Fall, damn entstehen anch die beiden Zahnpapillen gleichzeitig und in der nmmittelbaren Nähe von einander, wodurch eine räumliche Sonderung beider unterbleibt, sie sind zu einer einzigen Papille zusammengewachsen, welche nur in der späteren Entwicklıng ihre doppelte Herkunft durch die bukkale und mediale Höckerbildung verät.

Die Schlußfolgerung, welche mit strengster Logik aus dem Obenstehenden gezogen werden muß, ist, daß das Schmelzorgan cler Primaten mit zwei Schmelzorganen der Reptilien homolog ist, welche in bukkolingualer Richtung nebeneinander lagern. Zwei Schmelzorgane sind identisch mit zwei Reptilienzähnen, also muß der Primatenzahn aus einer Konkreszenz zweier, zu zwei verschiedenen Generationen gehörigen Reptilenzälnen entstanden sein. Der Bequemlichkeit wegen wünsche ich hier gleich ein Paar meinen Befunden entsprechende Bezeichnungen einzufiihren. Der Säıgerzahn ist durch Konkreszenz von zwei Reptilienzähnen entstanden, welche einander als eine ältere Generation und eine jüngere verwandt waren, erstere war bukkal von der letzten gelagert. Indem ich num den Zahn als ,dimeres“" Gebilde bezeichne, möchte ich den Zahnteil, der auf die ältere Generation zurückzufülren ist als cler ,Protomer" bezeichnen und den anderen Teil als der ,Deuteromer".

Ich glaube im Laufe dieser Arbeit diese Entstehungsweise des Säugerzahnes - deun sie gilt nicht nur von den Primaten - so fest begründet zu haben, daß in der Diskussion über Gebißprobleme nicht mehr die Frare, ob Konkreszenz eines Beweises harrt, sondern daß jetzt den prinzipiellen Gewern dieser Theorie den Beweis erbringen müssen, daß Konkreszenz nicht stattgefunden hat. Der ontogenetische Verlauf der Schmelzoromanlage und die Differenzierumgserscheinungen der Zahnleiste genügten schon an sich, um eine Konkreszenz von zwei Elementen wahrscheinlich zu machen. Denn deutlich sprach die Doppelnatur der Anlage sich sehon ans in der doppelten Verbindung des Schmelzorganes mit der Zahnleiste, weiter in wem Auftreten zweier Bildungszentren von Pulpazellen in dem Or:an und schließlich in dem Auftreten des Schmelzseptum. Es ist nicht versäumt worcien, bei der Beschreibung dieser Tatsache jeciesmal auf ihre Bedeutung als Zeugnis der Doppelnatur der Anlaje hmzuweisen. Die beschriebenen ontogenetischen Erscheinungen an Reptiliengebiß stellten damn schließlich die Tatsache wolll über allen Zweifel fest.

Es seheint mir dann anch prinzipiell die Frare über die Herkunft des Primatenzahnes (Säugerzahn im all emeinen) entschiecen. Es sei jedoch sofort bemerkt, daß die spezielle Form des Zahnes in ihren Einzelheiten noch nicht erklärt sei: Auf aiesen Punkt komme ich noch ausführlich zurück und möehte zuvor nuch einmal auf ein Paar Besoncierheiten zurïckliommen, welche uns jetzt besser verstänalich geworden sind. 
Bei der Beschreibung des Schmelzseptum ist daranf hingewiesen, daß ursprünglich, wenn in clen beiden Hälften die Pulpabildung angefangen hat, das Septum noch kein histologisches Gepräge hat. Es besteht aus den Rundzellen. woraus anfänglich das ganze Organ aufgebant ist. Anch das änßere Epithel behält noch längere Zeit den primitiven Charakter bei. Bekanntlich bilden sich die Elemente des letzteren zu Plattenepithelien aus. Es ist ausclrïcklich bei der Beschreibung des Septums betont worden, dab eine ïbereinstimmende histologische Umbildung anch an den Septumelementen wahrzunehmen ist. Es sind zwar nicht alle Objekte gleich stark beweisend, da die Schnittrichtung mit der Längsachse des Septums zusammenfallen muB. nm diese Form der Septalzellen hervortreten zu lassen, und das ist, bei der strangartigen Form des Septums in dem späteren Entwicklnngsstadium, nur selten der Fall. Doch habe ich davon einige sehr schöne Fälle wahrnehmen konnen ( $\mathrm{vgl}$. z. B. Fig. 40, 41 und 42). Es findet diese Erscheinung ihre Erklärung in der oben geschilderten Entstehungsweise des Septums. Durch Aneinanderlagerung von Wandteilen zweier Schmelzorgane entstanden, besteht es mithin aus äuBerem Epithel, und daß es in späteren Entwicklungsstadien den gleichen Charakter wie letzteres bekommt, darf nicht wundernehmen. Nan hat sich zu denken, daß an der Stelle. wo die Scheidewand sich am änßeren Epithel des Schmelzorganes festhaftet, das Epithel sich nach innen umschlägt. Und das ist bei den Halbaffen, wo das Septum sich offenbar besser erhält als bei den Affen, sehr evident. Man vergleiche z. B. die an Propithecus entlehnten Figuren 4. $c$ und $d$. In der Strulitur des Schmelzseptums habe ich jedoch Nichts finden können, was seine Zilsammensetzung aus zwei Blättern verrät, ebensowenig wie an der Schicht der Ameloblasten eine Grenzmarke zu sehen ist zwischen dem bukkalen und dem lingualen Abschnitt. Das Schmelzepithel zeigt keine histologische Abgrenzung zwischen den beiden Komponenten. Bekanntlich ist solehes jedoch in funktioneller Hinsicht wohl der Fall. Es hat Röse, als Anhänger und als kräftiger Förderer der Konkreszenztheorie, ontogenetische Beweise zur Stïtze dieser Theorie herbeizuführen versucht, und dazu zucrst die Ablagerung von Sehmelz auf vie Zahmpapille genaner untersucht. Seine Ergebnisse sind anch für uns sehr wichtig, denn es konnte festgestellt werden, daß bei mehrhöckerigen Zähnen der Schmelz anfänglich nicht als eine kontinmerliche Schicht abgesetzt wurde, sondern in der Form ron getrennten Scherbchen. welche den späteren Höckern entsprechen. Auf der bukkalen Seite tritt die Schmelzablagerung früher auf als auf der lingualen, eine Tatsache, die später von Schwalbe bestätigt worlen ist. In Prinzip schließe ich mich Röses Deutung dieser Tatsache an, die dem Autor ein Beweis ist. daß die bukkale Seite des Zahnes einer älteren Generation zugehört als die linguale. In einem sehr wichtigen Punkt jedoch bin ich ganz anderer Mcinnng als der genannte Autor, nämlich in der Auffassung, daß jeder Höcker des Säugetierzahnes einem Kegelzahn der Reptilien gleichwertig ist. Diese äußerste Durchführmng des Konkreszenzprinzips ist meiner Meinmm nach grünollich verfehlt. Ich bin rler Ansicht, daß nur zwei Reptilienzähne im Säıgerzahn enthalten sind. Ich komme jedoch ant diese Frage später ausführlich zurïck. Es empfiehlt sich, wie ich auch in meinem Münchener Vortrag vorgeschlagen habe, bei den Mammalien im allgemeinen an jedem Zahn zirei Glieder zu unterscheiden, den 
oben genannten Protomer und den Deuteromer. Der Protomer bekonmt, wie Röse, Schwalbe u. A. nachwiesen, den Schntelzïberzug getrennt vom Deuteromer und etwas frïher. Und darin äußert sich die funktionelle Doppelnatur der Ameloblastenschicht, an welcher, wic gesagt, strukturell nichts von einer Zusammenfließung zweier einstnals getrennter Stücke zu sehen ist. Ind wenn man jetzt noch einmal die Figuren 60 und 62 betrachtet, dann wird es deutlich, laß Röse richtig sah, wenn er den bukkalen Komponent des Sängerzahnes als eine ältere Generation, (lem lingualen gegenüberstellte ${ }^{1}$ ). Besonders die Fig. 60 ist in dieser Hinsicht sehr wichtig. Der Entwicklungsgrad der zu zwei anfeinander folgenden Generationen gehörigen Zähne ist relativ wenig verschieden, die Papille der älteren, bukkal gelagerten Generation trägt eine zarte Dentinschicht, welche der lingualen, jüingeren fehlt.

Ich schließe hiermit die Besprechung der Beziehung des Primatenzahnes zil den Reptilienzähnen ab. Es ist, wie ich meine, in unzweideitiger Weise festgestellt worden, daß die mehr komplizierte ontogenetische Entwicklungsweise, die in ihren Einzelheiten für den Primatenzahn in den ersten zwei Hauptstiicken bekannt geworden ist. die Ein sicht in der Herkunft desselben nicht verwickelter macht. Im Gegenteil, jene ontogenetischen Erscheinungen geben gerade den Schlïssel ab, wodurch das Problem der Phylogenese des Primatenzahnes gelöst werden konnte. Es ist derselbe ein Produkt von Konkreszenz. Das darf jetzt wohl als feststehend betrachtet werden. Aber mit der Feststellung dieser Tatsache ist die Frage nach der Herkmuft noch nicht ganz erledigt. Es ist damit nur das Grundprinzip festgestellt, und die Grunderscheimung. Die vielen Probleme, welche sich um die Formdifferenzen der Zähne gruppieren, harren noch ihrer Erledigung. Nun gedenke ich nicht in dieser Arbeit auf diese verschiedenen Probleme in der Tiefe einzugehen. Es kommt nir jedoch erwïnscht vor. daf. ich diese Arbeit nicht abschließe, ohne eine Übersicht meiner Ansichten über rlie weiteren Gebißproblene gegeben zu haben. Denn zwar kann man jedes clerselben als ein gesondertes betrachten, aber sie sind dennoch so eng miteinander verknïpft, daß der Nachweis einer fundantentalen Erscheinung bei einem derselben nicht ohne Einflub sein kann, auf die Ansichten, welche man über die rerwandten Probleme hat.

Die erste Frage, welche sich im Anschluß an die in den vorangehenden Kapiteln mitgeteilten ontogenetischen Erscheinungen erhebt,

1) Die Lagerungsbeziehung von Protomer und Deuteromer zueinander erleidet jedoch bei den unteren postcaninen Zähnen eine merkwïrdige Umänderung. Die Kronenentwicklung dieser Zähne, wie dieselbe uns durch Untersuchungen von Röse, Leche, Taeker und Woodward hei verschiedenen Säugergruppen bekannt geworden ist, und welche ich für mehrere Affen bestätigen konnte, scheint mit der oben gegebenen Darstellung in Streit zu sein. Denn bei diesen Zähnen fängt die Schmelzablagerung nicht an der bukkalen sondern an der vorderen Hälfte an. Dieser Widerspruch ist jedoch nur ein scheinharer, wie ich im nächstfolgenden meiner odontologischen Studien darlegen werde. Ich möchte jedoch schon an dieser Stelle in der Hauptsache die Lösung dieser Kontroverse geben. Es ist nämlich die folgende: im Unterkiefer haben sich in Anpassung an den Raumverhältuissen die postcaninen Zähnen gedrelıt, und zwar derart, daB der Deuteromer hinten und lingual vom Protomer zu liegen kommt. Dieser Vorgang bringt die Erklärung mehrerer morphologischer Erscheinungen, und die Lösung einiger Fragen. 
ist wohl diese: sind letztere auf die Primatengruppe beschränkt oder weist die Ontogenie der Zähne anderer Säıgergruppen die nämlichen Erscheinungen anf? Letzteres ist wohl a priori wahrscheinlich, dem man darf sich auf den Standpunkt stellen, daß die phylugenetische Entstehungsweise der Säugerzähne eine für alle Glieder dieser Vertebratengruppe ïbereinstimmende gewesen sein muB. Es soll damit nicht gesagt sein, daß die Gebißformen sämtlicher Sängetiere von einer einzigen Reptilienurform abzuleiten sind. Die ,,Lammalisierung“ des Gebisses kan zwal in einer einzigen Weise zustande, aber dieser Prozeb konnte seinen Ansgang nehmen bel Formen, welche ihrer allgemeinen Organisation nach zwar zu einer einzigen Reptiliengruppe gehörten, aber innerhalb letzterer komnte das Gebiß unter Beibehaltung seiner Reptiliennatur doch schon in verschiedener Weise spezialisiert sein. Ich komme anf tiesen Gesichtspunlit noch zurück. Aber wie gesagt, die Entstehungsweise der funktionell höheren Zahnform soll wohl für alle eine übereinstimmende gewesen sein. Und wenn jetzt für die Affen eine Entstehung durch Verwachsung nachgewiesen ist, da ist es wohl nicht zu erwarten, daß die Zähne anderer Säugetiere lediglich durch Differenzierung eines einzelnen Elementes entstanden sind. Doch genügt ein solcher theoretischer Standpunkt nicht, nur der Nachweis der Übereinstimmung kamn befriedigen. Meine Bemühungen in dieser Richtung haben nun ans Licht gebracht, claß wirklich ïbereinstimmende Entwicklungserscheinungen wie bei den Primaten nachgewiesen sind, anch bei den übrigen Sängern anftreten. Es ist mir dabei jedoch anfoefallen, dal. nicht bei allen Ordnungen die Erscheinungen in głeicher Dentlichkeit wie bei den Primaten auftreten. Ohne auf Einzelheiten einzugehen, glaube ich, daß diese Tatsache zugunsten der Ausicht spricht, welche man in der Literatur schon mehrfach ansgesprochen findet, daß das Primatengebil, zu den primitivsten gehört, welche man bei den Säugern findet.

Zum Beweis der obenstehenden Behauptung lasse ich in den Fig. 63 bis 68 einige Skizzen dureh Zahnanlagen ron Canis, Tragulus, Ovis,

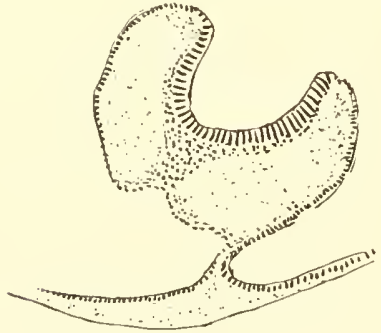

Fig. 63. Canis familiaris. Schmelzseptum und Schmelznabel.

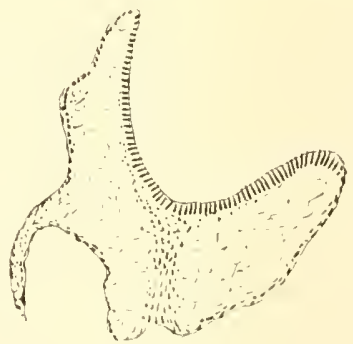

Fig. 64. Tragulus javanicus. Schmelzseptum und Schmelznabel.

Hyrax und Sciurus folgen. Die Figuren 63 und 64 illustrieren das Vorkonmen des Schmelzseptums bei Canis resp. Tragulus. Beide Schnitte gehen durch einen oberen Milchmolaren. Bei jenem des Hundes (Fig. 63) besteht das Septum, das sich durch vier von den 23 Schnitten von 25 " dieser Zahmanlage ausstreckte, aus Rundzellen, bei Tragulus waren die Zellen schon abgeplattet. Beim Hunde ist iiberdies der Schmetznabel sehr deutlich entwickelt. Die weiteren Figuren (mit Aus- 
nahme von Fig. 68) beweisen das Vorkommen der doppelten Verbindung des Schmelzorganes mit der generellen Zahnleiste und einer Schmelznische. Die Fig. 65 stellt einen Schnitt durch den medialen unteren Incisivus von Hyrax siriacus dar. Die generelle Zahnleiste zeigt schou deutliche Reduktionserscheinung, die spezielle Leiste dagegen noch nicht. Die laterale Schmelzleiste ist sogar noch sehr kräftig, die mediale steht im Begriff sich vom Organ abzulösen. Die Fig. 66 bringt wieder

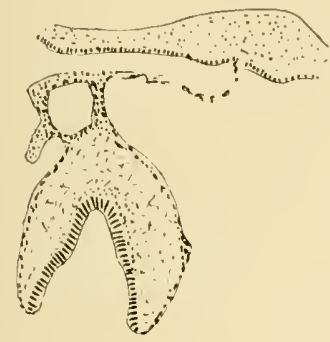

Fig. 65. Hyrax siriacus. Laterale Schmelzleiste. Schmelznische.

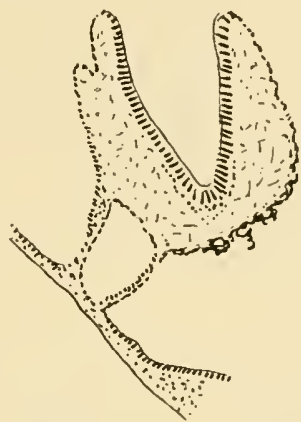

Fig. 66. Tragulus javanicus. Laterale Schmelzleiste. Schmelznische.

einen Schnitt durch einen oberen Milchmolaren von Tragulus. Es tritt dabei die gleiche Erscheinung vor, welche wir auch bei Molaren von Primaten nachgewiesen haben, es kommt nämlich die laterale Schmelzleiste nicht aus der generellen Zahnleiste zum Vorschein, sondern sie tritt selbständig ans dem Kieferepithel hervor, so daß die Schnelznische auch zum Teil durch dieses Epithel begrenzt wird. Ich mache anf die epithelialen Zellwucherungen aufmerksam, die sich an der bukkalen Seite des Schmelzorganes finden, und auf deren Bedentung ich bei der Beschreibung der Primatenzähne wiederholt hingewiesen habe. Ein wenig anders verhält sich die Anlage eines oberen Milchmolaren von Ovis, in Fig. 67 abgebildet, da hier die laterale Schmelzleiste von einer generellen Zahnleiste Ausgang nimmt. Der Zahn ist hier tiefer ins Kiefermesenchym eingerückt.

Die Fig. 68 illustriert sehr schön ein Verhalten, das auch wohl bei Primaten beobachtet wurde, wovon jedoch keine Moldung gemacht worden ist, da es aus gewissen Gründen einer speziellen Untersuchung iiberwert ist. Es betrifft nänlich die Tatsache, daß das Septum nicht immer das Schmelzorgan in zwei gleich große Hälften trennt, bisweilen verlänft es sehr schräg durch die Schmelzpulpa. Es ist nicht ganz ausgeschlossen, daß diese Erscheinung in Verbinclung' steht mit der ungleichen Entwicklung des lingualen und bukkalen Zahnkomponentes,

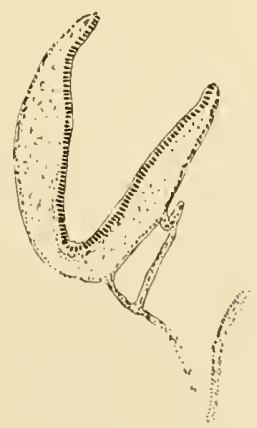

Fig. 67. Ovis aries. I,aterale Schmelzleiste. Schmelznische. ich möchte darüber jedoch kein Urteil aussprechen, da ich besondere Untersuchungen in dieser Richtung noch nicht angestellt habe. Ein sehr schönes Beispiel einer sehr exzentrischen Stellung 
liefert das Schmelzorgan der großen Schneidezähne von Sciurus, wie aus Fig. 68 ersichtlich. Die vier Skizzen stellen vier aufeinanderfolgende Frontalschnitte dar durch den meist vorteren Teil der Anlage. Der Schnitt $a$ ist ein Tangentialschnitt. wobei die Schmelzpulpa gerade getroffen wurde. Um rliese Figur zu verstehen, tut man am besten, von Schnitt d Ausgang zu nehmen, diese liefert keine schwierigkeit, die Skizze a liegt drei Schnitte weiter nach vorn. In dem Sehnitt $b$ ist
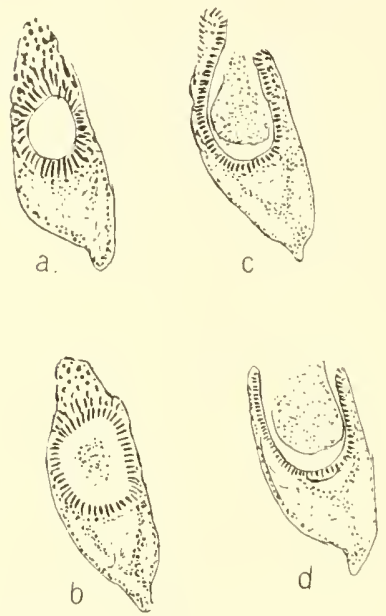

Fig. 6s. Seiurus rulgaris. innerhalb der Sichmelzpulpa das Septum zur sehen, aus Rundzellen aufgebaut und in Form von zwei dem äuBeren Epithel sehr dicht genäherten Bändern, die die Pulpa in eine zentrale Masse und periphere Schicht zu trennen scheinen. Gleiches ist noch in Skizze $c$ der Fall; hier ist die zentrale Masse kleiner geworden und im Schnitt $d$ ist letztere kaum angedeutet. Zwei schnitte weiter nach hinten ist von einem Septum nichts mehr zı sehen und es folgen damm noch mehr als zwanzig Schnitte durch die Zahnanlage. Versucht man nun den abgebilileten Zustand sich räumlich vorzustellen, damn ist es dentlich, daß hier das Septum als eine Lamelle sich vortut, welehe sehr kurz hinter der Vorderwand des Schmelzorganes und diesem parallel gestellt ist.

Die jetzt angeführten Beispiele genügen zum Beweise, daß die vier Bildungen, welche bei den Primaten nachgewiesen sind: laterale Schmelzleiste, Schmelznische, Schmelzseptum und Schmelznabel, nicht auf dieser Ordnung beschränkt sind, sondern anch bei der Entwicklung der Zähne anderer Sängetiere auftreten. Daraus folgt, daß die Bemerkmngen allgemeiner Art, welche sich an diese Bildungen anknüpfen lassen, nicht allein für die Affen Geltung haben. Wenn wir also vom Primatenzahn nachgewiesen haben, daP eine Zusammensetzung aus zwei Elementen darin vorliegt, dann gilt Gleiches für den Säugerzahn im allgemeinen. Damit soll jedoch nicht gesagt sein, daß bei dieser Regel keine Ansnahmen vorkommen können. Das muB Gegenstand spezieller Untersuchung sein. Insbesondere denke ich dabei an die Zähne der Cetaceen und der Edentaten, welche sekundär wieder zu ..einfachen", nicht zusammengesetzten Zähnen zurückgebildet sein können. Über den Elefantenmolar komme ich noch "zu sprechen.

Es ist die von mir als laterale Schmelzleiste bezeichnete Bildung in der Litcratur schon öfters erwähnt worden, aber wohl immer ist sie mit einer hypothetischen prälaktealen Dentition in Znsammenhang gebracht. Ein Paar sehr lehrreiche Beispiele davon will ich aus der Literatur anführen.

In cler Arbeit Adloffs: Das Gebib des Menschen und der Anthropomorphen ${ }^{1}$ ) bildet der Autor auf S. 136 einen Frontalschnitt durch den Schmelzkeim des unteren Premolaren eines Spermophilus ab.

1) Berlin 1908. Julius Springer. 
Die laterale Schmelzleiste, die Schmelznische und die generelle Zahnleiste sind deutlich differenziert und sofort $z u$ erkemmen. Und merkwürdig ist es, wie nahe der Auter der richtigen Interpretation kommt. Er kommt auf die Entstehung des Säugerzahnes durch Beteiligung mehrerer Dentitionen von Reptilien zu sprechen und fährt dann folgenderweise fort: ,Es sind neuerdings eine Reihe von Untersuchungen veröffentlıcht worden, die zum mindesten die Beteiligung mehrerer Dentitionen an dem Anfban eines Zahnes außer allen Zweifel zu stellen scheinen. Textfig. 9 (die bezügliche Figur in der Adloffschen Arbeit. Ref.) zeigt einen derartigen Befund. Es ist der Schmelzkeim des unteren Prämolaren von Spermophilus leptodactylus. Labial derselben liegt eine der sogenamnten prälaktealen Dentitionen angehörige Anlage, die sich teilweise mit ihm in Verbindung befindet."

Um noch ein zweites Beispiel - das wohl zu den überzeugendsten gehört, welche sich in der Literatur vorfinden - anzuführen, wähle ich die Beschreibung, die Kïkenthal von der Entwicklung dles Gebisses von Manatus gegeben hat. Ich verweise besonders anf die der Abhandlung beigegebenen Figuren $\left.{ }^{1}\right)$. Von der oberen zweiten Backzahnanlage - wovon zwei Frontalschnitte die Beschreibung illustrieren - sagt der Autor: ,Eine sehr auffällige Erscheinung ist cin Epithelstrang, der kurz unter dem Mundhöhlenepithel sich labialwärts von der Zahnleiste abzweigt und sich durch das Bindegewebe zur labialen Seite der Zahnanlage hinzieht. Fig. 4 zeigt aufs deutlichste, wie dieser Epithelstrang in die labiale Wand der Zahnanlage eintritt und wie er einen kleinen Vorsprung bildet. Daß die Verschmelzung der Zellen dieses Stranges mit den Zellen der Zahnanlage nicht vollkommen vollzogen ist, erkennt man daraus, daß sich zwischen ihnen und der Zahnanlage eine Lïcke befindet. Als was ist nun dieser Epithelstrang aufzutassen? Wir können ihn nur als die Anlage einer prälaktealen Dentition ansehen, die aber mit der zur ersten Dentition gehörigen Zahnanlage zu verschmelzen im Begriffe steht. Wir haben also hier eine Backzahmanlage vor uns, die aus zwei verschmelzenden Dentitionen besteht, der prälaktealen und ersten, von denen die erstere die labiale Wand der Zahnanlage zu bilden in Begriffe ist."

Nicht weniger deutlich tritt die laterale Schmelzleiste (mhi) bei der Anlage des dritten Backzahnes von Manatus in die Erscheinung; die Schmelznische (siehe Kükenthals Fig. 5) ist hier sogar anffallend groß. Auch vou den Backzähnen des Unterkicfers heißt es: „Ebenso wie auf der labialen Seite sich der prälakteale Epithelstrang an Aufbau des Zahmes beteiligt, so anf der lingualen Seite die Zahnleiste." Die von Kückenthal bei Manatus beschriebenen Entwicklungsvorgänge sind mit jenen der von mir bei den Primaten beschriebenen so stark übereinstimmend, als hätte das Gebiß eines Affenembryo vorgelegen. Wenn man in den diesbezüglichen Sätzen von Kükenthal jedesmal statt ,.prälakteale Zahnleiste" die in dieser Arbeit inaıgurierte Bezeichnung laterale Schmelzleiste stellt, dann decken sich nicht nur die Beschreibung, sondern auch die auf Grund der Beobachtung gezogene Schlußfolgerung vollkommen. Kükenthal betrachtet jedoch den von ihm beschriebenen Fall als eine Ausnahme. Ich glaube gezeigt zı haben, sowohl durch eigene Befunde als durch die zitierten Fälle

1) Anat. Anz. 1896, Bd. XII, S. 513. 
aus der Literatur, daß es sich $u$ m ein regelmäBig vorkommendes, essentielles Element aller Zähne bei im allgemeinen allen Sängern handelt. Und damit ist zugleich die Dentung dieser Bildung als ein Beweis einer sogenannten prälakitealen Dentition hinfällig geworden. Es ist etwas Überraschendes darin, daß zur Deıtıng der lateralen Leiste immer eine hypothetische prälakteale Dentition herangezogen wurde, statt die nehr anf der Hand liegende und mehr einfachere Erklärung zu geben, daß diese labiale Leiste der Entstehung des Sängerzahnes ans wenigstens zwei Reptilienzähnen zu beweisen imstande war. Man schuf sich doch dabei die Schwierigkeit, daß man eine Konkreszenz von Zähnen noch innerhalb des Säugetierstammes annahm.

Daß ich der Doktrin einer hypothetischen prälaktealen Dentition bei den plazentalen Säugetieren auf Grund meiner Untersuchungen an Sängetiergebissen abhold bin, brauche ich kaum besonders zu betonen. Ich verweise dazu an dieser Stelle kurz auf den Inhalt meines Vortrages anf der Anatomenversammlung zn München und besonders auf die darin enthaltene Schlußfolgerung, daß es keine Beziehung gibt zwischen den beiden Zahngenerationen der Mammalien und den vielen Zahngenerationen bei den Reptilien. Der Zahnwechsel der Reptilien ist ein ganz anderer Vorgang als jener der Säugetiere. Es würde jedoch zu weit führen, an clieser Stelle näher auf dieses Gebißproblem einzugehen, ich komme daranf an geeigneter Stelle noch zurück, möchte hier jedoeh einige kritische Bemerkungen folgen lassen über die supponierte prälakteale Dentition der Säugetiere, ganz unabhängig von meiner Auffassung über den verschiedenen Charakter des Zahnwechsels bei Sängern und Reptilien.

Der Begriff prälakteale Dentition hat in der Literatur große Verwirrung gestiftet. Man trug nicht immer der Tatsache Rechnung, dab derselbe eine theoretische Konstruktion war. $11 m$ der Konkreszenztheorie eine Stütze zu verleihen. Und, wie gesagt, es muB. wundernehmen, daß gerade jene Forscher. welche die Konkreszenztheorie zı nenem Leben gebracht haben, diesen Begriff in der Phylogenie des Säugergebisses eingeführt haben, auf Grund von ontogenetischen Benbachtıngen, statt den niehr auf der Hand liegenden Weg einzuschlagen und die von ihnen beobachteten Erscheinungen als Beweise zu deuten der Konkreszenz des Zahnes aus Einzelelementen. Bei der Ansicht, wie sie z. B. von Manatus durch Kïkenthal laut obigem Zitat verteidigt worden ist, daß hier die prälakteale Dentition durch Verschmelzung mit der laktealen untergegangen sei, muß sich doch sofort die Frage erheben, warum denn im allgemeinen die Zähne der laktealen Dentition nicht viel komplizicrter gebant sind als jene der permanenten. Fs hat diese Ansicht, đaß Dentitionen miteinander verschmelzen, Anlaß gegeben zu den so zahlreichen Auffassungen, welche man in der Literatur über die Natur der permanenten Molaren findet. Durch die Schöpfung des Begriffes prälakteale Dentition wurden die Gebißprobleme unnütz viel komplizierter gestaltet als sie es in der Tat sund, und es liegt anch etwas Inkonsequentes in diesem Begriff, dem der Kernpunkt der Konkreszenztheorie liegt in der Annahme, daf die zusammengesetzten Zähne durch Verwachsung von kegelförmigen Einzelzähnen der Reptilien entstanden sind. Wil brauchen uns vorläufig mcht mit der Frage einzulassen. inwieweit die Konkreszenztheorie in dieser Form 
richtig sei. Diese Hypothese ist allerdings eine in sich abgeschlossene, und aut ihre Richtigkeit ganz unabhängig von einer eventuellen prälaktealen Dentition zu prüfen. Aber in der Auseinandersetzung Kiikenthals mo anderer Anhänger der Verschmelzungstheorie wurde nun der Fehler begangen, daß man diese Theorie zu stützen suchte durch Beweise von Konkreszenz nıcht von Einzelzähnen, sondern von verschiedenen Dentitionen. Man kannte den primitiven Säugern mehr als zwei funktionierende Zahngenerationen zu. Aber diese Dentitionen müßten schon aus säugetierähnlichen Zähnen aufgebaut gewesen sein, es dürften keine einfachen Kegelzähne mehr gewesen sein, denn in einem solchen Fall würden es noch keine Sängerzähne gewesen sein. Man muß sich daher, wenn man ganz konsequent sein will, auch die prälaktealen Zähne mit den Merkmalen des Säugerzahnes ansgestattet denken, d. h. es waren schon zusammengesetzte Ełemente. Und die als solche gedeuteten Verwachsungserscheinungen eines prälaktealen mit dem laktealen Gebisse. kann daher nicht als Beweis angeführt werden, daß der Säugerzahn durch Konkreszenz von Kegelzähnen entstanden sei. Sie können nur zur Stütze der Richtigkeit des Verwachsungsprinzips überhaupt herangezogen werden. Die Natur der die Verwachsung angehenden Elemente bleibt dabei ungelöst.

Auf welchen tatsächlichen Beobachtungen beruht nun die Annahme, daß es jemals ein prälakteales Gebiß bei Säıgetieren gegeben hat? Es ist sofort darauf hinzuweisen, daß vergleichend-anatoniseh diese Annahme auf große Schwierigkeiten stößt, denn es liegt bis jetzt in der Literatur keine Beobachtung vor, weder bei dem rezenten noch bei dem paläontologischen Marerial, welche das einstmalige Torkommen ron mehr als zwei Dentitionen bei den Mammalien beweist. Der ganze Begriff ist ein rein theoretischer: weil bei den Reptilien Polyphyodontismus vorherrscht, bei den Sängern meistenteils Diphyodontismus (bisweilen Monophyodontisnus) ist letzterer Zustand zustande gekommen zu denken durch allmähliche Verringerung der Zahngenerationen, wobei auch einmal eine triphyodonte Phase durchlaufen sein muB. Diese rein theoretische Ansicht ist schon durch ebenfalls rein theoretische Argumente zI entkräften. Es liegt nämlich kein einziger Grund vor, uns diese Verringerung der Zahngenerationen bei den schon zı Säıgetieren differenzierten Vertebraten vollzogen zu denken. Wenn man den Zahnwechsel der Reptilien vergleichend-anatomisch studiert, dann trifft man Formen, wo dieser Vorgang ein sehr intensiver ist, aber ebenfalls andere, wobei die Zahl der Generationen äußerst beschränkt erscheint. Bei einer dritten Gruppe ist der Zahnwechsel im vorderen Teil des Gebisses viel intensiver als im hinteren. Bald werden die Zähne gewechselt, wenn noch nicht die geringste Spur von Abnutzung zu beobachten ist, bald werden dic Zähne in hohem Maße ahgenützt, ehe sie durch neue ersetzt werden. Bei letzteren Formen nimmt man die interessante Tatsache wahr, daß beim Abschleifen der Zähne infolge des Gebrauches, die Pulpahöhle - welche bis zur Spitze des Zahnes reicht - durch Ablagerung von Dentin auf die Abnützungsfläche geschlossen bleibt, bis schließlich die Kieferränder statt wohlentwickelte, scharfspitzige Zähne zu tragen, nur mit einer Dentinleiste besetzt sind, wo Einkerbungen und seitliche Furchen die Grenze der ursprünglichen Einzelzähne noch verraten. Sehr schön ist das z. B. bei Histiurus (Lophura) amboinensis zı sehen. Ich komme in einer 
späteren Arbeit anf diese Erscheinungen zurück und gebe dieses Beispiel, mu nm die bekannte Tatsache hervorzuheben, daß anch bei den Reptilien eine stark ansgesprochene Polyphyodontie keine Notwendigkeit ist. Von den Theromorphen lantet bekanntlich die Angabe, dab sie monophyodont gewesen sein sollen.

Wenn man sich nun auf den Standpunkt stellt, daß. jede Zahngeneration der Sängtiere einer Zahngeneration der Reptilien homolog ist, dann ist theoretisch denkbar, dab schon bei den reptilienartigen Vorfalıren der Sänger die Zahl der Generationen auf zwei beschränkt war. Oder wenn man in dem Sängerzahn jeder Dentition einen Komplex von mehreren zu verschielenen Zahngenerationen gehörigen Kegelzähne erblickt, und in dieser Verwachsung den Grund der Verringerung der Zahngenerationen bei den Sängern anf zwei (drei) sieht, dann ist dagegen anzuführen. dab schon bei den Reptilien eine Verringerung dieser Generationen anftreten kann, ohne daß es dabei zur Entstehung eines zusammengesetzten Zahnes kommt.

Aber, wie gesagt, alle diese Auffassungen gehen aus von der Grundanschammg, daß. der Zahnwechsel der Reptilien eine identische Erscheinung ist als jene der Sänger, dal, die Dentition als Zahngeneration anfznfassen sei, was meiner Meinung nach nicht der Fall ist. Nit dem oben Gesagten war es dann anch nur mein Zweek, anf einige Schwierigkeiten hinzuweisen. welche entstehen, wenn man das Konkreszenzproblem nit dem Dentitionsproblem verknïpft. Das Konkreszenzproblem darf nur mit der Entstehnug der Zahnformen in Beziehung gebracht werden und nicht mit dem Problem des Zahnwechsels.

Es bleiben zur Stïtze einer eventuellen prälaktealen Dentition mur ontogenetische Beobachtmngen übrig, denn die Erklärmng gewisser Zahnanomalien als Elemente des prälaktealen Gebisses ist doch schwerlich als ein Beweis für das einstmalige Vorkommen eines solchen Gebisses anzuführen. Und was die ontogenetischen Beobachtungen betrifft, stehe ich noch anf dem gleichen Standpunkt, den ich in meiner Abhandhung über die Entwicklnng des Ganmens und die Bedertung der Zalnuleiste eingenommen habe: es wirl manches als prälakteale Zahnanlage bei den Sängetieren angeführt, was in der Tat etwas ganz anderes ist. Die in der rorliegenden Arbeit nachgewiesene Nebenleiste der Primaten, welche der Zahndrïsenleiste der Reptilien in rudimentärer Form entspricht, mit ihrer rudimentären Sprossenbildumg, ist eine sehr fruchtbare Quelle von sogenannten prälaktealen Zahnanlagen. Eine weitere Quelle ist die laterale Schmelzleiste, welche, wie nachgewiesen wurde, bisweilen unmittelbar ans dem Mnndhöhlenepithel hervortritt. Hat einmal diese Leiste ihre Verbindumg nit dem Schmelzorgan teilweise gelöst, oder zeigt sie andere Rückbildnngserscheinnngen, dann trifft man in einzehen Schnitten bisweilen nur sprossenartige Reste, welche lateral von der Zahnleiste ins Kieferepithel eindringen.

Tenn man nun alles, was auf die rudimentäre Zahndrüsenleiste oder die laterale Śchmelzleiste zurückzuführen ist, ans den angeblichen prälaktealen Befunden ansschaltet, dann glanbe ich, dab wenig mehr anch von den ontogenetischen Beobachtungen ïbrig bleibt, was zugunsten dieser Hypothese spricht. Und dadurch werden, wie ich meine, die Gebißprobleme zn viel einfacher und leichter verständlichen Anfঘaben znrückgeführt. 
Auf die eben gegebene Deutung der sogenannten prälaktealen Zahmanlagen muß ich jedoch sofort eine Ausnahme machen, nämlich was die Befunde betrifft. welche bei der ontogenetischen Entwicklung des Beutlergebisses genacht sind. Bekanntlich spielt das Gebiß der Beuteltiere in der Theorie der prälaktealen Dentition, infolge der Untersuchungen ron Kükenthal, Leehe, Carlsson, Röse, Woodward, Dependorf ı. a. eine hervorragende Rolle. Wenn man als Kriterinm einer Zahnanlage nicht jede willkürliche Epithelsprosse annimmt, sondern als solches eine wirkliche Zahnbeinentwicklung fordert, dann entspricht das Marsupialiergebiß wirklich dieser Bedingung. Denn wie aus den Untersuchungen der genamuten Forseher hervorgegangen ist, erscheinen wirklich labial von dem funktionierenden Gebiß der Beutler, das wohl dem Milchgebiß der übrigen Säuger homolog ist, in Verbindung mit rudimentären epithelialen Bildungen, kleine Zahnseherbehen welche jedoch bald wieler resorbiert werden. Hier haben wir somit unzweideutige Anlagen von Zähnen, labial von der ersten oder Milehdentition. Diese Beobachtıngen bilden seheinbar wohl das kräftigste Argument für eine prälakteale Dentition. Ich möchte jerloch die rudimentären Zahnscherbchen bei dieser primitiven Säugergruppe in anderer Weise deuten, indem ich geneigt bin, sie zu indentifizieren mit jenen rudimentären Zahnanlagen, welehe schon mehrfach bei den Reptilien nachgewiesen sind, und ebenfalls schon während der individuellen Entwicklung verschwinden, und welche ich in meinem Münchener Vortrag schon als cten ,Parastichos" des Reptiliengebisses unterschieden habe. Auf diesen wichtigen Punkt kann ich jedoch erst näher eingehen, wenn ich die Auseinandersetzıng meiner Ansichten ïber die Bedeutung der Dentition bei den Säıgetieren und ihre Beziehung zur Struktur des Reptiliengebisses gegeben habe.

Daß es bei Säugern ehemals mehr als zwei Dentitionen gegeben haben sollte, ist eine Ansicht, welche man besonclers von Anhängern der Konkreszenztheorie verteidigt findet, bei jenen rler Differenzierungstheorie findet man sie fast nicht. Unverständlich ist das nicht. Denn es bildet eine der hauptsächlichsten Hilfshypothesen der Konkreszenztheorie, daß die Verringerung vieler Zahngenerationen der Reptilien zu den wenigen der Säuger eben die Folge der Konkreszenz war. Von Hause aus trägt daher die Verwachsungstheorie einen viel komplizierteren Charakter, da hierin die Probleme der Formentwicklung des Zahnes aufs engste verknüpft worlen sind mit jenen des Zahnwechsels. Diese Konfusion von Problemen vermißt man bei der Differenzierungstheorie, Formbildungs- und Dentitionstheorien bleiben hierbei scharf getrennt. Daß solehes auch der Fall sein kann mit Anwendung des Konkreszenzprinzipes, wird im Laufe dieses Abschnittes noch klar werden. Denn ich habe im Obenstehenden nur auf einige sehwache Punkte der Konkreszenztheorie in ihrer jetzigen Form hinweisen wollen. DaB es mir fern liegt, das Verwachsungsprinzip zu verwerfen, ist selbstverständlich, die ganze vorliegende Arbeit hat gerade zum Zweck, die Entstehung des Säugerzahnes durch Verwachsung zu beweisen. Es ist nicht gegen das Prinzip, daß ich opponere, sondern gegen ihre Verwendung und Ausarbeitung. Es ist meiner Meinung nach die Hilfshypothese einer prälaktealen Dentition nur zum Schaden dieser Theorie gewesen, ebenso wie eine zweite Hilfshypothese, gegen welche ich mich jetzt wende. 
Es darf in den vorangehenden Hauptstücken der tatsächliche Beweis als erbracht betrachtet werden, dab der Säugerzahn durch Verwachsung entstanden ist. Aber nur durch Verwachsung von zwei Elementen; nur von zwei. Und auf diesen Punkt wïnsche ich besonders die Aufmerksamkeit zu lenken. Denn darin kommt ein weiteres Prinzip zum Ausdruck, worin ich von der geläufigen Vorstellumg der Konkreszenztheorie abweiche.

Schon bei einem der Antoren, welche zuerst die Konkreszenzhypothese aufgebaut haben, nämlich bei Ameghino. findet man die Ansicht ansgesprochen, daß jedem Höcker des Sängerzahnes einem einfachen Kegelzahn der Reptilien homolog gestellt werden muß. Diese Ansicht ist wohl als die zurzeit herrschende anfzufassen. Bisweilen - wie z. B. bei Kramberger - wird sie noch auf die Zahnwurzel ansgedehnt. Es kommt mir vor, daß diese Annahme einer der schwächsten Punkte der Konkreszenztheorie ist. Röse hat dieselbe dadurch zu stützen versucht, daßs er bei seinen Untersuchungen besonders die Entwicklıng der Zahmpapille verfolgte, um zu erforschen, ob dieselbe ein zusammengesetztes Gebilde sei. Nun ist es wohl merkwürdig, daß sowohl beim Menschen als beim Opossum der Autor bei den zusammengesetzten Zähnen ursprïnglich immer nur ,Zwei Papillen direkt nebeneinander gelagert und teilweise verschmolzen" fand (Anat. Anz., Bd. VII, S. 392 f.). Auch verweist der Autor nach der Untersuchung von Mahn (IIorph. Jahrb., Bd. XVI), woraus zu ersehen ist, daß anch beim zweiten Molaren der Nager ähnlich wie beim Menschen ursprïnglich nur zwei Papillen vorhanden sind. Diese Tatsache ist wichtig, denn sie stimmt mit der von mir nachgewiesenen Doppelnatur des Schnelzormanes ïberein. Erst später entwickeln sich, wie der Autor anführt, im Anschlnß an die definitive Form der Zahnkrone, ,die weiteren Nebenpapillen, bis so viele Unterabteilungen vorhanden sind als der ausgebildete Molar Hauptstïcke besitzt" (1. c. S. 396). Sehr kemnzeichmend ist es, daß der Autor hier von Nebenpapillen spricht. Dadureh erlangt das Auftreten zuerst von nur zwei Papillen, die nebeneinander gelagert sind, noch mehr Relief. Doch hat Röse diese Erscheinung nicht weiter beriicksichtigt, da er eine Entstehung wenigstens der Prämolaren $1 m$ l Molaren aus einer größeren Zahl von Einzelzähnen bevorsteht. Gleicher Ansicht war Ameghino, der schon vor Röse die Konkreszenztheorie formuliert hat und der Meinung war, es wären die postkaninen Zähne der Sänger durch Verwachsung von sechs Reptilienzähnen zustande gekommen.

Es will mir scheinen, daß die Auffassung, daß jeder Kronenhöcker emem kegelförmigen Einzelzahn der Reptilien entspricht, die Konkreszenztheorie in unerwïnschter Weise kompliziert und schwerer verständlich gemacht hat. Denn bei dieser Annahme muß nicht nur eine Verwachsung von Zähnen, zı verschiedenen Generationen gehörig, stattgefunden haben, wodurch die Vielhöckerigkeit in transversalem Sinne zustande kam, sondern daneben eine Verwachsung von Zähnen derselben Generation, wodurch der Zahn in sagittaler Richtung zusammengesetzt wurde.

Ich bin der Überzengung, daß es gar nicht notwendig ist, das Konkreszenzprinzip in so ausgedehntem Maße anzuwenden und daß in Wirklichkeit der Vorgang ein viel einfacherer gewesen ist. Meine Auffassung ist kurz die folgende. Ich denke mir den Säugerzahn 
entstanden durch Verwachsung von zwei Reptilienzähnen, welche zu zwei aufeinander folgenden Generationen gehören und wovon der eine, ältere, deshalb bukkal von dem zweiten, jüngeren gelegen war. Dadurch wurcle der Säıgerzahn mehrhöckerig in transversaler Richtıng, er wurde aus einem Protomer und einem Deuteromer zusammengesetzt. Diese Entstehungsweise gilt für alle Zähne des Gebisses, sowohl Frontzähne als Molaren. Ein prinzipieller Unterschied in der Entstehung der sogenannten Monocuspidaten und Multicuspidaten besteht nicht, die Formdifferenzen zwischen den Zähnen sind nicht die Folge von verschiedenartiger Konkreszenz, sondern die Folge der weiteren Differenzierung. Bis so weit steht meine Auffassung auf gesichertem Boden, es ist vorher nachgewiesen, daß alle Zähne, Incisivi sowohl als Molaren, ontogenetisch durch Konkreszenz zweier Elemente entstehen, und daB die Ontogenese der Molaren in nichts abweicht von jener der Incisivi. Nun denke ich mir weiter - und was jetzt folgt, ist nicht auf tatsächliche Beobachtung gegründet, sondern beruht auf anatomischen Erscheinungen, welche man am Reptiliengebiß wahrnimmt - daß die beiden Elemente, aus deren Verwachsung der Säugerzahn entstanden ist, nicht einfache Kegelzähne waren, sondern schon mehrspitzig. Und zwar denke ich dabei an jene Form, die man nicht selten bei den Reptilien antrifft, nämlich die dreispitzige oder trikonodonte. Das Resultat der Verwachsung war somit in schematischer, idealer Form ein Zahn, der auf clen Kronenflächen zwei Reihen von drei Höckern trug, eine bukkale und eine linguale. Die Kompliziertheit des Säugerzahnes in Längsrichtung ist meiner Ansicht nach ein Erbstiick der reptilienähnlichen Stammformen.

Es war, wie ich meine, eine schwach begründete Annahme der früheren Konkreszenztheoretiker, die Verwachsung so intensiv sich zu denken und als Grundelement eines Säugerzahnes einen kegelförmigen Zahn zu postulieren. Es schwebte dabei als Grundform wohl ein wenig zu viel das haplodonte Gebiß der Krokodile vor dem Geist. Der kegelförmige Reptilienzahn ist zwar in seiner Gestalt der denkbar einfachste, aber in seinem Auftreten muß auch diese Form als Anpassungsprodukt an eine spezielle Funktion betrachtet werden. Kegelförmige Zähne trifft man überall da, wo die Beute nur ergriffen zu werden braucht; es sind vorzïgliche Hilfsapparate bei der Greiffunktion der Kiefer. Daregen trifft man, wo nicht nur Ergreifen, sondern auch Beißen und Zerschneiden der Beute vorkommt, mehr abgeplattete, seitlich komprimierte Zähne mit einer scharfen Kante, einer wahren Schneide ausgestattet. Solche Zähne, in einer geschlossenen Reihe stehend, sind vorzüglich instande, in die ergriffene Beute einzuschneiden. Rein haplodonte Gebisse, nur aus Kegelzähnen zusammengesetzt, trifft man hauptsächlich bei Reptilien mit einer verlängerten Schnauze, besonders den Krokociilen. Hier hat sich die Form der Zähne vorzüglich an den Greifakt angepaßt. Auch ihre stärkere Befestigung in den Kiefern ist wohl als eine Anpassungserscheinung von gleicher Bedeutung zu betrachten. Bei kurzschnäuzigen Reptilien kommen derartige einfache Zahnformen weniger vor. Nur jene, welche im Prämaxillargebiet stehen und ihre Gegenzähne im Unterkieter, also im allgemeinen die Frontzähne, besitzen noch meistenfalls eine konische Gestalt, die nach hinten folgenden nehmen dagegen mehr die abgeplattete Form an. Rein haplo- 
donte Gebisse gibt es bei den kurzschnäuzigen Reptilien viel weniger. Man kann mu öfters konstatieren, daß die Schneide dieses abgeplatteten Zahnes sich lompliziert, mehrspitzig wird. Es würde zı weit führen, in dieser Arbeit anf Einzelheiten einzugehen und ich beschränke mich auf die Bemerkung, dab der dreispitzige Zahn in dem mehr hinteren Abschnitt des Gebisses bei den rezenten Reptilien eine ziemlich verbreitete Form darsiellt. Es ist mir weiter wahrscheinlich geworden, dab anch das Krokodilengebiß erst sekundär ein rein haplodontes geworden ist, vielleicht wohl infolgc einer phylogenetisch erfolgten Verlängering der Kiefer. Es sind doch die hinteren Zähne dieser Reptilien bei ihrer ersten Anlage im Querschnitt weniger rund, und die kleinen Zähnchen, welche noch während der Embryonalperiode zugrunde gehen und zuerst von Röse beschrieben worden sind. haben sogar eine stark abgeplattete Form.

Es liegt somit meiner Meinung nach kein zwingender Grund ror, ım die Sängerzähne durch Verwachsung von Kegelzähnen entstanden zu denken, und ebensowenig - aber daranf komme ich unten noch ausführlicher zurïick - 1 m dem Säugetiergebiß ein rein haplodontes Reptiliengebiß als Ausgangsform zu geben. Bei den mehr spezialisierten und differenzierten Reptiliengebissen tritt der trikonodonte Zahn so häufig, um nicht zu sagen regelmäßig, auf, daß es mehr wahrscheinlich ist, daß dieser Zahn den Ausgangspunkt des Säugerzahnes bildete als der kegelförmige. Es wird anch durch diese Annahme - für welche auch paläontologische Befunde das Wort zu reden scheinen - die Konkreszenztheorie wieder zı einer viel einfacheren Form zurückgeführt und mit den ontogenetischen Befunden in Übereinstimmung gebracht. Denn wir finden bei den Zähnen des Mammaliengebissen während der Entwicklung nur die Spuren einer eimmaligen Verwachsung von zwei nebeneinander liegenden Elementen. Von einer Konkreszenz in longitudiualer Richtmng fehlt jede Spur.

Nun erhebt sich gleich die Frage, wie ist dem die trikonodonte Form des Reptilienzahnes entstanden? Wir stehen hier vor dem nämlichen Problem wie beim Sängerzahn: entweder Differenzierung oder Konkreszenz. Röse ist der Meinung, claß der trikonodonte Zahn der Reptilien (z. B. bei Chamaeleon) durch Verschmelzung von drei Kegelzähnen zustande gekommen ist. Auch von den gelegentlich vorkommenden zweispitzigen Amphibienzähnen glaubt er , annehmen zu dürfen, daß anch diese Zähne ursprünglich durch Verschmelzung von zwei cinfachen Kegelzähnen entstanden sind" (Anat. Anz., Bol. VII, S. 399). Von den Amphibienzähnen habe ich keine Erfahrung, aber was die mehrspitzigen Reptilienzähne betrifft, muB ich eine Entstehung durch Verwachsung unbedingt von der Hand weisen. Ich habe bei meiner Untersuchung über die Entwicklung des Reptiliengebisses sclbstverständlich dieser Frage besondere Aufmerksamkeit gewidmet. Und es ist mir dabei keine einzige Erscheimng begegnet, welche für eine Verwachsumg von mehreren Zähnen zu einem zusammengesetzten zeugt. Anfänglich sind die Nebenspitzen reine Dentinformationen, erst später bekommen sie - und nicht einmal immer - eine kurze eindringende Tebenpapille. Aber weder an der generellen Zahnleiste, noch im Schnclzorgan ist anch nur die geringste Andentung bei der Anlage und während der weiteren histologischen Differenzierung zu sehen, welche den Gedanken an eine vorangehende Verwachsung 
wachruft. Und diese Tatsache ist schwerwiegend, wenn man bedenkt, daß bei der Entstehung des Säugerzahnes die Beweise der Verwachsung ver zwei Elemente sich so vorzüglich äußern.

Die Trikonodontie der Reptilienzähne als die Folge von Verwachsung anzusehen, ist somit eine durch nichts begründete Hypothese, welche durch die Ontogenie als höchst unwahrscheinlich, um nicht zu sagen unrichtig, gekennzeichnet wird. Es ist der dreispitzige Zahn, der gewöhnlich gleichzeitig mehr oder weniger abgeplattet ist, als eine Differenzierung des Einzelzahnes zu betrachten, als eine der schneidenden Funktion des Gebisses angepaßte Gestalt. Dafür spricht z. B. noch der Umstand, daß die Zahl der Nebenspitzen nicht immer anf zwei beschränkt bleibt. Es kann die Schneide des Zahnes mit einer größeren Zahl feiner Spitzen ansgestattet sein. In einer folgenden Arbeit hoffe ich auf diese Erscheinungen ausführlich einzugehen.

Fasse jch jetzt das Obenstehende kurz zusammen, dann kommt also neine Auffassung über die Bezichung des Säugerzahnes zu dem Reptilienzahn im allgemeinen (über Besonderheiten siehe weiter unten) anf folgendes zurïck. Der Sängerzahn ist entstanden clurch Konkreszenz. Das ist durch den Inhalt der vorangehenden Hauptstücke wohl als cine gesicherte Tatsache zu betrachten. Es ist für jeden Zahn welcher Form er in erwachsenem Zustande anch sein darf und welche Stelle er im Gebif eimnehmen darf - nur eine eimmalige Konlireszenz zweier Elemente anzunehmen; es ist der Zahn ein dimeres Gebilde. Diese Elemente sind zwei aufemander folgender Generationen cles Reptiliengebisses homolog, der Protomer des Säugerzahnes entspricht der älteren Generation, der Deuteromer der jüngeren. Auch das ist durch die vorher mitgeteilten Beobachtungen aus der Ontogenie des Sängerzahnes und der Vergleichung mit der Enwicklung des Reptiliengebisses wohl als festgestellt zu betrachten, ebenso wie die Tatsache, daß jede Andentung einer Verwachsung in longitudinaler Richtung fehlt. Es ist also jeder Säugerzahn zwej Reptilienzähnen homolog. Daß hierbei stillschweigend die Zälne von Edentaten, Cetacaeen, Monotremen und des Elefanten außer den Kreis unserer Betrachtung gestellt werden, braucht kaum besonders erwähnt zu werden. Durch diese Verwachsung kam die Mehrhöckerigkeit des Zahnes in transversalem Simne zustande. Jene in longitudinaler Richtung ist nicht die Folge von Konkreszenz, diese wurde dadurch ins Leben gerufen, daß die die Verschmelzung eingehenden Elemente nichi einfache Kegelzähne oder nonokuspidate waren, sondern schon mehrspitzig. Diese Mehrspitzigkeit war nicht die Folge ven Verwachsung, sondern von Differenzierung. Die Mehrhöckerigkeit in transversaler Richıng ist somit vom Säugerzahı erworben, jene in longitudinaler Richtung ist von den reptilienartigen Stammformen ererbt worlen. Meine Theorie, welche als die ,DimerTheorie ' des Säugerzahnes zu bezeichnen ist, nimmt somit eine Mittelstelle zwischen Differenzierungs- und Konkreszenztheorie ein.

Ich werde jetzt auf ein paar Punkte eingehen, welche wieder das Gebiß als Ganzes betreffen, und zwar auf die Entstchung der Heterodontie und die Beziehung zwischen dem Zahnwechsel der Reptilien und jenem der Säugetiere.

Es ist früher schon darauf hingewiesen, daß man bei den Betrachtungen über die Umbildung des Gebisses dem heterodonten Gebiß der 
Sängetiere gem ein haplodontes Reptiliengebiß gegenüberstellt, und ein derartig gebautes Gebil als die primitivste Ausgangsform des Sängergebisses anffaßt. Die Ansicht vertreten sowohl Anhänger der Konkreszenztheorie als der Differenzierungstheorie. So weist Osborn öfters auf den Zahnban der Delphinen hin, dessen haplodontes Gebiß er als diese ursprïngliche Form des Sängergebisses anführt (vol. Evolution of Mammalian Molar Teeth, S. 64)'). Daß es sich bei diesen Formen jedoch $u m$ eine Anpassungserscheinumg handelt, $и m$ eine sekundär entstandene Form, ist wohl zweifellos, und durch die Untersuchungen Kükenthals über die Entwicklung des Walengebisses hinlänglich festgestellt. Osborn selber ist ebenfalls dieser Ansicht (l. c. S. 191), dürfte aber dann anch nicht solche Gebisse als die Urform des Sängergebisses vorstellen. Diese ideale haplodonte Ausgangsform des Sängergebisses scheint mir von den Begründern beider Gebißentwicklungstheorien dem Prinzip ihrer Theorie zu Liebe postuliert zı sein. Denn Sängetiere mit einem primären haplodonten Gebiß sind bis jetzt umbekannt. Und das darf kaum wumdernehmen. Denn auch bei den Reptilien trifft man rein haplodonte Gebisse nicht allzu häufig an. Es macht sich gewöhnlich eine allmählich nach hinten fortschreitende Spezialisierung der Zähne bemerkbar, sie werden größer und die Spitze wird mit Einkerbungen versehen. In den letzten Jahren ist num von mehreren Seiten die Aufmerksamkeit auf die merkwürdige Gruppe der Theriodontien, und die Bedentung dieser Gruppe als die vermutliche Stammform der Säugetiere gelenkt worden. So sagt Osborn in seinem oben zitierten Sammelwerk ïber die Entstehmng der Säugermolaren auf S. 9: ,The reptilian cone origin theory has recently gained strength by the very general admission that the Theriodont reptiles are at least nearly ancestral to the mammals." Es liegt in clieser Behamptung eine Überschätzung der Beweiskraft für die Differenzierungstheorie. Es können die Gebisse der Theriodontien nur angeführt werden als Beweis, daß die trikonodonte Zahnform, welche hier nicht selten ist, in irgendwelcher Weise zu den Zähnen der Mammalien in Beziehung steht, und weiter der Beweis, daf. die Trikonodontie nicht infolge von Verwachsung, sondern durch Differenzierung entstanden ist. Zu letzterer Ansicht sind wir anch anf Grund unserer ontogenetischen Untersuchungen gelangt. Aber es sind diese Zähne doch immer nur in Längsrichtung mehrspitzig, daß die Kompliziertheit der Säugerzähne in transversaler Richtung durch Differenzierung entstanden sei, das vermögen die Gebisse der Theriodontien nicht zu beweisen. An diesem Punkte divergieren die Ansichten von Cope-Osborn mol die meinigen, und zwar am schwächsten Punkte ihrer Theorie. Denn hier müßten die amerikanischen Forscher eine Verschiebung der Höcker gegeneinander postulieren, wofür genügende Beweise fehlen, während meiner Heinung nach hicr das Konkreszenzprinzip Geltung hat, wofür die enbryologischen Beobachtungen die unzweideutigen Beweise gebracht haben.

Auch von Fuchs ${ }^{2}$ ) ist neuerdings die enge Verwandtschaft der genannten Gruppe zu den Säugetieren betont worden, vornehmlich auf

1) New York 1907. Nac Millann Co.

2) H. Fuchs, Über die Beziehungen zwischen den Theromorphen Copes bzw. den Therapsiden Browns und den Säugetieren, erörtert auf Grund der Schädelverhältnisse. Zeitschr. f. Morph. u. Anthr., Bd. XIV, S. 36-. 
Grund von vergleichend-anatomischen Untersuchungen am Kopfskelett, eine Ansicht, der sich weiter Bluntschli ${ }^{1}$ ) angeschlossen hat. Auch dieser Autor faßt diese Gruppe als für den Ursprung der Säıgetiere am meisten in Frage kommende auf.

Es ist nun für die Anschaunngen über die Herkunft der Zahnformen der Säıger von der größten Bedeutıng, daß diese Gruppe eine bisweilen hochgradige Spezialisierung des Gebisses aufweist. Nicht selten ist das Gebiß deutlich ans einer präkaninen und postkaninen Reihe zusammengesetzt, welche voneinander durch einen bisweilen einem Säugereckzahn ähnelnden, stark hervortretenden Caninus getrennt sind. Besonders bei den Cynodontia, welehe auch, wie Fuchs hervorhebt, in anderen Beziehungen sich am meisten den Säugern nähern, ist die Differenzierung des Gebisses bisweilen sehr weit fortgeschritten.

Man braucht dann auch, wie ich in Übereinstimmung mit Fuchs meine, an der Wurzel des Sängetierstammbanmes sich keine Form zu denken mit einem haplodonten Gebiß, vielmehr spricht dafür, daß Heterodontie schon von den reptilienartigen Vorfahren auf die Säugetiere vererbt worden ist. Aber die Erscheinung gelangte bei den Säugetieren zu einer viel schärferen Ausprägung, und die Möglichkeit dazu wurde gerade durch die Entstehung des Sängetierzahnes durch Zusammenschmelzung zweier Reptilienzähnen von aufeinanderfolgenden Generationen gegeben. Denn wenn einmal diese Verschmelzung zustande gekommen war, konnte die Differenzierung und Spezialisierung auf dem vielhöckerigen Gebilde, das jetzt entstanden war, sich viel reichlicher entfalten und die Heterodontie immer mehr akzentuieren.

Und wenn ich mun die Resultate meiner Untersuchungen am laktalen und permanenten Primatengebiß von diesem Gesichtspunkte aus betrachte, dann erscheint mir, wie gesagt, dasselbe zurückzuführen. zu sein auf eine Grundform, worin die präkaninen sowohl als die postkaninen Zähne trikonodont waren, so daß jeder Zahn dieses Gebisses einen sechshöckerigen Urzahn zum Prototyp hat. Für den Caninus habe ich keine sichere Andeutungen gefunden, dab derselbe aus einer wirklichen mehrspitzigen Grundform liervorgegangen sein sollte, es ist zwar auch ein Doppelgebilde, aber wie es mir scheint, von rein kegelförmigen Elementen. Latent kann jedoch das Vermögen Nebenspitzen zu bilden sehr gut auch in diesen Zahn anwesend sein.

Nın würde man natürlich umsonst bei jedem Zahn des Primatengebisses die ursprüngliche Grundiorm nachzuweisen hoffen; ein einziger Blick auf das Gebiß eines beliebigen Primaten oder eine nur oberflächliche Vergleichung der Molaren einiger Primaten genügt, um sich von der starken Metamorphosierung zı überzengen, welche die einzelnen Zähne im Laufe der Entwicklıng unterlegen waren. Nur ausgiebige vergleichend-anatomische Untersuchungen machen es möglich, um zı entscheiden, in welcher Weise jeder Zahn infolge von Reduktion und Verlust von Spitzen oder Höckern von der Grundform sich entfernt hat. Dazı kommit, daß bei den Frontzähnen der Deuteromer des Zahnes immer nur in sehr stark reduzierter Weise als das sogenannte Tuberkulum anwesend ist, was als eine Anpassung an die Funktion zu betrachten ist.

1) H. Bluntschli, Zur Plyylogenese des Gebisses der Primaten und Ausblicke auf jenes der Säugetiere überhaupt. Vierteljahrschr. d. Naturf.-Gesellsch. in Zürich, Jahrg. 56. 
Es liegt ganz anBerhalb des Rahmens dieser Arbeit, welche nur die Gebißproblene im allomeinen zum Gegenstand hat, eine vergleichend-anatomische Betrachtung des Primatengebisses, vom von mir eingenommenen Standpunkt aus, zu geben. Ich beschränke mich an dieser Stelle darauf, meine Ansicht kemnen zu lernen. In der zweiten dieser odontologischen Studien hoffe ich, die Anatomie des Primatengebisses ron diesem Standpunkt aus zu bearbeiten. Nur möchte ich noch einmal hervorheben, daß diese Ansicht nicht eine aprioristische ist, sondern eine, wozu ich durch Vergleichung gekommen bin.

In Abweichung von der Differenzierungstheorie komme ich somit bezüglich des Entwicklungsganges zil einer gerade entgegengesetzten Anschanung. Während es der Hauptgedanke jener Theorie ist, eine Vermehrung der Zahnhöcker bis höchstens sechs innerhalb der Sängetierreihe anzunehmen, welche dann von einer Verringerung gefolgt sein kann, wobei dieser Vorgang auf den postkaninen Zähnen beschränkt bleibt, denke ich mir die maximale Zahl der Höcker gleich an Anfang anwesend, und weiter besteht kein prinzipieller Unterschied zwischen post- und präkaninen Zähnen. Alle Zähne sind von einer sechshöckerigen Grundform ableitbar. Im Laufe der weiteren Entwicklnng hat nur Verringerung der Höcker stattgefunden. Diese Verringerung kommt auf zweierlei Weise zustande, durch wirkliche Regression eines Höckers oder durch Verschnelzung zweier Höcker. Jener Zahn ist somit am primitivsten, der die größte Zahl der Höcker anfweist, und jene Form ist die ursprünglichste, bei der die Sechshöckerzahl der Zähne noch am reinsten vorhanden oder am dichtesten genähert ist.

Dieser Gedanke ist bekanntlich gar nicht net. Im allgemeinen wird er ron den Anhängern der Konkreszenztheorie geteilt mnd ist öfters ausgesprochen worden. Fast identisch mit der vou mir verteidigten Anschaumng ist jene von Ameghino, der ebenfalls unter Hinweis auf die MLolaren von Proteodidelphys den sechshöckerigen Zahn als die meist prinitive Form der Säugermolaren auffaßt. Ich weiche jedoch in zwei Punkten von diesem Konkreszenztheoretiker ab, nämlich wenn er diesc Form seines ,plexodonten" Zahnen durch Verwachsung von sechs Einzelzähnen zıstande kommen läßt, nnd wenn er einen Gegensatz zwischen postkaninen und präkaninen Zähnen macht.

Auch durch Forsyth major wird ein vielhöckeriger Zahn als die Urform des Säugerzahnes angesehen.

Von dem von mir eingenommenen Standpunkt betrachtet, erleiden die Gebißprobleme eine wesentliche Tereinfachung. Erstens wird dadurch der Gegensatz zwischen den präkaninen und postkaninen Zähnen hinfällig, die Elemente beider Abschnitte des Gebisses sind potentia ron gleicher Zusammensetzung, dic Anpassung an dic Funktion ist der alleinige Faktor, der die Formdifferenz geschaffen hat, und nicht eine Verschiedenheit in der Herkunft. Der Gegensatz zwischen einfachen und zusammengesetzten Zähnen im Gebiß der Säuger hat nur für die erwachsene Form und nicht für die Genese Bedeutung. Es soll damit nicht gesagt sein, daß bei den Stammformen der Primaten jemals Gebisse existicrt haben, welche ganz ans molarenähnlichen Zähnen aufgebant waren, denn schon bei den reptilienähnlichen Vorfahren war die Formdifferenz zwischen Frontzähnen und hinteren Zähnen anwesend, und die Entstehnug des Säugerzahnes durch Verwachsung von zwei solchen Reptilienzähnen akzentuiert, wie schon 
gesagt worden ist, dieselbe in hohem Maße. Wohl niemals wird diese Verwachsung zur Folge gehabt haben, daß die schneidende Funktion der Frontzähne eingebüßt wurde, der Deuteromer ist bei den Incisivi, wohl nicht immer, aber doch meistenfalls sehr rudimentär entwiekelt.

Eine weitere Vereinfachung erleidet von meincm Standpunlite aus das Gebißproblem noch bezüglich der Frage, welehe Zähne als primitiver zu betrachten sind, die Milchmolaren oder die diese ersetzenden Prämolaren. Diese Frage ist für mich als gegenstandslos zıl betrachten. Beide Formen sind von der identischen Urform abzuleiten, aus leicht zu durchschanenden Ursachen haben jedoeh die Milehmolaren diese Urform, die sich besser für ihre Funktion eignet, reiner konserviert als die Prämolaren. Das Studium der individuellen Variationen des Kronenreliefs letztgenannter Zähne beim Mensehen bringt jedoch merkwürdige Erscheinungen ans Licht, welche durch die von mir verfochtene Ansehanıng selbstverständlich erscheinen. Übrigens hat Leche schon betont, daß die Zähne der ersten Dentition Merkmale fossiler Vorfahren bewahrt haben. In der Deutung dieser Tatsache gehen jedoch unsere Ansichten auseinander.

Ich kann die Besprechung dieses Gegenstandes nicht absehließen ohne die folgende Frage noch kurz berührt zu haben.

Wenn ich als Grundform des Primatenzahnes den Sechshöckerzahn ansehe, dann möchte ich vorläufig diese Ansicht auf die Primaten (einschließlich die Prosimiae) beschränken. Nur von dieser Gruppe kenne ich anf Grund eigener Untersuchungen die Anatomie des Gebisses. Von den Gebissen der übrigen Säugerordnungen habe ich zurzeit noch zu wenig Detailkenntnis, um das oben genannte Prinzip auch dafür geltend zu machen. Damit soll nicht gesagt sein, daß auch bei den übrigen Säugern Übereinstimmendes nicht vorkommt. Ich erinnere daran, daß vorher nachgewiesen wurde, daß anch bei den meist verschiedenen Säugetieren der Zahn wie bei den Primaten durch Konkreszenz zweier Zähne entstanden sein mul. Aber fraglich bleibt es, ob bei allen Säugerordunngen die, die Verwachsung angehenden Elemente, alle eine dreispitzige Schneide besäßen, wie es bei den Stammformen der Primaten der Fall gewesen sein muß, und weiter ob der Deuteromer (der Zahn der jüngeren Generation) nicht bisweilen in ganz rudimentärer Weise mit dem Protomer verwachsen ist, auch bei postkaninen Zähnen, wie es bei den Primaten nur bei den präkaninen der Fall gewesen ist. Ich möchte somit vor einer Generalisierung, welche nicht auf spezieller Untersuchung beruht, warnen.

Und ich finde je mehr Anlaß dazu, weil die jetzt wohl allgemein angenommene verwandtsehaftliche Beziehung der Säugetiere zu den Theriodontien für die Herkunft der verschiedenen Formen des Säugetiergebisses eine breitere Basis schafft. Wie früher betont worden ist, liommt bei diesen fossilen Reptilien ein bisweilen schon hochgradig differenziertes Gebiß vor. Aber weder die Differenzierung noch die Form der Zähne beantwortet bei allen Repräsentanten clieser Gruppe an einem einzigen Muster. Es gibt hier schon sehr weit auseinandergehende Verschiedenheiten. Diese werden wohl zum Teil dureh die Art der Nahrung und die in Verbindung damit stehende Bewegungsart der Kiefer in Beziehung stehen Ietzteres Moment ist besonders von Bluntschli herangezogen worden. Eine gemeinschaftliche Urform für die Gebisse sämtlicher Säuger annehmen zı wollen, scheint mir eine 
nicht notwendige Hypothese. Es kommt mir wahrseheinlicher vor, daß die Divergenz der GebiBarten der Sängetierordnungen schon bei den reptilienähnlichen Vorfahren der Säuger angebahnt war, $1 \mathrm{~m}$ bei den Mammalien selber immer weiter fortzuschreiten. Es brauchen somit nicht immer gleichförmige Elemente gewesen sein, welche bei der Entstehıng der Säıger miteinander verschnolzen, ım den Säıgerzahn zu bilden. Und die Verschiedenheiten zwischen den homologen Zähnen der Sängergebisse können somit schon in der Differenz der Zähne der reptilienartigen Stammform der verschiedenen Ordnungen wureln.

In dieser Ansicht kommt jedoch nur eine Meinung zum Ausdruck, welche nicht durch tatsäehliche Untersuchungen in dieser Richtung gestützt wird.

Wit dieser Bemerkung möchte ich meine Betrachtung über die Heterodontie des Gebisses abschließen und werde ich anf das zweite große Gebißproblem eingehen, nämlich jenes des Zahnwechsels.

Es gibt wohl kaum eine morphologische Frage, welche zu sc vielen einander widersprechenden Meinmngen Anlaß gegeben hat, als die Erscheinung des Zahnwechsels. Eine Übersich der darauf Bezug habenden Theorien folgen zu lassen. kommt mir überflüssig vor, dla ich bezüglich - dieses Problems an lieiner der bis jetzt veröffentlichten Meinmngen anknüpfe, sondern anf einem prinzipiell verschiedenen Standpunkt stehe. Den sich für diese Frage interessierenden Leser kann ich zu einem raschen Überblick über lie Theorien auf das bekannte Referat von Schwalbe verweisen ${ }^{2}$ ). worin die verschiedenen Ansichten in vorziiglicher Weise dargestellt sind. Nur ein paar allgemeine Bemerkungen finden hier einen Platz.

Es ist ganz richtig, wenn Kükenthal in seiner Untersuchung ïber die Entwicklungsgeschichte des Pinnipediergebisses ${ }^{2}$ ) bemerkt, daß die vielen Widersprüche, welchen man in der Literatur begegnet, auf die große Tnsicherheit der Grindanschanungen zurïckzuführen sind. Doch ist das wohl nicht die einzige Ursache. Nicht wenig hat zu der Vielseitigkeit der Meinungen die Tatsache beigetragen, daß man zwei fundanental versehiedene Gebißprobleme miteinander verbindend, diese gleichzeitig zu lösen versuchte. Ausgehend ron der Ansicht, daß der Zahnwechsel der Reptilien und jener der Säugetiere identische Erscheinungen sind, war man bestrebt, eine Beziehung ausfindig zu machen zwischen der Verringerung der Dentitionen nud der Zahnzahl bei den Säugetieren und der komplizierten Form der Zähne dieser Gruppe. Besonders stellte man dabei die vielhöckerigen postkaninen Zähne den einfacher gestalteten Frontzähnen gegenüber. Diese Verknüpfung von fundamentell verschiedenen Erscheinungen miteinander hat Anlafo gegeben zu einem solchen Reichtum von individuellen Ansichten, Meinungen und Erklärungen, wie sich kaum anf einem anderen Gebiet der vergleichenden Morphologie findet. Nicht wenig hat der oben genannte Autor selber und anch in der zitierten Abhandlung zu diesen zahlreichen Meinungsdifferenzen beigetragen. Demn seine Befunde gaben den Autoren Anlab zur Behauptung, daß im Lanfe der Entwicklung des Gebisses (von Phoca) nicht nur die beiden mit erster und zweiter Dentition anderer Sängetiere zu homologisierenden Dentitionen auftreten,

1) Verhandl. der Anat. Gesellschaft 1894.

2) Jenaische Zeitschrift, Bd. XXVIII. 
sondern in der ersten Anlage können vier aufeinander folgende Dentitionen vorhanden sein. Eine von den beiden akzessorischen Dentitionen dokumentiert sich als ein starker Epithelsproß, welcher nach außen von der Milchbezahnung abgeht ınd ein kolbenförmiges Ende besitzt. Der Autor deutet letzteres wieder als die letzten Reste einer ehemaligen, bei den Sängetieren geschwundenen Zahnreihe, als eine prälakteale Dentition. Gegenüber der Lehre einer prälaktealen Dentition bei Plazentaliern habe ich schon früher Stellung genommen. Ein Teil der Angaben über eine solche Dentition beruhen auf Beobachtung von Teilstücken der lateralen Schmelzleiste, welche ein essentieller Bestandteil jeder Zahnanlage ist, und mit einer eventuellen Vormilchzahnreihe nicht in Beziehung steht, sondern die Folge ist von der Entstehung des Säugerzahnes aus zirei Reptilienzähnen. Jedenfalls geht aus der Kükenthalschen Untersuchung hervor, daß diese Doppelnatur des Sängerzahnes auch bei den Phociden besonders deutlich sich verrät.

Es hat bei den Plazentaliern wohl niemals mehr als zwei Dentitionen gegeben. Denn auch die Annahme einer vierten, sogenannten postpermanenten, beruht auf keinem ausreichenden Grund. Kükenthal wie Leche basieren die Möglichkeit einer solchen Dentition anf das sogenannte freie Zahnleistenende, das beim Abschnüren der Zahnanlage von der Zahnleiste auftritt. Ich kann mich dieser Meinung nicht anschließen, weil hierbei Zahngeneration der Reptilien und Dentition der Säugetiere als zwei identische Erscheinungen aufgefaßt werden, was meiner Meinung nach nicht der Fall ist. Über die Bedeutung des reifen Zahnleistenendes komme ich noch zu sprechen, denn meine Auffassung darüber wird allerdings erst verständlich sein, nachdem ich meine Ansicht über die Beziehung zwischen dem Zahnwechsel der Reptilien und jenem der Säuger auseinandergesetzt habe.

Wie schon gesagt, bin ich der Auffassung, daß die beiden Gebisse der Säugetiere nicht den Zahngenerationen der Reptilien entsprechen, sondern eine essentiell andere Erscheinung sind, welche aber zum Schlusse auf die Struktur des Reptiliengebisses zurückzuführen ist. Schon auf der Anatomenversammlung zu München habe ich meine diesbezïgliche auf anatomische Befunde begründete Ansicht ausgesprochen. Der Vollständigkeit halber, und um in dieser Arbeit meinen Auffassungen über das Säugergebiß in möglichst abgerundeter Form Raum zu geben, werde ich auch hier diese Herkunft der Dentitionen bei den Säugern, wie ich mir dieselbe denke, auseinandersetzen.

Das Kiefergebiß der Reptilien besteht aus einer bisweilen großen Anzahl ein- oder mehrspitziger Zähne, welche öfters ungleich groß, und in einer einzigen Reihe mit dem Kiefer verwachsen oder in Alveolen eingefaßt sind. Ein Gebiß, das nur aus einer einzigen Reihe von Zähnen besteht, möchte ich als ein ,monostichisches"unterscheiden, im Gegensatz zu solchen, wo - wie bei Fischen und Amphibien es öfters der Fall ist - die Zähne in mehreren Reihen nebeneinander vorkommen. Eine solche Gebißform ist als ,polystichisch" zu bezeichnen. Dem Anschein nach ist nun das Reptiliengebiß ein monostichisches. Wenn man jedoch die Untersuchung nicht auf das fertige Gebiß beschränkt, sondern die Anlage desselben untersucht, dann erscheint es in einem etwas anderen Licht, und bekommt man eine andere Auffassung über seine Struktur. Denn dann wird es deutlich, daß die Anordnung sämt- 
licher Zähne in einer einzigen Reihe bei den Reptilien keinen primären Zustand darstellt, sondern erst im Lanfe der Ontogenie zustande kommt. Auf die generelle Zahnleiste werden die Zähne nicht in einer einzigen Reihe angelegt, sondern sehr dentlich in zwei. Die eine derselben ist der Ansatzstelle der generellen Zahnleiste an Kieferepithel mehr genähert. Die Anschwellnng, welche die erste Andeutung des sich
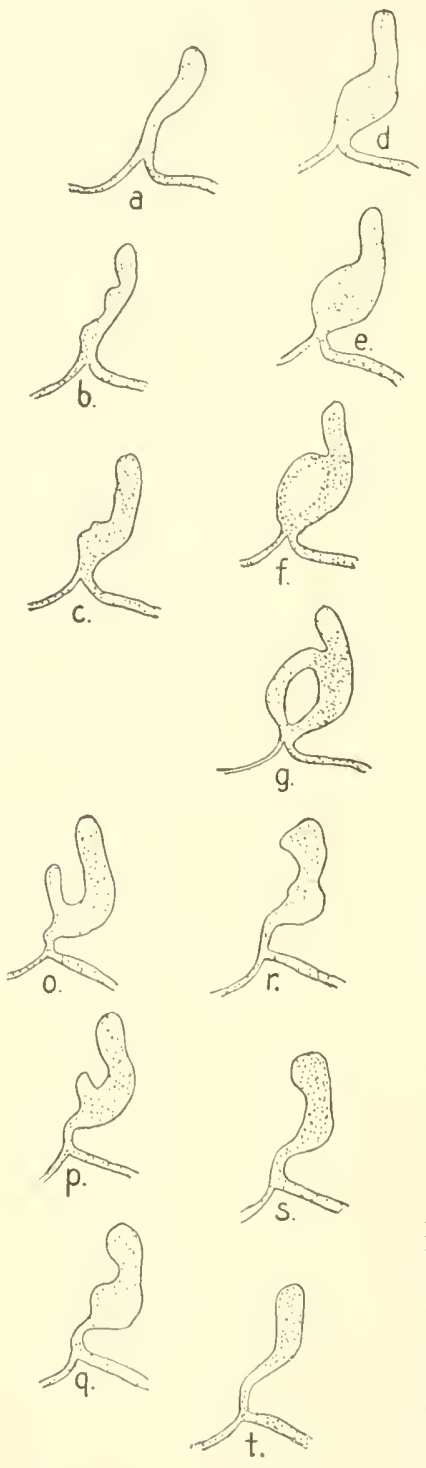
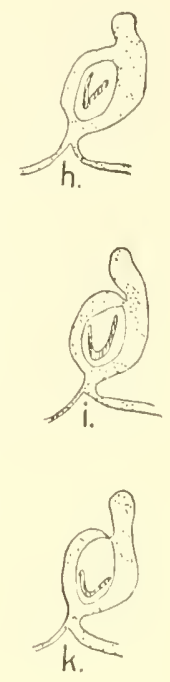

Fig. 69. Crocodillus porosus. Anlage eines Zahnes des Exostichos. ent wickelnden Schmelzorganes darstellt, liegt in der Kontinuität der Leiste, und wölbt sich bukkal vor, während die Zahnpapille auch von dieser Seite in das jumge Schmelzorgan einwuchert. In Wirklichkeit ist der Vorgang ein etwas anderer, da bei den Reptilien die Zahnleiste viel stärker als bei rlen Sängetieren den Charakter einer

Doppellamelle trägt. und die Glockenform des Schmelzorganes dureh Einfaltung der Leiste zustande kommt. Das Schmelzorgan der Reptilien ist dlann auch dem gleichnamigen Organ der Sängetiere nicht homo$\log$, denn das primäre Organ, oder die primäre Zahnanlage der letzteren umfaßt zwei Schmelzorgane der Reptilien und dazı ein Stiick cler generellen Zahnleiste. Eine eintache Vergleichung der Organe bei beiden Vertebratengruppen lehrt dann anch unmittelbar den selir verschiedenen Charakter kennen; bei den Reptilien erscheint die erste Anlage des Organes als eine einfache Einstiilpung der generellen Zahnleiste, bei den Säıgetieren kommt es zunächst zur Anlage eines kompakten birnförmigen Gebildes. Aber das sind für die jetzt verfolgte Frage nur Nebensachen. Kehren wir wieder zur Topographie der Zahnanlagen zurüek. Die Organe der zweiten Reihe entwickeln sich an freien Rande der Leiste, und besonders bei diesen Anlagen ist es evident, daß die Einfaltung der Anlagen zum glockenförmigen Stadium gar nicht dureh die Zahnpapille bedingt wird, 
denn die Einfaltung findet statt, wenn von einer Zahmpapille noch nicht die geringste Spur zu sehen ist. Auch hierin kommt wieder der mehr primitive Charakter vom Schmelzorgan zum Ausdruck.

In den Figuren 69 u. 70 gebe ich zwei Schnittserien durch die beiden Formen von Anlagen eines Embryo vou Crocodillus porusus. In Fig. 69 ist eine lückenlose |Serie durch eine ,,parietale“, in Fig. 70 eine solche durch eine terminale Anlage gegeben.

Bei der ersten Gebißanlage liegen somit die Zähnchen nicht in einer einzigen Reihe, sondern in zwei; das Gebiß ist daher in seinem Wesen kein monostichisches, sondern ein ,distichisches". Diese beiden Reihen sind am zweckmäßigsten als, Exostichos" und Endostichos" zu unterscheiden, denn bei den jüngeren Embryonen der Reptilien hat die generelle Zahnleiste meistenteils eine ausgesprochene horizontale Lage, welche besonders im Oberkiefer bei sehr vielen Reptilien das ganze Leben hindurch beibehalten bleibt. Die beiclen Reihen sind deshalb hinsichtlich einander als eine äußere und eine imnere gelagert.

Es ist num von der größten Bedleutung, daß dic Zahnanlagen in den beiclen Reihen regelmäßig miteinander alternieren, auf ein Zähnchen des Exostichos folgt eines des Endostichos, welches
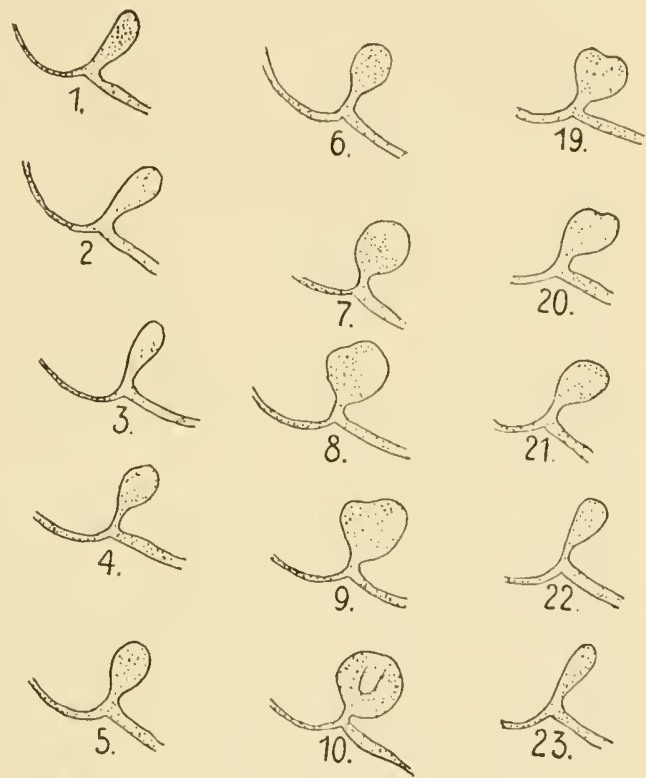
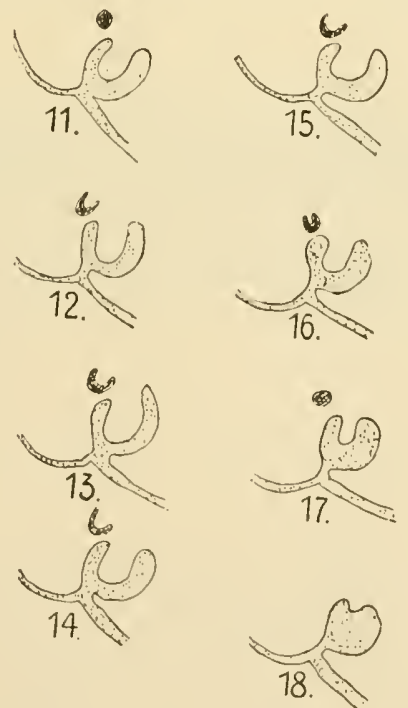

lig. 70. Crocodillus porosus. Anlage eines Zahnes des Endostichos.

wieder von emem exo-

stichalen gefolgt wird usw. Die Elemente des Exostichos sind dabei in der Entwicklung immer etwas bei jenen des Endostichos vor. Doch bestehen hierin sehr große Differenzen zwischen den verschiedenen 
Familien, sogar zwisehen nahe verwandten Formen. Bei den Krokodilen ist der Unterschied gering, bei Varanus z. B. sehr stark. Wir kommen auf diese Tatsache noeh zurïck. In Fig. 71 ist versucht worden, ein Stüek einer generellen Zahnleiste, von der bukkalen Seite gesehen

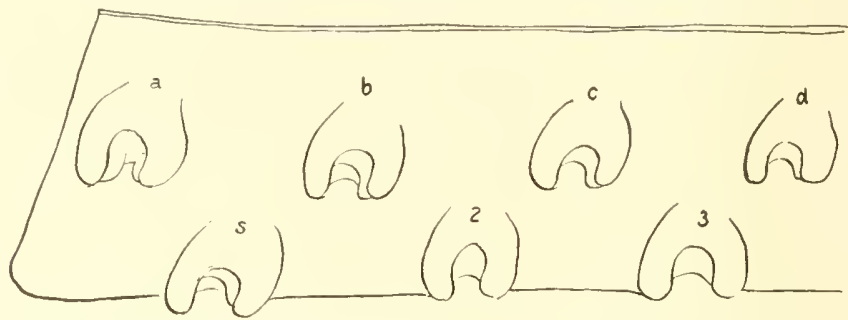

Fig. 71. Schema der Gehißanlage von Crocodillus porosus.

und mit Anlagen von sieben Zähnen besetzt, vier davon $(a-d)$ gehören zum Exostichos, die drei übrigen (1, 2 1. 3) zum Endostichos, schematisch wiederzugeben.

Eine distichische Anlage des Gebisses habe ich sehon für eine Reihe von Sauriern aus den verschiedensten Familien feststellen können. In meinem in München gehaltenen Vortrag sind einige weitere Beispiele angeführt und ist auch darauf hingewiesen worden, daß bisweilen am erwaehsenen Gebiß noch Erscheimmgen festgestellt werden kömmen, welehe"mit dieser"ursprünglichen Struktur des Gebisses in direkter Beziehmng stehen. Doeh sind das wohl Ausnahmen, denn als Regel ist am funktionierenden Gebiß von einem Distichismus nichts mehr zu

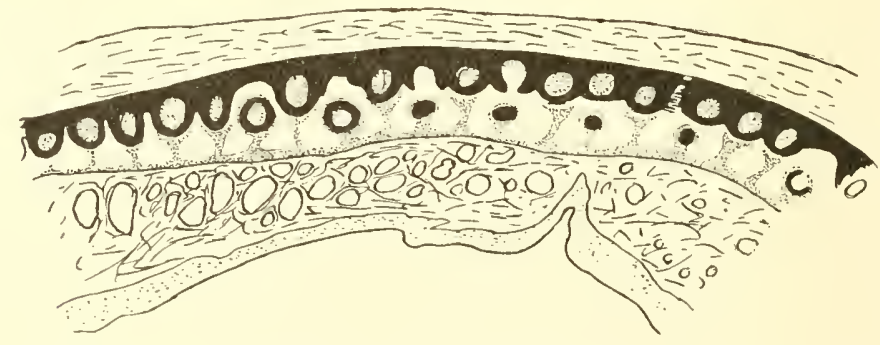

Fig. 72. Hemidactylus marginatus. Horizontalschnitt durch den Oberkiefer.

sehen. Das genannte Strukturmerkmal wird meistenteils schon während der embryonalen Entwicklung unkenmbar. Denn bei der weiteren Entwicklung rücken nun bald die Zähnchen des Endostiehos zwisehen jene des Exostichos, so daß eine einzige Reihe gebildet wird. Und in solch einer einfaehen Reihe kommen dann die Zähne mit dem Kiefer zur Verwachsung, oder werden in Alveolen aufgenommen und das Gebiß seheint monostiehiseh zu sein. Aber dieser Monostichismus ist kein wahrer, kein primärer, er stellt einen sekundär zustande gekommenen Zustand dar. Bei den folgenden Zahngenerationen äußert sich die wahre Natur des Gebisses noeh bisweilen, indem die Zähne alternierend geweehselt werden. In meinem in München gehaltenen Vortrag habe ich davon 
Beispiele angeführt, die in der Publikation abgebildet sind, ein weiteres gebe ich in untenstehender Fig. 72, die einen horizontalen Schnitt durch den Oberkiefer eines Hemidactylus marginatus darstellt. Die Zahnleiste ist der Länge nach getroffen, lingual von Maxillare. Ein genaues Studium der Figur läßt zwei Punkte ans Licht treten: zuerst daß von einer Reihe, welche in Begriff steht zu wechseln, die Zähnchen vollständiger sind je weiter sie nach hinten liegen, nnd weiter daß die Zähnchen dieser wechselnden Reihe mit jenen einer anderen alternieren, wovon alle Elemente mngefähr gleich alt mul alle mit dem Kiefer verwachsen sind. Die Tatsache, daß die Zahnernewerung in einer bestimmten Richtıng in einer der beiden Reihen allmählich fortschreitet, während die andere in einer Periode von Intaktsein sich befindet, trägt dazu bei, daß die Funktion des Gebisses am wenigsten dureh die Zähnung beeinträchtigt wird. Diese Regelmäßigkeit kommt nicht immer vor, ist häufig auf dlie Frontzähne beschränkt und wird in dem weitaus größten Absehnitt des Gebisses nicht selten gänzlich zerstört. Die Ursache liegt öfters schon darin, daß die Elemente der ersten Generation beider Reihen nicht alle gleich schnell wachsen, so claß z. B. ein mehr nach hinten gelegener Zahn schon weiter entwickelt sein kann als ein mehr nach vorn liegender, obwohl als Regel auch bei den Samriern während der embryonalen Entwicklung die vorderen Zähne an weitesten entwickelt sind. Doch sind das Details, anf welche einzugehen ich mir in einer folgenden Arbeit vorbehalte. In der Literatur finclet sich schon eine sehr merkwürdige Bestätigung meiner Befunde der distichischen Natur des Reptiliengebisses. Doch war der Fall vom Untersucher nicht richtig gedeutet. Es betrifft nämlich die änßerst genane Beschreibung, welche Harris on ${ }^{1}$ ) von der Entwicklung des Gebisses von Hatteria gibt. Es bestehen bei diesem Reptil angenfällige Verschiedenheiten zwischen den Zähnen des Exostichos und jenen des Endostichos. Erstere sind merklich größer als letztere, so claß an funktionierenden Gebiß ein großer und ein kleiner Zahn regelmäßig alternieren. Aber wie gesagt, Harrison gibt eine unrichtige Dentung des besonders ansführlich und genau beschriebenen Vorganges. Denn er sagt 1. c. S. 202: ,The teeth wich are developed on the dental lamina during the incubation period and wich function during the early life of the living animal, are almost certainly the members of two distinct clentitions, the later teeth instead of displacing the earlier coming to alternate with then." Auch der Autor beschreibt hier somit bei Hatteria den Vorgang, daß eine Reihe von Zähnchen alternierend zwischen einer anderen Reihe sich einschiebt, aber fälschlich dlentet er die beiden Reihen als eine ältere und jüngere Generation. Nach dem Autor hätten die Zähnchen der einen Reihe jene dler anderen ersetzen müssen. Über die Tatsache, daß bei Hatteria das in der Jugendzeit funktionierende Gebiß aus zwei Generationen besteht, äußert der Autor dann auch seine Verwunderung. Doch ist letztere nur die Folge einer unriehtigen Deutung. Die Zähnchen, welche sich zwischen den anderen einschieben, sind nicht solche einer jüngeren Generation, es sind jene der inneren Gebißreihe. Dasselbe, was Harrison für Hatteria beschreibt, kann man bei jedem beliebigen Saurier wahrnehmen, falls man die richrigen Entwicklungsstadien zur Verfügung hat.

1) Quat. Journ. of microsc. Sc., Vol. XLIV. 
Tch muß hier noch kurz auf einen Punkt eingehen, anf dem ich anch in meinem Münchener Vortrag schon hingewiesen habe. Es ist zuerst von Röse ein Befund beschrieben, den er bei Crocodillus gemacht hat nnd den ich bestätigen konnte. Er fand nämlich bei sehr jungen Embryonen eine Keihe kleinster Zähnchen. welche der Insertionshinie der Zahnleiste am Kieferepithel entlang direkt ans dem Mundhöhlenepithel entstehen. Diese Zähnchen treten vor der Anlage der Elemente des Exostichos und Endostichos schon auf, ohne daß es zur Bildung eines Schmelzorganes kommt, sinken in ter Tiefe des Kiefermesenchyms ein, nm bald vollständig resorbiert zu werden. In Fig. 70 ist ein solches Zähnchen mit abgebildet. Derartige rudimentäre Anlagen sind seitdem anch von Leche, Levy, Carlson nnd Harrison, sowie von mir bei anderen Reptilien angetroffen. Rïse dentet dieselben als die erste Zahngeneration der Reptilien. Ich kann mich dieser Auffassung nicht unbedingt anschließen. Nicht nnwahrscheinlich kommt es mir zu sein vor, daß diese Rndimente die Reste einer dritten Zahnreihe sind, welche bukkal von dem Exostichos verlief, und welche ich als „Parastichos6 andenten möchte. Tch muß jedoch bemerken, daß die Entscheidung über die Natur dieser Zähnchen nicht leicht ist, und daß ich eine feste Überzengung darïber noch nicht habe.

Bis so weit die Tatsachen. Das Reptiliengebiß erscheint jetzt in einem etwas anderen Licht, seine Struktur schließt näher an jenes der amnionlosen Vertebraten an. Bekanntlich konmit unter den Amphibien nur bei der niedrigsten Ordnung, bei den Perennibranchiaten, nach den bekannten Untersuchungen von Hertwig ein vielreihiges Gebiß vor. Es wäre jedoch wohl erwïnscht, anch die Gebißanlage im Kiefergebiet, bei den anderen Ordnungen, anf eine verdeckte ,Polystichie“ zu untersuchen. Zwar hat Hertwig anch am Unterkiefer einer Siredonlarve eine änßere und innere Zahnreihe beschrieben, doch diese dürfen nicht ohne weiteres mit den beiden Reihen bei Reptilien homologisiert werlen. Ich komme auf diesen Punkt noch zuriick. Wichtiger ist es vorläufig darauf hinzuweisen, daß. jetzt auch ïber die Beziehung vom Sängergebiß zı jenem der Reptilien nene Perspektiven geöffnet werden, da der Distichismus des Reptiliengebisses eine unerwartete Lösung des Problems rom Zahnwechsel bei den Sängetieren bringt. Demn wemn man die sämtlichen Produkte, die bei einem Säuger, z. B. beim Menschen, von der generellen Zahnleiste prodnziert werden, das sind also die Elemente von Milchgebiß und permanentem Gebiß, in ihrer topographischen Lagerung hinsichtlich einander ordnet. damn erscheint eine Gebißkonstrulition, welche mit jener des embryonalen Reptiliengebisses vollständig übereinstimmt. Die Zähne sind in zwei Reihen geordnet, eine bukkale Reihe (Milchgebiß) und eine linguale Reihe (permanentes Gebiß), nur sind die beiden Reihen nicht gleich zahlreich. Im hintersten Gebiete, von den permanenten ILolaren eingenommen, findet sich nur eine Reihe. Davon wird später noch die Rede sein.

Noch eine zweite wichtige Übereinstimmung ist zu verzeichnen, nämlich, daß die Anlage der permanenten Zähne - der inneren Reihe also - auch bei den Säıgetieren mit jenen der Milchzähne alternieren. Schwink hat das z. B. für Chiropterenembryonen ganz bestimmt ansgesprochen: "Das Schmelzorgan des bleibenden Zahnes", sagt er, ,legt sich nicht einfach in gerarler Richtung nach immen vom Milchzahne an, sondern nach imnen und vorn." Auf diese wichtige Tatsache weist 
anch Schwalbe in seinem frïher zitierten Referat hin, und verwendet diese Erseheinumg bei dem Aufbau seiner Theorie über die Zahnung der Sängetiere. Weiter ist diese alternierende Stellung der Zähne durch Carlsson bei den diprotodonten Beutlern nachgewiesen. Sie sagt darïber: ,Bemerkenswert ist der Platz des Ersatzzahnes, er wird konstant vor seinem Vorgänger angelegt"1). Ein Verhältnis, woranf auch sehon Kükenthal, Leehe n. a. hingewiesen haben.

Wir sehen somit, dab' in der ontogenetischen Anordnung der Zähne im Gebisse der Reptilien und Säuger eine sehr weitgehende, um nicht zu sagen vollständige, Übereinstimmung besteht, bei beiden erscheint das Gebiß anfänglich in zwei Reihen von Zähnen angeordnet, eine äıßere und eine innere, woron die Elemente miteinander alternieren. Liegt es da nicht auf der Hand, die Reihen ron beiden Gruppen miteinander zu homologisieren, und drängt sich nicht ron selbst der Schluß auf: der Exostichos der Reptilien sei jenen der Sänger, d. h. dem Milehgebib homolog, und das permanente Gebiß letzterer entspricht dem Endostichos der Reptilien? Diese auf der Hand licgende Schlıßfolgerung schafft aber unnittelbar einen prinzipiellen Gegensatz zwischen dem Zahnwechsel der Reptilien und jenem der Säıger, denn ersterer ist und bleibt eine Verdrängung einer älteren Zalngeneration dureh eine jüngere, es ist ein Elenentarwechsel, aber bei dem Zahnwechsel ver Säugetiere tritt die zweite, innere Reihe an die Stelle der ersten, äußeren Reihe. Es ist ein Reihenweehsel. Zahngenerationen gibt es bei den Säugetieren nicht mehr.

Die Struktur des Reptilien- und Säugergebisses ist somit urspriinglich eine vollständig übereinstimmende, beide Gebisse sind distichisch. In der weiteren Entwieklung jedveh treten nun merkwürdige Unterschiede anf, welehe bei der Entstehung der Säugetiere zustande gekommen sein müssen. Bei den Reptilien kommt nämlich eine sehr innige Mischung beider Reihen zustande, die Zähnchen des Endostichos dringen zwischen jenen der Exostichos ein, es wird eine einzige Reihe gebildet, wodureh die Zahl der gleichzeitig funktionierenden Zähne verdoppelt wird. Bei den Sängern dagegen kommt diese Mischıng nicht zustande, beide Reihen bleiben getrennt, und es tritt für die Elemente der inneren Reihe - des Endostichos - eine bisweilen ziemlich langdanernde Periode von Latenz oder sehr stark verlangsanter Entwicklung ein. Letzteres ist ein sekundär erworbener Zustand, es ist eine Ampassungserscheinung.

Die sclieinbar ohne Vermittlung zustande gekommene plötzliche Verringerung der Anzahl von funktionierenden Zähnen bei den Säıgetieren findet in dem beschriebenen Vorgang eine ungezwnngene Erklärung. Bei den Reptilien funktionieren gleiehzeitig beide Reihen, mnd wenn man die Anzahl der Zähne miteinander vergleicht, muß man somit anch für die Säıger die Totalsumme der Zähne beider Dentitionen nehmen. Wälılen wir als Beispiel die Zahnformel der Urprimaten, mit noch drei Ineisivi und vier Prämolaren, dann kommen wir zu einer Totalsumme von 19 Zähnen $(3+1+4)+(3+1+4+3)$ in jeder Kieferhälfte. Merkwürdig ist es nun, daß bei so vielen Saurien die Anzahl der Zähne in jeder Kieferhälfte $ı$ m 20 variiert. Zur Erlilärung der Verringerung der Zähnenzahl ist von Konkreszenztheoretikern die Ver-

1) Zool. Jahrb. 1899, XII. 
schmelzung zu Hilfe gezogen. Ich habe öfters betont, daß für eine solche Konkreszenz jeder Beweis fehlt. Die oben dargestellte Beziehung: zwischen den Gebissen beider Vertebratengruppen bringt eine mehr natürliche Lösung dieses Problemes. Die Verringerung ist nur eine scheinbare, und wird durch die chronologische Trenmung des Durchbruchs beıder Reihen vorgetäuscht.

Auch das sehr frühe Auftreten der sogenamnten Ersatzzähne bei den Sängetieren erscheint jetzt viel verständlicher. Diese sogenannten Ersatzzähne waren bei den reptilienartigen Vorfahren angewiesen, nicht um andere Zähne zı ersetzen, sondern um gleichzeitig mit den Elementen des Exostichos - das sind die Milchzähne der Sänger zu funlitionieren. Und daß die Ersatzzähne noch fast unnittelbar im AnschluB an die Milchzähne angelegt werden, kann uns auch jetzt nicht mehr wundern.

Jetzt tritt jedoch eine wichtige Frage in den Vordergrund, nämlich, warum sind bei den Säugern die beiden Zahureihen voneinander getrennt, oder richtiger formuliert, welches war die Ursache, daß bei den Säugervorfahren die Zähne des Endostichos verhindert worden sind, sich zwischen jene des Exostichos einzuschieben. Ich glaube dafür folgende sehr einfache Erklärung geben zı dïrfen.

Eine stark in den Vordergrund tretende Umbildung, welche bei der Entstehung der Sängetiere aus ihren reptilienartigen Vorfahren sich abgespielt hat, ist bekanntlich die Met anırphose des Kiefergelenkes, welches mit einer Verkürzung des Kiefers verknüpft war. Diese Verkürzung des Kiefergerüstes ist von den Konkreszenztheoretikern häufig als das ätiolngische Moment angefïhrt worden, welches die Verwachsung mehrerer Einzelzähne zı einem zusammengesetzten Zahn verursachte. Depend orf hat sich schon gegen die Verkürzung der Kiefer als Ursache von Zahnkonkrezsenz gewendet, indem er hervorhebt, daß eine solche Verkürznng zwar Zähne aus der Reihe zu beseitigen imstande sein sollte, aber nicht zu Verwachsungen Anlaß geben kann. Ich brauche kaum mehr zu betonen, daß auch von mir diese Ansicht nicht geteilt wird, da eine Verschmelzung von Zähnen in longitudinaler Richtung nicht stattgefunden hat. Aber abgesehen von der Anwendung, scheint mir anch das Prinzip murichtig zu sein. Es scheint mir, daß kein besonderer Grund vorliegt, un beim Übergang des Reptilienkiefers im Säugerlicefer einen solchen komplizierten Vorgang zu postulieren. Je kïrzer der Kiefer wird, desto kleiner werden die Zähne, davon sind sowohl bei den Reptilien selber als bei den Sängetieren Beispiele zur Genüge vorhanden. Das gilt nicht nur wenn man Repräsentanten verschiedener, einander verwandter Geschlechter untersucht, sondern auch wenn man innerhalb einer Spezies individuelle Vergleichungen anstellt. Der Kiefer bildet mit den Zähnen eine organische Einheit. Ein Zwerg mit ganz kleinen Kiefern besitzt nicht weniger zahlreiche Zähne als ein normales Individuum, sondern kleinere.

Es hat jedoch auch meiner Meinung nach die Verkürzung der Kiefer eine wichtige Rolle gespielt, denn sie mub dafür verantwortlich genuacht werden, daß die Zähne der inneren Reihe, des Endostichos, nicht mehr zwischen jenen der äußeren Reihe, des Exostichos, sich einschieben komnten. Mit anderen Worten, die Kieferverkürzung fixierte einen früh embryologischen Zustand. Denn in der Tat ist das Gebiß, z. B. beim Menschen, während einiger Jugendjahre noch ein rein 
distichisches. Wenn im Laufe der beiden ersten Jahre die Ersatzzähne zur Anlage gelangt sind und das Milehgebiß vollständig durchgebrochen ist, sind beide Reihen da und besteht, abgesehen von dem ungleichen Entwicklungsgrad der Elemente beider Reihen, während längerer Zeit ein Zustand, der bei den Reptilien nur äußerst kurzen Bestand hat.

Der Kicferverkürzung, welche aufs engste mit der Umbildung des Kiefergelenkes verknüpft war, teile auch ich somit eine sehr wichtige Rolle bei der Entstehung des Sängergebisses aus dem Reptiliengebiß zı, aber dieser Einfluß war nicht ein zahnumbildender, sondern hat das Gebiß als Ganzes zum Gegenstand. Immerhin darf man dabei nicht aus dem Auge verlieren, daß gleichzeitig mit diesem Vorgang, jener andere sich vollzog, wobei durch Verwachsung zweier Zahngenerationen aus dem Reptilienzahn sich der Säugerzahn bildete. Ob die Kieferverkürzung auch für diesen Vorgang ein ätiologisches Moment war, darüber bin ich im Unsicheren. Es sind mir die Griinde, warum diese Verwachsung zustande kam, nicht deutlich. Denı bessere Aupassung an ihrer Funktion kann solche Formen fixiert haben, sie kann dieselben nicht geschaffen haben.

Den prinzipiellen Gegensatz zwischen Reptilien- und Säugergebiß muß man also clarin erblicken, daß beim erstgenamnten die beiden Reihen gleichzeitig funktionieren (und die Elemente derselben öfters erneuert werden), während bei den Säugern die beiden Reihen einander in der Funktion zeitlich folgen (und die Elemente derselben nicht erneuert werden). Nun verhalten in dieser Beziehung die Reptilien sich nicht alle gleich, es gibt sogar höchst interessante Übergangsstufen zwischen beiden Vertebratengruppen, welche mit meiner Auffassung über die Beziehung der beiden Gebisse zueinander in vollkommenem Einklang stehen. Einen dieser Fälle, tler eine leicht zugängliche Form betrifft, werde ich kurz mitteilen. Es betrifft das Geschlecht Varanus. Wenu man das Gebiß eines jungen Varan untersucht (es standen mir verschiedene Exemplare von Varauls bivittatus und chlorostygma zur Verfügung), damn ist es auffallend, daß die funktionierenden Zähne in jerlem Kiefer so gering in Anzahl sind und so weit auseinander stehen. Regelmäßig jedoch sieht man dann in den Interstitien zwischen den sieben oder acht funktionierenden Zähnen aus der Zahnscheide die noch kurze Spitze eines auswachsenden Zähnchens erscheinen. Diese wachsen empor und sobald sie ihre definitive Größe erreicht haben werden die Zähne, die vor ihnen funktionierten, abgesto Ben und es finden sich wieder weite Spatia interdentalia in dem funktionierenden Gebiß. Eine geschlossene Zahnreihe trifft man bei den jungen Varanen ganz selten, bei älteren Tieren danern die Zähne länger und ist anch das soeben beschriebene Regelmaß etwas gestört. Doch liefern die jungen Varanen ein sehr lehrreiches Beispiel von Formen, welche gewissermaßen einen Übergang bilden zum Säugerzustand. Demm während der Jugendzeit funktioniert gewöhnlich nur eine Reihe von Zähnen, es sei Enclostichos oder Exostichos, und der junge Varan wird mur mit einer Reihe geboren, dessen Elemente allerdings ziemlich weit voneinander abstehen. Diese Reihe funktioniert einige Zeit, es entwickeln sich die Elemente der anderen Reihe, diese verwachsen in den Interstitien zwischen den funktionierenden Zähnen mit den Kiefern und letztere werden abgestoßen. Das Spiel wiederholt sich und alternierend funktionieren die Elemente je der beiden Reihen. Wie oft dieser Wechsel stattfindet, 
habe ich nicht feststellen können, man muß, um das zu entscheiden, ïber ein sehr reichhaltiges Material verfügen kömnen.

Das Kennzeichnende bei dem beschriebenen Vorgang besteht darin, daß die Zahmung bei Varamus während längerer Zeit den Charakter eines Reihenwechsels hat, ganz wie bei den sängetieren, mu mit dem Unterschied, daß dieser Prozeß bei den Säugetieren nur einmal und bei dem genannten Saurier mehrere Male sich abspielt. Auch treten hier die nenen Zähne nicht topographisch, sondern funktionell an der Stelle der älteren anf. Rammmangel, der erst infolge Kieferverkïrzung anftritt, und wodurch bei den Sängern die Zahmung zum Teil den Charakter einer mechanischen Verdrängung bekommt, macht bei Varanus seinen Einfluß noch nicht geltend.

Die Natur der Zahnung bei den Sängetieren, wie sie von mir gedacht wird, beseitigt noch eine Schwierigkeit, welche bei der gelänfigen Vorstellung sich hervortut und woranf schon von mehreren Seiten, besonders anch von Adloff hingeviesen ist. Es betrifft nämlich die ı. a. von Leche nachgewiesene Tatsache, daß bei den primitiven Säugetieren die beiden Dentitionen öfers gemischt funktionieren. Man sollte nach der alten Anffassung bei den primitiveren Säugern gerade eine schärfere Sondernng der Dentitionen erwarten. Von meinem Standpunkte aus besehen, ist dagegen die Erscheinung sehr natürlich. Bei den Reptilien funktionieren alle Elemente beider Reihen gleichzeitig. Und daß die temporäre Unterdrïekung der Entwicklung der imneren Reihe bei den niedrigsten Säugetieren noch nicht zur vollen Entfaltung gekommen ist, erscheint ganz natürlich.

Es darf auf Grund des Obenstehenden wohl als feststehend betrachtet werden, daß der Zahnweehsel der Säugetiere und jener der Reptilien zwei grundverschiedene Erscheinungen sind, der Diphyodontismus der ersteren ist nicht aus dem Polyphyodontismus der letzteren hervorgegangen. Um Zweidentigkeiten vorzubeugen empfiehlt es sich dann anch beide Erscheinungen mit besonderen Namen zu bezeichnen. Man brancht dazu keine neuen Bezeichmungen zu sehaffen, an einfachsten und nit der Wirklichkeit am meisten übereimstimmend kommt es mir vor, wemn man die Bezeichmung Zahngenerationen für die Reptilien wählt, und bei den Sängern von Dentitionen spricht.

Denn in Wirklichkeit sind Milehgebiß und permanentes Gebiß keine verschiedenen Generationen, ein Milehincisivus z. B. und der bleibende Schneidezahn, der an die Stelle des ersteren tritt, stehen in keiner genetischen Beziehmng zueinander. Sie sind rom Hause ans gleich alte Nachbarn. Die Entwicklung des bleibenden Incisivus ist aber verzögert worden. Die Zahngenerationen, welche bei den Reptilien in öfters großer Anzahl anfeinander folgen, treten anch noch - sei es in sehr beschränkter Zahl nud starker Konzentration - bei den Säugetieren anf. Wir haben sie bei den Primaten und mehreren anderen Säugern nachgewiesen in der Zweizahl, im von mir sogenannten Protomer und Deuteromer des Säugerzahnes.

Die Anhänger der Konkreszenztheorie haben immer die Ansicht verfochten, daß eine Beziehung bestehe zwischen dem Verlorengehen des Polyphyodontismus und einem Verwachsen mehrerer Einfachzähne zum zusammengesetzten Sängerzahn. Anch ich bin der Ansicht, aber in der Anwendung desselben nehme ich eine andere Stellung ein. 
Denn meiner Meinung nach sind nur zwei Zahngenerationen der Reptilien im Sängerzahn enthalten, und hat dliese Konkreszenz nur die Mehrhöckerigkeit in transversalem Simne zur Folge gehabt. Und diese Ansicht ist nicht theoretisch konstruiert, sondern stiitzt sich auf embryologische Befunde. Ich habe versucht, die Bezichung zwisehen den beiden Zahnreihen und dem Prozeß der Zahnung bei Reptilien und Sängetieren in Fig. 73 in sehematiseher VTeise zur Darstellnng zu bringen. Die linke Hälfte der Figur hat auf die Reptilien, die rechte auf die Säıgetiere bezug. Die Zähne, welche dem Endostichos zugehörig sind, sind durch Punktierung kembar gemacht, die Pfeilchen geben die Richtıng an, worin der Zahnwechsel stattfindet. Es sind beim Reptilienschema jedesmal drei Zahngenerationen angedeutet, beim Sängerschema sind zwei Generationen jedesnial zu einem einzigen Zahn zusammengewachsen gedacht. Es ist in diesem Schema ebenfalls Ausdruek gegeben von meiner Ansicht, daß rlie Primatenzähne nicht durch Verwachsungen von einfachen Kegelzähnehen entstanden sind, sondern durch eine solche von trikonodonten Zähnchen. Dieses Schema gibt den Grundgedanken meiner Theorie über die Bezichung von Zähnen und Gebissen der Reptilien zı jenen dler Säuger in einfachster Teise wieder. Es läßt hervortreten, wie der Primatenzahn durch Konkreszenz zweier trikonodonten Reptilienzähnen entstanden ist,

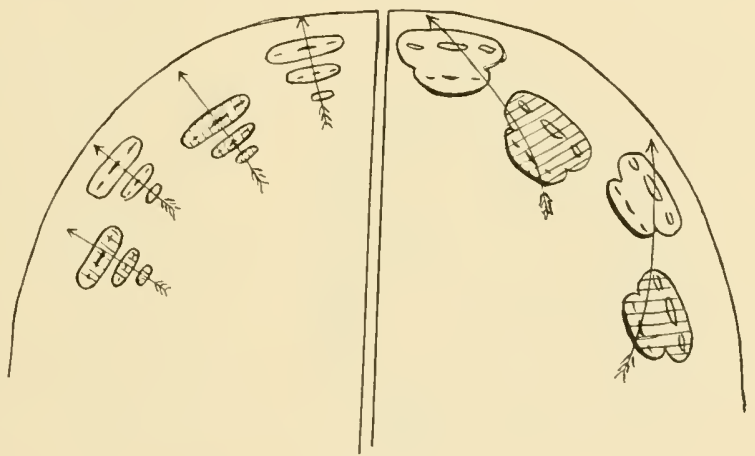

Fig. 73 . und daß der Zahnwechsel bei den Reptilien ein Individualwechsel ist, bei den Sängern ein Reihenwechsel. An der Hand dieser Schemen kann man sich leicht von den in dieser Arbeit gemachten SchlıBfolgerungen eine Vorstellung machen.

Am Schlı meiner Auseinandersetzung angelangt, müssen noch einige Bemerkmgen gemacht werden, welchen früher weniger gut eine Stelle eingeräımt werden konnte.

In seiner bekannten grundlegenden Untersuchung über das Zahnsystem der Amphibien hat Hertwig anf das Vorkommen von einreihigen und mehrreihigen Gebissen bei dieser Vertebratengruppe hingewiesen, wobei allerdings die einreihige Stellung die vorherrschende ist. Bei einer zweireihigen Stellıng, wie z. B. anf den Vomer, Palatum und Operkulare von Siredon pisciforme sind die Zähnchen derart geordnet, daß jene der zweiten Reihe hinter die Interstitien der ersten Reihe zu liegen kommen, mit anderen Worten, sie stehen alternierend in einer Zickzacklinie. Wenn man die Zone. worin die Zähne implantiert sind, als das ,Zahnfeld" bezeichnet, dann finden sich somit auf dieses Feld die Zähne in ähnlicher Anordnung wie bei der embryo- 
nalen generellen Zahmleiste der Saurier. Der Autor hebt jedoch ausdrïcklich hervor, daß die mit den Kiefern verwachsenen Zähne - mit Ansnahme ron Siren lacertina, wo anch dieser Absehnitt des Gebisses vielreihig ist - nur in einer cinzigen Reihe vorkommen. Haben wir es hier mit einem nrsprünglichen Zustand zu tum? Wahrscheinlich nicht, und es wïrde sich gewiß lohnen, die allererste Anlage des Kiefergebisses bei den Amphibien zu untersuchen, besonders in bezug auf die Frage, ob anch hier auf das zur Zahnleiste 1 mgebildete Zahnfeld die Spuren eines Distichismus sich noch auffinden lassen. Übrigens hat Hertwig selbst die Möglichkeit davon nicht auBer acht gelassen. Denn S. 44 wirft er die Frage anf, in welcher Beziehung die einzeilige Stellıng des Gebisses zur vielzeiligen steht, und bemerkt dazu. daß letztere als die urspriinghehe angesehen werden mul., woraus erstere sich entwiekelt hat. In welcher Weise das gesehehen konnte, darïber äuBert der Autor sich nicht. Ich möchte dazu folgendes bemerken.

Bei den Amphibien erstreckt sich das ganze zahntragende Feld an den genannten Stellen an die Oberfläche, nnd es sind die Zähne in melireren Reihen derart angeordnet, daß jedesmal die Elemente einer Reihe mit jenen der nächstfolgenden alternieren. Eine iibereinstimmende topographische Erscheinung findet sich bei jenen Reptilien, bei den der Zahnwechsel ein änßerst intensiver ist, nämlich bei den Schlangen.

Un sich davon zu ïberzeugen, empfehle ich die bukkale Seite der Zahnleiste einer Schlange zı betrachten. Es läßt sich hier mit geringer Hïhe der ganze Zahnapparat heranspräparieren. Betrachtet man nun die bukkale Seite dieses Apparates, dam hat man hier in Wirklichkeit die gleichen Verhältnisse wie bei einem viehreihigen Ciebil, eines Perennibranchiaten. Der Untersehied ist nur dieser, kaß. bei den letzteren das ..Zahnfeld ${ }^{66} \mathrm{ganz}$ an der Oberfläche liegt, bei den Schlangen dagegen ins Kiefermesenchym eingesunken erscheint und nur der ursprünglich bukkale Rand an die Oberfläche tritt, wobei nur die an diesem Rande gelagerten Zähne - ob zu einer oder zwei Reihen gehörig ist mir umbekannt - funktionieren. Fragt man somit, in welcher Weise kann ein vielzeiliges Gebiß wie bei einem Perennibranchiaten in einem einzeiligen iibergehen dann kann die Antwort lanten in einfachster Weise durch Einsenkung (les Zahnfeldes in der Tiefe. Durch diese Antwort wird die Frage nach dem Ursprung der Zahnleiste gestreift und möchte ich darïber cine kurze Benerkung einschalten. Die Zahnleiste wird gewöhnlich als durch Einfaltung der Schleimhait entstanden vorgestellt. Diese Auffassung entspricht jedoch meiner Meinung nach nicht dem wirklichen Vorgang, den ich mir folgenderweise vorstelle. Man denke sich als Ausgangspunkt eine Form wie z. B. Siren lacertina wo ein wirkliches .,Zahnfeld“" besteht, mit mehreren Reihen von Zähmen, wovon die mediale die jüngste ist, besetzt. Nun wächst von der medialen Seite eine Schleimhautfalte ïber dieses ,Zahufeld" hin, bedeckt es zum 'Teil und läßt nur die Zone, wo die zwei meist lateralen Zeilen implantiert sind, frei. Mit anderen Worten, das Zahnfeld sinkt nicht in die Tiefe, sondern wird zum Teil operknlisiert. Durch diese Operkulisierung wird nun eine ins Kiefermesenchym eingedrungene Falte vorgetäuscht. Aber eine wahre Falte ist es nicht. 
Für diese Entstehungsweise der Zahnleiste sprechen mehrere Erscheinungen. Es wird dadurch deutlich, warum die beiden Lamellen dieser Leiste, die äußere und innere, funktionell so ganz ungleichwertig sind, und auch so ganz verschiedene histologische Charaktere zeigen, wie das bisweilen bei Sauriern und auch noch bei Säugetieren so recht schön zu sehen ist. Die linguale Lamelle der Leiste hat niemals an der Zahnbildung Anteil gehabt, es ist die untere epitheliale Bekleidung des über das Zahnfeld ausgewachsenen Operculum, wie die bukliale Lamelle dieses von der Oberfläche abgedrungenen Zahnfeld selbst ist. Durch diese Entstehungsweise der Zahnleiste begreifen wir auch die Notwendigkeit der Erscheinung. worauf ich schon einmal hingedentet habe, daß bei den Sauriern die auswachsenden Zähne zwischen den beiden Lamellen der Zahnleiste eindringen und die beiden Lamellen voneinander spalten. Die Zähne kommen dabei zu liegen zwischen das ursprüngliche ,"Zahnfeld" und aie Unterfläche des Operculum. SchlieBlich wird uns durch diese Vorstellung der Enstehung der Zahnleiste die Beziehung zwischen einem vielreihigen und einem einreihigen Gebiß deutlich. Das Schlangengebiß ist ebensogut ein vielreihiges als jenes von Fischen oder gewissen Perennibranchiaten, aber das Zahnfeld ist operkulisiert, und nur die ältesten, an dem bukkalen Rande des Feldes gelegenen Zähne funktionieren.

Die Frage ïber die Herkunft der Zahnleiste und über die Beziehung des Gebisses der Saurier und Schlangen zu den mehr primitiven Formen habe ich im obenstchenden nur liurz beriihrt, es ist nur der Hauptgedanke zur Äußerung gebracht, für nähere Details muß ich auf folgende Abhandlungen ver-

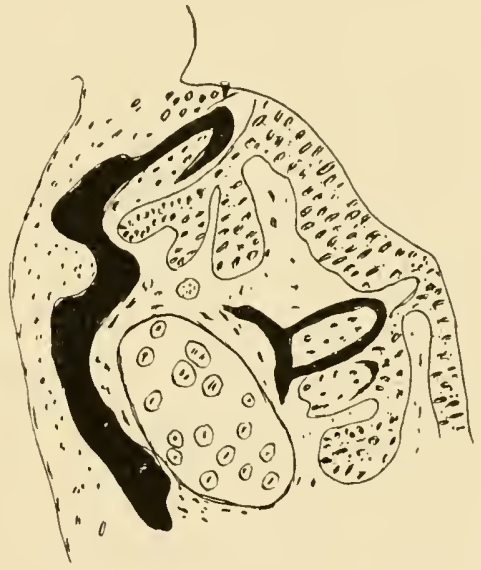

Fig. 74. Triton taeniatus. Larve $19 \mathrm{~mm}$. Doppelte Gebißanlage im Unterkiefer. weisen. Nur sei der Vollständigkeit wegen hier noch bemerkt, daß ich zu der oben gegebenen Ansicht gekommen bin auf Grund vou Befunden bei def Entwicklung des Reptiliengebisses.

An gewissen Stellen des Kiefergebisses (Unterkiefer) von Urodelen findet sich ein doppeltes Gebiß. Hertwig hat (l. c. S. 95) darauf schon hingewiesen. An Unterkiefer bemerkt man, sagt er, zwei Streifen von Zahnanlagen, einen äußeren und einen inneren; der äußere liegt in der Mitte und längs des oberen Randes des Meckelschen Knorpels, der innere liegt in geringer Entfermung einwärts von ihm auf der Innenseite des Knorpels. Ich möchte dagegen warnen, diese Erscheinung mit dem Distichismus des Sauriergebisses zu identifizieren. Ich habe den Befund Hertwigs bestätigen kömnen und gebe in Fig. 74 einen Querschnitt durch den Unterkiefer einer Tritonlarve von $19 \mathrm{~mm}$. Die beiden Zahnstreifen sind sofort zu erkennen. Wir haben es hier 
jedoeh nicht mit einem distichischen Gebiß zu tun, sondern mit einem doppelten Gebiß. Das laterale ist jenes GebiB, das speziell mit dem Dentale in Beziehnng steht, wie aus der Figur ersichtlich ist, das mediale ist jenes, das zum Operculare gehört. Dieses doppelte Gebiß kommt denn auch nur so weit vor, als Dentale und Opereulare nebeneinander liegen, mehr nach vorn findet sich ausschließlich das Dentalegebiß, weiter nach hinten hört letzteres auf und es findet sich nur das Operenlaregebiß. Es sehien mir nicht nnerwïnscht, auf diese Erseheinung, welehe zu Mißverständnissen Anlaß geben konnte, hinzuweisen.

Die von mir aufgestellte Dimer-Theorie ïber die Beziehung von Gebiß und Zahn der Tammalien zu jenen der Reptilien läßt im allgemeinen die Gebißprobleme viel einfacher erseheinen und bringt von einigen eine natürliche und auf der Hand liegende Lösung. Andererseits gibt sie jedoch anch Anlaß zum Stellen neuer Fragen. Warum sind z. B. bei den Sängetieren nur zwei Zahngenerationen der Reptilien an dem Aufban der Zähne beteiligt gewesen. Diese Erscheinung steht wohl im engsten Konnex mit den Momenten, welche die Konkreszenz iiberhaupt bedingten. Wir kömmen anläBtich letzteren Problens wohl Betrachtungen a posteriori anstellen und daranf hinweisen, daß das Produkt der Verwachsung ein funktionell mehr vollkommenes Organ war, aber diese Wahrheit entlerigt uns nicht der Aufgabe, das Kausalmoment zu erforschen, welches einerseits zwei ursprïnglich getrennte Organe zwang, sich zu einem einzigen zu verbinden und andererseits die Produktivität der generellen Zahnleiste derart beschränkte, daß nur die zwei ersten Generationen zur Anlage gelangten und die Anlage aller anderen unterdrückt wurde. In das ätiologisehe Moment der Verwachsung fehlt es mir zurzeit an ener Eimsicht, es diirfe in Beziehnng zur Umbildung des Kiefergelenkes stehen, aber die Art dieser Relation ist nir ganz diister. Wir werden auf den zuerst genannten Punkt etwas näher eingehen.

Daß die Zähne der Mammalien durch Verwachsung von nur zwei Generationen von Reptilienzähnen entstanden sind, kann in zweierlei Weise erklärt werden. Wir haben früher schon einmal daran erimnert, daß der Zahnwechsel bei den verschiedenen Samriern nicht gleich lebhaft vor sich geht, es gibt Formen, bei denen eine Zahngeneration nur kurz dauert, bald durch eine folgende ersetzt wird, und andere, wo die Zahnung nur selten Platz greift. Und dieser Tatsache gegenüber scheint der Auffassung nichts im Wege zu stehen, daß bei den reptilienartigen Torfahren der Mammalia nur zwei Zahngenerationen zur Anlage gelangten, und daß es diese zwei sein sollten, welche sich aim Aufbau des Säugerzahmes beteiligten. Wie einfach diese Erklärung aussieht und wie natürlich sie das Problent zu lösen scheint, liommt sie mir jedoch nicht plausibel vor. Ich habe folgende Bedenken gegen sie. Wenn man Formen untersucht, welehe nur einen beschränkten Zahnwechsel aufweisen, z. B. Calotes, Agama, dann kann man bisweilen die Zahnleiste im Ober- und Unterkiefer an lïckenlosen Serien verfolgen, ohne auch nur die geringste Spur der Anlage eines Ersatzzahnes anzutreffen. Die Zahnleiste ist in beiden Kiefern dann ganz normal, aber über ihre ganze Länge findet sie sich in einer Periode von Latenz. Den Gegensatz hierzu bilden jene 
Formen mit reichlichem Zahnwechsel, wo zwei, bisweilen sogar drei Ersatzgenerationen in verschiedenen Entwicklungsstadien anwesend sind und an der aboralen Fläche der meistenfalls horizontal liegenden Zahnleiste dicht gedrängt nebeneinander lagern. Hieraus geht hervor, daß bei den Reptilien mit wenig - sagen wir z. B. zwei - Zahngenerationen die zweite Generation erst zur Anlage gelangt, wenn der Zahn der ersten Generation schon längere Zeit funktioniert hat. Und nun ist es deutlich, daß eine Verwachsung der Anlagen zweier Generationen nur denkbar ist, wenn beide in unmittelbarer Nähe voneinander liegen und nahezu gleich weit in Entwicklung fortgeschritten sind, ein Zustand also, wie z. B. früher von Varanus geschildert worden ist. Eine solche Möglichkeit kommt jedoch nur bei jenen Formen vor, bei denen ein lebhafter Zahnwechsel stattfindet. Aus diesem Grunde kommt es mir nicht berechtigt vor - falls man nicht rein theoretische Hilfshypothesen heranziehen will - die Tatsache, daß mur zwei Zahngenerationen der Reptilien in Säugerzahn aufgenommen sind, zu erklären mit einem Hinweis auf Reptilien mit nur beschränktem Zahnwechsel. Ebensolche Formen kommen für diese Entstehungsweise gerade an wenigsten in Betracht.

Ist diese Auffassung richtig und ist als Ausgangsform des Säugerzahnes gerade ein lebhaft wechselndes Sauriergebiß cine notwendige Bedingung, dann wirl der Vorgang dieser Entstehung etwas komplizierter. Denn damn muß gleichzeitig zweierlei stattgefunden haben, nämlich Konlireszenz von zwei bereits angelegten Generationen und Unterdrückung der Anlage aller folgenden. Das heißt der Zahnleistenrand muß von einem Zustand hoher Aktivität in einen solchen vollständiger Latenz geraten. Nun zögere ich nicht, diese Ansicht als eine richtige zu betrachten. Und ich berühre hiermit gleichzeitig die Frage nach der Bedeutung des sogenannten freien Zahnleistenendes bei den Säugern. Bevor ich darauf eingehe, $m$ m ich jedoch noch über einen anderen Punkt äußern.

Es ist von der Seite der Konkreszenztheoretiker oftmals gegen die Differenzierungstheorie als Bedenken eine Gebißform angeführt, welche bei vorurteilsfreier Betracht ng in der Tat das Prinzip dieser Theorie auf lose Schranken stellt, nämlich jene der Multitubereulaten. Osborn selber ist sich der Schwierigkeit, welche diese Formen seiner Theorie bieten, wohl bewußt. Denn in seinem Sammelwerk: Evolution of Mammalian Molar Teeth findet sich S. 105 folgende Fußnote: ,One might alvance another speculation, that Microlestes, Tritylodon and the Multituberculates appearing in the Triassic, were not closely related to trituberculat mammals (wich are first known in the upper jurassic or Basal Cretaceous) but were independent offshoots from the Theriodontia." Dadurch wird jedoch die Entstehung der multituberkulaten Zahuform nicht erklärt. Es ist nun evident, daß die in der vorliegenden Arbeit aufgestellte Theorie der Entstehung des Säugerzahnes durch Konkreszenz von zwei Reptilienzähnen ebenfalls nicht ausreicht, $11 m$ die multituberkulate Zahnform zu erklären, besonders nicht in jenen sehr häufigen Fällen, worin dieser Zahn nicht zwei, sondern drei Reilen von Tuberkeln trägt. Daß diese Formen durch Konkreszenz ebenso vieler Kegelzähne entstanden sind als es Höcker gibt, kommt mir nicht wahrscheinlich vor. Auf zwei Möglichkeiten 
möchte ich hinweisen. Eine erste ist, daf. der multituberknlare Zahn entstanden ist durch Verwachsung von zwei, oder, wenn drei Reihen ron Höckern vorliegen von drei Generationen von Reptilienzähnen, deren Kanten nicht mit drei, sondern mit vielen Spitzen versehen waren. Diese Ansicht hat meiner Neimmg nach am wenigsten für sich. Mehr Wahrseheinlichkeit kommt folgender Ansieht zu. Der vollständigste multituberkulare Zahm ist jener, wobei es drei Längsreihen von Höekern gibt. Nun kann man sich die Entstehnng eines solchen Zahnes in folgender Weise denken. Man nehme Ausgang von einem Vorfahr dessen Zähne trikonodont waren, und bei welehem die Konkreszenz der Elemente von anffolgemlen Generationen schon zustande kam. ohne daß das Zahnleistenende schon jenes Stadium von Latenz erreicht hat wie bel clen späteren Säugetieren. Es war somit noch nicht wie bei den höheren Sängern in seiner Produktivität unterdrückt und konnte eine größere Zahl von Generationen erzengen, wovon jede folgende mit seinem Voryänger verlötet war. Es war somit die Entstehungsweise des Zahnes der höheren Formen nur unvollständig da: die Konkreszenz kam schon zustande, aber die zweite Notwendigkeit, worauf ich oben die Aufmerksamkeit lenkte: die Einschränkung der Produktivität der Zahnleiste, hat sich noch nicht geltend machen kömnen. Nun hat jedoch ein mechanischer Einfluß eingegriffen. Wenn die msprïngliche Lagernng der zu einem einheitlichen Gebilde verbundenen vielen Zahngenerat ionen beibehalten wiirde, dann miißte der Zahn mit seiner Längsrichtung senkreeht zun Kiéferrand zu liegen kommen. Der Zahn hat nun eine andere Richtung angenommen, indem er durch eine Drehnng $и$ m 90 Grad sich dem Kieferrand gleichlanfend stellte und in demselben aufgenommen wurde. Der ursprïngliche linguale Rand, der jüngsten Zahngeneration entsprechend, wurde dabei zum hinteren Rand, und die Zahngenerationen, welche den Zahn anfbauen, lagerten jetzt nicht mehr in einer frontalen Ebene neben-, sondern in einer sagittalen hintereinander.

In dieser Weise betrachtet, bildet der multituberkulare Zahn gerarle eine Zwischenstufe zwisehen jenem der Reptilien und der höheren Sängetiere, was mit dem historischen Auftreten dieser Formen gut in Einklang steht. Denn ich habe oben dargetan, daß die reptilienartigen Vorfahren der Säuger nicht pauciphyodont gedacht werden dürfen, es mï̈ssen Formen gewesen sein mit schnell aufeimander folgendem Zahnersatz, also nit sehr aktivem Zahnleistenende. Und das involviert wieder, daß die Aktivität durch irgendwelche Ursache unterdrückt wurde. Der Multituberknlatenzahn ist mun zu betrachten als eine Bildung, wohei die Verwachsung schon zustande kam, aber das Zahnleistenende noch nicht in jenen Zustand von Latenz geraten war, wie bei den höheren Sängern, es blieb eine größere Zahl von Generationen produzieren.

Nach der hier gegebenen Vorstellıng darf man somit den bukkalen Rand des multituberkularen Zahnes nicht mit der gleichnamigen der höheren Säuger identifizieren. Der vordere Rand des ersteren ist dem bukkalen der Sänger homolog, und die drei vorderen Tuberenla jener stimmen mit den drei Höckern des Protomeres vom Säıgerzahn überein. Diese Dentung der bezïglichen Zähne der ältesten Sängetiere 
hat, wie ich meine, die meiste Wahrscheinlichkeit, ich gebe sie jedoch nur als einen Erklärungsversuch wieder.

Ist jetzt, so darf man fragen, um auf unseren Ausgangspunkt zuriickzukommen, bei den Säugern, bei welchen der Zahn nur aus zwei Generationen anfgebant ist, die so energische Aktivität, welche der Zahnleistenrand bei den Vorfahren besaf, völlig erlöscht? Ich möchte diese Frage nicht unbedingt bejahend beantworten. Es scheint mir doch nicht ganz ausgeschlossen, daß das Cinguhm, das bisweilen so kräftig entwickelt, an dor lingualen Seite des Zahnes erscheint, die letzte schwache Äıßerung sei der fast gänzlich latente Potenz des Zahnleistenrandes zur Bildung weiterer Zahngenerationen. Ich bin geneigt, in diesem Cingulum die zu einem bandartigen Emailstreifen konzentrierte Anlage aller folgenden Zahngenerationen zu erblicken. Allerdings nicht in der Weise, daß das Cingulum als eine rudimentäre Zahngeneration gedentet werden soll, es ist die nicht weiter differenzierte Manifestation der fast unbeschränkten Zahnbildungspotenz, welche dem freien Ende der Zahnleiste ehemals zukam. Bekamntlich gehen aus dem Cingulum bisweilen Nebenspitzen hervor. Ganz indifferente Bildungen sind diese Erscheinungen nicht, ich möchte dieselbe als Ausdruck einer teilweisen Reaktivierung, als Abortivanlage einer jüngeren Zahngeneration auffassen.

In dieser Dentung findet gleichzeitig meine Meinung über die sogenannte dritte Dentition oder eines postpermanenten Gebisses ihren Ausdruck. Das Auftroten einer solchen Dentition ist mit meiner Theorie gänzlich unvereinbar. Die Annahme einer dritten Dentition geht von der Voraussetzung ans, daß der Zahnwechsel der Mammalia und jener der Reptilien identische Erscheinungen sind. Da ich zu ciner ganz entgegengesetzten Überzengung gelangt bin, ist für mich von selber die Möglichkeit ciner dritten Dentition gänzlich ausgeschlossen. Wenn überhanpt das freie Zahnleistenende wieder einmal scine ursprüngliche Produktionsfähigkeit zurückerlangen sollte, dann würde sich diese Wiederbelebung nicht in dem Anftreten einer dritten und vierten Dentition äuBern, sondern in Komplikation des schon bestehenden Zahnes. An der deuteromeren Seite desselben wïrde sich die nene Zahngeneration anschmiegen mnd an jener Stelle würden nene Höcker sich den schon vorhandenen zugesellen.

Ist das Anftreten eines derarticen Falles denkbar? Wiewohl ein Eingehen anf diese Frage eigentlich außerhalb des Rahmens dieser Arbeit liegt, kann ich es doch nicht unterlassen, auf dieselbe hier kurz einzugehen, da dabei ein Fall zur Sprache gebracht werden kann, der, im Lichte meiner Gebißtheorie betrachtet, sehr interessant erscheint. Auf die gestellte Frage möchte ich nicht nur eine zustimmende Antwort geben, was die Möglichkeit betrifft, sondern darauf hinweisen, daß sich diese Möglichkeit, meiner MLeinumg nach, sogar rerwirklicht hat, und zrrar bei den Elefantenmolaren.

Die Entstehung der Crestalt dieser eigentümlichen Bildungen ist in der Literatur sehon öfters diskutiert worden. Am eingehendsten ist dies von Röse-1) geschehen, der die Molaren der Proboscidier als

1) Morphol. Arbeiten 1S94, III. 
stark sprechende Beweise der Entstehung von zusammengesetzten Zähnen durch Konkreszenz angeführt hat. Mit der von Röse gegebenen Deutung der Entstehungsweise dieser Zähne kann ich mich jedoch nicht ganz einverstanden erklären, wiewohl der von mir unten gegebene Entstehungsvorgang mit jenem von Röse Übereinstimmung zeigt.

Es ist sehr merkwïrdig, daß die Hauptverteidiger der zwei Zahntheorien: Röse als Anhänger der Verwachsungstheorie und Osborn als jener der Konkreszenztheorie. wenn sie anf die Molaren des Elefanten zu sprechen kommen auf Übereinstimmendes dieser Zähne mit jenen der Multituberknlaten hinweisen. So sagt Röse l. c. S. 187: ,Der fertige Molar ist, wenn wir von der ganz sekmudären Zementablagerung absehen, ungefähr homolog einem Iultituberkulatenzahne." Und Osborn sagt in seinem schon mehrfach zitierten Sammelwerk anf S. 188: ".The plates of the teeth of Elephas owe their origine to upgrowths of the posterior basal einguhum", nachdem er auf S. 115 die Entstehung der Nultituberkulatenzähne ebenfalls durch Bildung von neuen Höckern aus dem Cingulum erklärt, um dann fortzufahren:..This law of successive cusp addition from the posterior basal cingulum (in Nultituberculates) is entirely analogous to that wich recurs in the complicated molars of Proboscidea." Es stimmt nun meine Auffassung über die Formbeziehung rom Multituberkulatenzahn und Elefantenmolar vollständig mit jener ron Osborn überein. Auch ich bin der Meinung, daß die Genese beider Zähne in übereinstimmender Weise verlanfen muß, nur mit dem Unterschied, daß die Entstehungsweise bei den Multituberkulaten ein primitiver Zustand gewesen sein muB, welcher sich sofort an jenen der Reptilien anschloß, beim Elefanten dagegen ein seliundär erworbener, gleichsam ein neues Aufblïhen einer Eigenschaft, welche seit einer ganzen Periode der Erdgeschichte in latentem Zustand geblieben war. Es sei, $n$ diesen Verband zwischen beiden Formen klarzulegen, daran erinnert, daß ich den Multituberkulatenzahn als ein polymeres Gebilcle auffasse, entstanden durch sukzessive Verschmelzung einer größeren Anzahl von Zahngenerationen, in Gegensatz zum dimeren Zahn der Pancituberkulaten, worin nur zwei Generationen enthalten sind. Bei letzteren geht der Zahnleistenrand, wenn die zwei Generationen zur Anlage gelangt sind, in Latenz ïber, bildet noch als schwache Äußerung seiner unterdrïickten Potenz das Cingulum. Bei den Multituberkulaten dagegen gelangen mehrere Generationen zur Anlage, aber da für ein daraus resultierendes Gebilde in Kieferrand kein Platz war, wenn es seine ursprünglich bukkolinguale Stellung behält (denn an der lingualen Seite kam der Zuwachs der nenen Generationen zustande), drehte es sich nm 90 Grarl nit der ursprïnglich lingualen Seite nach hinten und stellte sich so mit seiner Längsachse dem Kieferrand parallel.

Es ist num meine Meinung, daß bei den Proboscidien der gleiche Zustand von neuem erworben worden ist durch eine scluwerlich ausfindig zu machende Ursache. Der Zahnleistemand, der bei den ältesten Formen dieser Gruppe ebenfalls nur zwei Zahngenerationen entstehen ließ - welche auch je wohl einem dreihöckerigen Einzelzahn entsprachen -, die zu einem paucituberkulaten Zahn zusammengefügt waren, bekommt wieder die Fähigkeit, welche er bei den reptilien- 
artigen Vorfahren besaß, um eine größcre Zahl von Generationen entstehen zı lassen. Die latente Eigensehaft wird reaktiviert. Der primitiven topographischen Lagerung nach sollten die Zahngenerationen in bukko-lingualer Richtung angeordnet sein, aber wie ehemals bei den Multituberkulaten, paßt sich auch bei Elephas das Gebilde der Gestalt des tragenden Kiefergerüstes an, und es findet eine Drehung statt, wobei die Proliferationsseite hinten zu liegen kommt. Der vordere Rand des Elefantenmolaren ist dann auch dem protomeren der übrigen Säuger gleich zu setzen. Es ist leicht einzusehen, daß eine derartige progressive Entwicklung der Molaren mit Verringerung der Zahl der Zähne verknïpft sein muB, nicht weil alles Material für den Aufbau eines einzigen Zahnes verbrancht wird, wie es in analogen Fällen wohl vorgestellt wird, aber weil eine derartige Entwicklung notwendig die Anlage säntlicher ursprünglichen Zähne unmöglich macht.

Es findet sich in der hier gegebenen Vorstellung der Entstehung dies Elefantenmolaren somit Anklänge an die Ansichten sowohl von Röse wie von Osborn. Mit Röse bin ich darin einig, daß der Elefantenmolar ein schönes Beispiel darstellt von Konkreszenz. Aber nur von einer solehen anfeinander folgenden Generationen einer einzigen ,Zahnfamilie * und nicht von Elententen versehiedener Dentitionen (in der von mir an diesem Begriff gegebenen Bedeutung), oder ron solchen, welche im Kiefer urspriinglich hintereinander gestellt gedacht werden müssen. Mit Osborns Erklärungsweise ist die meinige insoweit verwandtschaftlich, als dieser Autor das Cingulum des Zahnes als die Bildungsstätte der neuen Höcker ansieht, und von mir das Cingulun als die morphologische Manifestation der unterdrückten Bildungsfähigkeit weiterer Zahngenerationen vom Zahnleistenrande gedentet wird. Ich homologisiere somit den Elefantenmolar mit einer ganzen Zahnfanilie der Reptilien, jede Lamelle stellt eine Generation, ein Glied dieser Familie dar. Wenn man die juingsten Glieder dieser Zahnfamilie - welche sich am hinteren Rande finden - bei den mehr primitiven Elephas africanus untersucht, dann erweisen sich anch diese wieder im Besitze einer dreispitzigen Krone, eine größere Mittelspitze wird von zwei kleineren begleitet. Durch die Abkaumng gehen jedoeh die durch Zement angefüllten Zwischenräume zwisehen denselben verloren und sie fließen zu einem einzigen Querjoeh zusammen.

Die Molaren von Elephas lehren uns was die Folge ist, wenn der Zahnleistenrand von nemem alitiviert wird. Das leitet nicht - wie vorher schon benerkt - zu einer dritten und weiteren Dentition, sondern zur Komplizierung der Gestalt der Zähne.

Zwei Punkte, welche in der odontologischen Literatur vielfach diskutiert worden sind, fanden in der vorliegenden Arbeit keine Erwähnung, nämlich die Frage ïber die Bedeutung der Wurzelzahl in der Phylogenese des Gebisses der Säugetiere, und zweitens das Vorlommen von Zähnen, welche nicht ersetzt werden: die permanenten Molaren. Beide sind Ausgangspunkte für mehrere Fragen, die in der Literatur gestellt und in verschiedenster Weise beantwortet worden 
sind. Auf keinen dieser beiden Punkte gehe ich in dieser Arbeit ein. Zu dieser Reserve sehe ich mich gezwungen, da ich zu einer abgeschlossenen Meinung ïber dieselben noch uicht habe kommen können. Zwar habe ich über beide meine Ansichten, aber es sind nir Tatsachen bekannt, welche mit diesen Ansichten sich weniger gut vereinigen lassen. Ich bevorzuge es also, über beide Punkte vorläufig zu schweigen, um nicht später eventuell gezwungen zu sein, eine Neinung zu viderrufen, wovon ich doch auch jetzt nicht eimmal fest überzeugt bin, daß sie richtig sei. 
$$
\text { . }
$$ 


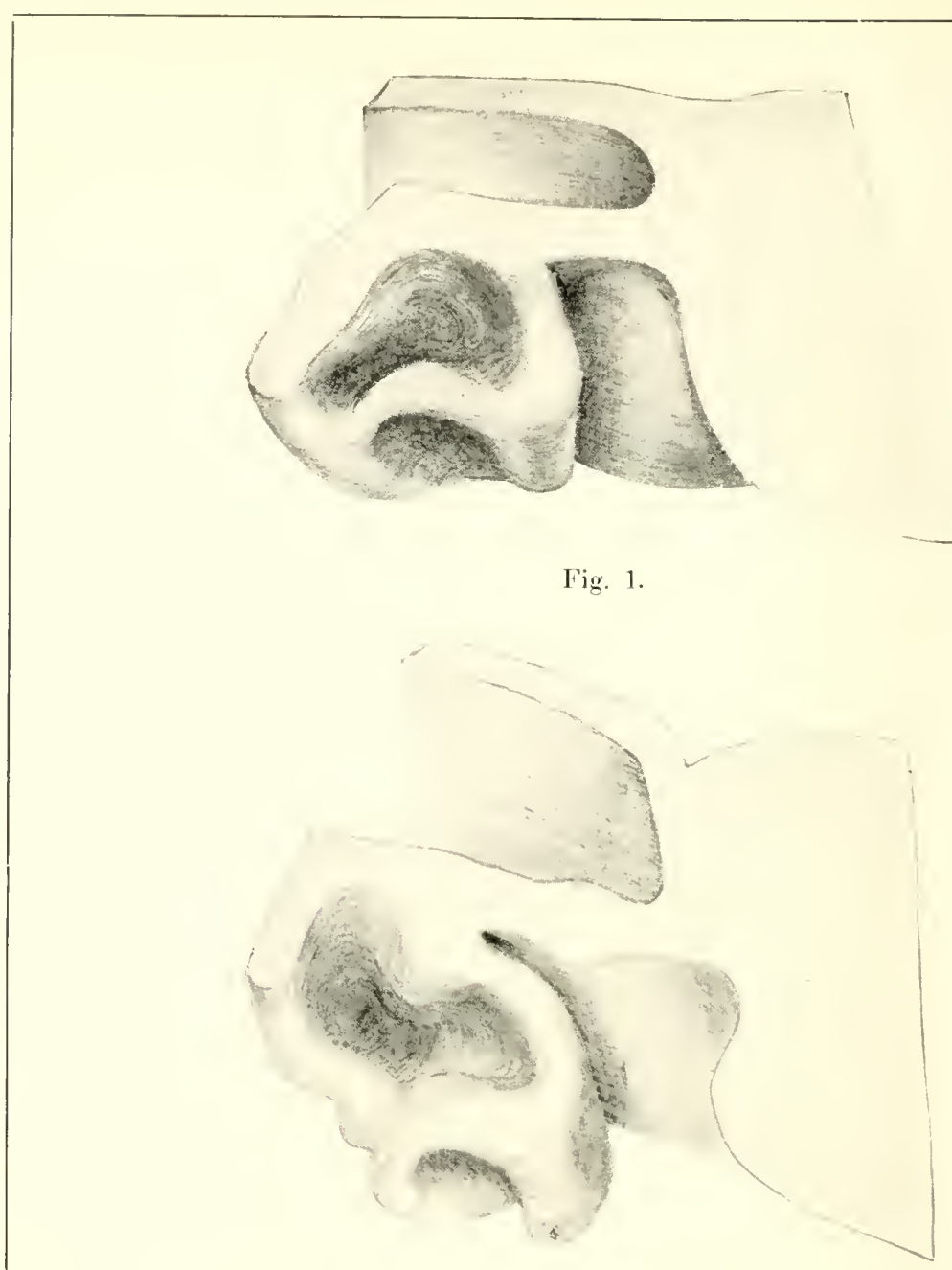

Fig. 2.

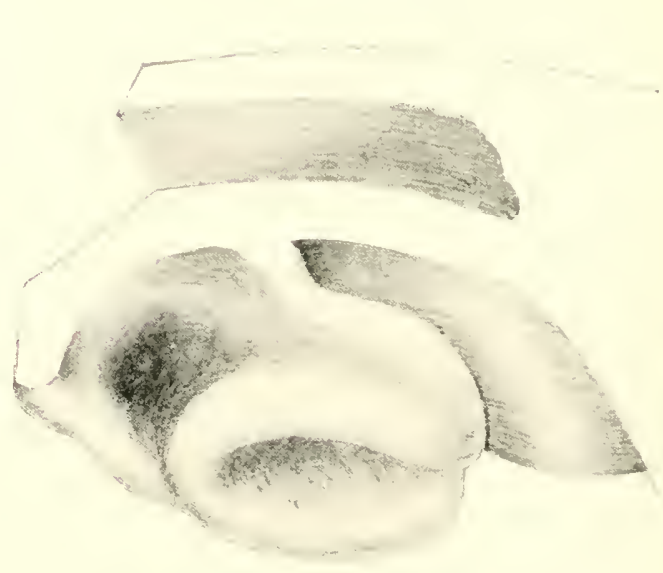

Fig. 3. 


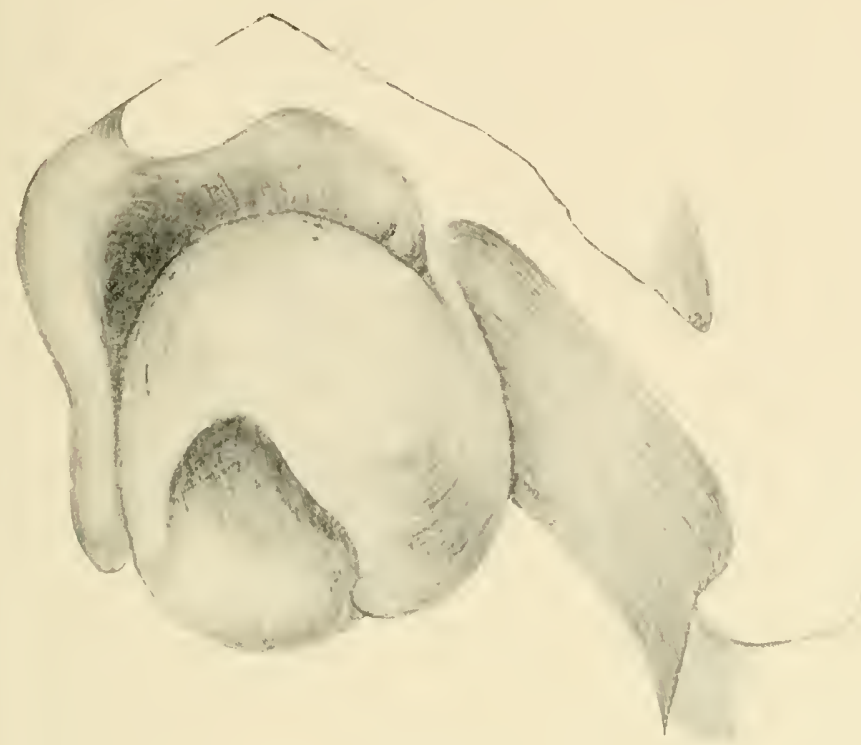

Fig. 4.

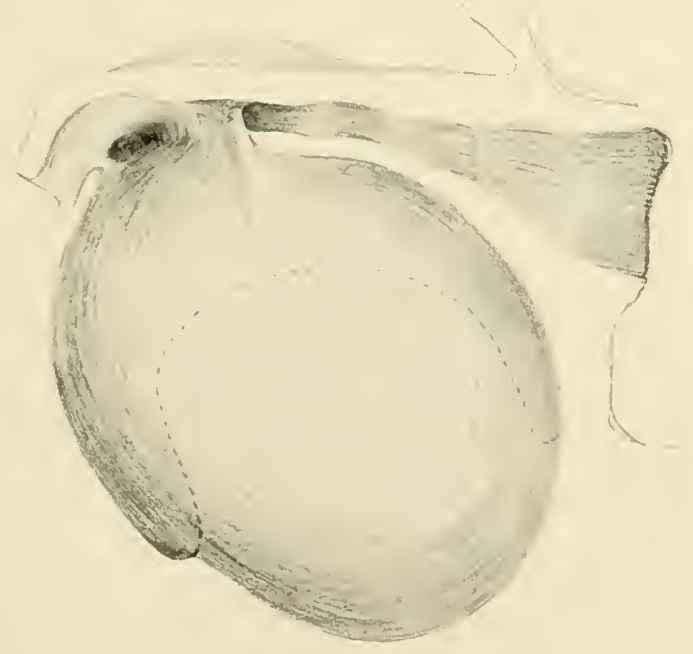

Fig. 5. 




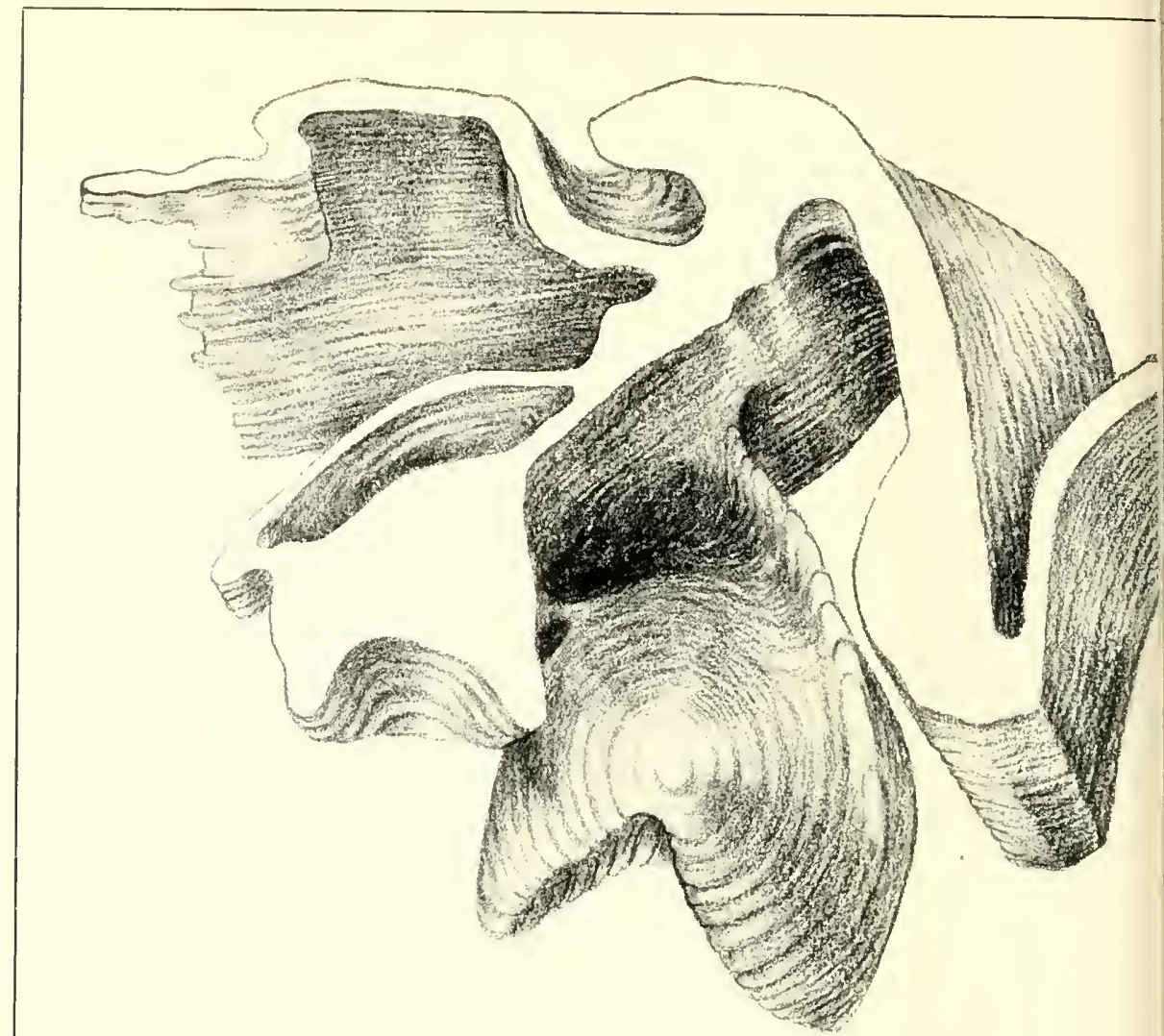

Fig. 6.

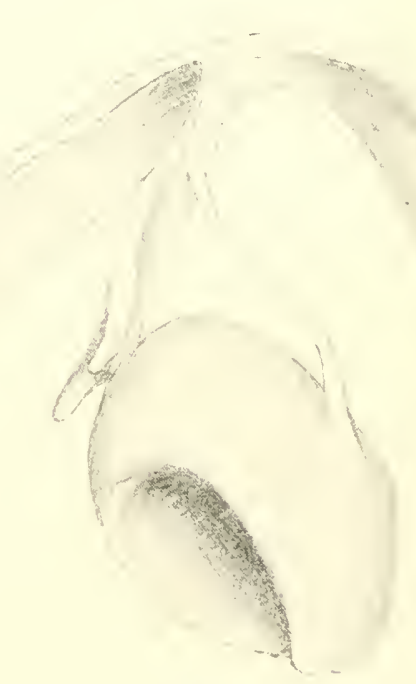

Fig. 7. 


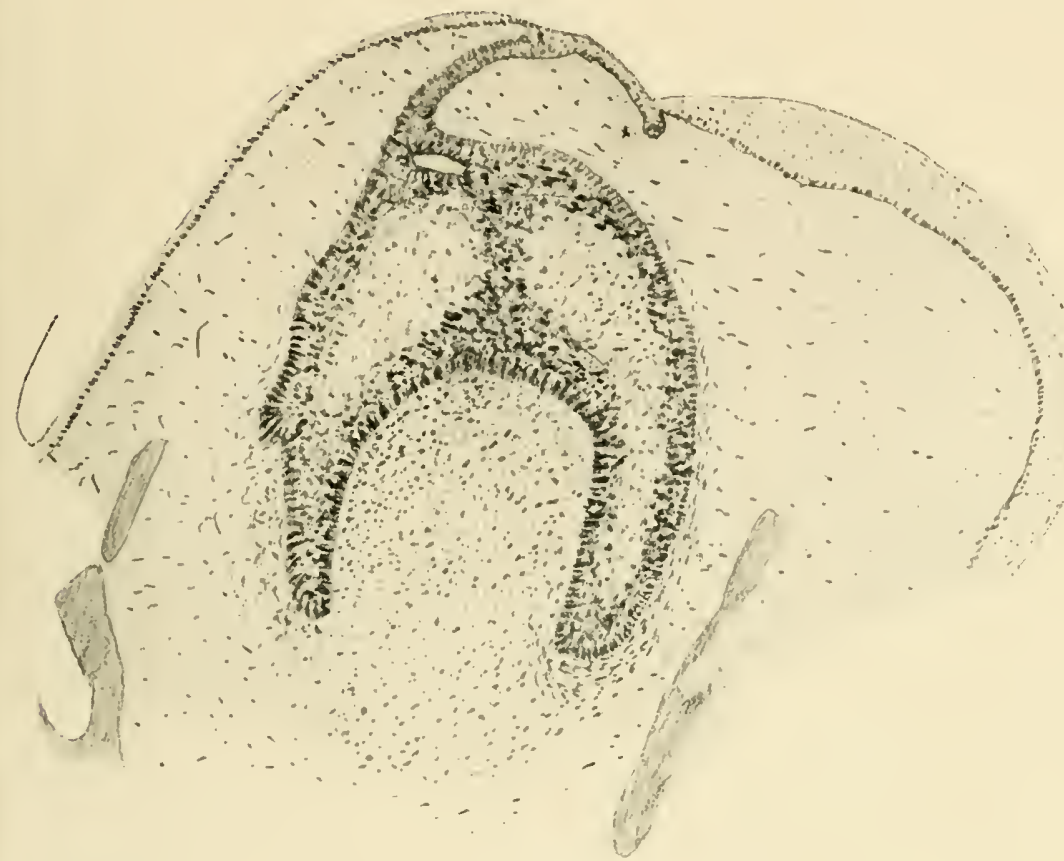

Fig. 8 .

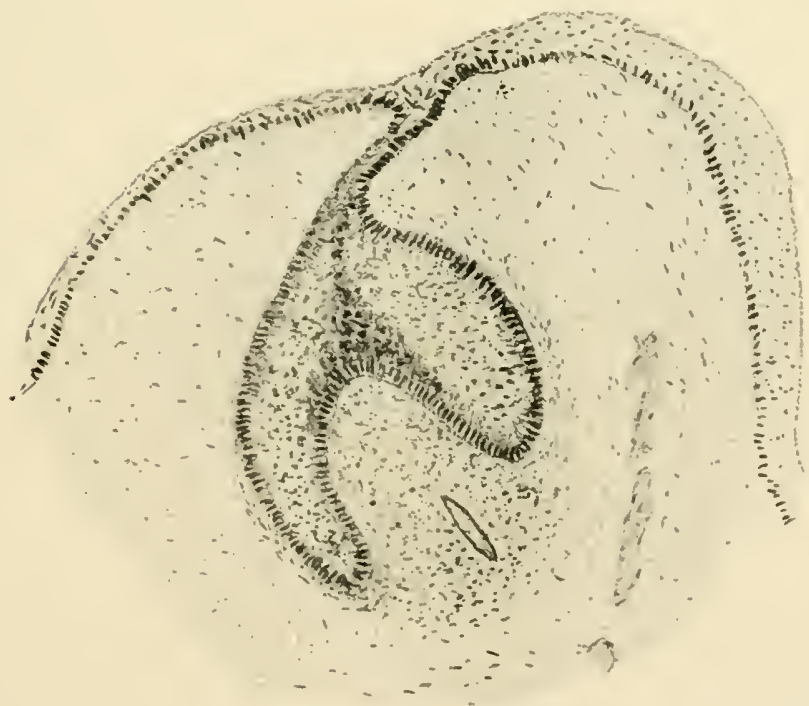

Fig. 9. 



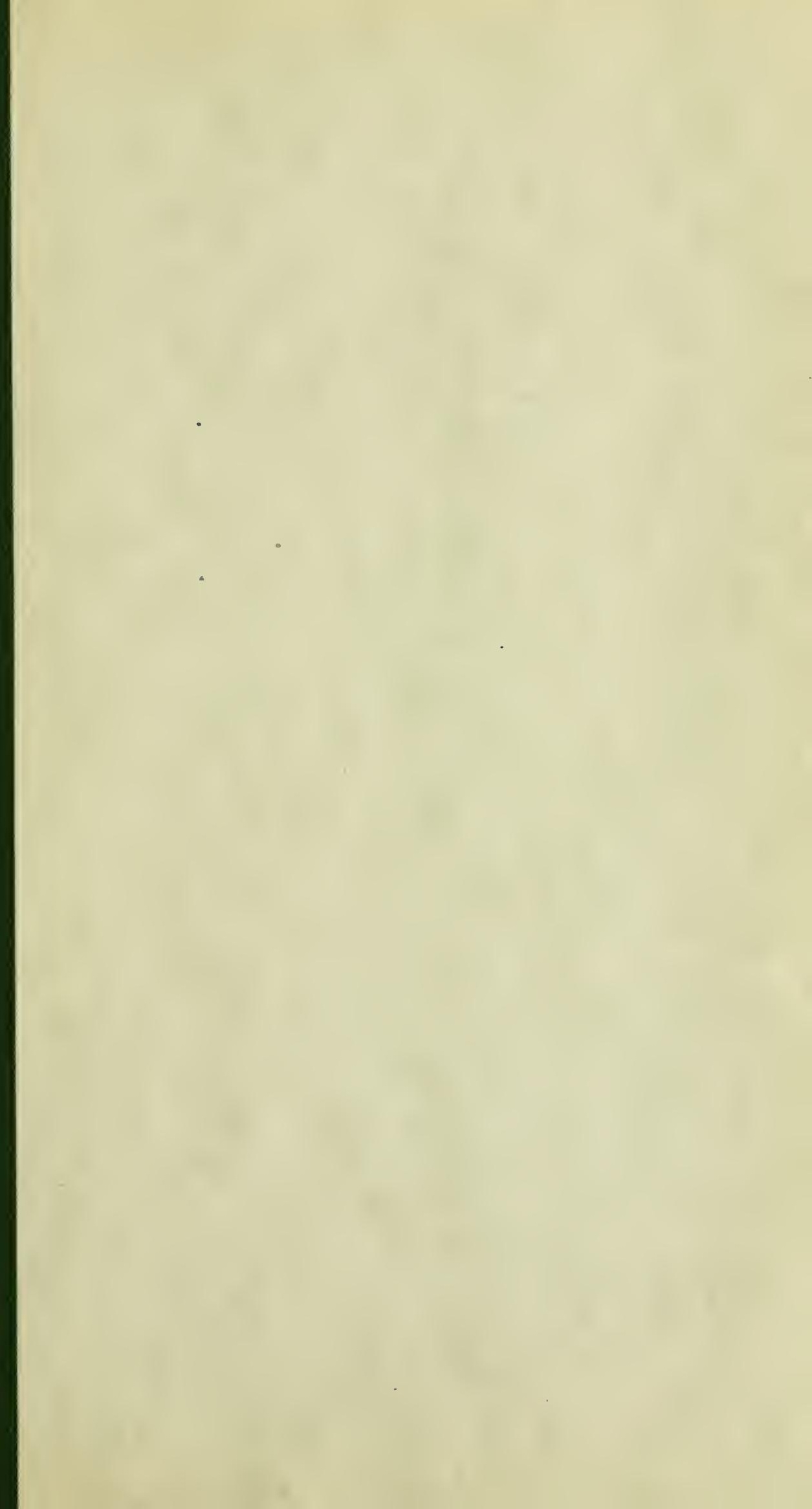


